914.94

B 44

WINTIZR SPORTS

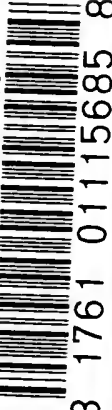

IN

SWITYISRRANDD 


$$
\begin{array}{r}
914.94 \\
3.44
\end{array}
$$




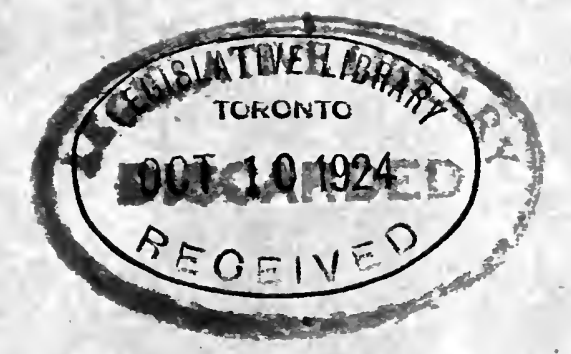


Digitized by the Internet Archive in 2007 with funding from Microsoft Corporation 


\section{WINTER SPORTS IN SWITZERLAND}




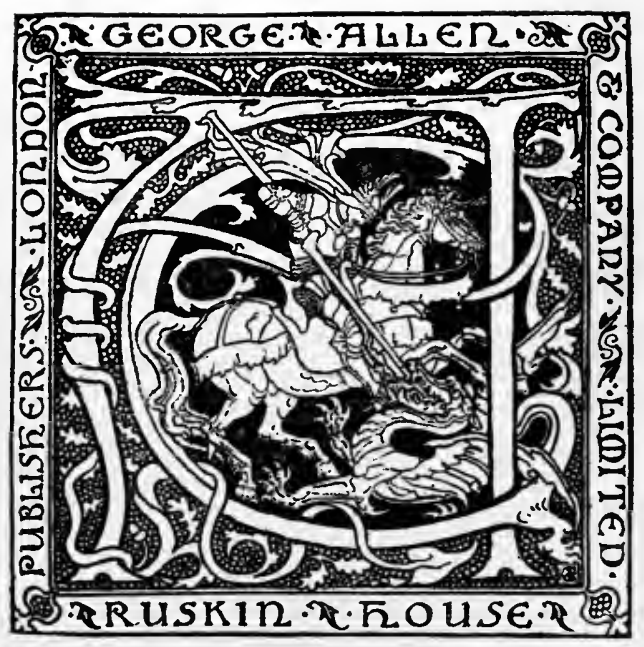




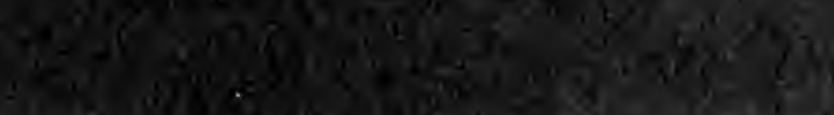

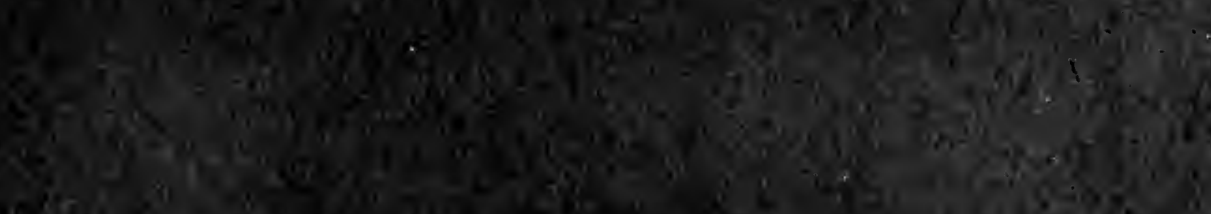
Fis.



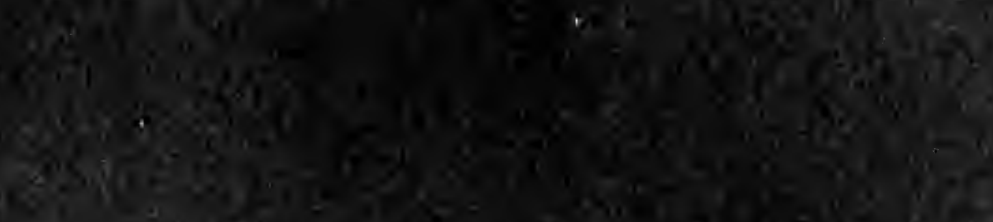









\title{
57084
}

\section{WINTER SPORTS \\ IN SWITZERLAND}

\author{
BY \\ E. F. BENSON
}

AND 47 REPRODUCTIONS FROM PHOTOGRAPHS BY MRS. AUBREY LE BLOND

\section{LONDON}

GEORGE ALLEN \& COMPANY, LTD. $44 \& 45$ RATHBONE PLACE

$$
\text { I } 9 \text { I } 3
$$

[All rights reserved] 




Printed by Ballantrye, Hanson \& Co.

at the Ballantyne Press, Edinburgh 


\section{CONTENTS}

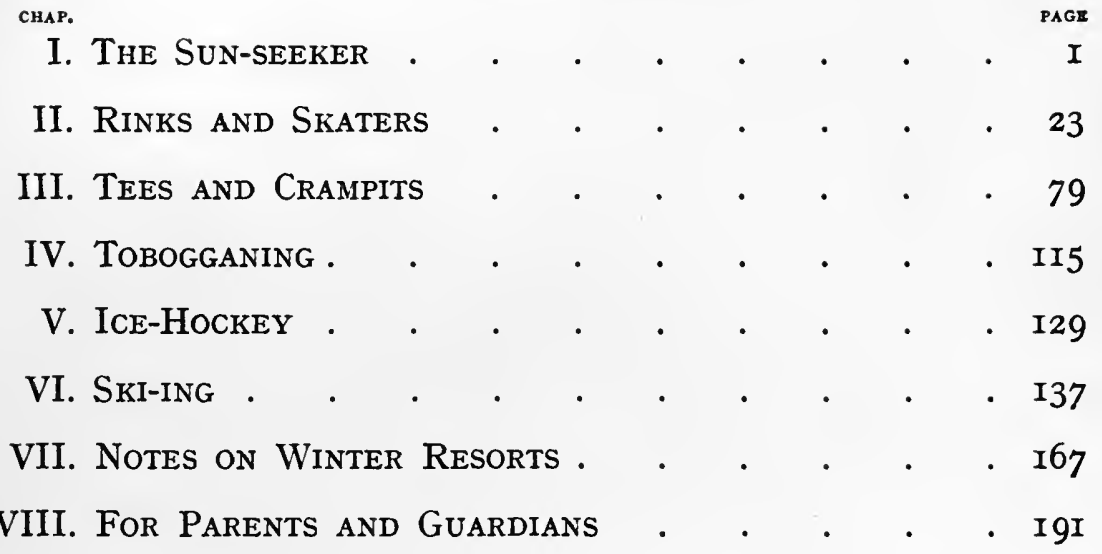





\section{ILLUSTRATIONS}

PLATE

THE EIGER (colour) . . . . . . . . Frontispiece

I. Winter Sunlight

II. By the Stream-Side.

III. HOAR-FROST

IV. JEWELS OF THE FROST

V. Black ICE on the Sils LAKe.

At end of

Chap. I,

between

VI. The Budding ICE Flowers · $\cdot \dot{\cdot} \cdot \cdot \dot{\cdot} \cdot$
VII. The FUlL-Blown ICE Flowers (twenty-four hours later)

VIII. ICE Flowers in Detail

IX. Magnified ICE Flowers .

X. Winter Moonlight .

Skating, English Style (colour) . . . . Facing p. 32

Skating, Continental Style (colour) . . . . " 34

At end of

XIII. Sprinkling the Rink, Château d'Oex . . . Chap. II,

XIV. Public RINk, Davos . . . . . . . $\}$ between

XV. Skating-Rink at MÜrRen . . . . . $p p .78$ and 79

XVi. Skating-Rink at Château d'Oex . . . . .

"She Lies" (colour). . . . . . . . Facing p. 98

XVII. CURLING . . . . . . . . . . At end of

XVIII. CuRLing at MÜrReN . . . . . . . . Chap. $I I I$,

XIX. The Three Kulm Rinks . . . . . .

XX. Ladies' Curling Match, St. Moritz . . . Ppp.II4 and II 5

"Achtung!" (colour) . . . . . . . Facing p. II6

ON THe CResta Run (colour) . . . . . "

TAILING (colour). 
PLATE

XXI. The Building of the Cresta-"Battledore"

XXII. The Top of the Cresta, St. Moritz

XXIII. Starting on the Cresta.

XXIV. Church Leap, Cresta Rún

XXV. Church Leap, Cresta Run

XXVI. "Battledore" Corner, Cresta

XXvil. Crossing the Road, Cresta

XXVIII. Near the Finish on the Cresta

XXIX. BOb-RUn, St. Moritz: IN the LaRch Woods

XXX. Rounding Sunny Corner, St. Moritz Bob-run

XXXI. BOB-RUn, St. MORITZ

XXXII. The Straight from the Bridge, St. Moritz BOB-RUN

XXXIII. ST. MORITZ BOB-RUN

ICE Hockey (colour).

The Telemark Turn (colour).

The Jump (colour)

SKI-JORING (colour)

XXXIV. At St. MORITZ .

XXXV. Practice Slopes, Montana, Switzerland

XXXVI. A SLIGHT Mishap

XXXVII. SKI-JUMPING

XXXVIII. Ski-Jumping, Montana, Switzerland

XXXIX. Veterans of the St. Moritz Ski Club.

XL. A Practice Ground

Xli. Crossing the Road on the Cresta

XliI. Top of Klosters Run, Davos

XliII. The Start, Schatz Alp Run, Davos

Xliv. Bobbing on the Schatz alp Run, Davos

XLV. Skating-Rink at Villars

Facing p. $\mathrm{I}_{32}$

$\eta \quad{ }^{56}$

" 164

" 166

Chap. IV

pp. 128 and 129

XlVI. At La Bretaye, Villaks

XLVII. "Blow, Blow, thou Winter Wind"

At end of

Chap. VII,

between

$p p . \mathrm{I} g \circ$ and $\mathrm{I} 9 \mathrm{I}$

The Ice Carnival (colour)

At end of

Chap. VI,

between

pp. 166 and 167

pp.

Facing p. 194 


\section{WINTER SPORTS IN SWITZERLAND}

\section{CHAPTER I}

THE SUN-SEEKER

THERE is an amazingly silly proverb which quite mistakenly tells us that " seeing is believing." The most ordinary conjurer at a village entertainment will prove the falsity of this saying. For who has not seen one of these plausible mountebanks put a watch into a top-hat, and, after clearly smashing it into a thousand pieces with a pestle, stir up the disintegrated fragments with a spoon and produce an omelette? Or who is so unacquainted with the affairs of the village schoolroom at Christmas as not to have seen a solid billiard-ball or a lively canary squeezed out of the side of a friend's head? Such phenomena are by no means rare, and occur periodically all over England. The observer's eyes have told him that he has seen such things, and the verb "to see" is merely a compendious expression to indicate that on the evidence of your eyes such or such a phenomenon has actually occurred. But no one believes that the disintegrated watch has become an omelette though ocular evidence-seeing-insists that it has. It was a conjuring trick. And this leads me to the consideration of the phenomena on which this whole book is based.

For High Alpine resorts in winter are a conjuring trick of a 
glorious and luminous kind. Our commonsense, based on experience, tells us that ice is cold, but is melted by heat; and that snow is wet; and that unless you put on a greatcoat when the thermometer registers frost, you will feel chilly; and that if you frequently fall down in the snow you will be wet through, and if you do not change your clothes when you return home you will catch a cold. All these things are quite obvious, and he who does not grant them as premises to whatever conclusion we may happen to base on them, is clearly not to be argued with, but soothed and comforted like a child or taken care of like a lunatic. But High Alpine winter resorts give, apparently, ocular disproof of all these obvious statements, and those who go out to these delectable altitudes in favourable seasons see (which is ocular evidence) every day and all day the exact opposite of these primitively simple prepositions regularly and continually taking place. They sit in the sun, when they are tired of skating, and see that though a torrid luminary beats down on the frozen surface, burning and browning the faces of their friends, the ice remains perfectly dry and unmelted; they trudge through snow, and find that they are not wet ; they see the thermometer marking anything up or down to thirty degrees of frost, and go out coatless and very likely hatless, and are conscious only of an agreeable and bracing warmth; they go ski-ing and all day are smothered in snow, and yet return dry and warm and comfortable to their hotels, and do not catch any cold whatever. Shakespeare once made an allusion of some kind ( $\mathrm{I}$ cannot look all through his plays to find it) about hot ice, meaning to employ a nonsensical expression. But it is the most striking testimonial to the magni- 
ficence of his brain that all he ever wrote meant something, although, as in this instance, he designed it not to. For without doubt he was alluding to what appears to occur at St. Moritz or Mürren.

But it is all a conjuring trick, or so these altitudinists are disposed to think when they return home to the dispiriting chills of a normal February in England, and find that when the thermometer marks $45^{\circ}$ or thereabouts they shiver disconsolately in the clemming cold. Even when they were out in Switzerland they hardly believed what appeared to be happening, for they found that if the weather changed, and instead of the windless calm, or a light north-wind, the Föhn-wind blew from the south-west, warm and enervating, then, in proportion as the thermometer mounted, they felt increasingly cold. All these things, though they thought they saw and felt them, were of the nature of a conjuring trick, and they never, after their return to the lowlands, really believed them. It was obviously impossible that they could have felt warm and dry, after being rolled in the snow. It must have been an illusion, capable of immediate disproof if they now went out without a coat, or sat down on a snowy London pavement. A pleasant illusion, no doubt, but clearly an illusion. It was like the omelette emerging from the top-hat, into which a watch had, only a moment before, been placed and pestled.

And if those who think they have experienced these phenomena, which so clearly contradict the most elementary laws of Nature, cannot fully believe in them when they re-enter the chilly spring of England, still less do those who have not experienced them find it possible even to simulate credulity when the foolish Alpinist 
recounts them. I rather fancy that people who have never been to the high altitudes in winter, believe that all those who say they have done so, and come back and tell their friends that sun does not melt ice, and that snow is dry, and that ten degrees of frost is an agreeable temperature to stroll about in without a coat, are in some sort of inexplicable conspiracy. But the conspiracy is so widely spread now, and is still spreading so fast, that one's remarks on the subject are received with politeness nowadays, though still with incredulity. Some strange wandering of the wits has taken possession of the conspirators, who are otherwise harmless. And, such is the force with which their illusion holds them, and so anxious are they that credence should be given to it, that they employ some sort of skin-dye to add completeness to their strange tales, and appear with brown hands and faces when they come back to the anæmic metropolis. They are clearly the victims of some obscure but infectious derangement of the brain, of which the chief symptoms are those strange illusions and an immense appetite. . . . And, as I have said, the victims of these illusions, before they have spent many days in England, are already themselves wondering whether all these things really were so, or whether they were but the fabric of a pleasing dream. But they make plans to dream again about the middle of the ensuing autumn, and for the most part find that the vision is recapturable. It is all great nonsense ; but if you take-a suitable ticket at a suitable time of the year, and go where that ticket will allow you, the nonsense is found to be recurrent.

I do not know whether ice and snow, and all the forms of the " radiant frost," as Shelley calls it, are in themselves more 
beautiful than the spectacle, to which we are accustomed, of an unfrozen world, or whether it is merely because we are unused to the gleams and sparkle of these whitenesses, that we find them so entrancingly lovely. It would be interesting, for instance, to ascertain whether an Esquimo or other dweller in the Arctics accustomed to ice, would go into ecstasies of admiration at the sight-shall we say — of Hyde Park Corner on a moist warm day of September, when the roadway is swimming in a thick brown soup of mud, and gusts of tepid rain stream on the wind-swept lamp-posts, thus supporting the idea that it is to the novelty of the spectacle that the arousing of our appreciation is due. Certainly it would be hard to say that anything in the world is more beautiful than a beech-tree in spring, or a crimson rambler in full flower, or glimpses of the Mediterranean in a frame of grey-green olive-trees; and I am inclined to believe that it is partly the contrast which a sunny morning in winter among the High Alps presents to all that a Londoner has known or dreamed of hitherto that partly accounts for the ineffable impressions it never fails in producing on him. And to that we must add the exhilarating and invigorating effect of the still dry air, and the sun that all day pours Pactolus over the gleaming fields. In such an air and in such a flood of light all our senses and perceptions are quickened, the vitality of our organs is increased, and with the wonderful feeling of bien-être which the conditions give, our appreciation is kindled too. I always feel that it must have been on a frosty morning that David said: "I opened my mouth and drew in my breath." And perhaps on that day the cedars of Lebanon were covered with the crystals of hoar-frost, and below the snowy 
uplands the dim blue of the sea slept insapphirined at the bases of the shining cliffs. ...

I lick the chops of memory, and go back in thought to the middle of December, when, having previously determined not to go abroad till January, I hurriedly fly the country, like a criminal seeking to escape from the justice that is hot on the heels of a murderer. In such wise do I fly from my conscience-conscience, I may remark, is one of the things that everybody leaves behind when he goes to the High Alps : apparently it and other poisonous organisms, such as the bacillus of tuberculosis cannot exist in those altitudes-while below my breath I again register the frequently broken vow that $\mathrm{I}$ will be at home again by the middle of January at the latest. For indeed it seems impossible to tolerate London any longer just now: the fogs have begun (these are the excuses with which I seek to stay the protests of conscience, before I fly from it), and for three days last week we lived in a thick and ominous twilight of dusky orange, tasting evilly of soot and sulphurous products. At intervals a copper-coloured plate showed itself above the house roofs : and, oh, to think that this mean metallic circle was indeed none other than the hot radiant giant that in the happier climes was rejoicing to run his course across the turquoise expanse of cloudless sky; that this remote and meaningless object was the same that sparkled on dazzling peak and precipice and turned the untrodden snows to sheets of diamond dust. Then after three days of Stygian gloom the fog was dispersed by a shrewd and shrill north wind, and for a whole morning snow fell heavily, which, as it touched the pavements and roadways of town more than usually befouled by the fog, turned 
into a base and degrading substance resembling melting coffeeice. The streets swam in the icy treacle of it, and motor-buses and other ponderous vehicles cast undesired helpings of it at the legs of foot-passengers. After this dispiriting day the weather changed again and a tepid south-westerly gale squealed through the streets. This was too much : I bought a quantity of what is known as sermon-paper and two new stylographs (this was another sop to conscience, and implied the intention of working out in Switzerland), made a few hasty and craven arrangements on the telephone, and slid out of Charing Cross Station at 2.20 P.M. precisely next day, leaving conscience, like an abandoned wife, sobbing on the platform.

Now, while journeys, whether on land or sea, are apt to be but tiresome businesses when they are undertaken at the call of some tedious errand, they are vastly different affairs when they conduct the traveller to joyful places and delectable pursuits. They are coloured by that which awaits him at the end of them (like the sweetness of sugar permeating tea), and this particular progress is to me full of romantic happenings. Dusk is already closing in before I reach the coast, and as the train halts on the hill above Folkestone, before being towed backwards down to the harbour, I can see the lights beginning to twinkle in the town and along the pier, which is surrounded by the great grey immensity of the wave-flecked sea. A fine rain is falling dismally, and as I hurry across the slippery quay I am weighed down by an enormous greatcoat (the pockets of which, I am sorry to say, are "salted" by various packets of cigarettes, which is why I wear it), and I stagger under the weight of a suit-case, sooner than part with 
which I would die. For the French or Swiss railway companies often (no doubt with humorous intent) arrange that the traveller's large luggage shall not arrive for twenty-four hours or so after he has got to his destination, and in less experienced years $I$ have packed my boots and skates in these detained trunks, and have been obliged to wait in savage inaction till the railway company has come to the end of its joke, just as one waits for the end of a long funny story. Not so now : my inseparable bag contains my large and cumbrous skate-shod boots as a first charge, and after they have been stowed, the mere necessities of life, like clothes and dressing-case, as opposed to its joys, fill the rest. Even in the harbour the steamer sways with the back-wash of the heavy seas outside, and the mooring-ropes squeak and strain to its unease. I stick in the narrow gang-plank that conducts in precipitous incline to the deck (at least the corner of my suit-case does, which is part of my identity) ; a faint and awful smell of red plush sofas and cold beef comes up from the stairs leading to the saloon; the tarpaulins, rigged up along the open passage between decks, flap uneasily and are buffeted by the rain-soaked wind, and sailors hurry about with white japanned tin objects in their hands. . . .

All this sounds dismal and dispiriting enough, but such incidents, I repeat, take their colour from that to which they lead the traveller, and when bound for Switzerland they are all haloed in a vague pleasurable sense of excitement and romance. We put out on the turbulent and windy sea, and as we round the end of the pier the whole boat shivers as a great white-headed wave strikes her. It is cold and wet on deck, but I have to linger there while the cliffs of my beloved native land vanish into the grey of 


\section{THE SUN-SEEKER}

the swift on-coming night, and feel a perfect glow of enthusiasm at the idea of not setting eyes on them again for another month or so (probably "so": because conscience is now far away, perhaps still waiting at Charing Cross Station, in case I return by the next train), and already I am beginning to be doubtful whether I really made a vow to be back by the middle of January. I pass rows of silent figures with closed eyes reclining on deck-chairs in the more sheltered corners: then the whole ship makes a scooping curtsey into the trough of a wave, and the water pours sonorously on to the deck. Shrill whistles the wind in the rigging, and a raucous steam-siren proclaims to all the traffic in the Channel that we are off to Switzerland to skate, having left our consciences and the white cliffs of England behind us, and not caring two straws, at this delightful moment, as to whether we ever see any of them again.

I love the landing on the friendly shores of France, the waiting while the ship is reluctantly coaxed sidling up to the pier, the hustle to get through the custom-house and enter the warm, welllit train. The foreign tongue is delightful to the ear: so, too, to the eye, the blue-bloused porters, and the unplatformed station, where the huge carriages tower high above one, emitting mysterious jets of steam. All is strange and new and delightfül : the engine of unaccustomed build and outlandish voice, the grey upholstered compartments with their hot-carpeted floors, the restaurant car with bottle-filled racks, where presently I sit, part of a moving pageant of eating and drinking, as we shriek through stations and scour with ever-increasing velocity through the darkness of a stormy night. At Laon mysterious jugglings take place : another 
string of carriages is slowly shunted on to our train, to the accompaniment of many cries of warning and encouragement and wavings of lanterns, and the buffers come home with a soft thud. We cast off our tail, lizard-like, which is hauled away to travel divergently to Basle, and soon we are thundering on again by the more direct route to Berne. At some timeless hour a long halt is made, and compartment doors are flung open with the sonorous proclamation of the arrival of les messieurs de la douane. Enter les messieurs, and at their sesame bags fly open, and with strange staves they explore the hidden recesses under the seats, in their nightly search for laces and spirits and cigarettes and all the contraband of peace. Soon this complimentary visit is over, the green shades are adjusted again over the lamps, and the vibration and rhythm of the racing wheels mingle and blend themselves into the blurred edges of dream. . . .

I do not wake until we are actually slowing down to enter Berne-that city so justly famous for its bears, its President of this delectable republic, and its terrace from which the eager tourist vainly scans the impenetrable clouds which invariably screen from his view all possible glimpses of the mountains of the Oberland. Whenever I arrive at Berne it is always a grey chilly morning, just above freezing point, so that the icy streets are half slush. At first this used to depress me with ominous forebodings. of a thaw at the higher altitudes : now I know that all the winter through it is always just thawing at Berne, and that the sky there always is heavily be-clouded. I think a sunny frosty morning there would cause me some considerable anxiety, for it would imply a complete upset of climatic conditions, and midsummer 
might be expected to hold its abhorred sway on the heights. So in perfect equanimity I climb back again into our train-heated to the temperature of the second hottest room in a Turkish bath -and we jog in more leisurely fashion through the half-frozen villages towards the lake of Thun. These villages are mainly composed of houses taken from the larger-sized boxes of toys, with stones fastened down on their wood-shingle eaves to prevent their roofs blowing away, and with staircases, clearly built for ornament, and completely unpractical, climbing up the outside of their walls. Stations and banks and hotels seem to be constructed with a view to moderate permanence; the rest are clearly so made that they can be taken up and planted down somewhere else. Then as we emerge on to the edges of the lake, higher hills begin to tower across its steely-grey levels, and rifts in the clouds that shroud their heads and hunched shoulders show glimpses of sun that shine on the whiteness of snow. Mile after mile we pursue a meandering way along the shores, and thread the darkness of hoarse tunnels, whose lips are fringed with dripping icicles, and the sense of something coming, something high and clear, begins to grow. Though in front, where Interlaken lies, a veil of grey-blue mist is interspersed between us and that which, I know, soars above it, the clouds are beginning on all sides to become unravelled like wool-work pulled out, and through the rents and torn edges gleams of turquoise sky are seen. High up climb serrated rims of rock, cut vividly clear against the blue and fringed with aspiring pines; higher yet, where the boldest of these brave vegetables can find no footing, further ridges appear austere and empty and gleaming. Yet these are but the outlying but- 
tresses and ramparts of the great towers at the base of which they lean and cluster : to-night we shall sleep in an eyrie far above them, and far above us yet will watch the unscaled precipices of the great range, over the edge of which the unheeding stars climb and swim into sight all night long, pouring the golden dew of their shining upon forest and glacier, until the snows are rosy with dawn.

We paused in Interlaken Central Station to draw breath after our lake-side amble. Here the snow lay crisp and hard-trodden in the streets, but overhead the gutters gurgled and the eaves of houses dripped with its melting in this brilliant morning. No shred of cloud was left in all the shining heavens, and like the flanks of a galloped horse the pine-clad hillsides steamed in the sun. . . . And then the miracle. . . . As we steamed forth again to the Eastern station, a long valley lying between two wooded hills opened out, and there, clear in the light of the young day, and white with virgin snows and blue with precipices of ice, and set in the illimitable azure, rose the Queen of Mountains, the maiden, the Jungfrau, peaked and domed and pinnacled in ineffable crystal.

The Jungfrau is and will always be my mistress among mountains, as she was when I first saw her at the age of twelve. One mistake $\mathrm{I}$ have made in my conduct towards her, and that was ten years later when I climbed her-and yet who could tell she would prove so tedious and heavy (not in hand but in foot)? For I approached the lady of my adoration from the Concordia hut, and instead of feasting my eyes at every step on her queenly gracious carriage and maiden slenderness, I found that the 


\section{THE SUN-SEEKER}

closer I got to her the more did she appear round-shouldered, not to say hump-backed. In addition, a quantity of fresh snow had fallen, and we had a long tiresome and utterly unexciting trudge, a hot and stodgy affair. I had imagined that ventures and perils would have to be encountered for this wooing and winning of her, with balancings and poisings on stairways of precipitous ice and needles of pinnacled rock: instead she had to be solidly and laboriously and dully approached; it was like wooing some great bolster or gigantic cow. For a little while after that I cared nothing for her; she was a mature and silent barmaid of vast proportions, but gradually her charm and enchantment cast their spell over me again, the dissolution of which I intend never to risk in the future, unless I approach her by a more hazardous and daring route. To those who approach her dully, she gives herself dully : the more daring wooer she may perhaps kill, but she does not bore him.

But the wonder of her, when seen through clear air with the brilliant winter sky around her head from the entrance to this valley that leads up to Lauterbrunnen! Up it we steamed in a little angry rattling snorting train, which cut itself in half to take some of its aspiring contents to Grindelwald on the left, and others among whom I numbered myself to Wengen and to Mürren. By the side of our way ran a turbulent mountain stream fed by the glaciers of the Oberland, too swift to freeze altogether, but with its backwaters and sheltered reaches covered over with lids of ice. For all its glacier-birth steam rose from it in the icy air that hovered in shaded places, and the alders and hazels that hung over it were thickly encrusted with the marvellous jewellery 
of the hoar-frost, spiked and parsemès and refoliaged in wondrous winter growth with tendrils and scrolls of minutest diamond-dust. Narrower grew the valley, steeper and taller the wooded hills that overhung it till at last we reached Lauterbrunnen, close to which the Staubbach, most amazing of all waterfalls, leaps a clear eight hundred feet from the edge of the high plateau-shelf, which skirts along the mountain-side on to the rocks below. Even in summer, when the melting of the snows that feed the stream make it of far greater volume than when the stricture of frost is on it, the water, poured as from a jug-spout, disintegrates in its fall, so that it reaches the valley more in wreaths of mist than in solid water, and collects again from the dripping rocks; while in winter its diminished volume is further spent in the manufacture of the huge icicles that fringe the edge of its leaping-place, and hang in great streamers, the beard and hair, you would say, of the very Frost-king himself, who sits at ease on this precipitous throne. Little water to-day runs away from where the clouds of mist and water-smoke fall on the rocks, for most of them are frozen there, and a layer of ice covers the boulders where they come to earth. For here, so engorged lies the valley, so close to the great rampart of the Oberland, that the sun which blazed on Interlaken has not yet surmounted the barrier of mountain-peaks.

Parallel with the Staubbach, and up a hillside which appears hardly less sheer than the precipice itself, runs the funicular railway which leads to the Mürren-plateau. At first sight it seems as if it must be meant for a practical joke, constructed by humorous engineers to astonish the weak minds of travellers, and, though practical from the point of view of a joke, to be perfectly impracti- 


\section{THE SUN-SEEKER}

cable as a means of conveyance. Its steepness is that of disordered images seen in a dream, and it was with a sense of utter incredulity that I first took my place in one of the small wooden compartments and was locked in by an apparently sane and serious conductor. He blew a whistle, or a bell sounded, just as is done on real lines of traffic, and immediately afterwards we began to ascend that impossible line of rails, sauntering with smooth and steady progress up that ridiculous precipice. More amazing still we soon observed a similar car sauntering steadily down it, just strolling down, even as we were strolling up. We met, we passed, and I had a vision of passengers smoking and chatting, as if nothing in the least remarkable was happening and imminent death did not await us all. . . .

But more remarkable things than that were happening. Upwards from the valley we climbed on this Jacob's ladder that reached if not to Heaven, to very heavenly places. Pine woods and rocks melted away below, streaming quietly downwards; presently we were level with the top of the towering precipice from which the Staubbach was discharged, and presently that too was left below. But higher as we mounted there climbed with us, in fresh unfoldings of glaciers and peaks and glittering snow fields, the great range of the Oberland. New peaks "met Heaven in snow," new arêtes, too steep and wind-swept to allow a vestige of snow to lie there pointed arrow-like to the tops above them. Eiger, Monch, Silberhorn, and Jungfrau towered glittering just across the Lauterbrunnen valley from which we had come, and as we sidled along the upland shelf on which Mürren stands, gradually the whole range spread itself out in tremendous rampart, 
radiant, rejoicing, and austere. For foreground was this narrow ledge of white fields dotted here and there with cattle-châlets, and pines scattered singly or in companies, all wearing plumes and tippets of snow that made their foliage seem a black blot in the sunlight, and soon the congregation of village roofs appeared, and Mürren stood bathed and basking in sunshine, drowned, so to speak, in the sparkling champagne of the invigorating winter morning. And the intoxication of the high places, an entrancing vintage of oxygen and ice and sun, invaded limb and sinew and brain.

It is supposed by those who have never seen the infinite variety of forms into which frost converts mist and dew and all manner of water, that there must be a monotony in those vast expanses of snow and ice. They figure to themselves the depressing spectacle of snow as it usually appears in England, smooth and soft and wet, and too close a cousin to slush not to be tainted with a family resemblance; the image called up by ice is a grey surface in which are imbedded dead leaves, twigs and stones thrown on to it by boys for purposes not clearly understandable, while all they know of hoar-frost is an evanescent decoration that occurs at the edges of ditches and on lawns when tea is being made in the morning and disappears as soon as the poached eggs, leaving the grass soaked and dripping. But as is crystal to soap so are those radiant congelations of the High Alps to the same as seen beneath grey skies and unluminous days. Here, if snow has fallen, as sometimes happens, while wind is blowing, it is driven into all manner of curving wave crests and undulations; then when the fall is over, the sky clears again, a night of frost hardens and congeals the outlines, and the trees wear fine feathers and 


\section{THE SUN-SEEKER}

plumes of whiteness. As the snowfall packs with its own weight, there grows on the surface of the fields a crust half snow, half ice, covered with dazzling minute crystals. During the fall of the snow there has been moisture in the air, and often on that brilliant morning that succeeds the fall, the air is full of minute frozen particles of water that sparkle like the old-fashioned glass-decoration on Christmas cards, so that one walks through a shining company of tiniest diamond fire-flies. And the frozen surface of snow reflects the wonderful azure and gold of sun and sky, and here in the blaze it lies white beneath a vivid yellow, there in the shade a dim blue permeates it. After a few days of hot sun more of the fall will have melted and slipped from the trees, and they stand black-foliaged and red-trunked waiting for the decoration of the hoar-frost. The one more night of frost covers every sprig and fir-needle with amazing spikes and fernlike sprays of minute crystal. Wondrous are their growths, more particularly if, as sometimes happens, some cold mist comes up from the valleys. Then with a craze for decoration almost ludicrous, you shall see your friends with hair and eyebrows bedecked with these jewels, each separate hair wearing its frozen garniture, and their coats and stockings ornamented in like manner. They grow white in a single minute almost'; and such as have moustaches, close to the moisture of their breath will suddenly turn to walruses with long dependence of icicles. And yet-here is a conjuring trick again-though ice and frost frame their faces they are conscious of no cold at all.

Marvellous, too, are the dealings of the frost with the running streams and the lakes such as those at St. Moritz or Davos or 
Sils. Often, unfortunately, it happens that a snowfall will occur when they are but lightly frozen over, in which case the snow quite covers them, breaks through perhaps in places, and with the ice already formed, makes a rough uneven surface useless to the skater, and to the beholder no more than a level snowfield, with perhaps ugly stains on it where the water has come through and formed the grey ice, which is of no artistic moment. But sometimes it happens that a snowfall occurs before any ice has formed on the lake, and thus, though it lies on the surrounding ground, it melts in the water, and at the end of the fall the lake is still unfrozen, though the winter mantle lies over field and wood. Then let us suppose there comes a hard frost with no more snow. Night after night ice absolutely clear like glass forms on the water and gradually thickens. If the days are windless it is entirely smooth, and practically invisible, so that it is impossible to believe that you are not looking on a sheet of water. Then the glad word goes forth that the lake bears, and you hurry forth to skate on it. But mountain and wood and landscape are all mirrored in it as in perfectly still water, and it is almost incredible that here is ice a foot or two thick. Tremblingly you launch yourself on it, scarcely able to believe in its solidity; for through that unwavering surface you see every weed and stump under water. The very fishes flit and flick visibly below your feet, and so glassy is it that through it it is possible to see the subaqueous foundations of the lacustrine dwellings in the lake of Sils, never to be seen unless the lake is frozen, since the slightest ripple of the water sets the surface a-quiver and mars its translucency. But seen through this foot or so of perfectly clear ice-black ice, 


\section{THE SUN-SEEKER}

as it is called-it is as if one looked through that charming contrivance called the bathyscope, by which you can observe the depths of the sea. Below the ice, the water lies still and in a calm sheltered by this solid ceiling of crystal, and you see, as if in an aquarium, the fishes and the water-weeds, and all the gales that ever blew will not shatter the reflections or obscure the depths. Then when your courage has come to you, and you begin to grasp the fact that an army might march across this invisible plain of ice without breaking through, you will no doubt venture forth from the shore, and feel what you never feel on rinks and other prepared surfaces of ice, the divine elasticity of your floor. And very likely just when you are some half-mile from the shore, you will be terror-stricken to hear a crack as of artillery resound close to you, and a great crack will zigzag like lightning through the ice. The first time you hear that, the present writer is willing to wager any reasonable sum that your face will blanch (unless too sun-tanned) and you will skate with incredible celerity for the nearest land. But that salvo portends no danger whatever, except if your skate-blade enters such a crack (of which there will be, unfortunately, a considerable number in the course of a few days) longitudinally. Then it is true you may have a fall, but these explosions do not mean that you will ever be food for fishes.

But after a few days, in all probability, even though no snow falls, the surface of the ice, except where it is kept swept, becomes useless for skating, thanks to another of the wonderful conjuring tricks of the frost. Owing to dew, or from other moisture in the air, there begin to form upon the ice little nuclei of hoar-frost such as are seen in Plate VI. They look harmless enough, and 
with perfect justice you admire their exquisite fanlike fronds, and think no more of them. But in a couple of days the same surface, as shown from the identical point of view in Plate VIF, presents a totally different aspect, and one which is clearly discouraging to the most ardent of skaters. But then, since you are finally and completely and irrevocably thwarted in any ambition to skate on this depressing surface (for it is as if all the ice-moles in the world had made their common earth there, multiplying exceedingly), you will be wise to examine and admire the astounding forms of this fairy frost-work before it becomes confluent, and, losing the individuality of its separate tufts, covers the whole lake like powdery snow. In Plate VIII you may see the marvellous delicacy in detail of these bouquets of frostflowers, and the same on larger scale in Plate IX, where they are already becoming a very jungle of anti-tropical growth.

In that wonderful poem "By the Fireside," Robert Browning, in speaking of the Alps in autumn, says :

\footnotetext{
" But at afternoon or almost eve

'Tis better; then the silence grows

To that extent you half believe

It must get rid of what it knows

Its bosom does so heave."
}

And that which he weds to such lovely language is another of the spells which the circle of the Alpine day and night weaves round us. Only, $\mathbf{I}$ think, in winter the silence which he speaks of at evening, or, he might have added at night, is a thing incredible to those who, I may almost say, have never heard that silence. In spring or summer or autumn it is broken by sounds of cow- 
bells perhaps, and, almost certainly by a murmur of wind in pine-woods, or of water hurrying from the heights. But in winter, on a still evening those evidences of life are dumb, and yet the silence itself is pregnant with vitality. At sunset the high tops burn in rose-coloured flame, and as the glory fades into the toneless velvet of the frosty sky, the stars in their wheeling are of a brilliance utterly unknown to lower altitudes, except perhaps where the desert lies fallow and dry beneath Egyptian skies, and no emanation from the earth dims the burning of these "patins of bright gold." But that " quiring to the bright-eyed Seraphim" reaches not the mortal ear, and at evening or at night in these High Alps, there is felt, as it were, that ecstasy of silence that seems on the point of bursting into chorus : "it must get rid of what it knows." Nowhere else have I felt so rapturous a quality of stillness : the frozen snow lies taut under the grip of the immense energy of the frost : no avalanches slipping from the snowladen flanks of the Jungfrau under the hot beams of the sun, startle the valley with sonorous thunder: the wind stirs not the lightest needle of the pines; the villagers are home from the frozen fields, and doors are shut. Slowly the last rose-colour fades from the peaks, and the stars brighten, and you hold your breath to hear the most wonderful thing you have ever heard -utter stillness, that yet is strained almost to bursting point with the energies that make it, the peace that passes understanding that lies above the snow and beneath the stars. . . .

Then having heard it, having thought perhaps you understood it, or best of all, being conscious that you do not understand it at 
all, you may start for home, and glide on your skis down a pleasant slope to the very doors of your hotel. Probably you will have a great many falls, for it is the most difficult thing in the worldwhich is saying a good deal-to ski with the smallest success in a fading or faded light. But you will have heard the silence of the winter night: that will generously console you for your misadventures. . . . 


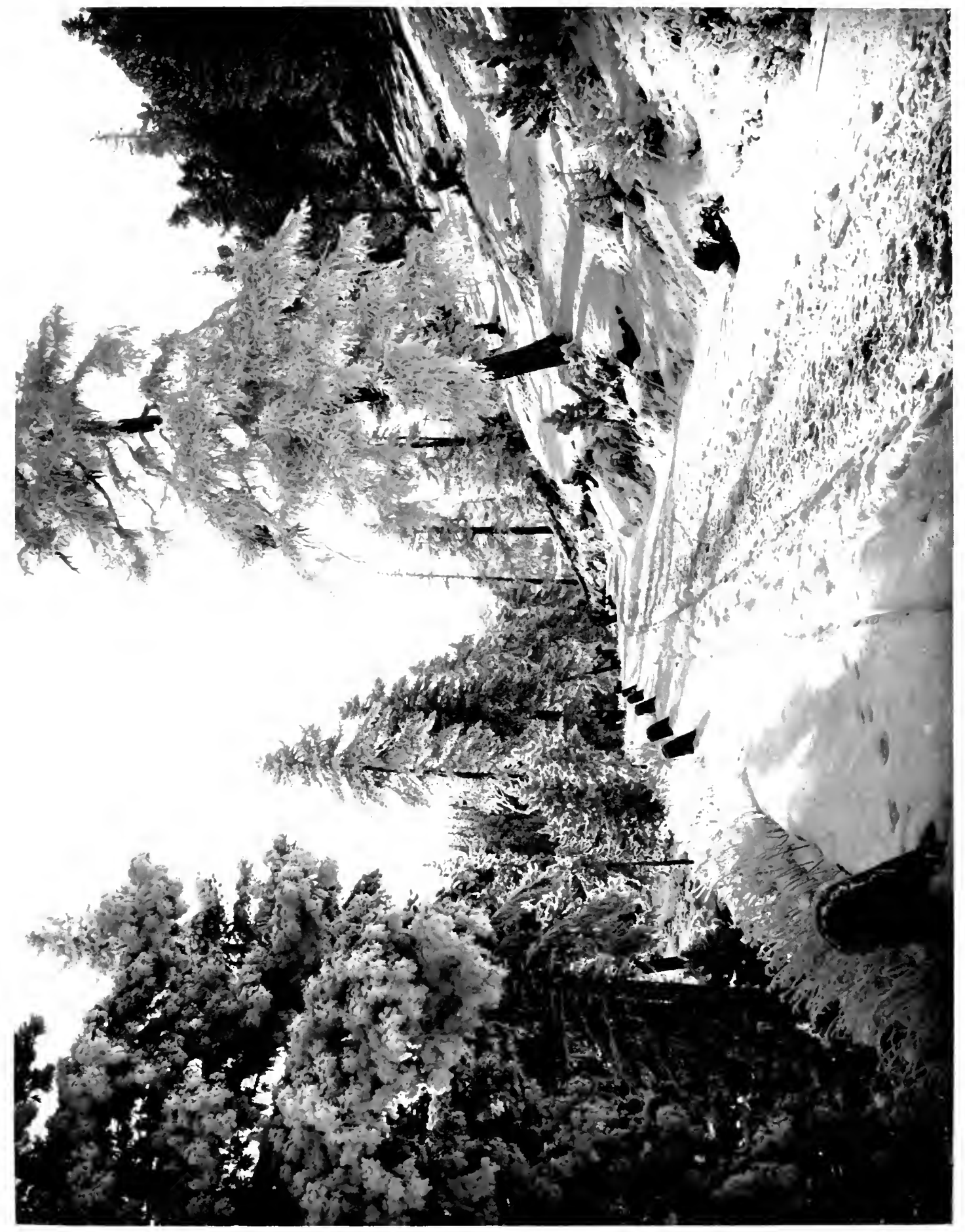




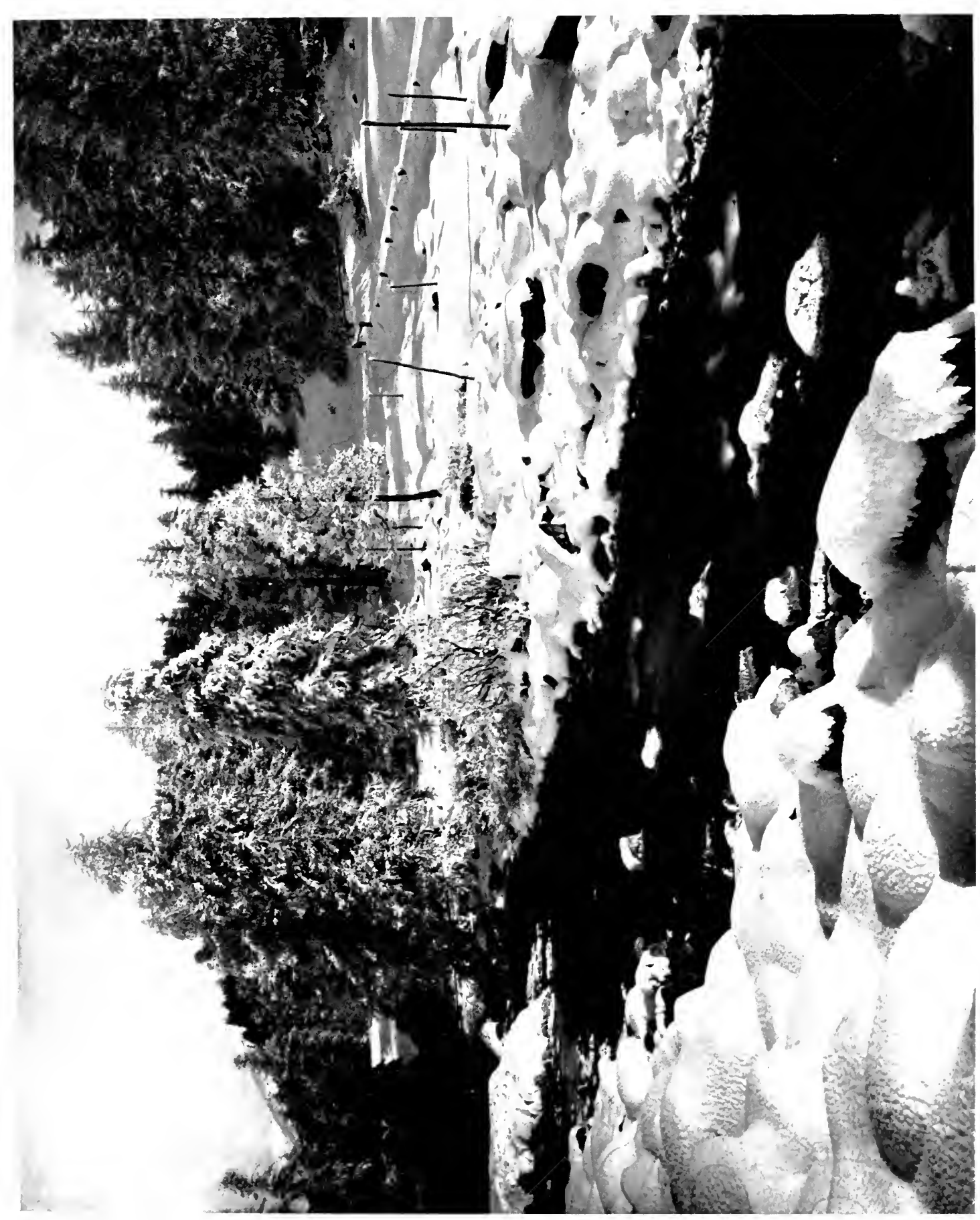





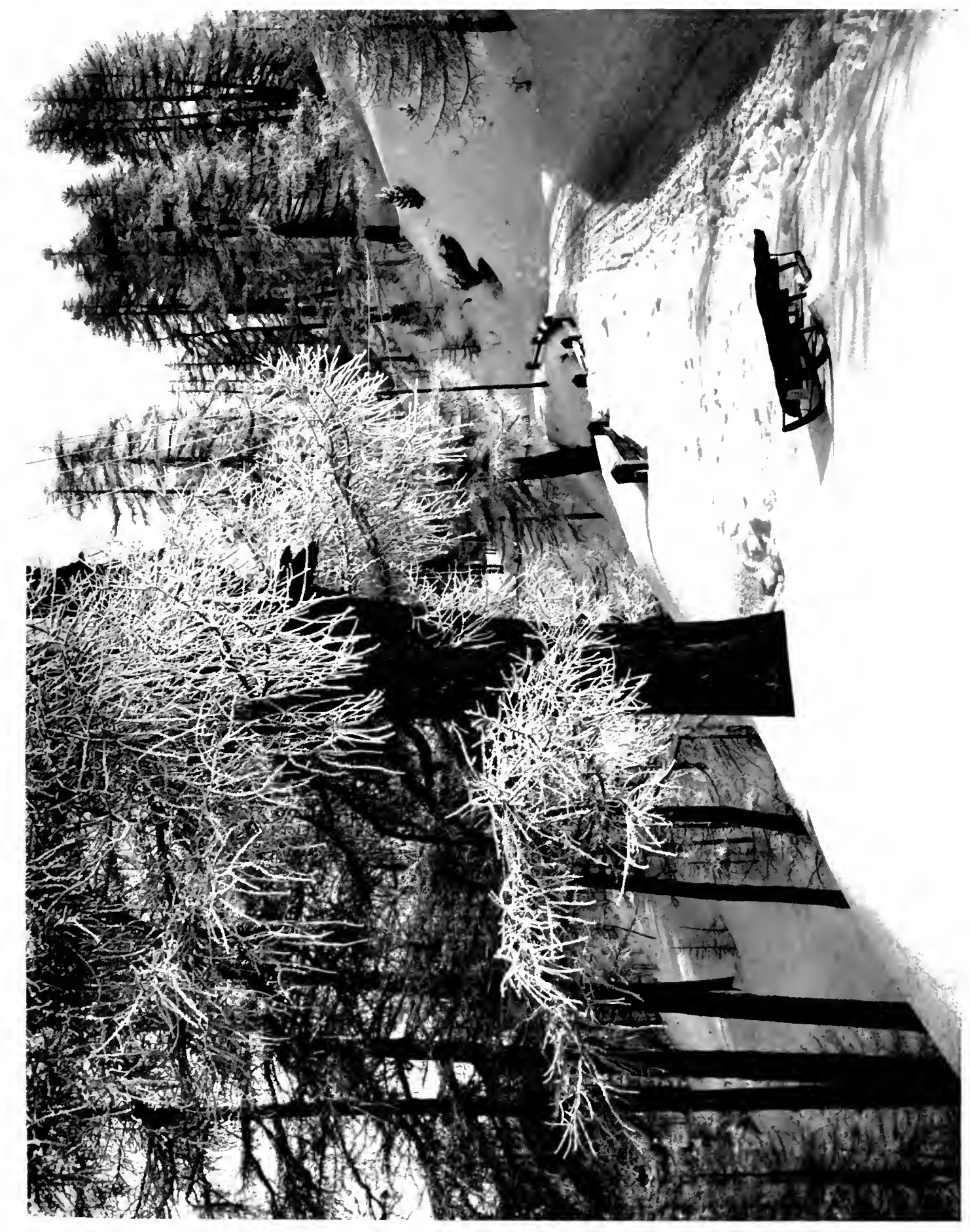





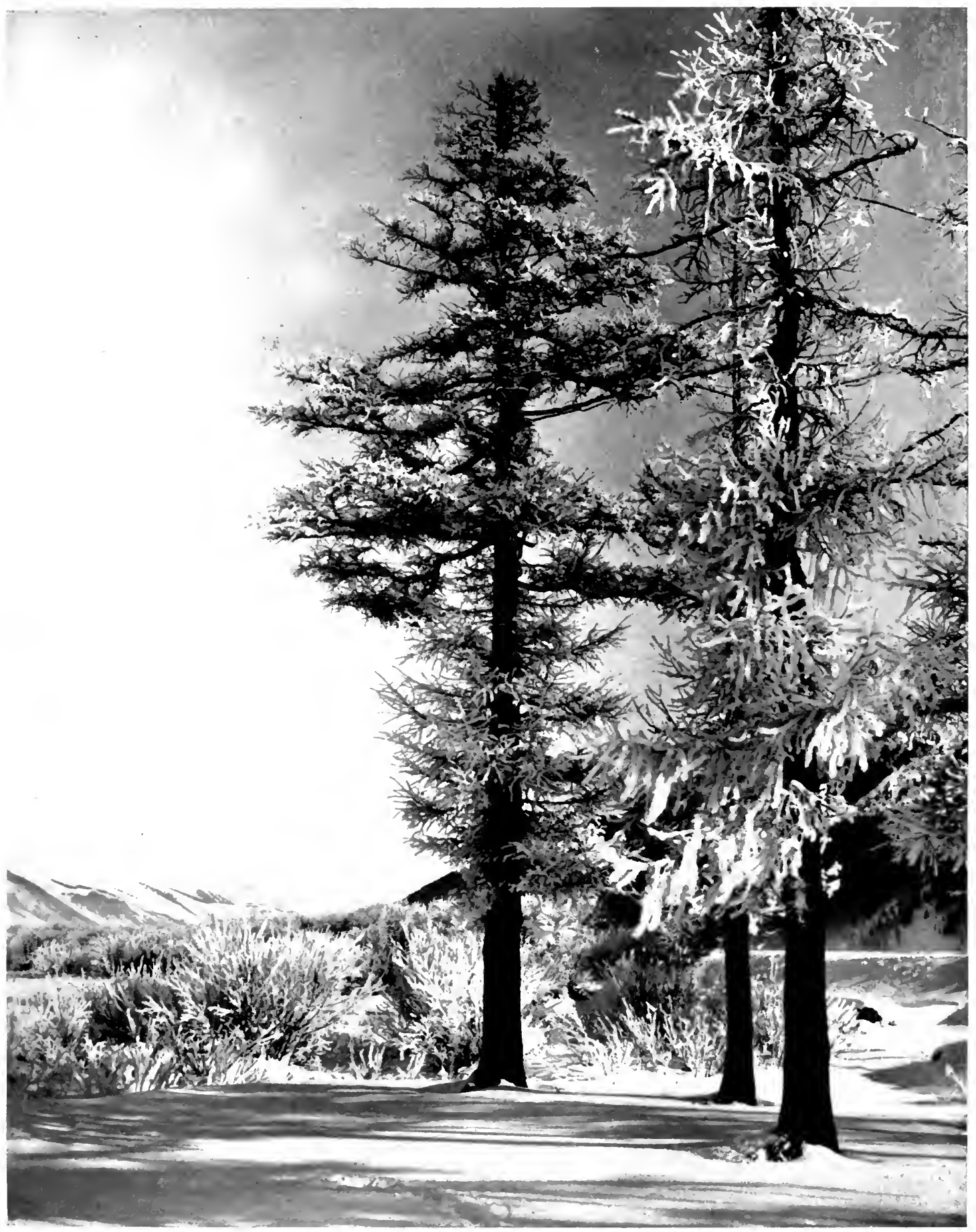





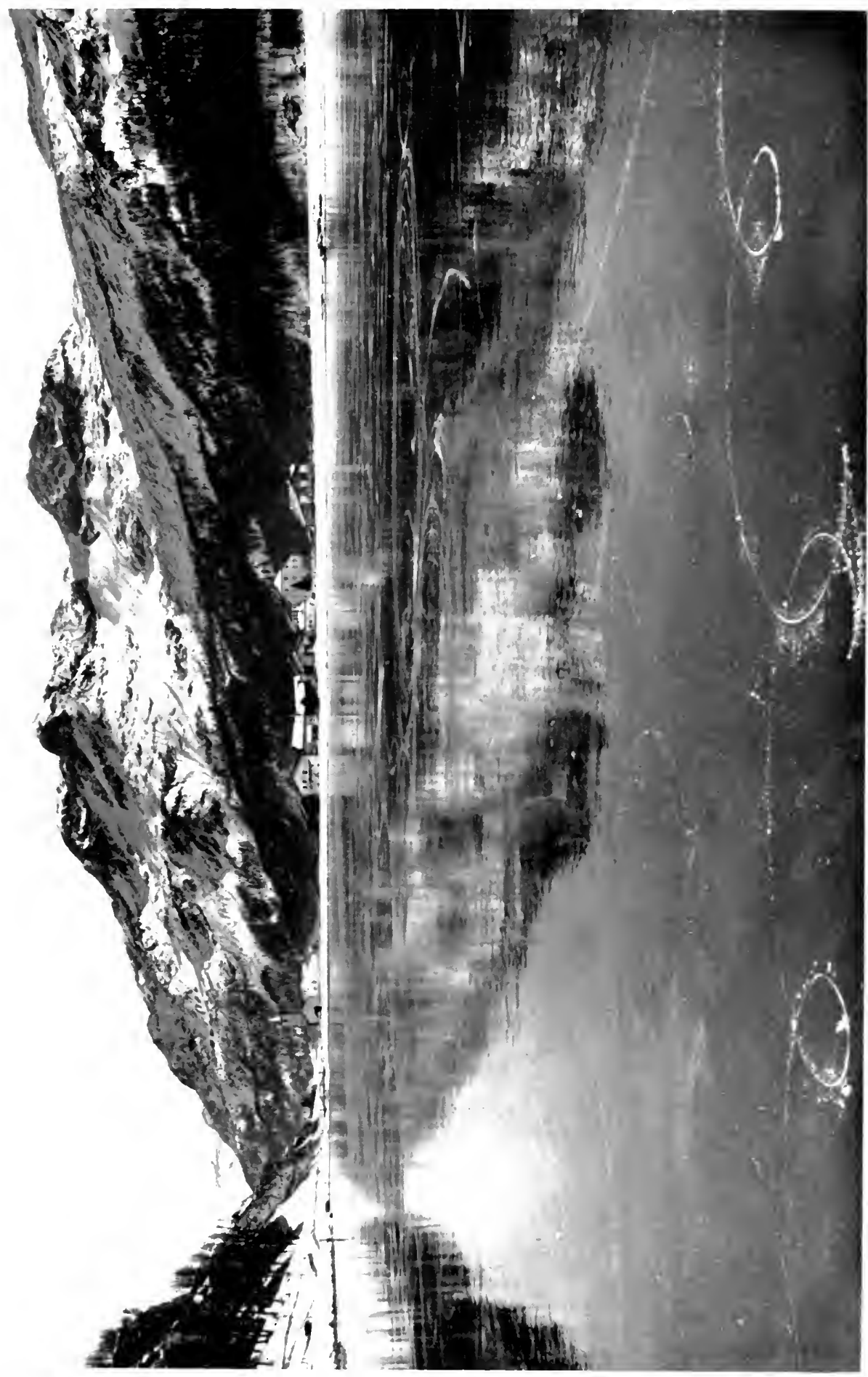





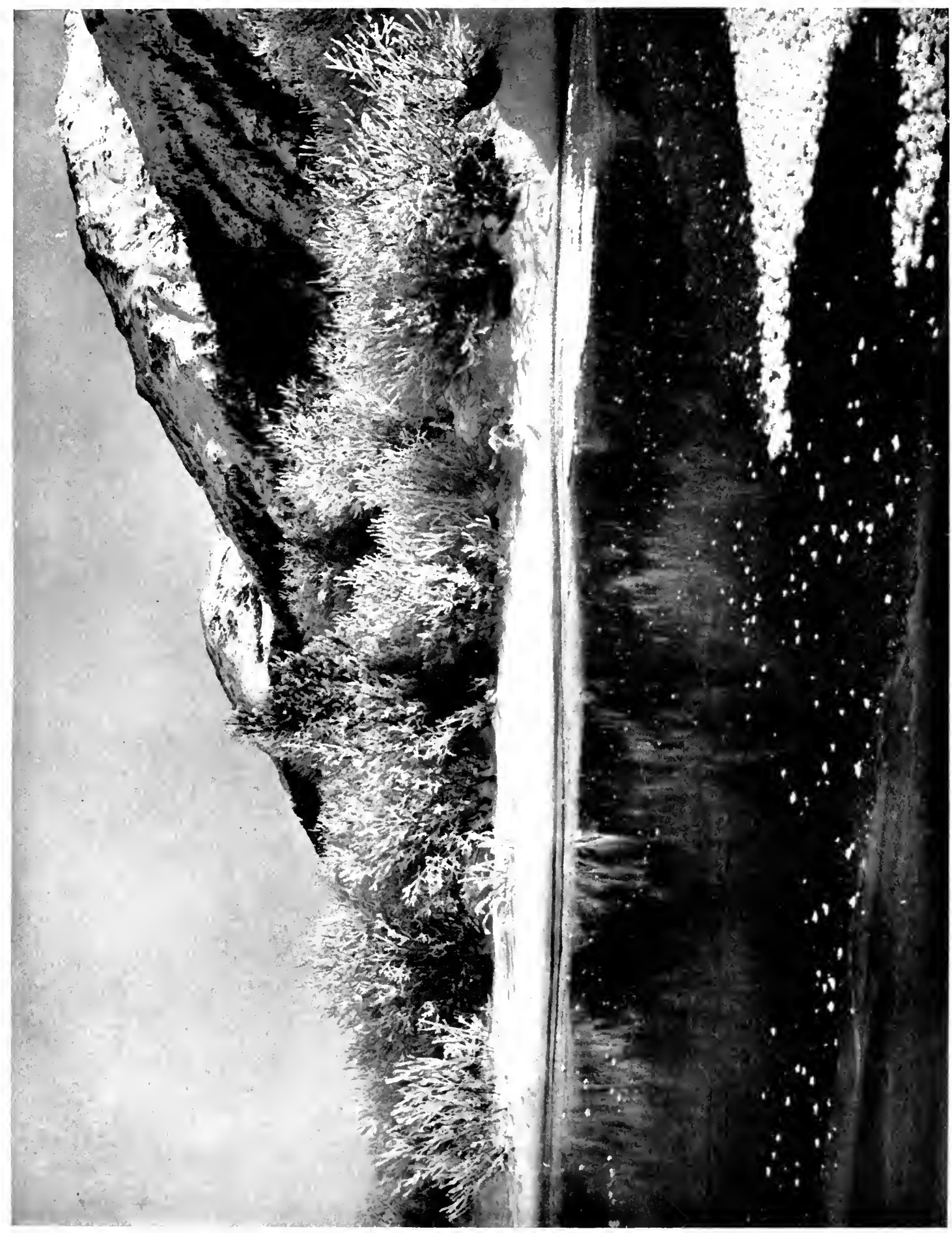





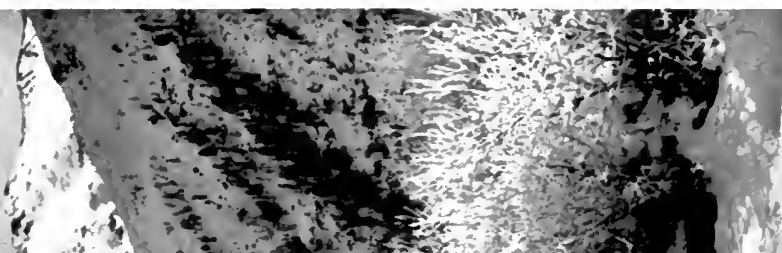

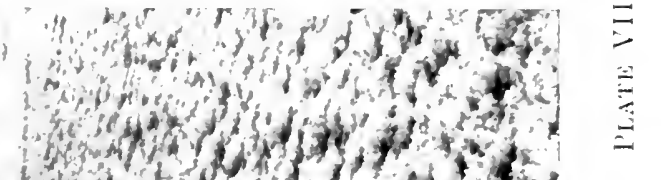

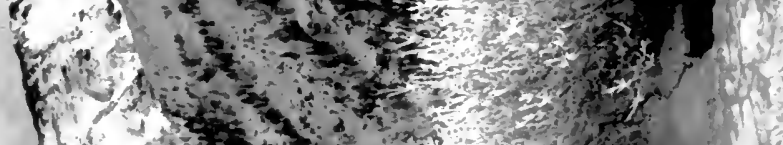
(1) $3 \times$. Wat

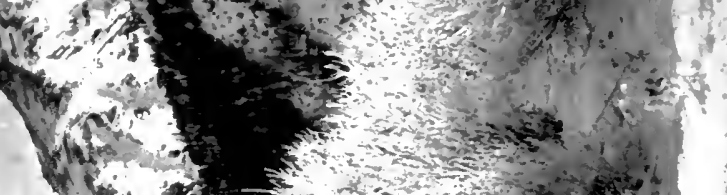

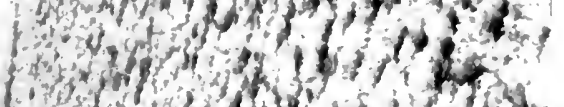

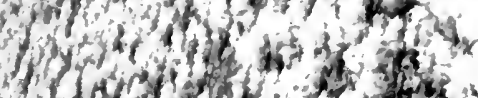



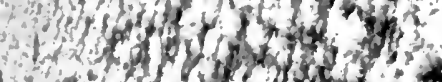

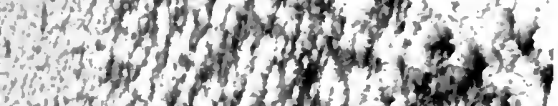

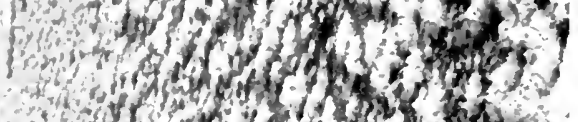
inf - nom

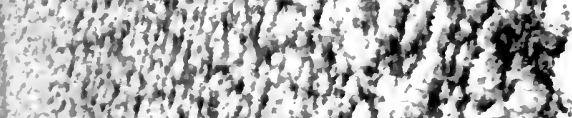

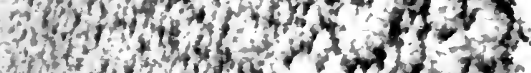

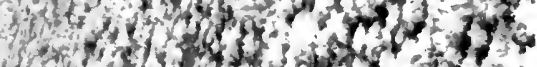

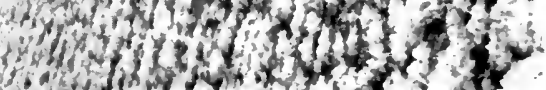

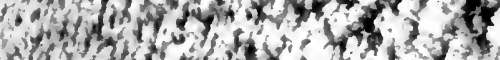
Mon.

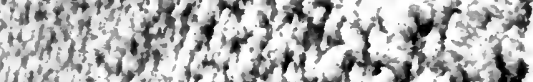

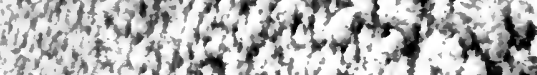



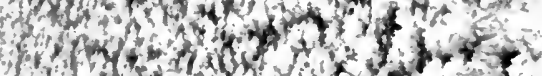

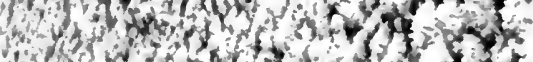

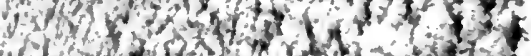

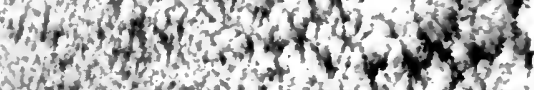

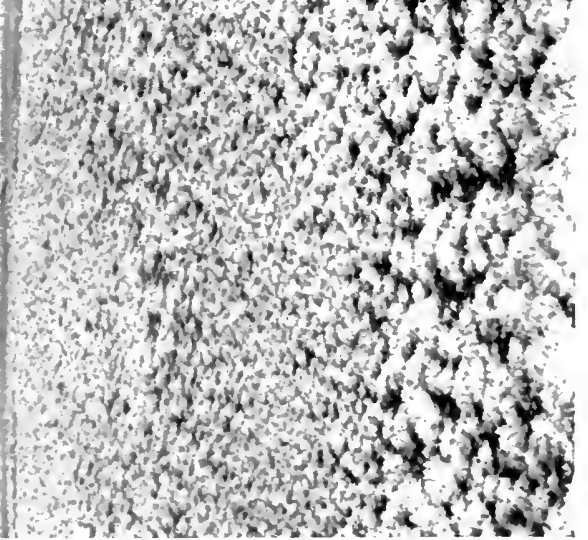


ify

Bx $x^{m}$

Int

5. 4,

$4-3 x+2$

$A=x+2 y$

betar

t.

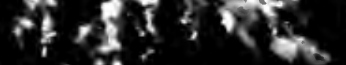

if 8 is?

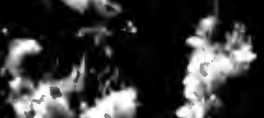

\section{(1)}



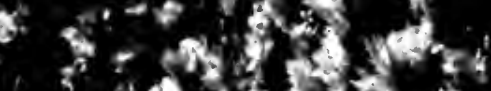

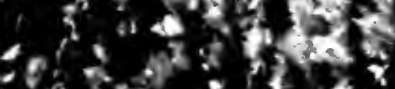

$\therefore+\frac{1}{20}$ :

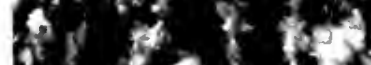

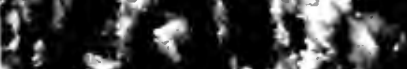

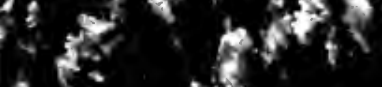

i) $2=2$.

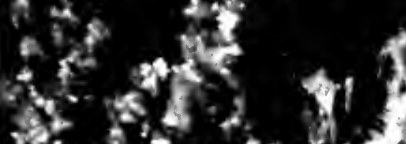

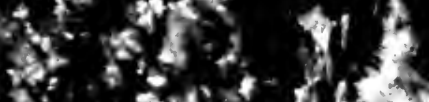

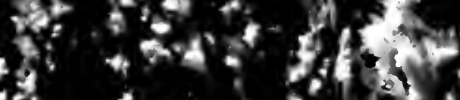

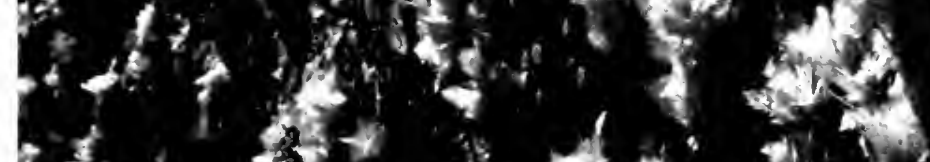

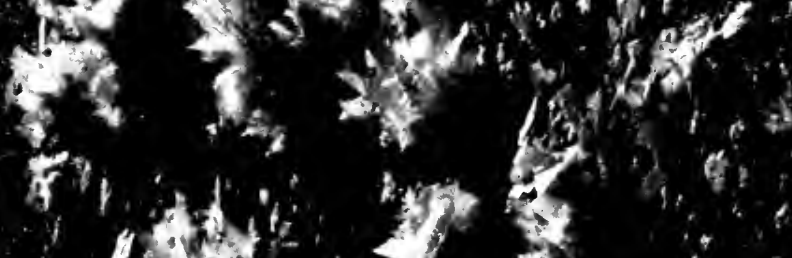

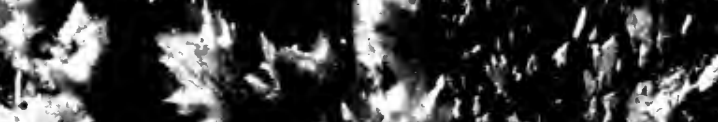






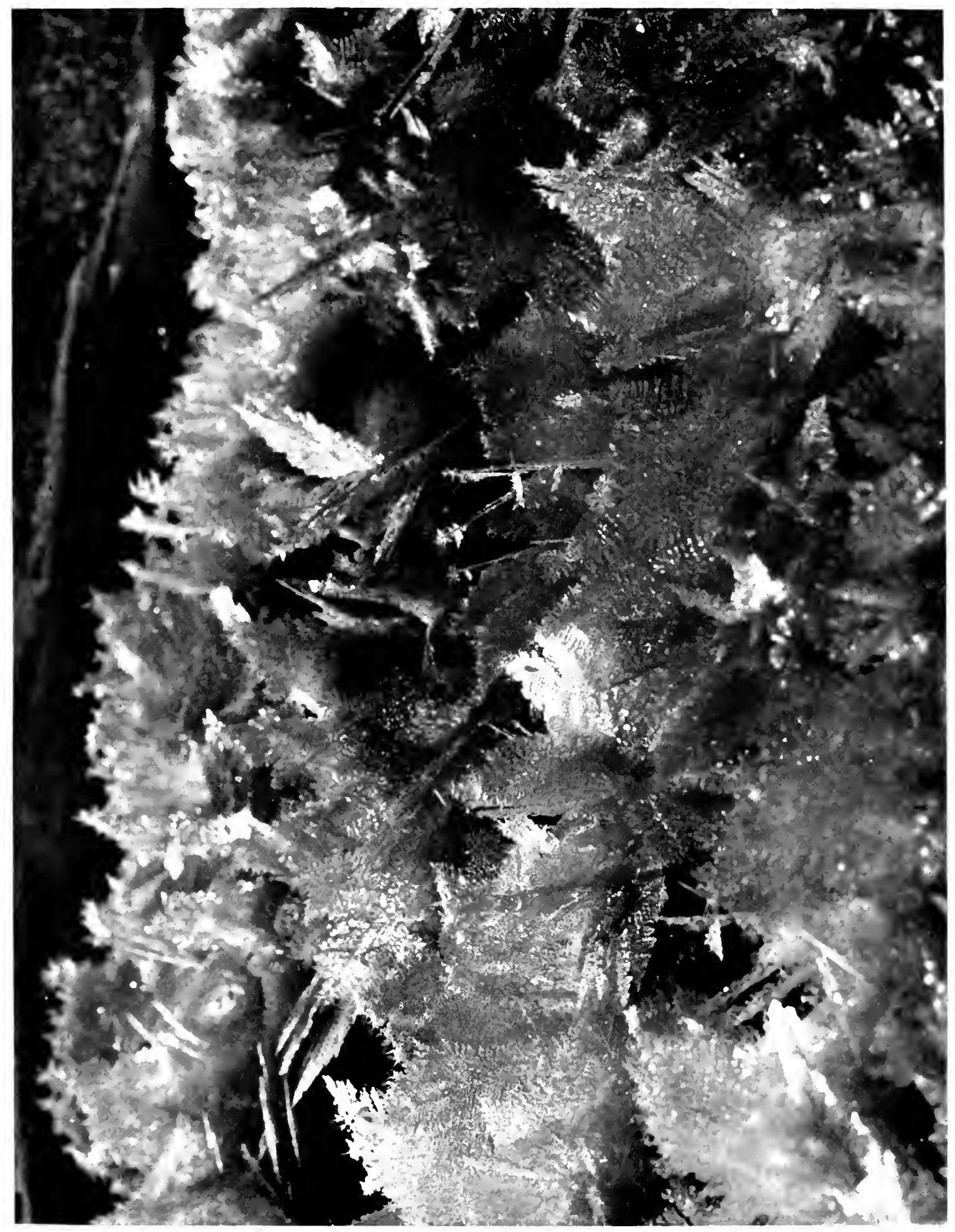





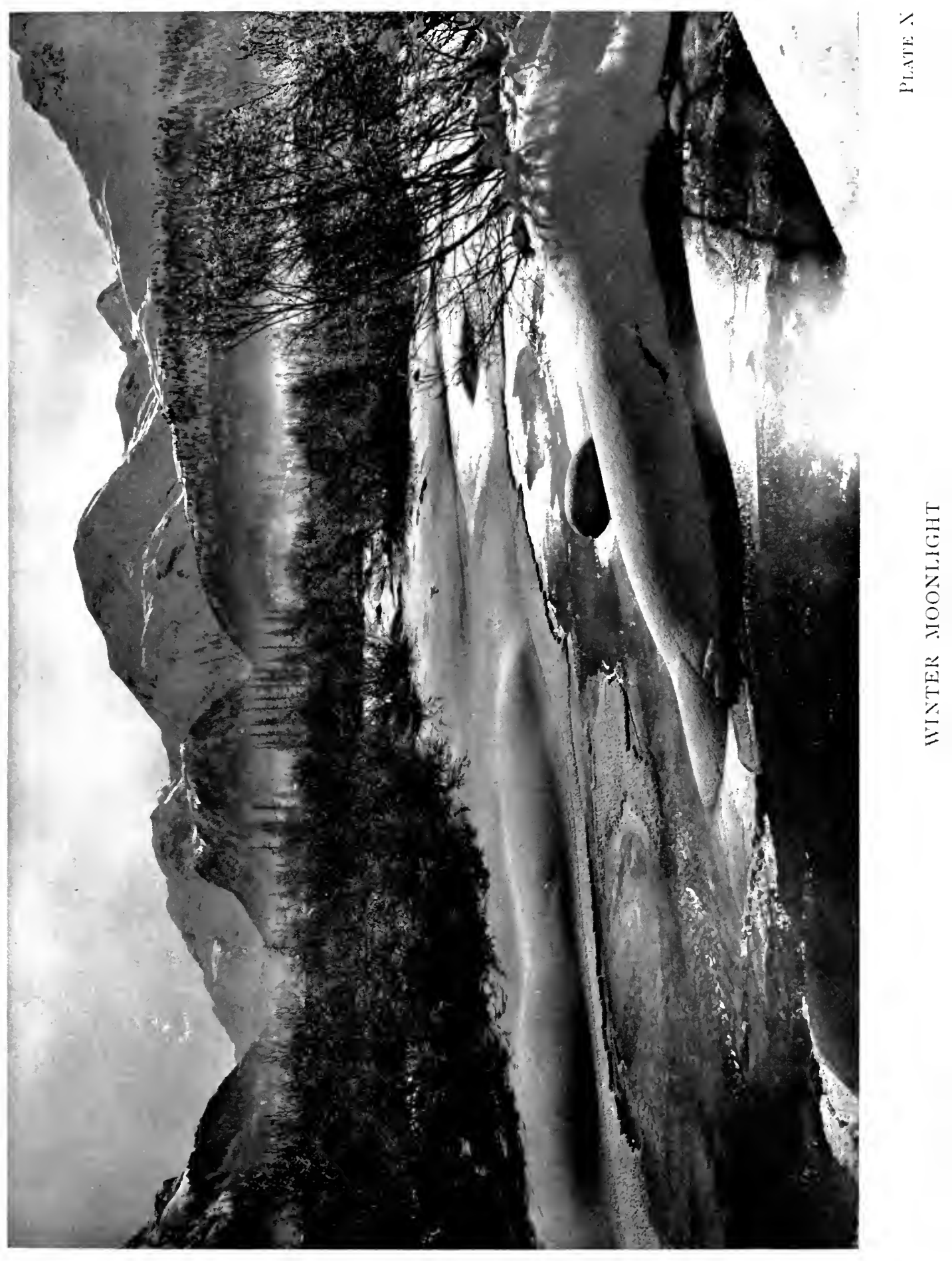





\section{CHAPTER II \\ RINKS AND SKATERS}

Something has already been said about the swift-growing jungles of frost-flowers that so speedily cause the lakes in Switzerland to be utterly useless for all purposes connected with skates. It suddenly strikes the writer that the inexperienced in these matters will have concluded that I mean that when once those frostflowers have formed all skating is over, and that if they have gone to Switzerland for the indulgence of this taste, all that is henceforth to be offered them is the opportunity to admire this frozen vegetation instead of cutting figures. I therefore hasten to assure them that lake skating in Switzerland does not count: indeed most winter resorts have no lake at all; and even if they have, skating there is quite the exception and not the rule. In nine cases out of ten the snow spoils the ice before it bears, and the frost-flowers spoil the greater part of it, even if the snow has held off, almost immediately afterwards. Lake-skating, in fact, is of the nature of a bonus rather than a dividend : to be enjoyed if it happens, but by no means to be reckoned on.

But at every Swiss resort there are rinks made, which render the skater independent of natural surfaces of ice, and those, at all well-conducted places, are " new every morning," because every evening they are swept and sprinkled with water, which by the ensuing day has frozen, and presents a fresh surface to the 
zealot. In fact, an artificial skating-rink is as necessary an equipment in the Swiss winter resort as is the hotel itself. The construction and renovation of these rinks is most interesting, and ranks among the fine arts, just as does the architecture of a fine golf-links or the preparation of good wickets. These rinks are used for two purposes : skating, including bandy or ice hockey, and curling. I do not count ice-gymkhanas or ice-carnivals, because anything is good enough for them. You can play the shovel-game or crawl through barrels among the jungles of frostflowers. I do not imply that such entertainment is not exceedingly amusing; I only mean that the artist in rink-making paints his masterpieces primarily for the sake of the skater and the curler, not for the Pierrot with his Chinese lantern, or those who win three-legged races.

The technique of these ice-pictures is in brief as follows:

In the beginning of the creation (from the skater's point of view) a piece of ground is carefully and accurately levelled. This, if it is to be the foundation of a well- and truly-laid rink in the ensuing winter, should be done early in the spring, because the ground will have then had time to settle down, and the inequalities which always occur in this settling can be made good, before the first frosts of the autumn begin, and the soil gets fixed and frozen. Also, so $\mathrm{I}$ am told, the fact that the ground will then be covered with a growth of weeds and grasses, causes the foundation of the rink to be of better quality. This is easily understandable: the base is matted, and is probably more coherent in texture and less liable to contain holes through which the water may drain away. Then. when the whole ground has been 


\section{RINKS AND SKATERS}

doctored, i.e. when the small inequalities have been corrected and it is as uniformly level as can be expected of anything in this shifting world, everybody sits down and smokes (as is the habit of the Swiss peasant) till the first good snowfall comes, probably in November or early in December. Then the merry peasant has to put down his pipe and work begins again.

A row of them (I am describing the most up-to-date method) stand close together with arms interlocked, in as straight a line as may be, and trample down all this beautiful fresh snow. Up and down they go, in slow time, stamping heavily with their great feet, and making out of perhaps a foot of snow some 3 or 4 inches at the most, of really compact and hard foundation. It will resemble at the best, as regards evenness, a lane over which flocks of ponderous sheep have passed; but the groundwork (this is the main point) will be of hardened snow, though extremely rough of surface. Then they may all sit down and smoke their pipes again-all, that is, except the headman and those who pull about, at his bidding, the yards of hose which at one end terminate in a brass nozzle, at the other in the water-supply, which should run in the main at high pressure. This water is then turned on to the compacted snow which gets soaked with it, and, if a few nights of hard frost follow the original snowfall, becomes gradually converted into a sort of rough but glazed and solid ice. Then, if nothing untoward happens, in the shape of thaw or further snowfall, the next step is taken. But if there is during these few days a thaw, they have to wait for more snow to fall, and do their trampling over again; while if there is more snow, the poor wretches have still to trample and get the foundations firm again. 
But if all goes well-and the experienced iceman will delay the original trampling until the barometer or his weather-sense (preferably the former) promises cold weather to follow-he makes his second operation. He will have built a small bank of snow perhaps 3 feet high and well-spaded down, round his rink, and have sprinkled that as well as his rink surface, so that it is at any rate glazed with ice and water-tight. Then, waiting for a bright sunny morning, he floods the whole rink with perhaps 2 inches of water. The sunniness of the day is most important for this operation: if he put on this flood on a cold day, or at evening when a frosty night was imminent, all the water he put on, lying on the cold frozen surface below, and with the frosty air above it would freeze solid without cohering to the original frozen foundation. But putting it on while the sun is hot, the top surface of the foundation is percolated with the flood, and when the frost of the night follows, the flood binds with it. One night possibly may not consolidate the flood: if it does not, he waits till another night completes the work. All the time, it must be remembered, the rink presents the most depressing appearance: little bits of frozen snow have floated up to the surface, frost-flowers perhaps have made their ill-starred appearance, and it still somewhat resembles a sheep-trampled lane. But then things begin to look better: and another inch of water is put on, and then another inch, and then another, each being consolidated before the next is applied, and each being applied not in the evening, but when the sun will slightly melt the previous surface. With each of these floodings the ice grows more desirably smooth, and more immaculately clean, till at the end of perhaps a fortnight 
there is something like 18 inches of solid ice over the ground that was levelled in the spring. At least this thickness is required if the ice is to last properly, for even in mid-winter the most sickening series of climatic catastrophes may occur, which, unless there is good thickness of ice originally built up, may spoil the rink altogether. For on hot sunny days, though the surface of the ice remains quite dry, very great evaporation occurs, and the dryness of the air drinks up the melted ice before it visibly or tangibly becomes water. Or again, even in the most well-conducted winters, at the most approved resorts, there may be a complete thaw, and "the pools are filled with water," which also evaporates. In both these cases, there is a consequent loss of ice, and the bullion, so to speak, must be able to stand the drain upon it. Still worse, there may be a snowfall followed by a thaw, followed by a frost. The thaw has eaten into the ice; the frost has caused this rodent mixture to get encrusted again. And then, if there is not good depth of ice, the most excruciating events tread on each others' heels. The ground below the thin ice is warmed with the penetrating sun, and begins to exude bubbles; the bubbles rise, and horrible water-blisters, skinned over with ice, appear. The skates crash through them (" and langwedge which 1 will not pollewt my pen with describing," as Miss Fanny Squeers said) and cut into the half-frozen ground, which thereupon begins to leak. The most awful mess . . . there are no words for it. Therefore it is necessary, as soon as possible, to get a good thickness of ice.

But this building-up of the rink requires immense patience and forethought. Night after night when the building is going on, 
and the weather is warm and beastly, the head iceman, if he is really competent, will sit up through the long tale of dark hours, keeping himself awake with coffee, and watching the thermometer to see when it registers sufficient degrees of frost to enable him to put more water on to the ice. He will wait all through a cloudy night, hoping for the sky to clear, in order to get a half inch more foundation. It is useless and worse than useless to apply more water unless there are several degrees of frost, for this only weakens his original trampled foundation of snow, and leads to the awful trouble of blisters coming up from the ground. But if even an hour or two before daybreak the temperature sinks, and there is a chance of gaining a further thickness of ice, he will rouse his men, and at any rate spray or sprinkle the whole surface of the rink, in order to get a little more ice, just a little more. Night and day, like a mother over a sick child (I am not exaggerating), a man like Rudolf Baumann, and others not so well known to me, will watch over their rink, to console, to fill up holes, to add another fibre of underlying muscle.

But even when a couple of feet of solid ice are built up over the ground, the trouble of the iceman is not over. Again a snowfall may come, followed by a thaw, and the removal of this reveals sometimes a terrible sort of chicken-pox on the ice. If the snowfall is followed by cold weather, not much harm is done, for the snow is removed by shovels and barrows, and a sprinkle of water over the whole rink-sprinklings being made at night, since a sprinkle freezes almost as it falls, opposed to the slower habits of a flood-shows next day that the rink is no whit the worse. But if a thaw follows a snowfall, the general laws of nature are 


\section{RINKS AND SKATERS}

suspended, in order to thwart icemen and skaters. Theoretically, the surface of the ice below the melting snow will thaw evenly. Practically, it does nothing of the kind. The surface is unaffected in one spot, and immediately adjoining it has thawed into a small round hole about 6 inches in circumference. Why this happens I cannot say, except that it is part of the general malignity of natural law; but the effect is apparent enough, and when the thawing snow is removed, the ice is found to be covered by numberless small holes. Each one of these has to be filled up by hand, with a freezing mixture of snow and water, or better of pounded ice and water. . . . There are rinks in Switzerland 300 yards long-I leave the consideration of these, in the matter of labour required, to mathematicians who like dealing with progressions that approach the infinite.

Now the shrinkage of the ice already gained goes on all winter long, owing to the evaporation of the surface, and owing to the cutting edges of skates, which cover it with a sawdust of frozen stuff that has to be swept off every evening. This perpetual loss must be made good, or else the rink would soon vanish altogether, and it is made good by floodings or sprinklings. A flood of a couple of inches over the whole surface is of course the easiest way of doing this, but it is far the least satisfactory. For, as I have said, the flood must be put on while the sun is still on the ice, to enable it to bind into the ice already formed, and thus hours of daylight are lost to the skater. Furthermore, unless a really severe night follows, it will not be all properly frozen. So the good ice-maker, instead of turning skaters off the ice, and getting by one flood sufficient thickness to last for three or four days more, 
sprinkles instead. This is a far longer and more troublesome process, for with his hose-pipe with its small nozzle he has to go over the ice again and again, six or seven times perhaps, or even more, in a single night, if ice is badly wanted. If it is freezing hard, each sprinkle will solidify almost as soon as it falls, and sometimes he sprinkles all night long; while if it is far too warm for a flood to have a chance of solidifying, he will, unless a real thaw is going on, still find it possible to sprinkle once or twice before morning, even though there is but a degree or two of frost. Another immense advantage that sprinkling has over flooding is, that ice thus made, little by little, in exceedingly thin layers, lasts, for some reason, far longer than a greater thickness of ice frozen solid in a single night. Why this should be so, I do not know; but the fact is incontestable. Certainly also a flood of a couple of inches frozen solid is far more brittle in itself than ice built up in thin layers, and an awkward toe-strike with the tip of the skate will cut a great chunk out of flood-ice, whereas it makes far less impression on sprinkled ice. The sprinkle should be thrown far and high (as illustrated in Plate XIII), so that it comes down on to the ice in fine mist-like rain that freezes quickly and freezes tightly into the ice already there. Of course all these difficulties are not encountered in a perfectly cold winter. Given a hard frost every night, it is easy to keep pace with the daily evaporation. But even in the loftiest winter resorts in this excellent republic, mid-winter thaws occur.

Such in brief is the making of these rinks that seem such simple affairs when made, just a level piece of ice with a smooth surface. But the knowledge, the care, the watchfulness which are necessary 
to secure good ice that will last all winter and reasonably resist any thaws and snowfalls that may occur, are enormous. And the same care that is lavished on their making must be expended on their keeping. No one with soil on his gouties or a cigarette even in his mouth should be allowed on the sacred surface, for even a feathery ash of tobacco if allowed to lie on the ice will get warmed by the sun and gradually melt its way into the ice. The sprinkle that night covers it, and it is embedded in the ice like a fly in amber. Again the sun shines on it, it melts a little water round it, and forms the nucleus of what will spread into a blister in the ice. Any dirt in the same way makes similar holes, and nothing but the clean skate-blade and the necessary and privileged boots of the icemen should ever be allowed on the rink. How amazed would be the pioneers of outdoor artificial rinks if they could see the huge and perfect surfaces now yearly prepared for the hordes of foreign visitors who flock to Switzerland. Of those pioneers John Addington Symonds was one, and in his charming essays he recounts how at Davos he and a few enthusiastic friends took exercise by incessantly working the handle of a pump that stood in the middle of a level field, until, I think, the pump froze. Then greatly daring they proceeded to skate over the amazing ridges and shelves of ice which must certainly have been the result of this hardy undertaking. Nowadays a reservoir must be built at a sufficient height above the rink to secure a good pressure of water for the sprinkling, and patient laudable men sit up all night watching the thermometer to see if it is safe to offer water to the delicately-nurtured crystal. But from these fine-art rinks has fine-art skating been evolved, and if the pioneers of rink- 
making wondered at our reservoir, our cohorts of workmen, our huge glassy surfaces, still more perhaps would the skaters of those days be astonished to see some champion of the Continental style execute his " back loop change loop eight" laying the loops one on top of the other, or observe four gentlemen of the English style swoop down at top speed and on back edges to their centre, flick out four creamy rockers and glide away again to their appointed circumference. So much then for the skater's material needs: we pass on to consider the use he puts them to.

Now there are two styles of skating ( $\mathbf{I}$ do not refer to good skating and bad skating), known respectively as the English and the Continental or International. In past days, certain exponents of one or the other school, with the mistaken idea that to belittle another was to magnify themselves, fell into the stupid error of comparing the two to the accompaniment of robust vilifications of that style which happened not to be so fortunate as to number them among its adherents. But it is no exaggeration to say that the two styles have nothing whatever to do with one another. It is true that the performer in each case is on skates, and that the skates progress over ice; but the very skates are different; so, too, is the whole mode, manner, style, and effect of performance, and it would be as reasonable for the Rugby football player to assert that Association is not real football, as for the English skater to label the International skater an acrobat or contortionist, or for the International skater to call his detested English brother an exponent of the ramrod school. Many flowers of speech bloomed in the gardens of these controversialists, the more exotic and violently coloured blossoms springing, I think, from 


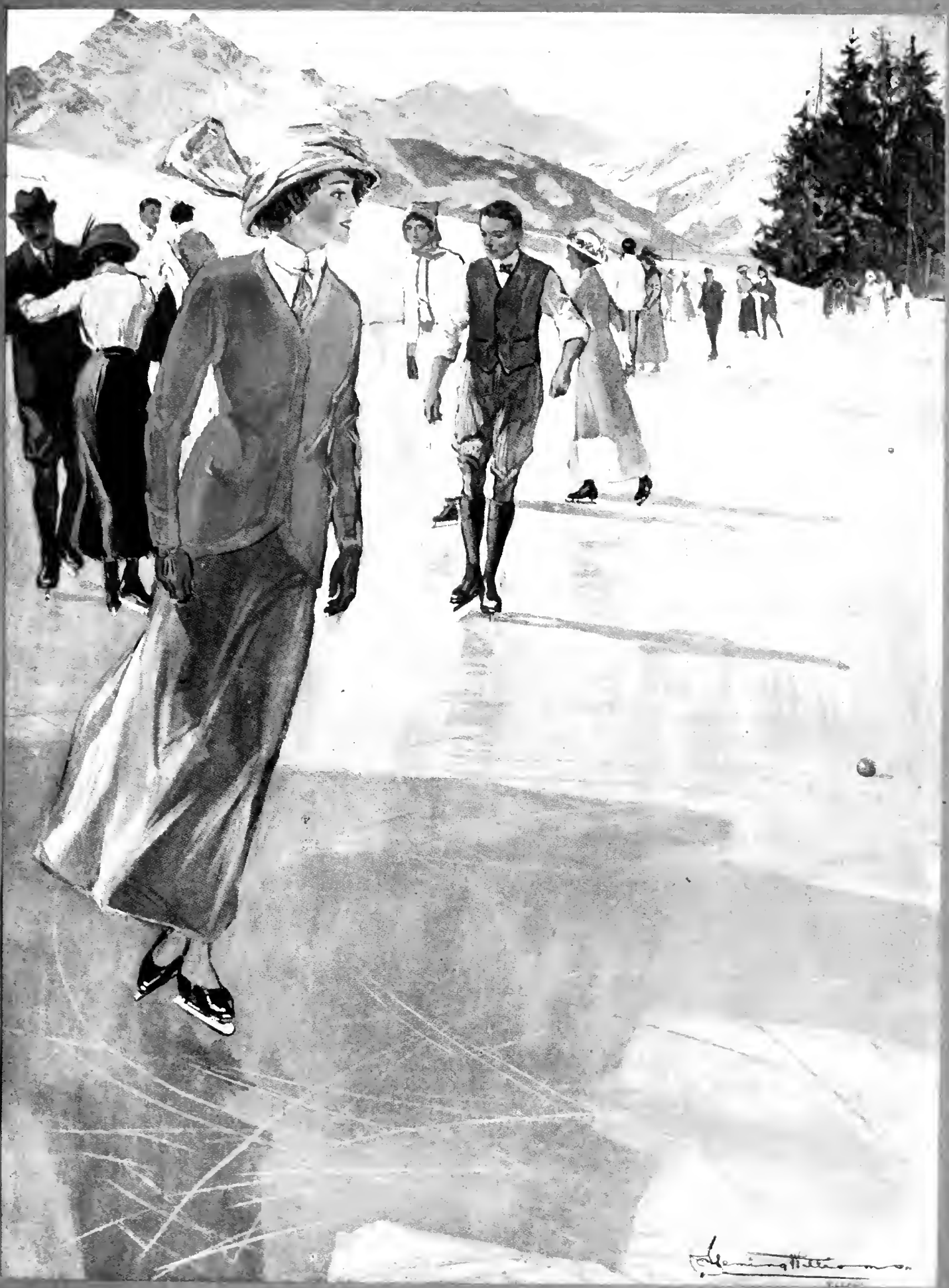


C.

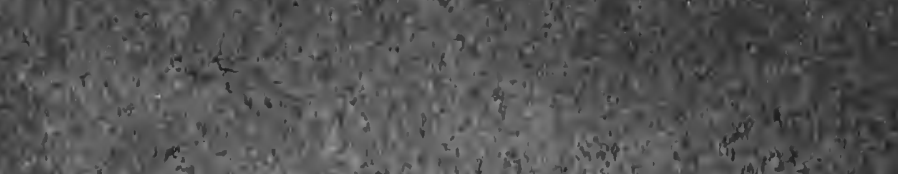

Deta



(19) (1) $\lim _{1}$ site.

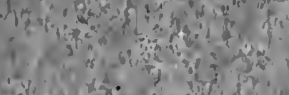

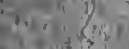

(.)

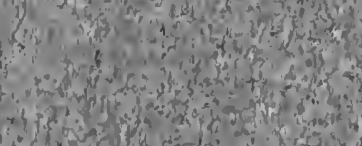
-

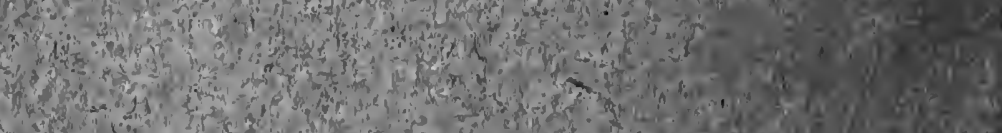

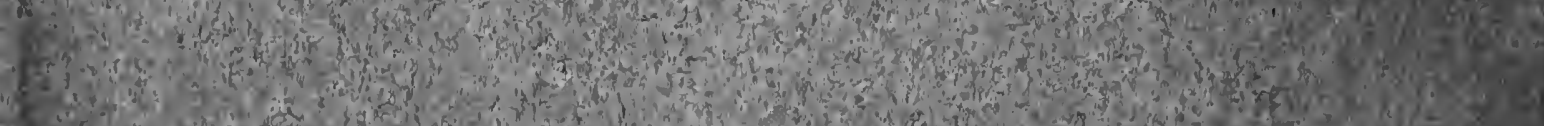

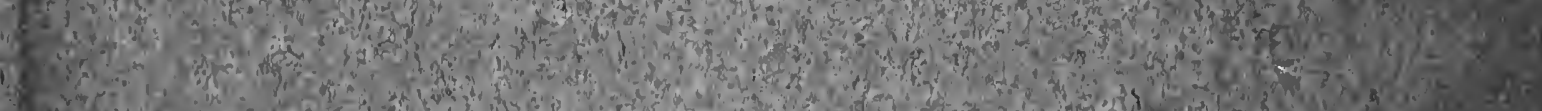

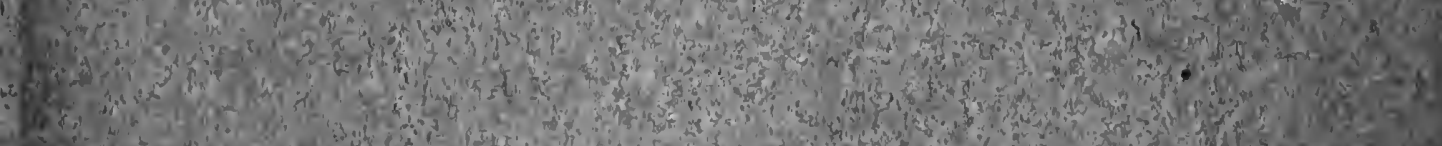


25e $\frac{1}{4}$

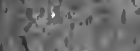

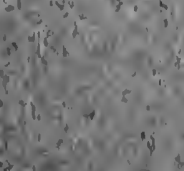

$-4 y^{2} \cdot e^{2}$ is S. (5) ing $x_{x \rightarrow 2}+x_{2}$

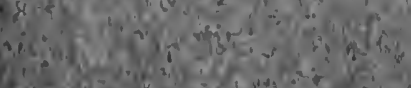

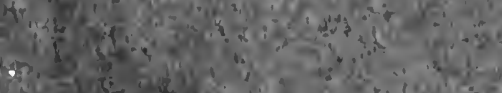
Po $x=1$

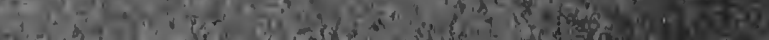




\section{RINKS ANND SKATERS}

certain skaters in the International style, who were admirably industrious at one time in their denunciation of anyone who ventured to skate in the English style. The present writer, for instance, who, poor fool, thought he was amusing himself quietly in attempting unambitious feats in English skating, without interfering with anybody, had an open letter addressed to him in the Engadine Post, pointing out the vileness and wickedness of his heretic ways; and a precious little book, that now lies open before me, which did not attract as much attention as its unconscious humour seems to warrant, informs us that the theories on which English skating are based are " diametrically opposed to every principle of nature, science and art, and at variance with the unrestrained freedom of action and movement which prevails in every other branch of athletic sport." Probably the writer felt better after that, for we have heard nothing of him since; while with regard to the above-quoted criticism, the only comment that need be made is, that on the same silly lines it would be reasonable to call lawn-tennis at variance with unrestrained freedom of action and movement, because it is not part of the game to slog the ball wildly out of court.

But of late this controversy has somewhat died down, the fact being that no one with the smallest knowledge of the difficulties and beauties of skating at all, in whichever of these two styles, ever joined in it, since, whether in personal preference he was English or Continental, he had sufficient acquaintance with skating matters to appreciate and admire the excellence both of his own school and of that to which he owed no allegiance. He saw also that the two schools had nothing to do with each other, 
and instead of jeering at the other, contentedly practised at the one he happened to prefer. Naturally, most Swiss resorts tend to one style or the other; but at Davos, the original cradle of the modern English style, the two schools flourish side by side, as also they do at Mürren, one of the newly-opened Swiss centres. There particularly - at Davos there is a separate English rink, mainly occupied by English skaters-you may see the votaries of the different schools of this now obsolete controversy cheek by jowl on the ice, and lying down together, after a fall, like the lion and the lamb. At St. Moritz, similarly, both styles are bloodlessly practised, though the International style is the more popular; while Grindelwald is nowadays exclusively International, after having been exclusively English. So, too, is Wengen. On the other hand, at Villars, one of the largest skating resorts in the country, there is scarcely an Internationalist to be seen, and Château d'Oex, Montana, and Morgins are similarly almost entirely English in their leanings. But without more enumeration it is sufficient to say that both schools flourish exceedingly, and will undoubtedly continue to do so, and nothing that anybody says will detract from the prosperity of either.

Now skating, in both these styles, is largely a matter of form, and herein it differs from nearly every other sport. It does not suffice in skating, whether you are English or Internationalist, to do certain things, to cut threes, to execute rocking-turns, or loops or back-brackets. All these things have to be done in the manner prescribed by the Vedas, so to speak, of your school. Without doubt there is reason at the base of these methods, for it is clear that if, in a combined figure, four English skaters were 


\section{IITTE JATИHUTVOD- DVITAXZ}

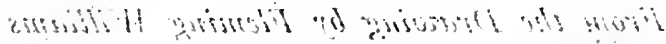




\section{SKATING-CONIINENTAL STYLE}

From the Drawing by Fleming Willians 


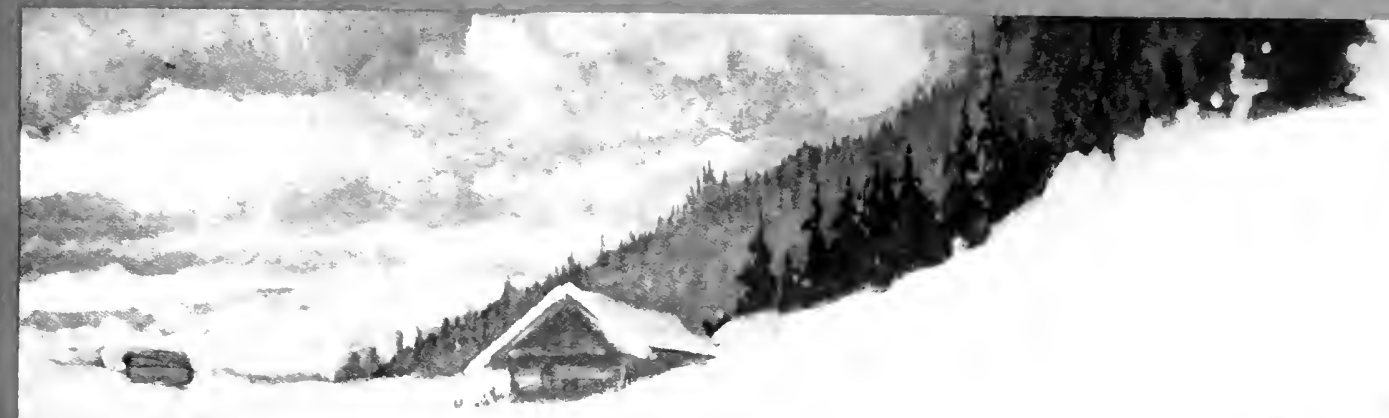



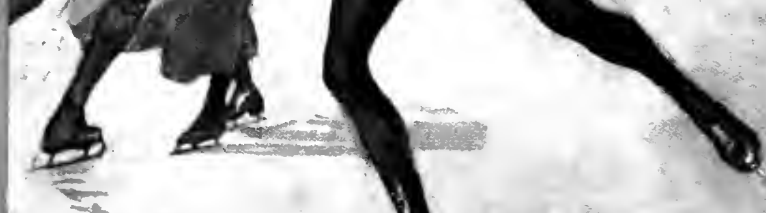

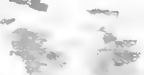

Ex

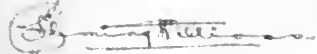

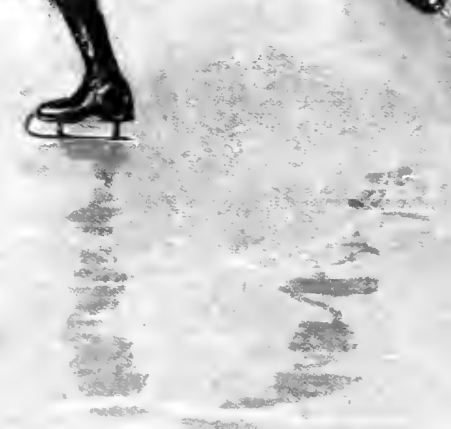

$\sum_{t=2}^{2} \div-15$






\section{q

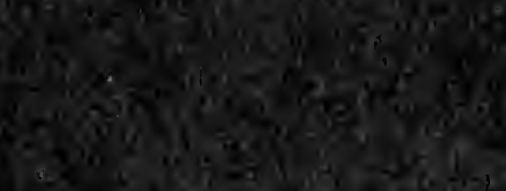

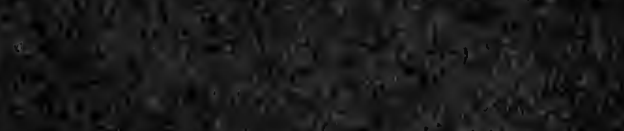



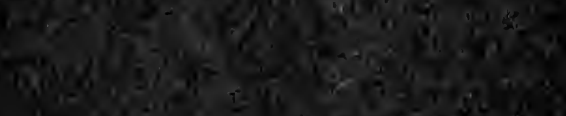

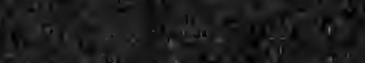

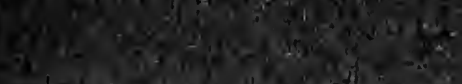

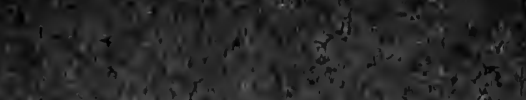

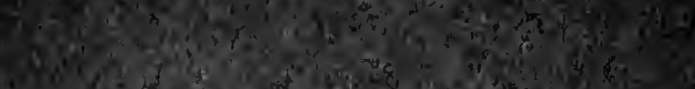

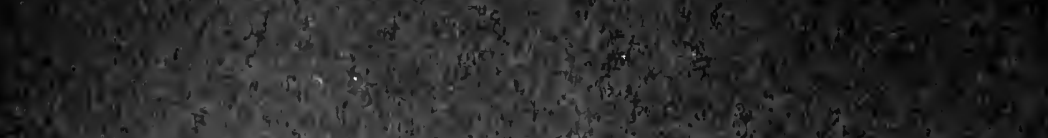

If

5.

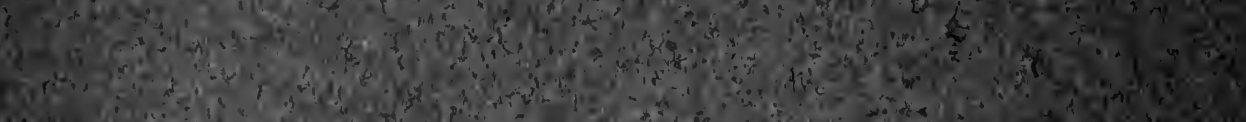



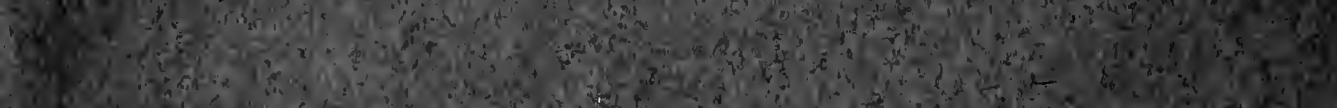

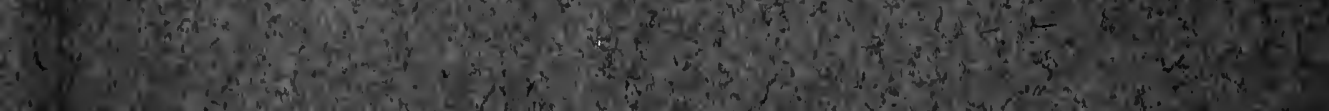

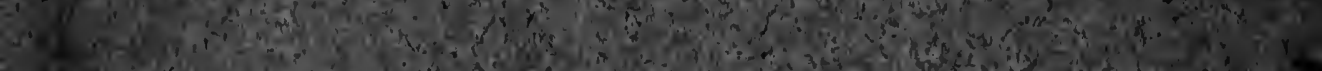

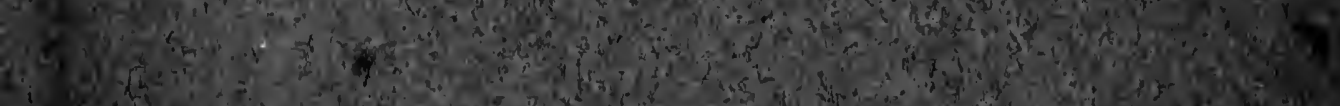

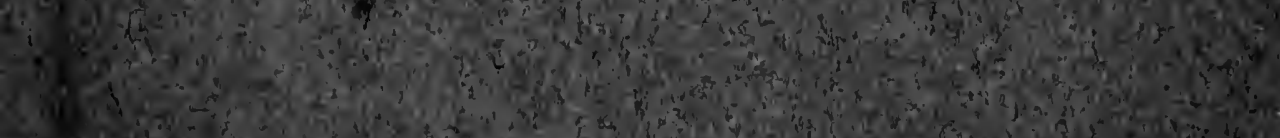
Hon S.



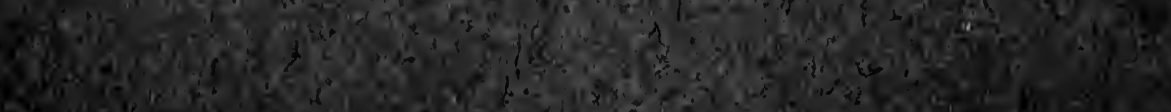

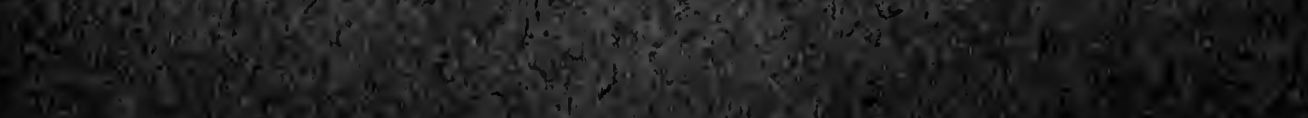




\section{RINKS AND SKATERS}

allowed to fly into their centre on a back edge with their unemployed leg waving, and there execute a rocker, there would immediately be a heap of mangled bodies on the ice, a result which is not recognised as being among the objects of combined skating; and similarly, in the International style, the graceful poses of arm and leg, which ignorant English skaters look upon as mere display, are designed to assist the movement. But in all other games (and this is where skating differs from them all) the point is to achieve a certain object, and the achievement of that object, however attained, renders the achiever a notable performer if he consistently attains it. The golfer, for instance, who consistently drives a long straight ball, puts his mashie shot near the hole, and generally putts out, is a magnificent golfer, in whatever manner or style he executes these tyrannously difficult feats. There are a hundred and a hundred hundred styles and modes of putting, and they are all good, provided only they enable the putter to hole his ball. At cricket, similarly, a man may bowl fast or slow with any sort of break, and with any sort of action (provided his shirt sleeve is not wantonly flapping), and he is a good bowler if only he gets wickets cheaply. But at skating the prescribed thing has to be done in the prescribed manner, and the prescriptions of the English school are, broadly speaking, all of them diametrically opposed to the principles of the International school. In the English style the employed leg (i.e. the one which for the moment is being skated on) must be straight; in the International style it must be bent. In the English style the unemployed leg must be close to the other, and hang beside it, loosely and easily; in the International, wherever the exigencies 


\section{WINTER SPORTS}

of the movement demand that it should be, it must at any rate never be there. In English the arms must not be spread and swung abroad to assist the movement, but must be carried inactively by the side, whereas in International, as long as the skate moves the arms must be engaged on their assigned activity: In both schools, in fact, every movement must be executed in a given way, but in no case is there the smallest resemblance between those ways, though both should result in clean edges and clean turns executed at defined places.

It is not my intention to give here a manual of English skating, beginning with instruction to beginners and ending with timorous hints to experts, but any book on Winter Sports would necessarily be incomplete unless it babbled to some considerable extent about skating, which, without doubt, is the sport in pursuit of which the large majority of English folk visit the High Alps in winter. From whatever cause, this slippery art exercises a unique spell over the able-bodied and athletic section of Anglo-Saxon mankind. It may be that this is partly accounted for by the comparative rarity of the occasions on which we can skate, owing to our Gulf-Stream-beridden and generally pestilential climate, and it is sufficient that some puddle-place in a village green should be half-frozen to cause the majority, not only of youth but of sedate men and women, to hurry down to the spot, and there slide about on both feet with staggerings and frequent falls and the ever-present possibility of occasional immersions. But the rarity of even half-frozen puddles in England does not wholly account for the transcendent spell: there is something in the 


\section{RINKS AND SKATERS}

quality of motion which is started by a stroke of the tense muscles, and then continues of its own accord, without effort or friction, until the impetus is exhausted, that appeals to our unwinged race, who must otherwise keep putting foot before foot to get anywhere. The sensation itself is exquisite, and the sensation is rendered more precious by the fact that from the days when the tyro slides cautiously forward on both feet, to the days when, having become a master in his art, he executes back-counters at the centre in a combined figure, there is always a slight uncertainty as to what is going to happen next. The tyro rejoicing in the unaccustomed method of progress is conscious of a pleasing terror as to whether he will not fall flat down, and glows with callow raptures all the time that he does not; while the finest skater who ever lived, will never be quite sure that he will flick out his back-counter cleanly and unswervingly. We can all walk pretty perfectly-at least, there is no pleasing terror that we may be going to fall down-but none of us at our respective levels as artists in skating can skate pretty perfectly. We can only skate moderately well, considering how well we can skate. And the joy of it! The unreasoning, delirious joy of the beginner who for the first time feels his outside edge bite the ice, and, no less, the secret elation of the finest performers in the world, when they execute their back counter close to the centre, at high speed, and without the semblance of flatness in the edge! And even if any of us was so proficient as to perform such a feat with absolute certainty, there is no doubt whatever that we should find some further feat that would put us back into the dignified ranks of 
strugglers again. And the same holds good with regard to International skating : at least if there is any among those delightful artists who will execute the Hugel star first on one foot and then on the other without a pleasing anxiety gnawing at his heart, I should very much like to know his name and black his boots for him.

To go more into detail with regard to the manner and style of these antipodal twins, we will take first the twin known as English skating. This falls into two broad classes, namely, single skating and that which is the cream and essence of English skating, combined skating. A further development of combined skating, namely, combined hand-in-hand skating, has not long ago been undergoing a successful evolution, under the auspices chiefly of Miss Cannan, Lord Doneraile and Mr. N. G. Thompson. Without doubt it holds many charming possibilities, and very likely there is a great future before it, but owing to right of primogeniture we will first consider the two elder branches. In both the technique, so to speak, is the same. The object is to skate fast on large bold edges, to make turns of all sorts and changes of edge cleanly and without effort, and to skate all these turns and edges in a particular and prescribed manner.

The first consideration, therefore, is the manner. The stroke must be taken, i.e. impetus must be set up, not with a push of our skate-toe into the ice, but from the inside edge of the skate blade. The reason is obvious, for if a skater thrusts his sharp skate-toe into the ice he will make a hole in it, and damage the ice. That is sufficient: I think there are probably four or five 


\section{RINKS AND SKATERS}

other reasons, which in a general and unspecialised treatise like this need not be gone into.

The skater having got his impetus by leaning against the inside edge of one skate, launches himself on the other. Now there are two edges to a skate, namely, the inside and the outside. There is also the flat base of the skate. Both theoretically and practically, he never uses the flat of the skate in his actual progress. When he turns, whether the turn is a three-turn or a rocker, or a counter or a bracket, he comes up to the flat for a moment, but instantly leaves it again. He progresses on one edge, the inside, or on the other edge, the outside. And while he progresses, he must progress in the prescribed manner. And the prescription is this :

I. His head must be turned in the direction of his progress, whether he is progressing forwards or backwards. Again commonsense is at the base of this rule. For if his head is turned in the direction of his progress, he is looking, unless unfortunately blind, where he is going. This avoids trouble to himself, if there are holes in the ice, and trouble to other people if there are other people on the ice.

II. He must be standing erect with his shoulders and body siderways to the direction of his curve, not facing square down it. In other words, he must, among other things, be travelling not further forward than on the middle of his skate, otherwise he will not be standing erect, but leaning forward. This attitude is that which is referred to, in the humorous book I have already quoted, as characteristic of the ramrod school. But the author, in his blissful ignorance of skating matters, is not aware that it is im- 
possible to execute a long smooth circumference of curve if you progress on the forepart of your skate. If you are on the forepart of the skate, you must be leaning forward, and no one of known anatomy can lean forward and execute a long smooth edge. The balance is unsteady, and the edge wobbles. Commonsense, then, again endorses this rule. In order to be steady on a long edge, your balance must be of the established order. You must be upright, and travelling without muscular effort to retain your position. This is only attained by travelling on the middle or the aft part of the skate. For nobody can stand still on their toes. But standing on the middle part of the foot or with the weight on the heel it is perfectly easy to do so. But when this humorous author (whom I drag out of his obscurity for the last time) calls this the ramrod school, he proves himself ignorant of the first principles of English skating, or perhaps has only observed himself in some mirror at Prince's Club attempting to assume the correct attitude himself. As a matter of fact, the proper attitude of the skater in the English style is exactly that of a man who is well made and master of his limbs standing still with the weight chiefly on one foot. While skating, it is true, the weight is entirely on one foot, and the performer is moving, and not standing still. But the pose necessary to smooth and swift progression is exactly that. It no more resembles a ramrod, when decently done, as every good English skater does it, than it resembles a coal-scuttle or a pince-nez, or what you will.

III. The unemployed leg, i.e. the leg of the foot which is not skating, must hang close to the employed leg. Again the reason is obvious. If four persons came into their centre with a waving 


\section{RINKS AND SKATERS}

unemployed leg, they would hit each other. Also, if the unemployed leg is put out behind, the skater must lean forward in order to counteract its weight. He will then tend to skate on the forepart of his skate. In a series of long edges this attitude is impossible to maintain except by effort. Nobody could skate for a quarter of an hour in combined skating, accurately and largely on such a principle.

IV. The arms must hang by the side, and be carried loosely and easily, close to the body. Again the explanation is obvious. There is no need for their flying abroad, since a long edge is most easily accomplished with the limbs and body in rest after the stroke, and these long smooth edges are part and parcel of English skating : it is founded on them. English skating postulates so perfect a balance, travelling on the middle of the skates, that it chooses (this is the reason for the rule) not to let that balance be assisted by the added or subtracted weight of a correcting arm. It says (this is what it comes to) that you must be so firm on your travelling root, so to speak, of balance, that you dispense with all adjustments of weight. The weight has to be practically perfectly adjusted. There must be no adjustments adventitiously obtained.

Now these four rules are at the base of English skating. If you happen to play a game, you conform to the rules, and you do not argue, for instance, when you are playing cricket, whether you should be given out, when quite clearly you have been caught at the wicket. If you are at all sensible, or in any way like cricket, you pocket your duck's egg and retire. Superb strokes may be made at cricket, which nevertheless are fatal to the striker. 
Superb attitudes, similarly, may be made in the International style, which are quite completely wrong. They may be supremely statuesque, but they are not skating. The case is exactly the same with the English style. Certain canons have been laid down, all of which seem to be necessary to the attainment of excellence: It is no doubt possible to skate charming "threes to a centre" doing everything quite wrong from beginning to end. But if you choose to adopt a style, you must conform to the rules of that style. Similarly, it is quite possible to skate the same " threes to a centre " in the International style, which shall leave the same mark on the ice (though the skating of them broke every possible rule) as the most finished performer could leave there. But who would not applaud the International judge who ruthlessly ploughed such a candidate? He has not kept the rules, which in contradistinction to other games prescribe not only what the object in view is, but the manner in which the performance is to take place. But this manner, we venture to point out, has not been laid down in an arbitrary way: it is the manner, both in International skating and in English alike, in which the feats demanded can alone be properly performed.

Now if the skater will take the trouble to conform to the four rules given above, he will find that even at the outset of his career there is great fun in store for him. Should he conform to them completely, when the complication of turns is added, he will quite certainly find that there is a championship, if he cares for that, in store for him also. The rules were not negligently made; indeed they were never made at all, but are simply the condensed experience of the best skaters, the methods by which 


\section{RINKS AND SKATERS}

the fittest survived. And the fittest did, and always will do, that which is recorded in these rules, and the ensuing complications, even the most complicated of them, are comparatively easy to those who can maintain the proper travelling position. But nobody who cannot hold a long firm edge, for which the proper travelling position is essential, need ever trouble his dreams with the notion of becoming a good skater. And no one's edges approach perfection, if he cannot traverse, on backward and forward edges, outside and inside alike, a distance of at least a hundred yards, given that the ice is reasonably good, without stirring from the attitude he has taken up after his stroke. A really fine skater will traverse much more, and be still as a rock throughout his travel; but no good skater will be so unsteady that he will not easily traverse that. In his actual skating he will, probably, never be called upon to make so lengthy an edge, but its accomplishment should present no difficulty to him, if he aspires to be a fair performer. Even as the pianist, when performing, is not called upon to play simple scales with both hands, so the skater will not be called upon, in his combined figure, to skate for a hundred yards on one edge. But both pianist and skater ought to find no difficulty at all in executing these simple feats.

The beginner is advised to get a fair mastery of all the edges before he begins to attack the fortress of the turns. He should be able to progress steadily and smoothly both on the outside edge and the inside edge forward, and to make some progress also on the back edges, namely, outside back and inside back. This last is far the most difficult of the edges, and it will be a long time before he is able to take fast bold strokes on it. But he should 
have some acquaintance with it before he attempts to make the turns that necessitate its employment, and be able to hold it in the correct position. He can then set about turns and changes of edge, which all imply correct travelling.

Now there are four groups of turns, common both to the English and International styles, each group of which contains four turns to be executed on each foot. Altogether, therefore, there are sixteen turns to be learned which employ each foot singly. These with the four edges, executed in the prescribed manner, form the material of the art. These turns are common both to English and International skating,

I. The first group is known as simple turns, and consists of turns (or changes of direction, from backwards to forwards or forwards to backwards) from :

(i) Outside forward to inside back.

(ii) Inside forward to outside back.

(iii) Outside back to inside forward.

(iv) Inside back to outside forward.

They are all of the same shape with regard to the marks they leave on the ice, and from their shape are known as "three" turns, or " threes."

Thus :

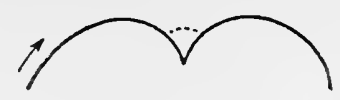

The arrow shows the direction of progress : the turn is the cusp in the middle between the two curves. Thus if the first edge is outside forward, the second is inside back : if the first is inside forward the second is outside back : if the first is outside back 


\section{RINKS AND SKATERS}

the second is inside forward : if the first is inside back the second is outside forward.

II. The second group of turns is known as rocking turns, or more generally as "rockers." Like the "three" turns, they are all of the same shape, thus :

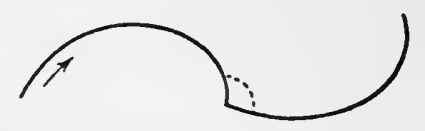

and are four in number, namely:

(i) Outside forward to outside back.

(ii) Inside forward to inside back.

(iii) Outside back to outside forward.

(iv) Inside back to inside forward.

Now, in both these groups the body revolves or rotates at the moment of making the turn in the direction indicated by the dotted lines; it revolves, that is to say, outside the direction of the first curve. But it is possible for the body to revolve in the opposite direction, that is to say, inside the direction of its first curve. This makes possible the third and fourth groups of turns.

III. This group, which is known as brackets, from the mark left on the ice, corresponds to Group I, and the edges employed in it are the same, namely, outside forward to inside back, \&c. But in this group the body revolves on the inside of the direction of the first curve, and the mark on the ice, consequently, is as follows, the dotted line again indicating the revolution of the body:

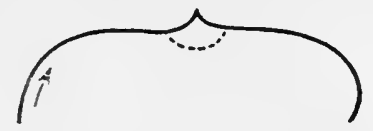

IV. The fourth group is known as counter-rocking turns, or 


\section{6}

\section{WINTER SPORTS}

more generally as counters. It corresponds with Group H, for the marks on the ice are approximately the same, and the edges employed are outside forward to outside back, \&c. But here again the revolution of the body, as in the brackets, takes place inside the direction of the first curve, thus :

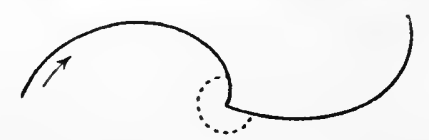

These sixteen turns, or changes of direction while skating on one foot, comprise all the varieties of so doing that seem theoretically possible, since they include every forward edge to every back edge and every back edge to every forward edge, skated with rotation of the body both outside and inside the direction of the first curve, and until somebody discovers a third edge to a skate, or a third direction of rotating the body, it is not possible that they will be added to.

But changes of direction may be made by the employment, not of one but of both feet, and though these might be more properly described as strokes rather than turns, there are two groups of them which enter largely into English skating. These are known as mohawks and choctaws.

I. Mohawks consist of either forward edge combined with the corresponding back edge taken up by the other foot. Thus if the right foot starts as an outside forward, the left, to complete the mohawk, is put down on the outside back edge, thus :

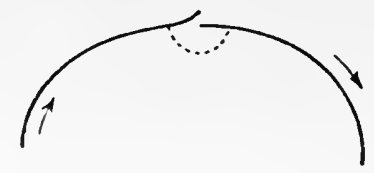




\section{RINKS AND SKATERS}

Here the rotation is made, as in the brackets and counters, on the inside of the direction of the first curve, and the figure is known as the outside forward mohawk. Similarly, the mohawk can be skated on the inside edges, i.e. the right foot starts with an inside forward, and the left completes with an inside back. Here the rotation, as in the threes and rockers, takes place on the outside of the direction of the first curve.

II. Choctaws also employ both feet, but the second curve of a choctaw is on the opposing edge to the first curve. An outside forward choctaw thus consists of an outside forward on one foot completed by an inside back on the other, thus :

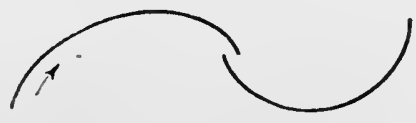

In this, as in the corresponding mohawk, and the brackets and counters, the rotation of the body takes place inside the direction of the first curve. Similarly, the inside forward choctaw consists of an inside forward on one foot and an outside back on the other. Here, following the corresponding mohawk, the rotation of the body takes place outside the first curve.

Theoretically, of course, there are corresponding mohawks and choctaws starting from the back edges, i.e. outside back to outside forward, \&c., but though these strokes are constantly used, both in single and combined skating, they are never dignified by this sounding title of "back mohawk" or "back choctaw," merely because the manœuvre is so simple and common a one, that it needs no name at all, and if, for instance, in combined skating, the caller (who directs what shall be done) has his skaters on a 
back edge, and desires that the next stroke, let us say, shall be an inside forward edge, he calls " inside forward " merely.

Finally, in giving this catalogue of material out of which all English skating is built, there remain only the changes of edge, made on one foot, to enumerate. They, as must naturally be the case, are four in number :

(i) Outside forward to inside forward.

(ii) Inside forward to outside forward.

(iii) Outside back to inside back.

(iv) Inside back to outside back.

With regard to the cross-mohawks and cross-choctaws-in case the skater ever " hears tell" of them-he need not worry himself even to remember their existence, since, most rightly, they have been blotted out of the book of English skating, owing to their clumsiness and the fact that to skate any of them violates some canon of the essential form of English skating. Apart from them, the whole material of English skating has now been stated, namely, the four edges, the sixteen turns, the two mohawks, the two choctaws, and the four changes of edge.

But when we consider that the first-class skater must be able to skate at high speed on any edge, make any turn at a fixed point, and leave that fixed point (having made his turn and edge in compliance with the proper form for English skating, without scrape or wavering) still on a firm and large-circumferenced curve, that he must be able to combine any mohawk and choctaw with any of the sixteen turns, and any of the sixteen turns with any change of edge, and that in combined skating he is frequently called upon to do all these permutations of edge and turn, at a fixed point, and 


\section{RINKS AND SKATERS}

in time with his partner, while two other partners are performing the same evolution in time with each other, it begins to become obvious that there is considerable variety to be obtained out of these manœuvres. But the consideration of combined skating, which is the cream and quintessence of English skating, must be considered last; at present we will see what the single skater may be called upon to do, if he wishes to attain to acknowledged excellence in his sport.

Now the National Skating Association of Great Britain encourages both the English and International styles, and for each there have been instituted certain graduated tests, not competitive but standard, of three orders. The third or lowest test in the English style is broadly designed to encourage skaters, the second to discourage them again (i.e. begin to make them feel the diffculty of the whole affair, just when they thought by passing their third test they had broken the back of their difficulties), and the first or highest to give them healthy occupation for a few winters, and fit them for becoming really first-class skaters. All of these tests must be passed before at least two qualified judges, appointed by the N.S.A., and they are as follows :-

\section{THIRD-CLASS TEST}

(a) A forward outside three on each foot, the length of each curve being $I_{5}$ feet at least. The figure need not be skated to a centre.

(b) The four edges, outside forward, inside forward, outside back, inside back, on each foot alternately for as long as the judges shall require, the length of each curve being 


\section{WINTER SPORTS}

I5 feet at least on the forward edges and ro feet at least on the back edges.

(c) A forward outside 8, the diameter of each circle being 8 feet at least, to be skated three times without pause.

Here, it will be seen, is the beginning, the ground-work of English skating. The easiest turn has to be skated, the four edges have to be skated; also the easiest " 8 " has to be skated, in order to familiarise the beginner with the idea of leaving a point on one stroke and continuing to travel on that stroke (with turns to punctuate it, as he will see later) until he arrives back at that point again. The point in question is marked for him on the ice with an orange or a ball. And whether in single skating or in combined, it is called the centre. Simple as this third test is, it has to be skated in proper English form, which the learner should begin to acquire from the first moment he takes a serious stroke on the ice. For it is vastly easier to acquire good form at the beginning of his education, than to acquire bad habits which must subsequently be got rid of.

\section{SECOND-CLASS TEST}

(a) A set of combined figures skated with another skater, who will be selected by the judges, introducing the following calls in such order and with such repetitions as the judges may direct :-

I. Forward three meet.

2. Once back-and forward meet.

3. Once back-and forward three meet.

4. Twice back off meet-and forward three meet.

5. Twice back meet-and back-and forward three meet. 


\section{RINKS AND SKATERS}

(b) The judges shall call three "unseen" figures of quite simple character, in order to test the candidate's knowledge of calls and power of placing figures upon the ice. These shall be skated alone.

(c) The following edges on each foot alternately for as long as the judges shall require, namely :-

r. Inside back, each curve being $20 \mathrm{ft}$. at least.

2. Cross outside back, each curve being $12 \mathrm{ft}$. at least.

(d) The following figures skated on each foot, namely :-

r. Forward inside three, the length of each curve being $40 \mathrm{ft}$. at least $\left\{\begin{array}{l}R \\ L\end{array}\right.$

2. Forward outside three " " " $5 \circ \mathrm{ft} . \quad$ " $\left\{\begin{array}{l}\mathrm{R} \\ \mathrm{L}\end{array}\right.$

(e) The following figures skated to a centre on alternate feet without pause, three times on each foot, namely :-

r. Forward inside three, the length of each curve being $15 \mathrm{ft}$. at least.

2. Forward outside three

3. Forward inside two threes

4. Forward outside two threes

5. Back outside two threes

$\begin{array}{llll}" & " & \text { 15 } & \\ " & " & \text { 10 } & " \\ " & " & \text { 10 } & \end{array}$

$(f)$ The following figures skated on each foot, namely :-

r. Forward inside " $Q$," the length of each curve being $3 \circ$ ft. at least $\left\{\begin{array}{l}R \\ L\end{array}\right.$

2. Forward outside "Q" " " " $\quad$ " 3 ft. ." $\left\{\begin{array}{l}\mathrm{R} \\ \mathrm{L}\end{array}\right.$

3. Back inside " $\mathrm{Q}$ " $\quad$ " $\quad$ " $25 \mathrm{ft}$. " $\left\{\begin{array}{l}\mathrm{R} \\ \mathrm{L}\end{array}\right.$

4. Back outside "Q" $\quad$ " $\quad, \quad 20 \mathrm{ft} . \quad$ " $\left\{\begin{array}{l}\mathrm{R} \\ \mathrm{L}\end{array}\right.$

Here, it will be seen, the test begins with a combined figure. The whole subject of combined figures will be treated of separately, 
and for the present we need only remark that this is a very simple one. Then follow the inside back edge, which, as I have said, is the most difficult of the edges, skated larger than before, in curves of 20 feet, and the cross-stroke on the outside back. This means that the stroke is taken with the feet crossing, the one that is taking the stroke being crossed behind the other. As a matter of fact, this stroke, which at one time played a considerable part in English skating, since in combined figures all strokes from outside back to outside back were bound to be taken from the crossing position, is now not obligatory. But it is a pretty stroke in itself, and necessitates the skate being placed on the ice on the edge. Then follow the two forward turns, skated rather large, in order to begin to familiarise the learner with the feeling of turns taken at a high speed. This necessitates clean skating of the turn itself, since if a turn is skated fast, and not clean, it is quite possible that the skater may fall, and he will in any case make a blur instead of a sharp cut turn. Also these turns teach him to hold his edges out after the turn, the tendency being to let the body rotate, whereby the curve curls in, and the skater soon finds himself in a position that it is impossible to maintain. But if he skates his turn, and then can hold an edge for 50 feet away from it afterwards, he may congratulate himself on the fact that he is beginning to skate his edges big and in the proper style. For these cannot, practically speaking, be held out, unless the rules for position are being conformed with. Then follow four simple figures of the class known as 8's, of which the simplest is that required in the third-class test, namely, an outside forward 8. All 8's, as their name denotes, are of the same general shape, i.e. the shape implied 
by their name, but between the edges that trace the shape of the 8 , the skater is now required to put in certain turns. He starts, for instance, on an outside forward edge, when half round his circle makes a three turn, and comes back to his centre on the inside back edge. Or he starts on an inside forward edge as in the third 8 , and has to make two turns before he arrives at his centre again, which he reaches as an inside forward edge. Or, more searchingly, he has to start his 8 on an outside back edge, and make two turns and aim at his centre again on an outside back edge.

The remainder of this test is taken up with the figures known as Q's. In these the skater is required to start, at some speed, on any edge forward or back, and after travelling on it for varying distances, as laid down, to change his edge (from outside to inside, or inside to outside) and after holding that edge for the prescribed distance make the three appropriate to that edge. The Q's are very largely used in combined skating, the change of edge being coupled not only to "three" turns, but to rockers, counters and brackets. Here the name " $\mathrm{Q}$ " is becoming obsolete, and indeed has become so in combined skating, the figure being called "forward change three " or " inside back change three," \&c.

Now, as I have said, while the third test is supposed to encourage the skater, the second is supposed to discourage him. What is meant is that he has now run up against the really crucial difficulties in English skating, of which perhaps the greatest of all is to stand still, as the Irishman might say, while moving rapidly. As will be already seen in this test, he is required to do this for somewhat extensive travel : in his outside forward turn, 
for instance, he has to proceed for at least fifty feet on his forward edge before making his turn, and the same distance on his back edge after making his turn. And though this present disquisition is intended to be a statement of English skating and not a book of instruction, the writer cannot bear to let this one opportunity slip of giving just one hint. It is perfectly impossible to travel steadily for distances like these-and the skater will have to learn to go much further yet on his edges-if he is travelling on the forepart of his skate. All forward turns, by the slight check they give to the speed ( $\mathrm{I}$ am not now talking of those ideal skaters who actually get speed out of a turn), tend to put the skater further forward on his skate. He must therefore approach all forward turns on the back part of his skate, so that by this tendency to rock forward he will make the turn itself on about the middle of the skate. Never for a moment, if he can help it, must he get on the toe of his skate, and if ever he does, he must regain position again by leaning fearlessly back. And in this second test, he will find that the difficulty of travelling well back on his skate is at first appalling. But having learned that, and learned it thoroughly, he will probably not come across any subsequent requirement which appears to him so clearly impossible.

\section{FIRST-CLASS TEST}

\section{Section A}

This section consists of the combined figures in Parts $I$ and II. The judges may also give such simple calls as they think fit, to enable the candidate to recover his position, to alternate the feet, \&c. 
The figures shall be skated with another skater, to be selected by the judges, but if there are only two judges, neither of them shall skate.

Each call must be skated at least twice, beginning once with the right foot and once with the left.

Subject to these conditions the calls shall be skated in such order and with such repetitions as the judges may, while the set is in progress, direct.

In calls introducing "twice back" the candidate must recede at least 35 feet from the centre.

To pass this section the candidate must satisfy all the judges in the manner in which he skates each set considered as a whole, and also in the manner in which he skates each individual call.

The judges may pass a candidate in Part $I$, notwithstanding a reasonable number of errors on his part in the course of the set, provided that he ultimately skates all the calls to their satisfaction; and in Part II, notwithstanding errors, provided that the candidate has shown competent skill in skating unseen calls.

\section{Part I}

I. Twice back-and forward three-and forward inside three, off meet.

2. Twice back-and forward three threes-and back meetand back two threes-and forward two threes, meet.

3. Twice back-and forward three about, change, meet.

4. Twice back, about-and back off meet.

5. Twice back-and back inside centre three, change-and forward meet. 
6. Twice back three, centre three, off meet.

7. Twice back centre change, three, meet.

8. Once back - and forward-and forward inside two threes centre change meet.

9. Twice back-and forward two threes, pass, meet.

ro. Twice back two threes, off pass, meet.

Ir. Inside twice back-and forward inside two threes, meet.

I2. Forward change, three, change, three, circle-and forward three, change, circle-and forward about change, three, off meet.

\section{Part II}

In addition to the above, the judges shall call a further set of not more than six or less than four " unseen " figures of moderate difficulty, in order to test the candidate's knowledge of calls and power of correct placing. This unseen set must include rockers, counters, and brackets, and shall be skated by the candidate alone.

\section{SECTION B}

No candidate shall be judged in Part II of this Section until he has passed in Part $\mathrm{I}$.

The judges may allow a candidate any number of attempts at a given figure which they consider reasonable.

\section{Part I}

The turns, mohawks, and choctaws of this part must be placed close to and on the near side of an orange or other fixed point on the ice. They must all be skated on each foot to the satisfaction of the judges. 


\section{RINKS AND SKATERS}

The curve before and after the turn or change of foot must be 40 feet long at least.

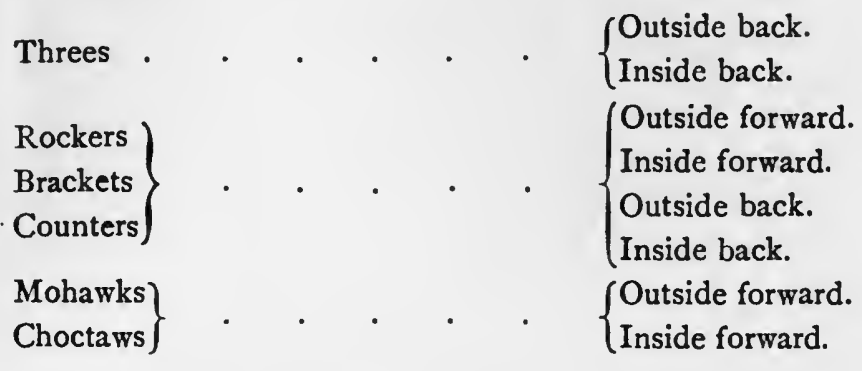

\section{Part II}

To pass in this part, a candidate may select not more than one figure in each group, and must score forty-five marks at least. A selection once made by a candidate must not be altered.

No marks shall be scored in respect of any one-footed figure unless it is skated on each foot, and the number set against each figure represents the maximum that can be scored for that figure.

A candidate shall not score for any figure on which he shall not have obtained at least half marks.

Eights.-In marking these figures, the judges will take into consideration the general symmetry of the figure, and the approximate equality of corresponding curves.

In each figure the complete 8 is to be skated three times without pause.

The figures need not be commenced from rest.

In groups $\mathrm{D}$ and $\mathrm{E}$. the turns and choctaws respectively are to be made on the near side of the centre. 
The following eights are to be skated to a centre on alternate feet :-

\section{Group $A$}

Outside back two threes

Inside back two threes .

Outside forward bracket

Inside forward bracket .
Max.

Marks.

\section{Group $B$}

Outside forward two brackets

Inside forward two brackets .

Outside forward bracket, three

Inside forward bracket, three

Outside forward three, bracket

Inside forward three, bracket
4

13

6

4

\section{Group C}

Outside back two brackets

Inside back two brackets

Inside back two brackets . $\cdot \bullet^{\circ} \cdot$ II

Outside back bracket, three . . . . . . 16

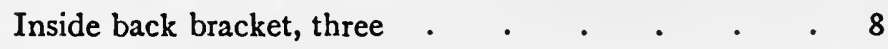

Outside back three, bracket . . . . . 5

Inside back three, bracket $. \quad . \quad . \quad . \quad . \quad$ I4

\section{Group D}

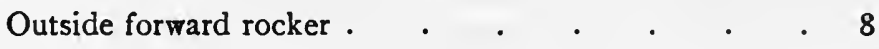

Inside forward rocker . $\quad . \quad$. $\quad . \quad$. 4

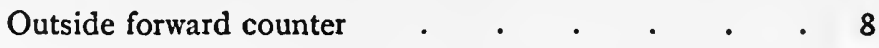

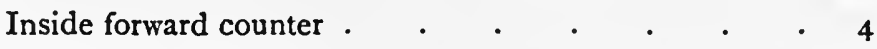

Outside forward centre choctaw and inside forward centre choctaw, beginning on each foot . . . 4

Outside forward mohawk and inside forward mohawk to a centre, beginning on each foot $\quad$. $\quad$. $\quad$. 4 


\section{RINKS AND SKATERS}

\section{Reverse Q's}

The turns and changes are to be made on the near side of fixed points determined by the candidate ; the distance between these, and the lengths of the first and last curves, are to be each not less than 50 feet beginning on forward edges, 35 feet beginning on back edges.

Group $E$

Outside forward three, change

Inside forward three, change .

Outside forward rocker, change

Inside forward rocker, change

Outside forward bracket, change

Inside forward bracket, change

Outside forward counter, change

Inside forward counter, change

Group $F$

Outside back three, change

Inside back three, change

Outside back rocker, change

Inside back rocker, change

\section{Group $G$}

Outside back bracket, change

Inside back bracket, change . $\quad$ - . . . $\quad$. 8

Outside back counter, change . . . . . $\quad$ 16

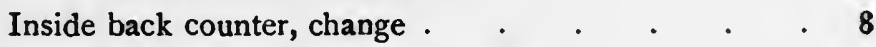

Max.

Marks.

\section{Grape Vines \\ Group $H$}

Single, each foot leading

Double forward

Double backward .

Pennsylvania

Philadelphia 
Now, again omitting for the moment the subject of combined skating, we see that in Part II the rest of the groundwork of English skating is very thoroughly traversed. To pass this final test the skater has to be able to execute all the threes (the two simple ones are omitted, as they have already been required in the second test), rockers, brackets, counters, mohawks, and choctaws at fair speed and on large edges at a given point on the ice. Having done that to the satisfaction of the judges, he has then to make his selection from a large number of 8 's, which include practically most possible 8's comprising one or two turns, excepting these simple ones with regard to which he has already satisfied the judges in his second test. Here he has to score marks, selecting not more than one 8 of each group, and by the devilish ingenuity of those who drew up this test, it is impossible for him to get through unless the majority of the 8 's he selects to skate are really difficult. He may then add to his marks by executing what are called reverse Q's at two given points on the ice. At the first of these he has to make his turn, whatever it is, and at the second to change his edge. This requires a considerable degree of accuracy, for in order to arrive smoothly and still at a fair travelling pace at the second point, he will find that he has to have a practically perfect control of the edge, which has not been disturbed by executing a difficult back turn, let us say, at the first given point. Finally, if he is still in want of marks, he may earn a few more by a grape-vine. This latter does not properly belong to English skating, since it is a two-footed figure, and those responsible for the test might have omitted this group with advantage. 
The Combined Figure.-Probably no branch of sport-except, perhaps, flying-has undergone such improvement and revolution within the last fifteen years as this art of combined skating. Not only are there a vastly multiplied number of competent and even first-rate combined skaters, but the skill demanded of a first-rate combined skater, and the variety of the manœuvres he may be called upon to execute, is immeasurably greater than a decade and a half ago. I do not mean that there were not in 1897 a certain number of skaters who might have been able to execute a difficult set as directed by a caller of to-day, but these were, in golfing parlance, "plus players," and the ordinary " scratch" skaterone, that is, who had passed his First Class N.S.A.-would have had no more chance of getting through such a set without throwing everybody out, and himself down, than he would have of flying. Both the speed and the size of these combined figures has greatly increased, and the whole of the material of English skating is employed. And the main reason for this improvement and revolution is due to the greatly augmented number of English skaters who now go to Switzerland in the winter, and the multiplication there of really large rinks.

That this immense improvement has taken place in combined skating is proved, luckily, not only by the fallacious memory of individuals, but by printed records. I have before me the Badminton volume on skating (edition I902), in which, for instance, we find the following figure (among many others like it).

"Forward two turns. This movement skated to a centre is very difficult, and is a great test of good skating, and many men make a practice of devoting five or ten minutes to skating it every 
day when they come on the ice, feeling that if they can skate it, making the curves between the turns of equal length and making the turns clean without any scrape and yet coming true to the centre, they are in good form and equal to skate anything that may be required of them."

Now no doubt two turns to a centre, as required in the secondclass test, is a very good elementary figure, but it no longer has anything whatever to do with combined skating, whether it is skated with a partner or with a second pair, or simultaneously with other skaters. Speed and size and difficulty (as demanded by the scale on which combined skaters now move) are necessarily absent from it, and from a hundred others of these calls which then were the last word in combined skating. A man who had passed his second-class test would be capable of doing this, which was then considered a criterion of good combined skating, whereas the same man could not live for two calls in a combined figure of moderate difficulty to-day. The whole nature of the business has changed: turns have to be executed at high speed far away from the centre, and the curliness and smallness of such skating as is here implied and necessitated has vanished altogether, giving place to a far more difficult style and speed.

Nor, again, in this respect, is Part I, in the first-class English test, up-to-date in requirements of size. Here we read that on a "twice back" the candidate must recede at least 35 feet from the centre. That no doubt was laid down because on the artificial rinks available in England, such a distance took the skaters nearly to the bounds of the space at his disposal. But any candidate who, on the Swiss rinks, where nowadays almost all first-class tests are passed, 


\section{RINKS AND SKATERS}

receded but 35 feet from the centre would have, practically speaking, no chance of getting through. His lawless judges would inevitably tell him to skate larger. Still less would he be able to take part in any combined figure-skating for amusement by skaters who had any pretension to be of the first-class. With these big surfaces of rink, the whole style and method has become larger and faster, and therefore more difficult.

A third instance, to prove how greatly the art of combined skating has progressed, has the ring of pathos about it, and, though only oral, is trustworthy. A friend of mine, who resides at that excellent English skating centre, Oxford, told me that in old days he could scarcely get a combined figure, since the most elementary calls were sufficient to floor his partners. But not so long ago he told me he could scarcely get a combined figure, since nobody cared to skate such elementary calls as he was capable of. But he assures me that he skates just as well now as he did in the days when there was nobody up to his standard. Perhaps in twenty years more, no first-class skater will care to engage in such simple stuff as we now think rather advanced. And dearly will such present-day skaters who are fortunate enough to be alive then, love to see the newer and more arduous manœuvres! But since it is impossible to prophesy about the things we cannot imagine, it must be sufficient to give the outlines of combined skating as practised by fairly expert gentlemen to-day.

There are two manners of combined skating, called respectively pair-skating and simultaneous skating. The first of these (which we will first consider) is the more difficult, and, so to speak, the more classical. Theoretically it can be skated by two, four, six, 
or eight persons : practically it is skated by four persons, grouped, at the beginning of things, at right angles to their neighbours, and at a few yards distant from their centre. One of these, who skates in the first pair, is known as the caller, and he announces (in a loud mellifluous voice) what he is about to skate, and what the trembling gentleman opposite, who is his partner, must also skate. They advance to the centre, from opposite sides, and begin skating whatever is ordered. The moment after they have left their centre, speeding out to the circumference of the huge imaginary circle, of which their orange or india-rubber ball, from which they have started, is the centre, the second pair (at right angles to them) proceed to do exactly the same. The size and pace of the figure, as well as its details, depend entirely on the caller : as he skates, so must his partner skate, putting down his edges and turns simultaneously and at like speed to him, and as the first pair skate, so (with certain modifications) must the second pair skate.

Now, the whole material of skating is at the caller's command. $\mathrm{He}$ can (and does) order threes, brackets, rockers, counters, mohawks, choctaws and changes of edge to be skated when and how he wishes them. He can (and does) couple any pair or any three of these movements, to be skated on one foot or on both, one after the other. He directs, with a word of power, from the elaborate vocabulary of combined skating, the length of an edge, and can command it to be held so long that the direction of progress is reversed, or to be further continued till a complete circle is made and the original direction of progress resumed again. Then, with another word, he brings himself and his partner (fol- 


\section{RINKS AND SKATERS}

lowed closely by the second pair) back to their centre again, on the off side or the near side of it, and orders that they shall start a fresh figure there, or that they shall make a turn there, or scud by it like four express trains which just, and only just, arriving from the four parts of the compass, do not collide with each other, and scatter again to east and west and north and south. Sometimes he brings them in simultaneously, so that they converge till they almost touch, and then spread out again. And if the figure is going decently well, there is no pause, no foot without its edge and turn assigned to it. This mystic, swift, interweaving dance lasts perhaps a quarter of an hour of hard, enraptured skating.

Simultaneous combined has this advantage, that an uneven number of skaters can take part in it. The caller's duties are the same, but there are no pairs of partners. All leave the centre simultaneously, all (it is hoped) arrive back at it simultaneously. Since there is no crossing of pairs at the centre, a far larger number of skaters can take part in it, as they have not to wait for a prior pair to clear, and if elementary calls only are ordered, upwards of ten or twelve skaters can join the dance with effect. No one of them, as in pair skating, crosses the path of another skater : they leave and arrive at the centre on converging not crossing lines. Thus it is an easier sport than is crossing pairs, since in the latter case the edges that leave and approach the centre intersect each other. Vastly enjoyable as it is, it lacks to the present writer that classical distinction that characterises pair-skating.

The final item in English skating is hand-in-hand skating in the combined figure. Here, instead of single skaters combining 
to perform in unison, pairs take the place of units. Necessarily the figures compassable by a man and woman hand in hand are fewer in number, as at present worked out, than those which can be skated by single skaters, and the speed at which such figures are skated is less than in the combined skating of single skaters. Hand-holds have to be changed, and partners brought into the new position required by turns, \&c., by pulls, or by what in the nomenclature is called "steps"-i.e. single strokes and edges. Already this style has taken the place in the annual championship of English skating, and without doubt it will grow both in the number of its practitioners, and in the force and speed of their movements. It is scientifically based, being evolved from the charming movements that are possible to hand-in-hand skaters when going free on the ice, and not bound to consider their opposing partner, or to arrive in a given manner at a given point. But it resembles, at present, in the opinion of the writer, the performance of a yearling. It requires the devotion of a dozen first-class skaters of both sexes to determine its possibilities. His wish is, that it will get them. His fear is that the necessarily cramping influence of conjoined hands will prove to debar it from the speed and largeness of other branches of English skating. He sincerely hopes that his fears are quite unfounded.

\section{INTERNATIONAL STyLE}

It has been already remarked that the two styles, English and International, have nothing to do with each other, and that the practitioner of one who is so imbecile as to belittle the other, is 


\section{RINKS AND SKATERS}

no less crack-brained and idiotic than a Rugby football player who calls Association a "rotten game." Personally, I do not skate in the International style, but to attempt to depreciate the beauties of it would be to me as unthinkable as it would be to run down polo. To the spectator, whether of polo or of International skating, the skill and the splendour of these sports are, unless he is entirely lunatic, beyond any question at all. But it is as an admirer, pure and simple, that $I$ venture to embark on a subject with which $I$ have no practical acquaintance.

Spectacularly there is no doubt that to the ignorant the International style rightly makes the most powerful appeal. A simple manœuvre, as for instance a forward three to a centre, looks far more difficult and hazardous when executed even only moderately well in the International style than when executed almost perfectly in the English style. In the one case, to the ignorant, arms and legs are flying: it seems impossible to maintain a balance, and the attitude itself is charmingly graceful: whereas in the English style the whole difficulty of the manœuvre, such as it is, lies in the necessity of making it look easy, and standing quite still and at rest.

But the difficulty of doing it perfectly in the English style is, as a matter of fact, far greater than that of doing it properly in the International style. Of that there is no question whatever. A good English skater will put down his turns and edges one over the other, in the accurate fashion so rightly demanded by the International style, without producing half the effect that a good International skater will produce. But the English skater has done the more difficult feat. On the other hand, I do not think 
that the skater in the English style is ever called upon to do anything so difficult in his highest test as the back-loop 8, or perhaps the rocker 8 , as required by the first-class International test. And then I think of a back bracket, executed at good speed at a certain point, in the correct style. Really $\mathbf{I}$ do not know. . . . Also I do not care. The back-loop 8 of the International skater is altogether lovely, which is all that matters.

But, as I have said, the two styles have nothing to do with each other, either as regards tests or as regards the general sport of them. I can imagine no more glorious athletic feat than that of four first-class English skaters performing a really difficult combined set properly, a set that is as far away from the compulsory set of the first-class test as is the first-class test from the second; nor, on the other hand, can I imagine a more glorious athletic feat than the free skating of some champion of the International school. But when Mr. Grenander or Herr Salchow are so kind as to show me the Hugel star, I no more think of comparing that with the combined skating of fine performers in the English style, and others, than I compare it with Mr. Baerlein in the tennis court or Mr. Jessop slogging his sixes. They have nothing to do with each other.

As in English skating, I propose to lay before the reader the tests of the International school, and in contrast to the rule of English form, I subpend the essential requirements of International excellence, as laid down by the collective experience of its senators. Proper form is no less essential in one than in the other, and the same sternness : of requirement is insisted on in both. But the 


\section{RINKS AND SKATERS}

effect is poles apart: in the International style a fixed freedom of the unemployed limbs is necessary, in the English a fixed quietness and immobility. Neither is laid down in an arbitrary manner : it is impossible to perform the necessary evolutions in first-class skating otherwise than is provided by the rules. No English skater could, in his prescribed form, execute the International figures: no International skater in his could do what is required of his English brother. Here, then, are the essentials of good form as demanded by the International school:

"Carriage upright but not stiff; the body not bent forwards or sideways at the waist; all raising or lowering of the body being effected by bending the knee of the tracing leg with upright back; the body and limbs generally held sideways to the direction of progress. The head always upright. Tracing leg flexible with bent knee. The eyes looking downwards as little as possible. The knee and toe of the free leg turned outwards as far as possible, the toe always downwards; the knee only slightly bent. The free leg swinging freely from the hip and assisting the movement. The arms held easily, and assisting the movement; the hands neither spread nor clenched. All action of the body and limbs must be easy and swinging with the direct object of assisting the movement of the moment; violent or stiff motions are to be avoided, the figure should seem to be executed without difficulty.

"The figures must be begun from rest-that is, by a single stroke with the other foot; and at the intersecting point of two circles. Every figure must be repeated three times consecutively. 
No impetus may be taken from the ice by the foot which is about to become the tracing foot; and every stroke should be taken from the edge of the blade, not from the point."

There are also the following directions for correct tracing, i.e. the marks left by the skate on the ice.

"The essentials of correct tracing are :

"Maintenance of the long and transverse axes (as the long axis of the figure a line is to be conceived which divides each circle into two equal parts; a transverse axis cuts the long axis at right angles between two circles); approximately equal size of all circles, and of all curves before and after all turns ; symmetrical grouping of the individual parts of the figure about the axes; curves without wobbles, skated out-that is, returning nearly to the starting-point. Threes with the turns lying in the long axis; changes of edge with an easy transition, the change falling in the long axis."

In this form, then, and with this accuracy of tracing, the following figures must be skated for the third test :-

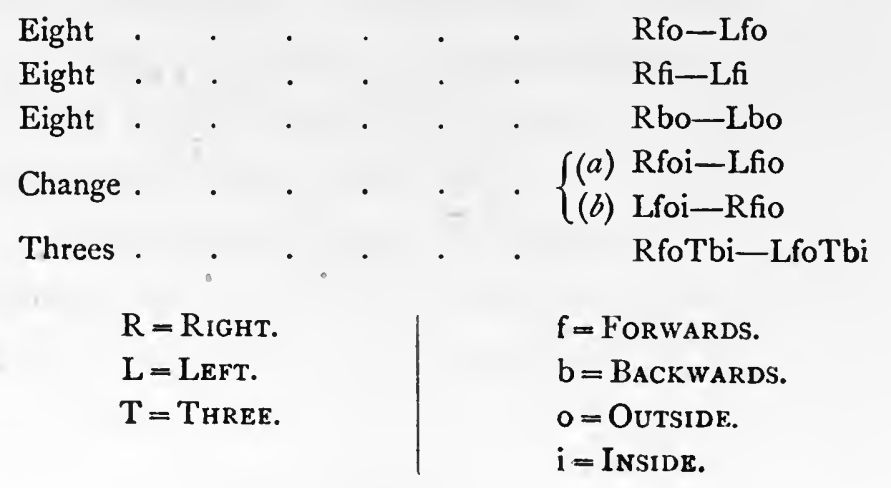




\section{RINKS AND SKATERS}

Into the system of marking-candidates have to get a certain proportion of marks in each figure-we need not go. It will be sufficient to say that it is necessary to skate each figure passably, and to earn more than half marks on the whole.

\section{SECOND-CLASS Test}

This has to be passed before three judges, and is divided into two parts-(I) Compulsory Figures; (2) Free Skating. The regulations for them are as follow :-

(I) Compulsory Figures.-Each figure may be marked up to a maximum of 6 points. The marks given for each figure are multiplied by the factor of value for that figure. In order to pass, a candidate must obtain a minimum of 2 marks out of 6 in each figure, and an aggregate of 130 out of the maximum of 234 marks.

(2) Free Skating.-The candidate will be required to skate a free programme of three minutes' duration.

This will be marked :

(a) For the contents of the programme (difficulty and variety) up to a maximum of 6 marks.

(b) For the manner of performance up to a maximum of 6 marks. In order to pass, a candidate must obtain 7 marks for $(a)$ and $(b)$ together.

The marks for compulsory figures and for free skating must be obtained from each judge. Judges may use half marks and quarter marks. 


\section{Compulsory Figures}

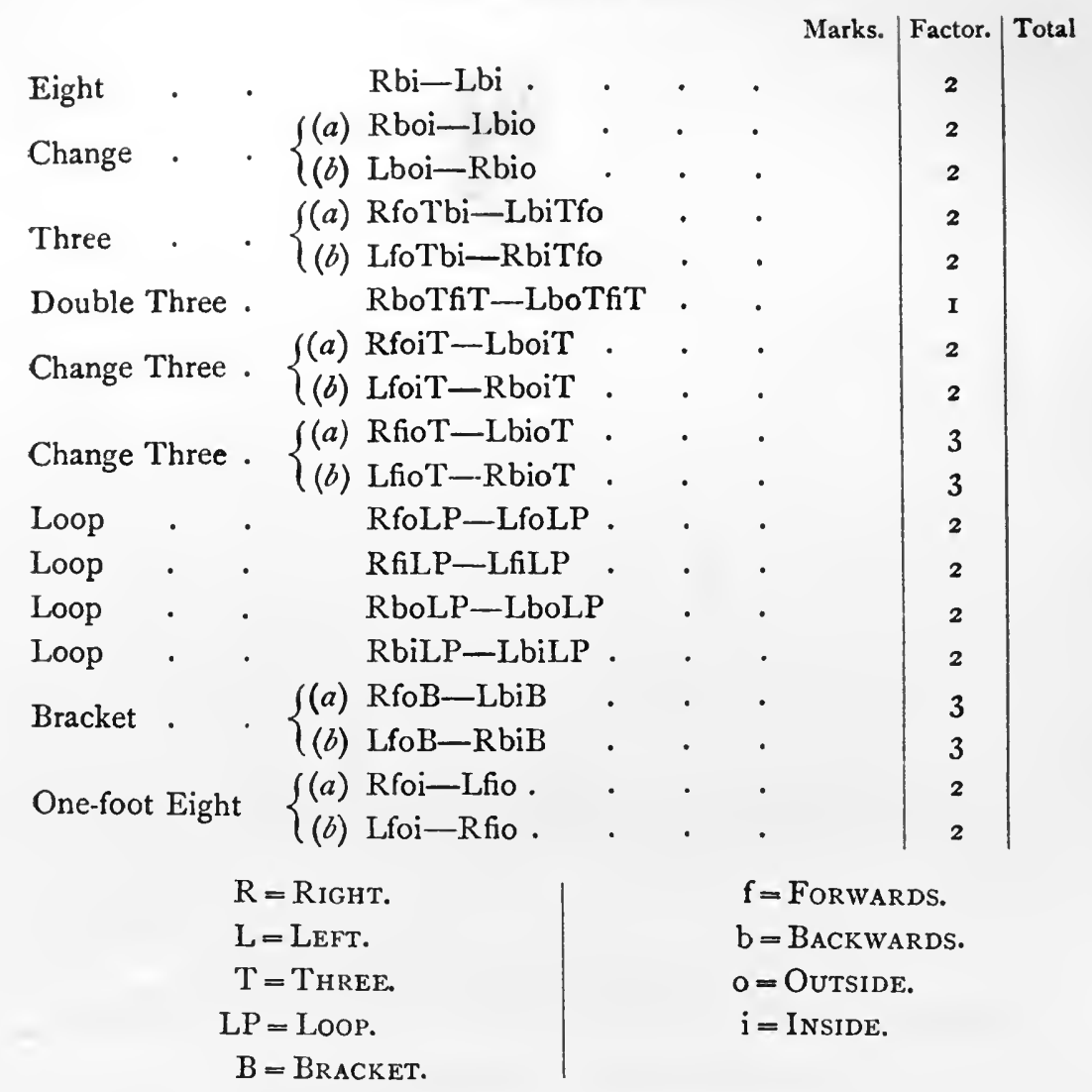

Here is a remarkably varied programme, and one that will obviously give a good spell of regular work to a candidate who intends to grapple with it. It contains more of the material for skating than does the corresponding English second test, in which only the four edges, the four simple turns, and the four changes of edge are introduced, since this International second test comprises as well as those, the four loops, and two out of the four brackets. 
These loops, which are most charming and effective figures, have nowadays no place in English skating, since it is quite impossible to execute any of them, as far as is at present known, without breaking the rules for English skating, since the unemployed leg (i.e. the one not tracing the figure) must be used to get the necessary balance and swing. They belong to a great class of figures like cross-cuts in all their varieties, beaks, pigs-ears, \&c., in which the skater nearly, or actually, stops still for a moment, and then, by a swing of the body or leg, resumes or reverses his movement. By this momentary loss and recovery of balance there is opened out to the skater whole new fields of intricate and delightful movements, and the patterns that can be traced on the ice are of endless variety. And here in this second International test the confines of this territory are entered on by the four loops, which are the simplest of the "check and recovery" figures. In the loops (the shape of which is accurately expressed by their names) the skater does not come absolutely to a standstill, though very nearly, and the swing of the body and leg is then thrown forward in front of the skate, and this restores to it its velocity, and pulls it, so to speak, out of its loop. A further extension of this check and resumption of speed occurs in cross-cuts, which do not enter into the International tests, but which figure largely in the performance of good skaters. Here the forward movement of the skate (or backward movement, if back cross-cuts are being skated) is entirely checked, the skater comes to a momentary standstill and moves backwards for a second. Then the forward swing of the body and unemployed leg gives him back his checked and reversed movement.

Similarly, the bracket 8 is fresh material in this set of com- 


\section{4 \\ WINTER SPORTS}

pulsory figures. The shape and nature of the bracket is the same as that in English skating.

The candidate for the second International test has also to skate a free programme of three minutes' duration. This takes the place, so to speak, of the section in the English test devoted to combined skating, which is not practised in the International style. This free skating is spoken of in its place under the firstclass test.

\section{First-class Test}

This has to be passed before three judges, and is divided into two parts-(I) Compulsory Figures; (2) Free Skating. The regulations for them are as follow :-

(I) Compulsory Figures._Each figure may be marked up to a maximum of 6 points. The marks given for each figure are multiplied by the factor of value for that figure. In order to pass, a candidate must obtain a minimum of 2 marks out of 6 in each figure, and an aggregate of Igo out of the maximum of 336 marks.

(2) Free Skating.- The candidate will be required to skate a free programme of three minutes' duration.

This will be marked :

(a) For the contents of the programme (difficulty and variety) up to a maximum of 6 marks.

(b) For the manner of performance up to a maximum of 6 marks.

In order to pass, a candidate must obtain 7 marks for $(a)$ and (b) together. 


\section{RINKS AND SKATERS}

The marks for the compulsory figures and the free skating are arrived at by taking the total marks of the three judges and dividing by three. Judges may use half marks.

This free skating is a charming item in the system of International skating, and might, with great advantage, be introduced into the English branch. It is in itself perfectly fascinating to look at, and from the technical point of view it is quite admirable as a test of knowledge. A good programme will contain dozens of turns and changes of edge, all melting into each other without break or pause. None who have seen the free skating of a fine performer can ever forget or question the brilliance and variety of this three-minute free skating. As likely as not, he will make his entry on to the rink in a spiral edge, and before it has come to rest at the centre, start off on his coruscating performance. Rockers, brackets, counters, and turns succeed each other with bewildering rapidity; and all are performed with the utmost ease and grace. It seems impossible to tell where the motive-power comes from, so smooth and effortless is the travelling; you would have said the skater was wafted by some localised wind, or impelled by some invisible mechanism. But before he arrives at this part of his test, he has to skate his compulsory figures, the list of which is subjoined.

Compulsory Figures

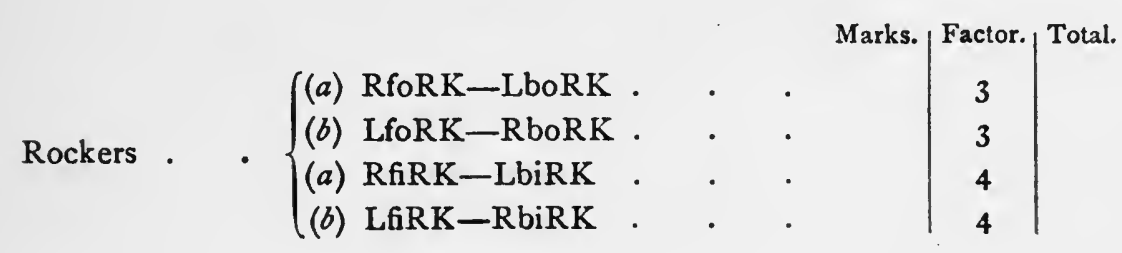




\section{Compulsory Figures (continued)}

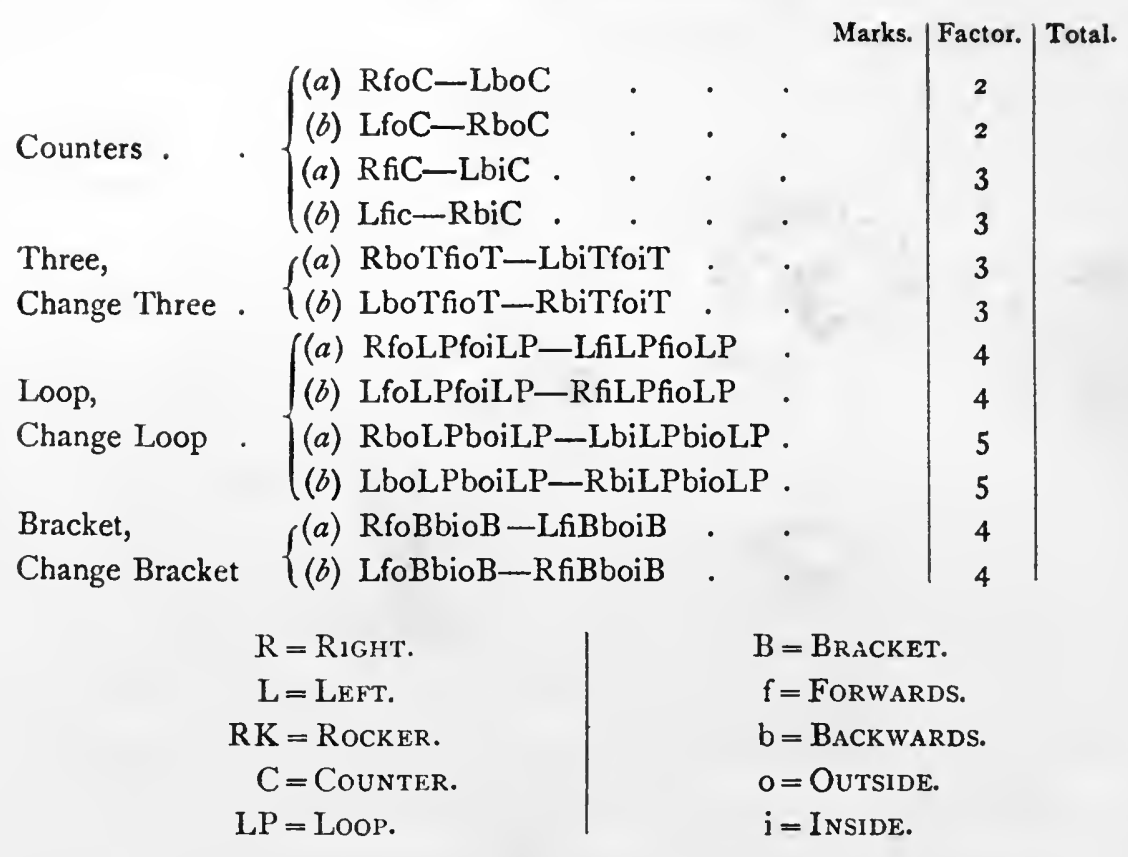

Now, here is a list of requirements which, when we think of the accuracy demanded by the International style in the matter of tracing, will clearly be too much for any but the very elect. Not only has a figure as difficult as the back-loop 8 to be skated, but it has to be skated with accuracy: the loops must lie approximately one on the top of the other, and the edges that lead into and out of them must be symmetrically laid down. It is this accuracy which makes the International style so hard of achievement in its higher branches; to hope to get through this list of searching figures, it is clear that the balance, the pace, and the power of the skater must be in perfect control. And all the time 


\section{RINKS AND SKATERS}

the appearance of insouciant freedom is there; though all the time that freedom is bound by laws as relentless as those which regulate the tranquillity of the English style. The feats are so difficult that they cannot be executed except in a certain way, just as the ball that spins so carelessly over the tennis net cannot win a short chase off the back wall unless it has been hit in one way and no other.

A further important branch of International skating is the pair-skating, which ranges from the simple waltz-step to the most intricate evolutions. The rhythm and grace of this delightful exhibition is beyond all words; beyond all words, too, is the training and skill which it implies. Every bar of the music which accompanies it has its appropriate movement : it is a perfect song of motion set to the band. But the beauty and swing of it are things quite indescribable; one might as well hope to reproduce the dancing of Pavlova in pen and ink as to convey any sense of it to those who have not seen it. And those who have seen it would very wisely yawn and pass on if they observed a purple paragraph on the subject looming ahead. But thistledown is not so light in a warm west breeze, nor the curves of a swallow's flight more deliciously unconjecturable than a well-matched pair in this pastime so perfectly preconcerted that it looks entirely unrehearsed. On they drift, gliding, turning, parting to come together again. . . . Mrs. Gummidge, for the moment, would cease to think of the old 'un, and inquire the price of skates-and knee-pads. 



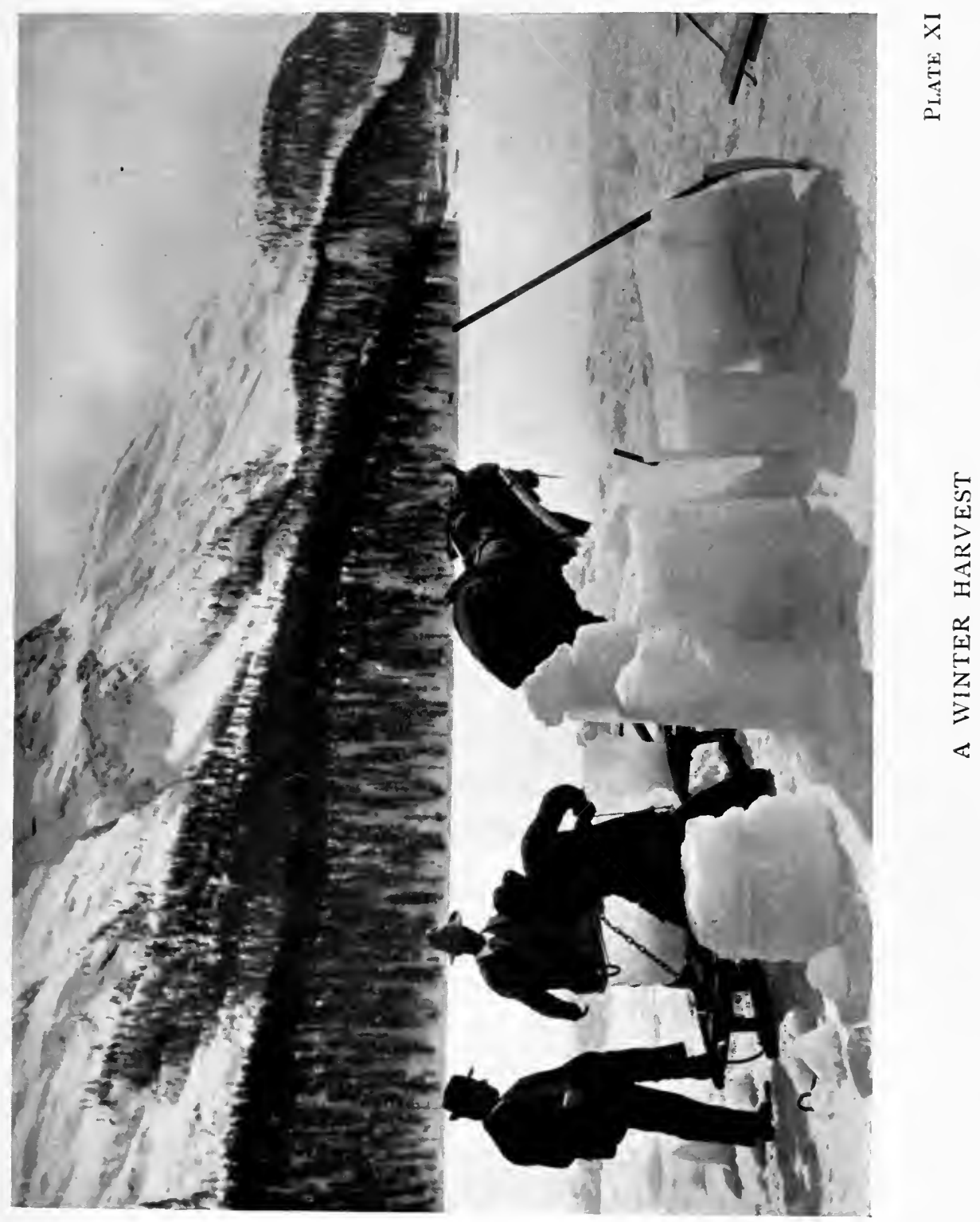





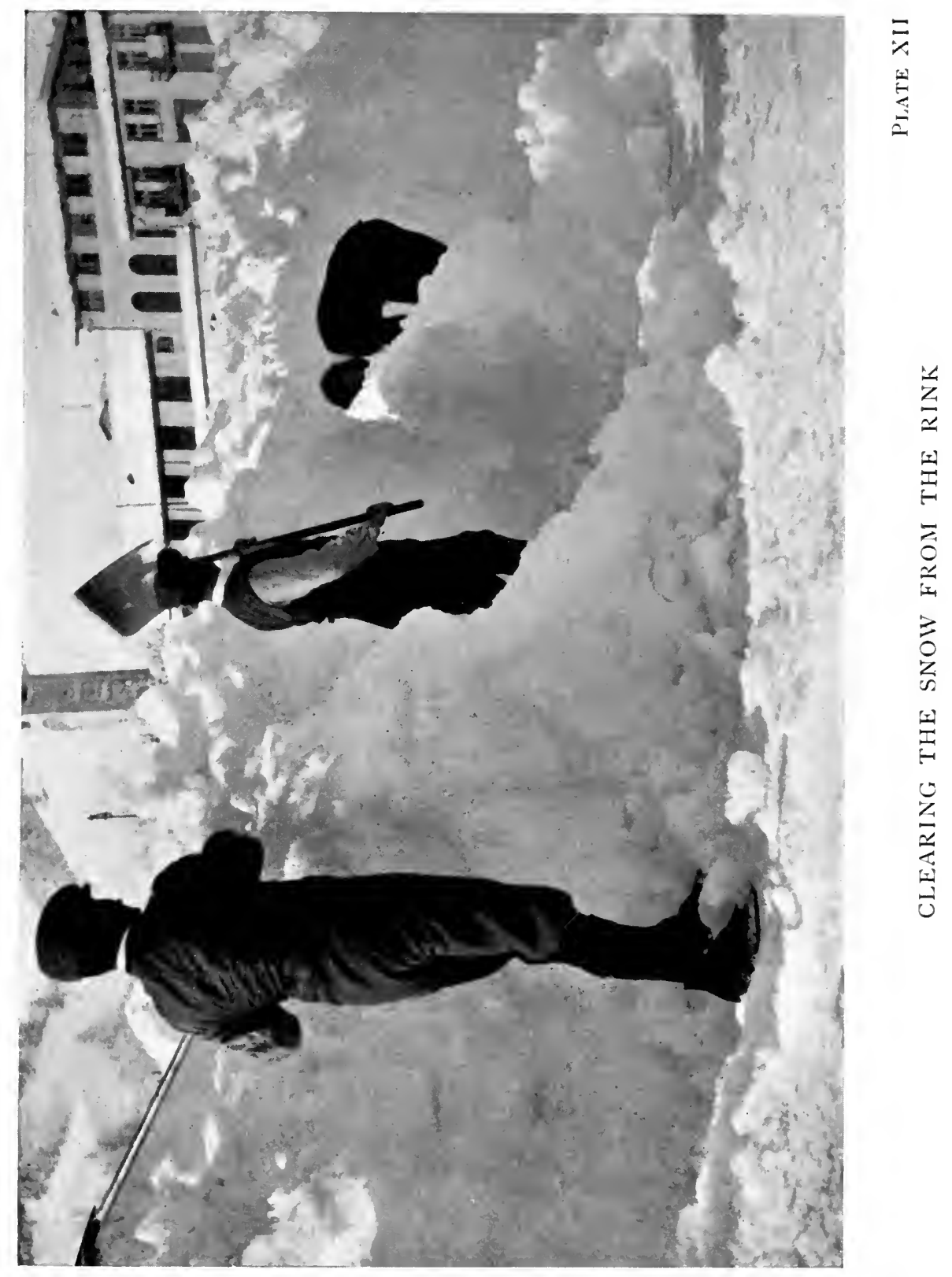




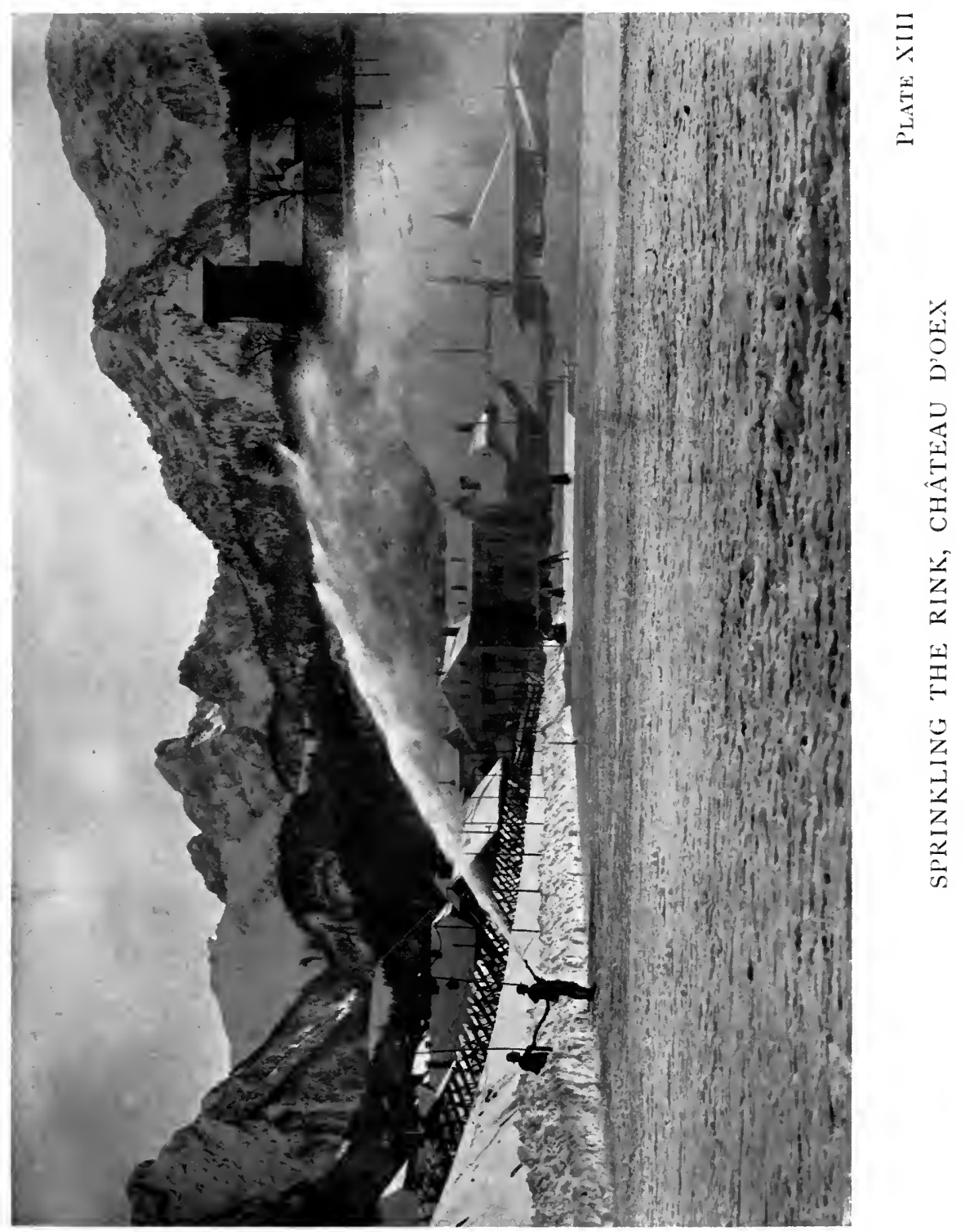











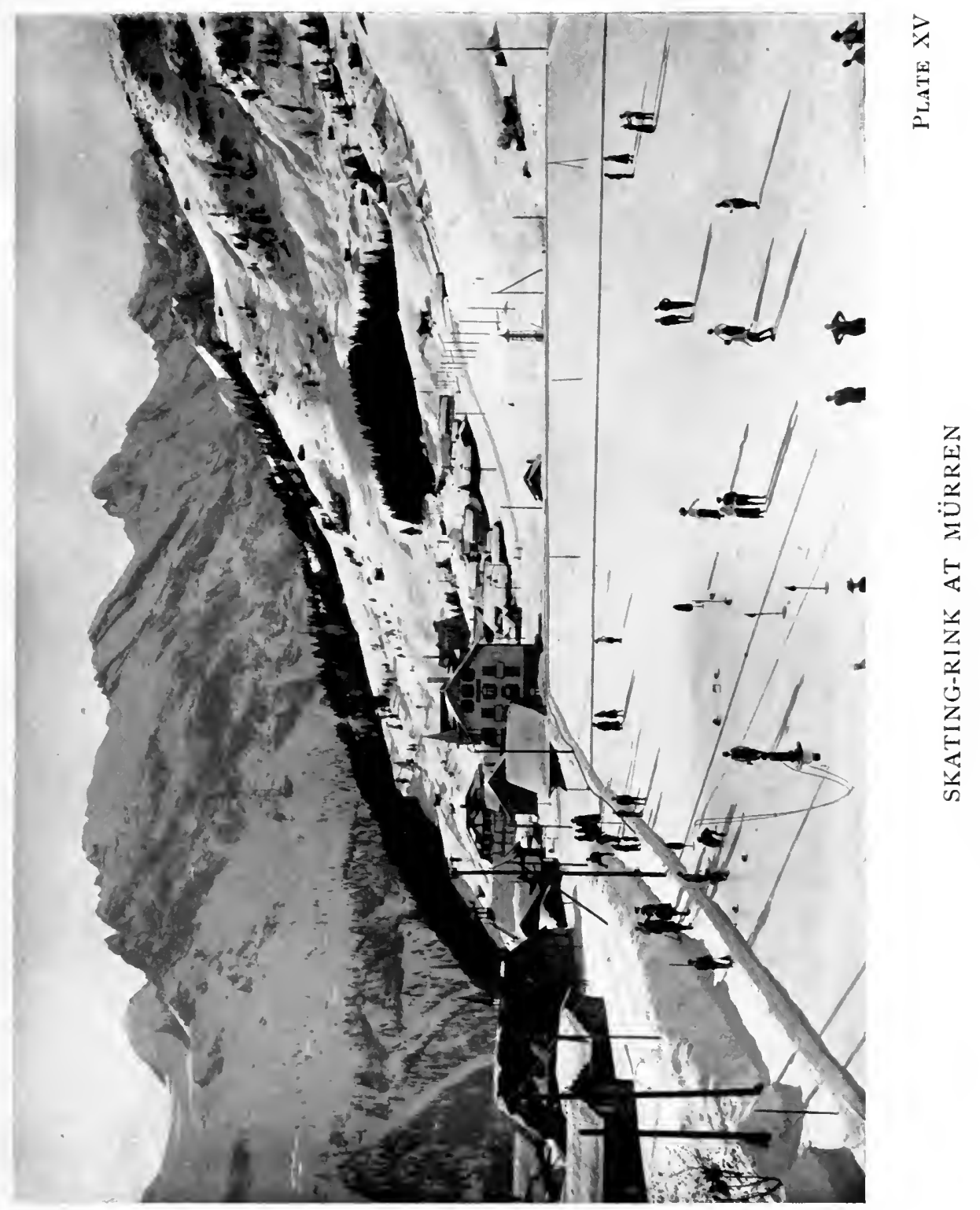





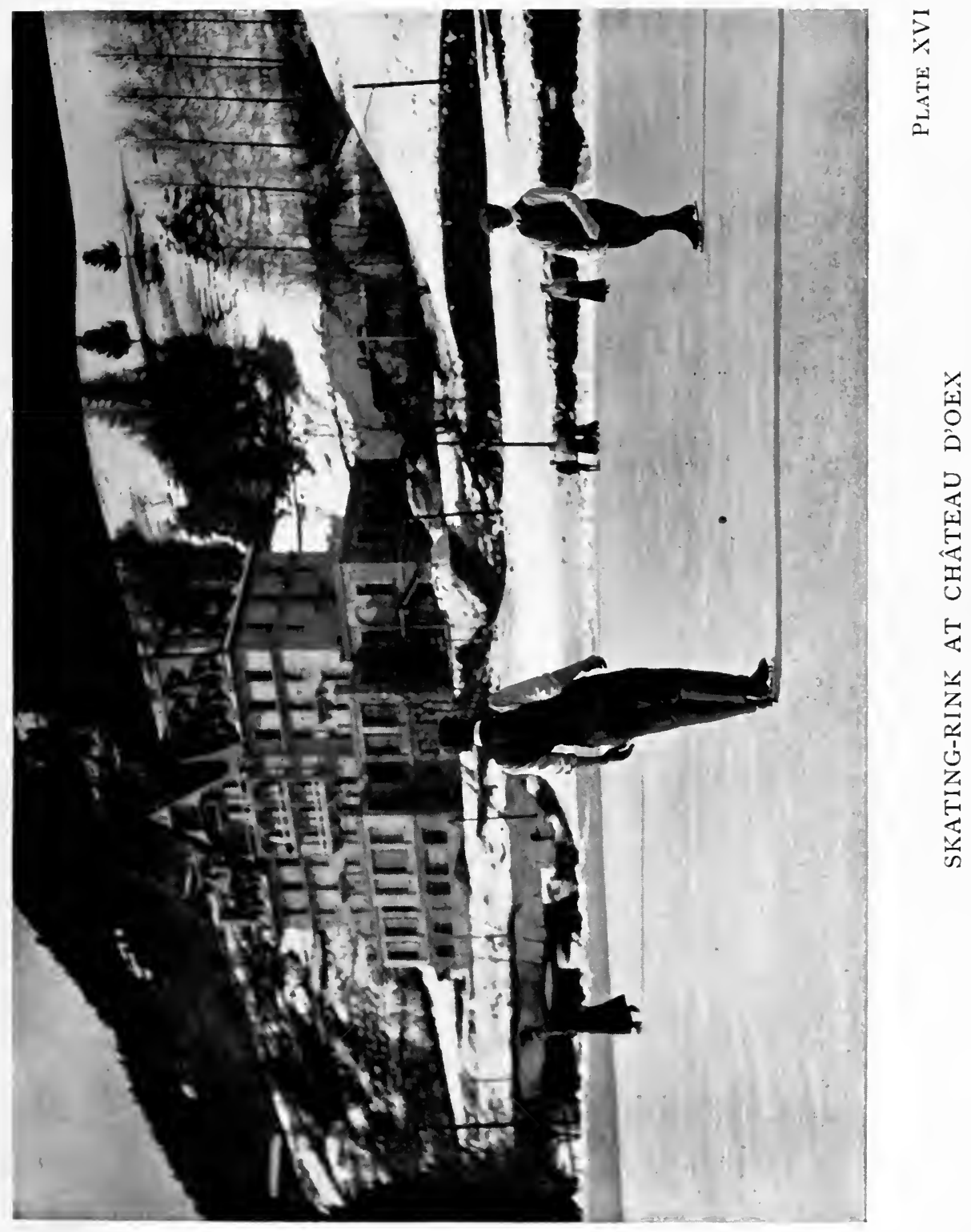





\section{CHAPTER III \\ TEES AND CRAMPITS}

THESE great Swiss rinks, the construction of which has already been dealt with, are made for the benefit of the skater and the curler, but wherever possible the curler should be accommodated with a separate rink of his own. Epicure though the skater is, with regard to the smoothness and levelness of his ice, the curler, quite rightly, is even more exigent, and slight slopes of surface and minute inequalities and roughnesses which do not interfere with the skater at all, make it impossible for the curler to have a satisfactory rink. In any case, the curler's portion must be roped off from the skating part of the rink, for, naturally, no skate blade must make the smallest scratch on his sacred enclosure; while, on the other side, the curler is liable, in the ecstasies of his "sooping," to shed and scatter pieces of broom which wander on to the skater's ice and cause falls. Besides, the skip habitually shouts at the top of his voice, and a good stone evokes choruses of open-throated music: thus, if many curlers are shouting at the top of their voices, combined skaters cannot hear the caller, unless he shouts at the top of his voice. If he does this while skating a figure, he will speedily become purple in the face and quite breathless. Also, the curler smokes when he curls, which tempts the skater to do likewise, and for the sake of the rink he must not. For those and many other reasons, the curler should, when possible, have a 
separate rink of his own, where he can soop and shout and smoke without interfering with anybody.

Now, just as the art of skating has enormously progressed owing to the facilities afforded by Swiss rinks and winters, so too has that great sister art of curling. As in all forms of sport where delicacy or "touch" are essential to success, occasional practice is not enough to produce really first-rate curlers, or, indeed, to keep the first-rate curler at the top of his game; and any who wish to excel must have constant practice, such as Swiss or Canadian winters give him. But Canada is a far cry to go a-curling, and we may put down the vastly-growing number of curlers, and their growing skill, to the opportunities afforded by Switzerland. There, all day long, in a brilliant sun and yet on unsoftened ice, harder and faster than is ever procurable in English or Scotch winters, the game goes on, and I do not know of a single Swiss resort where provision is not made for those who practise this delightful sport.

Into the history of curling there is not space to penetrate, and we must, in a treatise of which the range is confined to the present and does not explore into the mists of antiquity, confine ourselves to considering the practical aspects of the game. As St. Andrews is to golf, as the N.S.A. is to skating, or the M.C.C. to cricket, so to curling is the Royal Caledonian Club, whose rules are the acknowledged authority on all points in connection with the game. It would take too much space to give these in extenso, but the following extracts, with certain notes, will be found to explain the principles and practice of the game, and enable anyone to construct a standard rink. 


\section{TEES AND CRAMPITS}

I. The length of the rink for play, viz. from the hack or from the heel of the crampit to the tee, shall be 42 yards-in no case shall it be less than 32 yards.

2. The tees shall be 39 yards apart-and, with a tee as the centre, a circle having a radius of 7 feet shall be drawn. Additional inner circles may also be drawn.

3. In alignment with the tees, lines, to be called central lines, shall be drawn from the tees to points 4 yards behind each tee, and at these points foot scores 18 inches in length shall be drawn at right angles, on "which, at 6 inches from the central line, the heel of the crampit shall be placed; when, however, in lieu of a crampit a hack is preferred, it shall be made 3 inches from the central line, and not more than $\mathrm{I} 2$ inches in length.

4. Other scores shall be drawn across the rink at right angles to the central line, as in the diagram, viz. :

(a) A hog score, distant from either tee one-sixth part of the distance between the "foot score" and the farther tee.

(b) A "sweeping score" across each 7 -foot circle and through each tee.

(c) A "back score" behind and just touching outside the 7 -foot circle.

Note.-In these four rules are contained the complete directions for the marking out of the rink. But as they contain certain terms of mystic meaning, it may be useful to state them in a less technical manner.

In other words, then, you start with a point on the ice, 
which is the "tee," and using this as a centre you draw round it a circle of 7 -foot radius. This is done by means of a lath or strip of wood with two nails or steel points projecting from the lower face, 7 feet apart. Inserting one of these in the centre you pull the lath round, so that the other scratches on the ice a circumference at a distance of 7 feet. As stated in Rule 2, "additional circles" may also be drawn. These circles are drawn from the same centre, with a radius of $2 \frac{1}{2}$ and 4 feet respectively from it. This is done for convenience in measuring the distance from the tee of stones lying within the 7 -foot radius, as it gives additional lines of measurement. This whole system of circles with the central tee is called " the house," and, as we shall see, all stones which, after being played, have come to rest with any part of them lying within the house, may add to the score of the side which has projected them there. Behind the house, in the position specified in Rule 3 , is placed the crampit. This is a strip of iron long enough for the player to stand on with one foot in advance of the other. It is roughened with spikes on its lower side, so that it maintains a firm position on the ice, and at the back of it is a ridge against which the player places his right foot before delivering the stones. It forms, in fact, a firm base for playing from, since, if anybody attempted to put down a curlingstone, while standing on the ice itself, with sufficient velocity to make it slide over the 42 yards to the other tee, he would quite certainly slip and put himself down instead. It is from a crampit that almost all curlers nowadays play. As an alternative they may use what is in the rule called a " hack," which is a small iron contrivance fixed to the boot, and which answers the same 
purpose as a crampit. But it is not, in Switzerland anyhow, often seen, for it requires adjustment for each individual player, whereas the crampit fits all alike.

Now this arrangement of hog-score (usually called "the hog "), back score, sweeping score, "house" and crampit (or hack)," scratched in the ice according to these directions, completes the construction of one end of the rink. At the other end a similar construction is made in alignment, the centre of the two houses being 39 yards from one another. Here is the rink ready for play, and the rest of the rules deal entirely with the game itself.

Note.-Now I have before me the Rules of the Royal Caledonian Curling Club of IgII-I9I2, which, I believe, are the latest. But neither there nor elsewhere can I find the slightest allusion to the principles of scoring at the game, foreknowledge of which is probably assumed. But since it is possible that there are those who do not know how the score is made, it is well to state it. Briefly, then, the stone which, at the end of a "head " or " end " of the match (which is made up by every player having had his turn, and having played his two stones), lies nearest to the tee counts one point to the side to which the stone belongs, given that it or any part of it lies within the house. If the stone that lies next nearest to the tee belongs to the same side it counts one also; so also does the next nearest and the next nearest and the next nearest, provided they are all in the house and belong to the same side. But if, after the stone lying nearest to the tee, the next nearest belongs to the opposing side, the first-named counts one, but this second stone takes precedence of all others lying in the house, and the side that owns the nearest one counts one only. Suppos- 
ing there are two stones which, after measurement, are found to lie exactly equidistant from the tee, the head or end is a draw, and is like a halved hole at golf.

5. All matches shall be of a certain number of heads or shots or by time as may be agreed on, or as fixed by an umpire at the outset. . .

6. Every rink of players shall be composed of four a side, each using two stones, and no player shall wear boots, tramps, or sandals with spikes or other contrivances which shall break or damage the surface of the ice. The rotation of play observed during the first head of a match shall not be changed.

Note.-Players are usually shod with "gouties." These are cloth overshoes with india-rubber soles, and are put on over the boot. What is required is (by the rule) something that will not injure the ice, while the player for his own sake will wear something that enables him to run with the stone he is sweeping with the least possible risk of falling down. On the whole, rubber-soled footgear is the best.

7. The skips opposing each other shall settle, by lot or in any other way they may agree upon, which party shall lead at the first head, after which the winners of the preceding head shall do so.

Note.-The head, as already stated, consists of the projection of sixteen stones from one crampit towards the house at the other end of the rink, for each player puts down two stones, and there are eight players. Then when all have played the head is complete, the score is recorded, and the next head is played from the cram- 
pit behind the house into which they have just been playing. They " cross over," that is to say, to the other end of the rink.

The skips (short for skippers) are the captains of the opposing sides. They have complete control of their sides, and direct each player (with due regard for his capabilities) what shot he is to play for. The skips "toss up" who shall have the choice of beginning (stones being played by opposing sides alternately), and the side which scores at the first head takes the honour (as at golf) at the second head. If neither side scores (the head being halved) the honour remains as it was. It may be noted also that though in regular matches (as stated in Rule 5) the number of heads to be played is settled beforehand, in an ordinary friendly game it is more usual merely to see how time is going when play has been in progress a couple of hours or so, and then determine how many more heads shall be played.

8. All curling-stones shall be of a circular shape. No stone, including handle and bolts, shall be of a greater weight than $44 \mathrm{lb}$. imperial, or of greater circumference than 36 inches, or of less height than one-eighth part of its greatest circumference.

Note.-The stones, then, are great granite buns with a handle to project them by. The usual weight is from about 36 to $40 \mathrm{lb}$., and the reason why a limit is given to their weight is that people like Mr. Sandow could doubtless deliver stones which weighed as much as grand pianos. These could not be shifted by lighter granite buns, which would merely recoil from them. Two or three of them would also fill up the greater part of the fairway of the rink. 
9. No stone shall be substituted for another (except under Rules Io and I4) after the match has begun, but the sole of a stone may be reversed at any time during a match, provided the player is ready to play when his turn comes.

Note.-The question of the reversing of stones is dealt with later in the practical part of this essay. For the moment it is sufficient to say that one side of the stone is very highly polished, the other less so. When the stone is put down on its highly polished (or " keen ") side, it will, of course, with the same initial velocity travel further than if put down on its rougher (or "dour") side, the friction on the ice being less.

ro. Should a stone be broken, the largest fragment shall be considered in the game for that head-the player being entitled to use another stone or another pair during the remainder of the match.

II. All stones which roll over, or come to rest on their sides or tops, shall be removed from the ice.

Note-So weird a phenomenon seems impossible, but then curlers are very weird also. Incredible as it may sound, it is quite possible to put down one of these great granite buns with the handle in the centre of its top crust so unevenly that, after a drunken wobble or two, it turns right over amid howls and shouts and execrations. Probably you could not do it if you tried, any more than you could cut a golf-ball smartly to square leg when you mean to go quite straight. But these distressing feats are known to occur, without the player having had the smallest desire to accomplish them. The traditional penalty for thus mishandling a stone is "drinks all round." The present writer 


\section{TEES AND CRAMPITS}

has never seen a stone come to rest on its side, but "credit, quia impossibile."

I3. Players, during the course of each head, shall be arranged along the sides, but well off the centre of the rink. . . . Skips only shall be entitled to stand within the seven-foot circle.

I4. . . Should a player play a wrong stone, any of the players may stop it while running; but if the mistake is not noticed till the stone is at rest, the stone which ought to have been played shall be put in its place, to the satisfaction of the opposing skip.

I6. The sweeping shall be under the direction and control of the skips. The player's party may sweep the ice from the hog score next the player to the tee, and any stone set in motion by a played stone may be swept by the party to which it belongs. When snow is falling or drifting, the player's party may sweep the ice from tee to tee. . . Both skips have equal rights to clean and sweep the ice behind the tee at any time, except when a player is being directed by his skip. . . .

Note.-The all-important question of sweeping is dealt with later. The principle at the base of the rule is that a player's side may encourage (or not) his stone to proceed, but the other side may not interfere with it in any way at all. In accordance with this principle is the direction that says that if a stone during its course moves a stone belonging to the other side, that stone may be swept or left alone at the option of the other side.

I7. (a) If in sweeping or otherwise a running stone is marred by any of the party to which it belongs, it may, in the option of 
the opposing skip, be put off the ice; but if by any of the adverse party, it may be placed where the skip of the party to which it belongs shall direct. . . .

(b) Should any played stone be displaced before the head is reckoned, it shall be placed as nearly as possible where it lay. . . .

I8. No measuring of shots shall be allowed previous to the termination of the head.

I9. The skip shall have the exclusive regulation and direction of the game for his rink, and may play last stone or any part of the game he pleases. . . . When his turn to play comes, he shall select one of the players to act as skip in his place.

22. Every stone shall be eligible to count which is not clearly outside the seven-foot circle. Every stone which does not clear the hog-score shall be a hog, and must be removed from the ice. . . Stones passing the back-score, and lying clear of it, must be removed from the ice, as also any stone which in its progress touches the swept snow on either side the rink.

Note.-Thus there is only a certain portion of the ice on which stones may remain during the progress of each " end " or " head." If a player sends down a stone too weakly so that it does not reach the hog-score, or so crookedly that it goes into the swept snow at the side of the rink, or so strongly that it passes over the backscore, it is at once removed from the ice. But, strangely enough, it is nowhere laid down what the breadth of a rink should be. Somewhat pathetically this rule presupposes that there is always "swept snow" at the side of the rink, which, happily, is not the case. As a matter of fact the space allowed for each rink is, roughly speaking, about 20 feet, though $\mathrm{I}$ am not aware that it is 


\section{TEES AND CRAMPITS}

laid down authoritatively anywhere. In any case a stone, to be of the slightest use, must be lying not so wide as ro feet (lateral measurement) from the tee, and those lying wider, as well as those which have definitely passed beyond the back-score, cannot conceivedly come into play, and so may as well be removed. But the case is different with stones lying short of the hog-score, and in a straight line between the tees. Such stones, as will be readily understood, might possibly be of the utmost value to guard other stones lying in the house, and perhaps to be promoted into possible scorers. A guard, then, which is so important an item, must be put down with some skill, and with requisite strength, and thus it is laid down that stones lying short of the hog are considered not to have been sufficiently skilfully played to take part in the game and be of value to their side. These are therefore ignominiously removed.

Here, then, have been given the conditions under which, and the court, so to speak, in which, this great game is played, and we will suppose ourselves on the fast, perfect ice of a Swiss resort on a sunny morning. The skips have "picked up" their sides; every player has a broom or " besom," which we will hope sweeps clean; the four players on each side, namely No. I as lead, No. 2, No. 3, and No. 4, have had their places allotted to them. As a general rule it is the skip who plays in the most difficult placei.e. No. 4, where, if the other three players under their skip's direction have built up an interesting house, he will have the most delicate and hazardous shots to negotiate. But it sometimes happens that the skip, who primarily should be chosen because of his knowledge of the game, may not have the requisite skill of 
hand for that post: it may happen that a player on his side is a finer performer in the delivery of his stones, though his skill in tactics and generalship may be inferior. In such a case the skip, who directs the place of each player, may put himself in another position, and, if he does not play as No. 4, will usually lead. Then he goes first, and can devote a mind, untroubled by the thought of the shots he will himself have to play, to the tactics of his campaign. But, as a rule, the player with the best knowledge of the game is usually the best player also, or, at any rate, is good enough for the critical post of No. 4, and in general the skip occupies that position.

Round about the crampit, behind the back-score, are ranged the sixteen stones which the players have selected, and if they are wise they will have turned them momentarily upside down, so that they rest on their handles on the ice, and their bases, or soles, are exposed to the rays of the sun. This should be done because it often happens that some fragment of broom or some little congelation of frost has frozen on to the soles, which will impede their smooth passage down the rink. But if they are slightly warmed like this, a polish on the side of the besom or on the glove will ensure their being quite free from any such impediment. In order to identify the stones of each side, it is usual to tie some fragment of ribbon to the handles or otherwise distinguish the stones of one side from those of the other, since without some such mark they are as alike as sheep, and, as is obvious, the whole game depends on the relative position of the stones of one side as opposed to that of the stones of the other. But if one side is "ribbons" and the other " plain" the skip sees 


\section{TEES AND CRAMPITS}

at a glance, even when the house is growing most populous and complicated, how his enemies lie and what is the position of his own stones.

The skips, then, take up their positions by the house into which the stones are about to be played. Only one skip, as laid down by the rules, may be in the house at any given moment, and that skip is the skip of the player then delivering his stone. The other skip stands outside and behind the house, but ready, if the stone of his opposing side has been put down too strongly, to sweep it out of the house when it has once passed the tee. Till it reaches the tee he may not interfere with it in any way, but once past that he may (and certainly will) polish the surface of the ice over which it is going to travel for all he is worth, so as to assist it in passing through the house altogether and so be taken off the ice. If, on the other hand, his side has the house, he stands inside the house, or in front of it, calls out how he wants the stone laid, and holds his broom as a mark on to which the player is to aim his stone. On that mark the player, if he hopes to deliver a successful stone, must fix his eye with the hungry steadfastness with which he has to look at his ball at golf.

Then, in order to grasp the hang of the game, we, the invisible spectators, must leave the skip with the besom pointing on to the ice and observe the other players. Down the rink they are ranged, No. 2 of one side opposite No. 2 of the other, No. 3 opposite No. 3, leaving the centre of the ice, the " howe-ice," as it is called, clear for the passage of the stones. Thus to No. I, who is about to deliver his stone, the whole of the house with its seven foot radius is unimpeded. Just outside that empty riband of ice, so 
soon to ring with the sliding stones, stand No. 2 and No. 3, his own No. 2 and No. 3 on one side, the inimical No. 2 and No. 3 on the other. His own side should be alert for any direction from the motionless skip; the other side are sublimely indifferent, for they may not interfere with the course of his stone.

He delivers the stone: the skip, eagle-eyed, watches the pace of it. It may seem to him to be travelling with sufficient speed to reach the spot at which he desires it should rest. In this case he says nothing whatever, except probably "Well laid down." Smoothly it glides, and in all probability he will exclaim "Not a touch ": or (if he is very Scotch, either by birth or by infection of curling) " not a cow" (which means not a touch of the besom). On the other hand he may think that it has been laid down too weakly and will not get over the hog-line. Then he will shriek out, "Sweep it ; sweep it" (or "soop it; soop it ") "man" (or " mon"). On which No. 2 and No. 3 of his side burst into frenzied activity, running by the side of the stone and polishing the surface of the ice immediately in front of it with their besoms. For, however well the ice has been prepared, this zealous polishing assists a stone to travel, and vigorous sweeping of the ice in front of it will give, even on very smooth and hard ice, several feet of additional travel, and a stone that would have been hopelessly hogged will easily be converted into the most useful of stones by diligent sweeping, and will lie a little way in front of the house where the skip has probably directed it to be. If he is an astute and cunning old dog, as all skips should be, he will not want this first stone in the house at all ; in fact, if he sees it is coming into the house, he will probably say " too strong." Yet, since accord- 


\section{TEES AND CRAMPITS}

ing to the rules only stones inside the house can count for the score, it seems incredible at first sight why he should not want every stone to be there. This "inwardness" will be explained later.

No. I of the other side delivers his stone: No. I of the first side delivers his second stone, and No. I of the opposing side delivers his second stone. And from this moment the whole problem of the game becomes as complicated and interesting, given that the stones perform something like that which is required of them, as does a game of chess when the first four or five moves of a recognised gambit have been played and countered. Even at so early a period of a head at curling, the possibilities of its subsequent development are almost infinite; the building up of the house may progress in a hundred different ways, and it will be possible only to consider only one or two of the problems with which the skip is confronted.

In actual "moves," what has happened is this: the leads (No. I) of each side have played their stones, and No. 2 on each side go up to the crampit for their turn. No. 3 on each side thereupon moves towards the crampit, while No. I on each side becomes the sweeper nearest the house, so that each stone as it comes down the ice may have its sweeper ready if sweeping is ordered. No. 3 (when No. 2 is playing) is nearest No. 2 : he dances sideways along the ice ready to sweep if the order comes, until he delivers the stone into the keeping of No. I, who has just played. Often, if sweeping is an urgent necessity, both he and No. I will vigorously scour in front of the progressing stone, since often in the ensuing situations it is not a question of additional feet that are required, but of an inch or two. There may be a stone in the 
house already, and it is doubtful whether an opposing stone has "legs" or vitality enough just to pass it, and thus lie nearer to the tee. In such a case all possible assistance must be rendered it ; the skip will career wildly out of his house and join No. 3 and No. I in their operations. Anything, anything to give this dying stone an inch more of travel ! . . . Also, a stone with smooth ice in front of it will travel more directly, that is with less curl upon it, as it is becoming moribund, than a stone which has the infinitesimal fractions of tiny frost-flower or moisture to encounter. But that opens up the awful question of "handle." . . . There will be something about that in its appropriate place.

But here, at any rate, we have the rink moving. Slow stones are being encouraged to cross the hog, or to enter the house, or, even at this early stage, to cannon rudely against the stones already in the house which must be ejected. Theoretically, I think, in the ideal game of curling, which we shall never see on this side of the grave, the leads should have laid down four stones a little in front of the house, or perhaps each lead should first have put down a stone in front of the house, and then delivered their second stones with in-handle or out-handle, round their first stones, which thus become guards of their second stones, which should lie, say, in the four-foot circle. But we need not consider so perfect an opening. If any leads led like that, they would be skips of a team of archangels, who would be soundly rated for their clumsy play.

As a matter of fact, what usually happens in a good team is this sort of thing. The first man to play miscalculates the speed 


\section{TEES AND CRAMPITS}

of the ice (though he is quite a good player) and is soundly hogged. His opposing No. I, being too frightfully intelligent, and profiting by that which he has seen, puts down a stone that passes the tee, and rests perhaps in the seven-foot circle beyond it. And though that stone for the moment "counts": that is to say it is in the house, and, theoretically, may be a winner, it will not in real practice be of any good when the head is finished. There is bound to be a better stone than that, and any other stone over the hog that lies in front of the house, though not counting at present, is far superior, for it can be promoted (i.e. brought nearer the tee) by any stone that strikes it, whether of its own side or of the enemy, and thus is both dangerous to the other side and helpful towards its own. Also it can become the most valuable guard for a stone that has curled round it and lies in the house and behind it, whereas the stone that comes to rest beyond the tee can, if struck, only travel further away from the tee instead of towards it.

The two leads put down their second stones. They have gauged the speed of the ice, and this time do as their skip tells them. They both put down stones that come to rest just in front of the house, or perhaps just in it. But if either of them make what would be the most perfect shot of all, if they were playing the last shot of No. 4, namely one that rests on the tee itself, or in the $2 \frac{1}{2}$-foot circle (called the pot-lid), he has not done probably as much for his side as if he had laid his stone just in front of the house, for No. 2 of the other side follows, and he has only to be straight irrespective of too great speed to dislodge that perfect stone and in all probability lie there himself. A guarded stone in such a position is the most valuable stone that can be imagined, 


\section{6}

\section{WINTER SPORTS}

but without a guard its worth is enormously decreased. Indeed it is positively a dangerous stone, since it gives the other side something to rest on.

We will suppose, then, that when No. 2 plays there are lying on the ice two stones, both a little in front of the house, one right in the middle of the ice, the other three or four feet to the side of it. The object now will probably be to get past those stones, and, by the twist imparted to the stone No. 2 now delivers, to lie behind one or other of them in the house, and thus be guarded. If this shot is perfectly played there will be lying a stone close up to the tee and incapable of being directly attacked (i.e. by a hard shot played down straight on to it), for the guarding stone in front of the house prevents this, and it is a very different thing to be obliged to play round this guarding stone so as to hit the other. Thus it may be necessary for the opposing skip to direct that this guard should be removed by a fast straight stone, so as to open up the house again. But this costs a stone, even if successful, and stones are not lightly to be squandered. Should this shot come off, the first skip will probably direct that another guard be laid to protect this asset in the house. Having once got a stone in a probably winning position, the skip is right to guard it and to guard it and to guard it, directing that stones should be laid to right and left of it, so as to block the passage of a stone which, by curling inwards or outwards, can reach and dislodge it, and perhaps lie there in its place. Practically speaking, a stone which lies close to the tee should be guarded at the cost of every stone belonging to the side if necessary (i.e. if the guards are being removed by the enemy), and no skip in his senses will direct his player to put 


\section{TEES AND CRAMPITS}

other stones in the house until he has rendered reasonably secure from attack the stone of his which lies close to the tee.

The above analysis of these early stones takes, of course, only one case out of the hundred ways in which they may lie, and gives but one instance of the value of stones lying in front of the house, rather than (in the early stages of the game) in the house. Among other values they possess they are also capable of being promotedi.e. a subsequent player may be directed to hit one of them gently, so as to push it into the house, while his will lie there in its place guarding it. Or he may be told, if the stone in question is lying rather wide, to get an inwick off it-i.e. play on to the inner side of it, as in the manner of a half-ball shot at billiards, and, cannoning off it, slip into the house himself. Perhaps it will be an enemy's stone selected for this manœuvre, and perhaps, also, he will hit the wrong side of it (i.e. the outer side), and instead of slipping into the house himself, will kindly promote the other stone instead. Thus these stones in front of the house are both an asset and a danger, and it is not too much to say that their presence, lying there, is about the largest constituent in the interest of the "end " and the building of the house. They present, as has been seen, infinite possibilities of value and menace. And all their terrific potentialities have to be weighed and pondered by the skip.

When twelve stones have been put down (i.e. when the first three players on each side have contributed two each) the skips, if playing four, leave the house and go down to the crampit to deliver their stones. One in all probability looks troubled, the other in that case will almost certainly wear a face of benignant elation and call attention to the beauty of the morning. Their 
places in the house to direct and hold the guiding besom are taken by other members of their side (probably the No. 3s), and before they go they will almost certainly hold a secret and muttered conversation with these gentlemen, consulting and conferring over the shots to be attempted. For by this time the situation, if the play has been respectable, is sure to have become complicated. Very likely four or five stones are in the house, and of those four or five all but one may happen to belong to one side. But that one is sitting there on the very tee itself, and thus takes precedence of all the others. If only it could be got at and evicted and soundly butted out of the house, the other four would all count. But it lies well guarded, for just in front of the house are two stones a little to right and left of it. There is clear ice (a "port" as it is called) of not more than two feet between them, through which it is possible to send a stone that will reach that tee-sitter. But, oh, how small a two-foot port looks at the distance of nearly forty yards!

Now, it is to the first skip that this by-every-means-in-hispower-to-be-guarded stone belongs, and with justice he fears that his opposing skip is perfectly capable of sailing blandly through that rather narrow port, butting the stone that lies so perfectly on the tee out of the house altogether, and lying there himself instead. So he has elected to play a shot that will close up that port and leave the stone on the tee for the moment impregnable. He wants to lie just over the hog and no more, for the nearer a stone is to the hog the more it blocks the passage. So, calling on his sweepers to be ready to sweep ("Sweepers wake!" in fact), he puts down his stone with in-handle on it, directing this a little 



\section{"SHE LIES"}

From the Drawing by Fleming Williams 


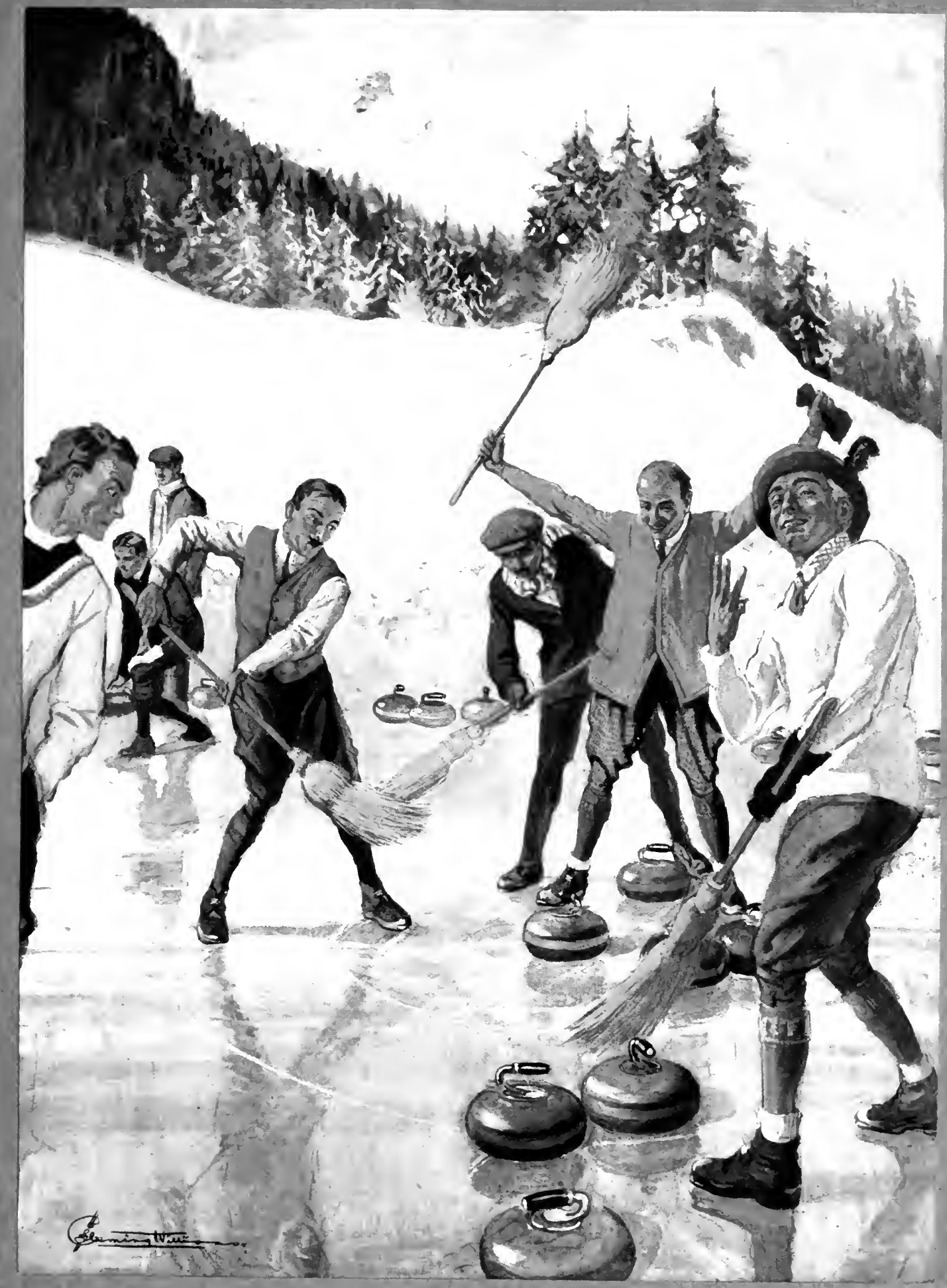





\section{TEES AND CRAMPITS}

wide of the left-hand stone of those two guards, by which the temporary skip is holding his besom. For one moment he watches its passage, eyes glued to it, stricken to stone. Suddenly an awful misgiving occurs to him, his face turns to a perfect mask of agonised fury, and he yells at the top of a naturally powerful voice:

"Sweep her, don't leave her for a moment. Sweep! Sweep ! Don't leave her. Good Lord, can't you sweep? Oh, well swept, well swept indeed!"

Then probably with infernal superiority he shouts, "Is that about where you wanted it?" knowing perfectly well that it is.

All this means that

(i) He was afraid he had put down his stone too weakly, and that it would not get over the hog.

(ii) It would then be ignominiously removed, and he would wish he had never been born.

(iii) The opposing skip would sail through that port, and out the winning stone.

(iv) That it is all his fault, and that he will never curl again, but take to that degraded pastime, skating.

(v) Finally, that his stone has been swept over the hog and lies now bang in the middle of the passage, closing it completely - a perfect gem, pearl, peach.

Says the other skip grimly, "You've got some good sweepers on your side."

Says the first skip (airily and forgetting that he has been howling to his side to sweep), "Oh, it had lots of legs." (Liar : it is just over the hog.) 
Ensues a shouted colloquy between the other skip and his lieutenant (No. 3) in the house.

No. 3. Can you see anything of the port?

Skip 2. No.

No. 3. Can you see anything of the stone that lies?

Skip 2. No.

(Skip I here probably lights a pipe and talks gaily to a friend.)

No. 3. Can you get round their guard with out-handle ?

Skip 2. No.

No. 3. Can you get round the other guard with in-handle?

Skip 2. No.

(Long pause.)

Skip 2. Yes, I can. At least there's nothing else to be done. No, give me more ice than that! (This means that he thinks his stone will take more curl, and wants the directing broom to be put wider.) That's about right.

He plays his shot amid dead silence. It soon becomes apparent that his stone is not going to curl round this guard at all, but will hit it. It does so, and lies by its side, merely giving an additional rampart to the granite fortification in the middle of the ice. The silence becomes rather painful.

Skip I. Bad luck! (He does not mean that at all.) I think I'll try and get another stone in the house.

Skip I's No. 3. For heaven's sake don't disturb our stone here.

Skip I. No, I'll play it just tee high. . . .

(He puts down a hopeless hog.) 


\section{TEES AND CRAMPITS}

Skip I. I wish you fellows would sweep !

(His pipe goes out.)

Skip 2 shouting to his No. 3. Well ?

No. 3. Well ?

Skip 2. See what happens, I think. There's nothing to play for.

This means he is going to play for a fluke. There is no reasonable chance whatever of reaching that stone on the tee, and a wild toboggan of a shot sent down among all those guards may do something, though heaven alone knows what. He puts down stone with full swing, most unevenly, so that it careers up the ice violently rocking. It hits the long guard by the hog, which is exactly what he didn't want to do, almost full in the face, and sends it scudding off into the abominably bad stone he himself has just put down before. It hits this nearly full, and starts it on its way. Bang into the middle of the house it goes, sends that impregnable tee-lying stone flying, and lies there itself. The five other stones in the house are all on its side, and instead of Skip I scoring one, Skip 2, off an incredible, revolting, pitiable fluke, scores five. Roars of execration and applause rend the skies, and Skip 2 modestly remarks, "Well, there are more ways than one of playing any shot!"

Here, then, is a rough sketch of the game as it is played, as it appears to the spectator; and after this bird's-eye glance at it it is time to start again at the beginning and see how to play it. And the first consideration is the stance which the player takes up on the crampit before delivering his stone. Here, as at golf, there 
are great varieties of stance, all of which are perfectly right and proper, provided the curler can deliver his stone from them with effect. But, as at golf also, there are certain principles that will be found common to all those stances, and perhaps the most important of all is that the curler should feel perfectly comfortable and be maintaining his stance by balance and not by muscular effort. In every case again (if he be right-handed) his right foot will be firmly resting against the rim at the back of the crampit, for it is there that he gets the purchase which enables him to give the needful velocity to his stone. Similarly, his left foot will be advanced, and he will be facing full in the direction in which he is about to send his stone, and his left foot will also be pointing in that direction. He will also be bending down, since he has not to drop or fling the stone on to the ice, but to place it-to lay it there smoothly with a forward swing of his arm and body. But any kind of divergence is proper as regards this stooping attitude: some men get their stone down to the ice by bending the body strongly above the hips, keeping the legs comparatively straight, while others get down by bending the knees so far that they are sitting on their right heel, and their right knee is absolutely touching the crampit. And all these styles are perfectly right provided only that (i) the player feels comfortable and unstrained ; (ii) he can get his stone well down on to the ice; (iii) his head is facing and his eyes looking in the direction of his skip's besom. All three of these provisions are essential to successful curling, and if one thing can be more essential than another, it is that the player should be looking straight at the skip's besom.

Next comes the actual delivery of the stone, the handle of which 


\section{TEES AND CRAMPITS}

should lie lightly in the crook of the fingers and not be grasped like a battle-axe. This delivery of the stone is accomplished not by a jerk, as if throwing it, but by a steady swing forward of the body and arm together. The whole arm of the hand which carries the stone is brought slowly and steadily back (as in the back swing of golf), while the weight is resting almost entirely on the right leg. Then arm and body come forward together, without muscular exertion and without pressing, and the stone is placed on the ice, while the weight of the whole body, which at the top of the swing was on the right leg, has come forward on to the left. Should the ice be slow, greater force is given to the stone by a longer swing, and should the ice be fast the swing is shortened. But in no case, if the ice is playable on at all, should the impetus be derived from a muscular effort of the arm as in throwing; but as in golf, the swing of the arm and body together give the stone its impetus. And throughout the swing the eyes of the curler must never leave the directing besom of his skip. It is as fatal to look away from that as it is to take the eye off the ball at golf.

Now, if the stone is put down like this, without jerk or exertion (except such as is entailed in the swing), the stone will be laid evenly, and will start on its course without wobbling, but sliding truly on its polished base. But if it has been jerked or chucked on to the ice instead of being laid there, the chances are ten to one that it will be what is called a "quacker"-i.e. it will be oscillating from one side to the other and rolling like a ship in a cross sea. This sort of stone is quite useless, and if quacking badly will go staggering right through the house without ever 
having slid at all. Sometimes, if merely a very fast stone is wanted to break up a rampart of guards, or just " to see what will happen " in a hopeless position, a quacker is as good as anything else. But it is not curling.

Now there is a very important item in the swing at golf called the "follow-through." This means that after the ball has been hit and is on its way, the club and the hands and arms holding it fly out after it, while the whole weight of the body goes on to the left foot. There is no question that what happens to the club and the arm and player generally, after the ball has gone, cannot make the least difference to the flight of the ball, but this "followthrough" is a symptom, an indication of what has already taken place, and if the follow-through is satisfactory and full it shows that the swing has been unchecked and smooth. Just in the same way the curler has to follow through, and though no doubt both curler and golfer can, theoretically, check their swing the moment after the stone and the ball have started, they would be most illadvised to attempt to do so, since they run a grave risk of checking their swings before the stone or the ball have gone, and thus giving to their shot only a fraction of the force of the swing. So the curler is strongly advised to let this forward swing of his arm and body work itself out in the natural follow-through. And this followthrough may express itself in various ways. Most curlers express it by letting themselves run or slide a few steps after their stone, the forward swing of the body overbalancing their left foot, so that they instinctively (for fear they should fall down) put the right foot in front of it-in other words, take a few steps. Others again, and chiefly those who deliver the stone with right leg very 


\section{TEES AND CRAMPITS}

strongly bent, so that the knee touches or nearly touches the ice, have not time to scramble to their feet, and usually express their follow-through by falling forward on their hands on to the ice. But in whatever way they conduct themselves, this little run and slide which some take and the falling forward of others are the result of the player's proper and correct follow-through. He has not, at any rate, interfered with or checked his swing: he has delivered his stone with the force that he believed to be required.

And now we come to the most delicate and interesting part of the delivery of the stone, namely, the question of "twist" or "elbow" or "handle," as it is called, which is universally practised by all curlers. This "handle" gives a rotatory motion to the stone, so that as it is travelling up the ice it is also slowly revolving on its own axis, either from right to left or left to right, and this rotation imparts to it, as its initial velocity diminishes and its pace slows down, a curling movement, in the manner of a break from the off or a break from the leg at cricket, or, if you will, a swerve in the air, or, as in golf, of a pull or a slice. Thus, though a stone on the tee may be completely guarded and covered, the player can, by imparting this rotatory movement to his stone, curl round the guard and reach his goal. Moreover, he can curl round the straight guard from either side, from the leg or from the off, so that if one path is blocked by another guard, he may yet get access by the other. He can, too, if there is, as often happens, a slight bias in the ice, apply the handle opposite to the direction in which the bias of the ice would deflect his shot, and thus keep his stone straight. Or again, by aiding the bias by the other handle, he can get round a very wide obstacle indeed. 


\section{06}

\section{WINTER SPORTS}

Heaven knows that these shots so glibly recorded are not easy; but there is hardly a shot or a manœuvre in any game which is easy. But the man who aspires to be a curler at all must have a fair command of this thing called " handle." He must be able to direct a shot with moderate accuracy on the skip's besom with either out-handle or in-handle. It is not enough equipment for the most modest player, who is a curler at all, to be able to play with one handle only. He must have a tolerable command of both.

Now, strange as it may at first appear, it is far easier to send down a stone with in-handle or out-handle on it than to send down a perfectly straight stone with no handle at all. Furthermore, the slightest frozen chip of ice, or minutest fragment of broom may, in passing under one side of the stone, impart a fortuitous and rotatory motion to it, so that a stone arriving in the house with practically no curl at all upon it is (except in the case of a fast hard stone) a rarity. Since, then, it is almost bound to have some handle on it, it is wiser for the player to put on the handle himself intentionally and allow for its curling course. This rotatory motion of the stone is imparted to it by a very slight turn of the arm just before the stone leaves the hand. If the elbow is turned outwards, it is called "out-elbow" or "out-handle," though I am inclined to think that it is the wrist which makes the turn (some people say the fingers alone), the elbow merely following the wrist. This gives the stone a twist from right to left, and the effect of it is that it curls in from the right in the manner of a ball bowled with leg-break. This out-handle curl is easily imparted to the stone by turning the handle of it, as the hand grasps it, outwards at 


\section{TEES AND CRAMPITS}

right angles or thereabouts to the direction of the stone's travelling, and by holding the handle "overhand," as it were, with the knuckles and back of the hand facing the ice in front. The curl is then naturally imparted to it, and the player will not have to think about it at all. If he delivers his stone in this way his wrist, if he holds his arm slack, as he always should (giving the velocity to the stone only by the swing), will naturally and inevitably make the outward turn. And it is a most important thing that the player should not think of handle at all when he delivers his stone, but leave that to develop automatically from the correct delivery, since the consideration of the pace and direction of the stone are enough to fill the most capacious mind and tax the utmost of his skill. How much allowance should be made for the curl, and how much the stone should be aimed to the right of where it is desired that it should come to rest, is a matter which is largely left to the judgment of the skip, who has been observing how much curl the ice takes. This differs very considerably, and depends on the condition of the surface. For instance, if the ice is very slow, a stone dies quickly, and since the curl does not begin to take effect till the initial speed has very much diminished, it will not curl for so long as it would on keen ice. On slow ice, in other words, the course of the stone is less influenced by handle. But again, the vigorous polishing of the ice in front of a stone tends to keep it straight, since then the roughnesses of the ice, on which the rotatory motion bites, are much diminished. But as a rule, after a few stones have been sent down, it is clear to a good skip how much handle they are taking, and he directs accordingly. 
The in-handle or in-elbow is produced in precisely the converse way to the out-handle, and the stone, instead of curling in from the right, curls in from the left like a ball with off-break on it or a slice at golf. Here the stone should be held with its handle pointing inwards towards the player, and he should hold it in the crook of his fingers with the inside of his hand instead of the back of it facing the direction in which he lays his stone. This grip, again, naturally gives the required twist, and he can concentrate himself on pace and direction. But often during the course of a match the character of the ice will change, and it will begin to take the handle more or less as the case may be. Both skip and individual players should be on the lookout for this, and the tactics should be altered accordingly. Hard ice-ceteris paribus-is the keener, and thus in the afternoon, when the rays of the sun shine less directly on to the rink, it tends to get faster and to take more curl. On the other hand, in the morning ice tends to get slower, as the sun plays on the surface of it.

All stones are polished differently on their two faces, one side of the stone being less inexorably smooth than the other. A stone travelling on the keen or smoother side naturally goes further starting at the same initial velocity than if travelling on the rough side, and should the ice be very keen and fast, it is difficult to estimate the strength which will take them over the hog, and yet not send them roaring through the house. But the handles of stones can be unscrewed in a very few seconds and fixed on the other side, so that the stones will now travel on their rough or slower side. Conversely, also, if the ice has been very fast, and a player has been using the rough side of his stones, he may even, during the 


\section{TEES AND CRAMPITS}

course of the match, if the ice for some reason gets slower, reverse his stones and use the keen side. This will make it possible for him to play without effort, instead of " shifting " the stones along.

I am aware that in touching on the question of handle at all I do a thing that is provocative of discussion. There are many ways of putting on handle, and the adherents of any such will certainly maintain that their own method is the best if not the only proper one. But I think the majority of players will allow that the grip which $\mathrm{I}$ have mentioned, namely the overhand grip for imparting out-elbow and the underhand grip for imparting in-elbow, lead, more or less, provided only the arm is held slack, to the required result. But I freely allow there are many other methods: some curlers put on handle consciously, and consciously twist their arms as they deliver their stone, others trust to the slight adhesion of the little finger to the handle after the other fingers have quitted. But it seems to me that any grip which automatically imparts the desired handle is preferable to all grips which demand that the player should be obliged to think about his handle. $\mathrm{He}$ has enough to do without that, and enough to think about. So let him, if he finds these grips unsatisfactory, learn any grip under the sun (and over the ice) that naturally imparts the curl he wishes to put on.

A further question arises. Is it not possible to regulate the amount of handle and the consequent amount of curl that the stone will take? Without doubt it is; but the curler who can put on a great deal of handle or a little handle at will is not a person who can be instructed. Certainly it is possible to make one stone curl a little and another much, but he who can do this 
and regulate it is not a first-class curler merely but a supreme curler. For us, duffers and strugglers, there is a simpler method, which is to aim the shot always with the curl that we naturally impart to it, and take more or less "ice" as the case may be : aim it, that is to say, closer to the required resting-place for the stone if the ice is taking but little bias, and further from it if the ice is encouraging the deflection. The superior curler, in critical situations, it is true, when guards are spread about like the rocks in some dangerous archipelago, will make curves, as his stone is dying, which it would be madness for the ordinary decent player to attempt. But he will have made such curves by the conscious application of muscular force, sending the stone literally spinning down the ice. We admire, we applaud, 1 hope, even when he is on the other side, but unless we are more than first-rate at the game we will not try to imitate. Personally, I have a theory which concerns the thumb. Not for worlds would I divulge it for fear of encouraging disasters as bad as those that $I$ myself perpetrate. All the same I am convinced it is right: I lack the skill to execute it. . . .

But whatever the method of grip, whatever the curl to be imparted to the stone, the handle should be at rest in the crook of the fingers. To hold it tight implies muscular exertion, and muscular exertion, unless the object is to send a fast straight stone, the only requisite of which is great pace and moderate direction, is out of place at this delicate and "touchy" game. Even when the ice is very slow, better practice will be made with a longer and untightened swing than with momentum derived from the elbow and shoulder. 


\section{TEES AND CRAMPITS}

Finally, but no less importantly, with regard to sweeping. It is hardly too much to say that a good sweeper is almost worth his place in a side, even though he is an indifferent player, so tremendous is the part which a good sweeper plays, for he is like a good field at cricket. He should always start before the stone gets to him, so that by the time it is opposite him he is moving down the rink with it, ready to begin operations the moment his skip tells him. The word of command may come at any second, and it is often of vital importance that he should begin instantly. Even skips have errors of judgment, and the skip may have not given the order to sweep soon enough. This can often be rectified by instant and vigorous sweeping, and the error repaired, whereas if a sweeper is slow to go about his job the mistakes on the part of the skip may be irremediable. All down his allotted portion of the ice the good sweeper will sidle along by the travelling stone, even though no order comes, until he has given it into keeping of the next sweeper or of the skip himself. And with the same promptitude as he began to sweep must he stop sweeping when he hears the word "Up brooms!" Another yard of polish may, if the skip is correct in his estimate, be the death of a winner. Often again it is but a question of an inch or two to turn a hog into the most perfect of long guards, and this inch or two is entirely a matter of sweeping. The most moribund of travellers may be coaxed over the line and make an incalculable difference in the score by protecting a winner. But " a little less and what worlds away." . . . A shot that good sweeping would have made into a gem is bundled off the ice like the worst stone ever sent down on its degraded handle. 
Besides matches between teams there is a very searching affair to be played with curling-stones called a "points" competition. Here single players compete against each other in attempting to make certain shots which are set them. Stones are put on the ice in certain given positions, and each competitor in turn has to try to bring off a certain definite shot. For instance, he will have to guard one stone, to promote another, to get an inwick off a third, to draw a port between two others, \&c. It is, of course, a very high test of skill, but is somewhat a Lenten or humiliating affair, since the very finest players seldom get as much as halfmarks. It is, moreover, lacking in all the "team-feeling " which is one of the greatest charms in match play, and is also, in the present writer's humble opinion, a terribly tedious affair, since after each shot, if the lying stones have been touched, they must be replaced on their marked spots, and a competition of this kind, if there is at all a large field, goes on rather longer than into eternity. According to the regulations drawn up by the Royal Caledonian Club there are nine shots to be played and a tenth is added in case of a tie. The necessary stones to play on to are placed in or around the house, and the competitor has then nine different shots to play.

These are-(i) striking; (ii) inwicking; (iii) drawing to the tee ; (iv) guarding ; (v) chap and lie (i.e. playing on to a stone on the tee, ejecting it, and remaining in the house); (vi) wick and curl in; (vii) raising; (viii) chipping the winner ; (ix) drawing through a port. In case of a tie between competitors, those who are equal play four shots of " outwicking."

Different marks can be earned by each of these shots. For 


\section{TEES AND CRAMPITS}

instance, if a competitor playing chap and lie remain in the seven-foot circle he scores one, if within the four-foot circle he scores two, given that he strikes the placed stone out of the house in both cases. Complete details are published by the Royal Caledonian Curling Club. 


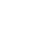




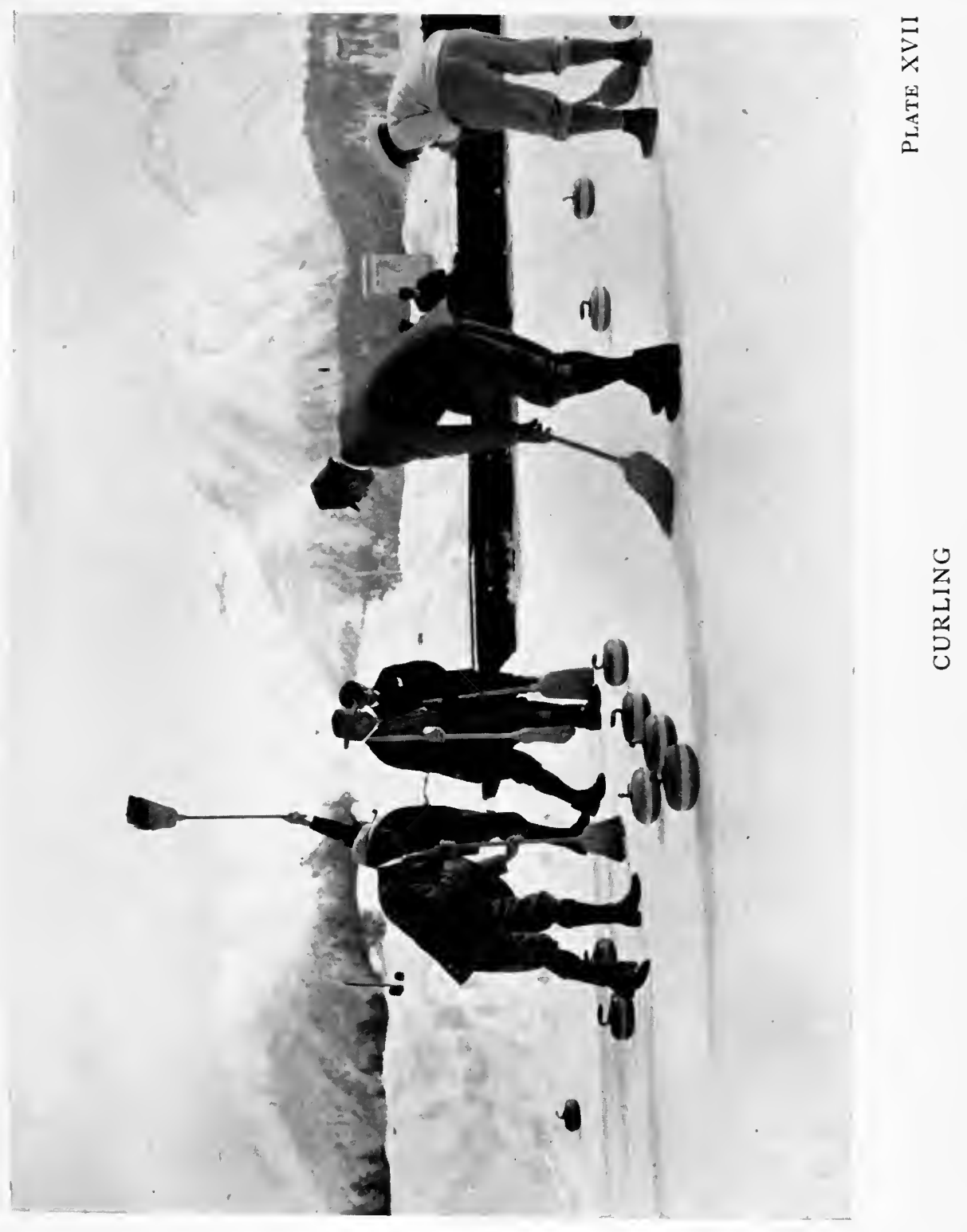


, 


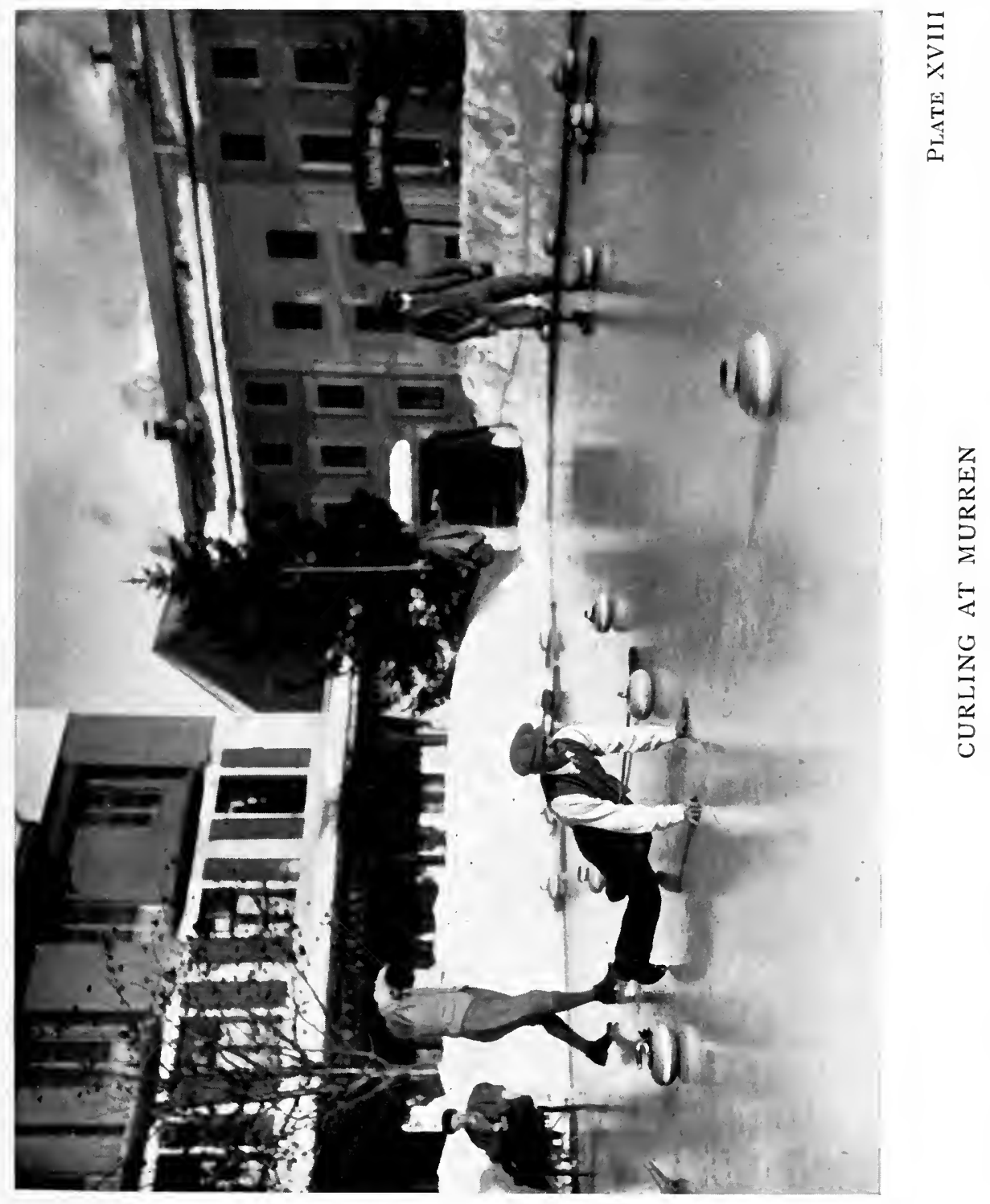





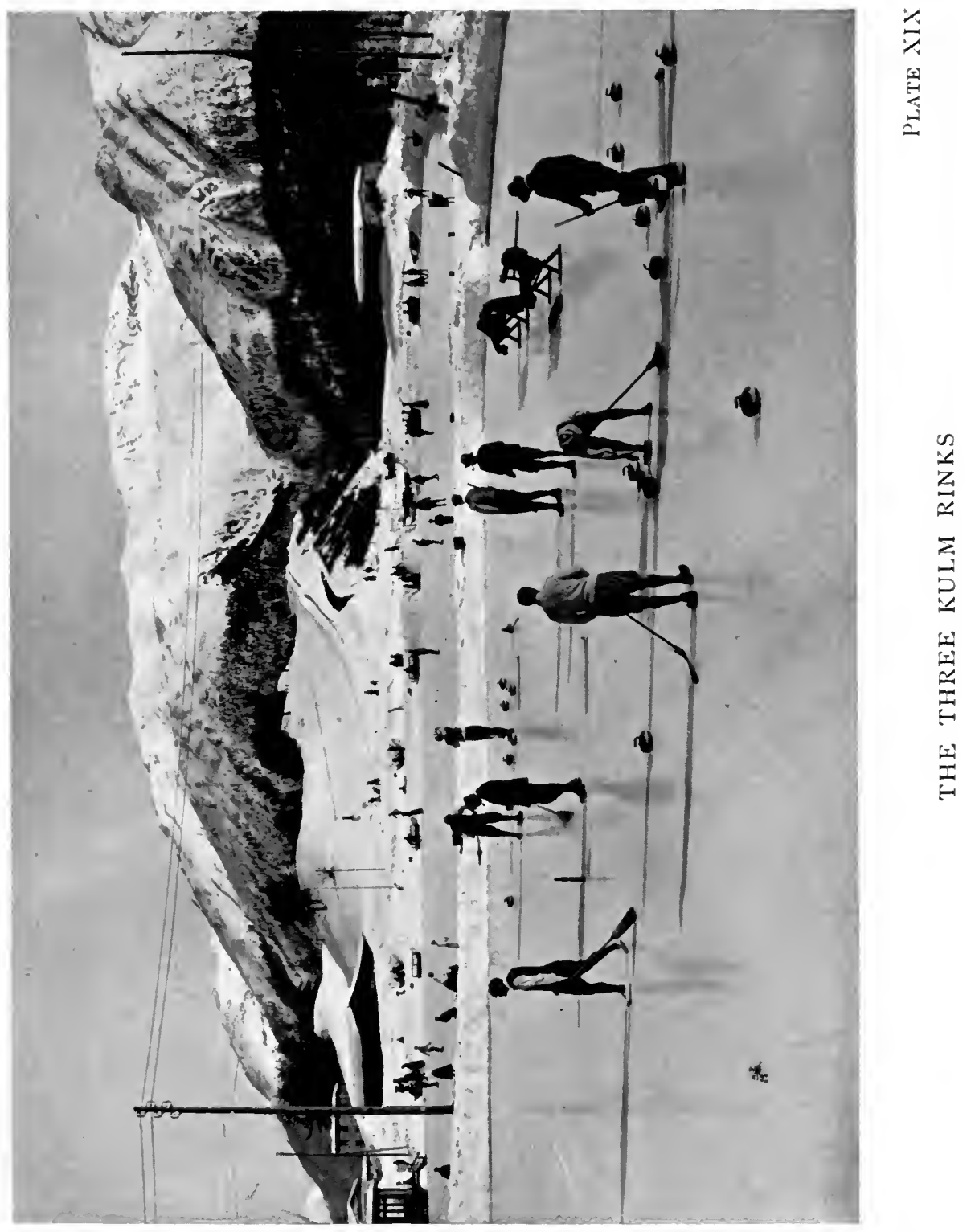




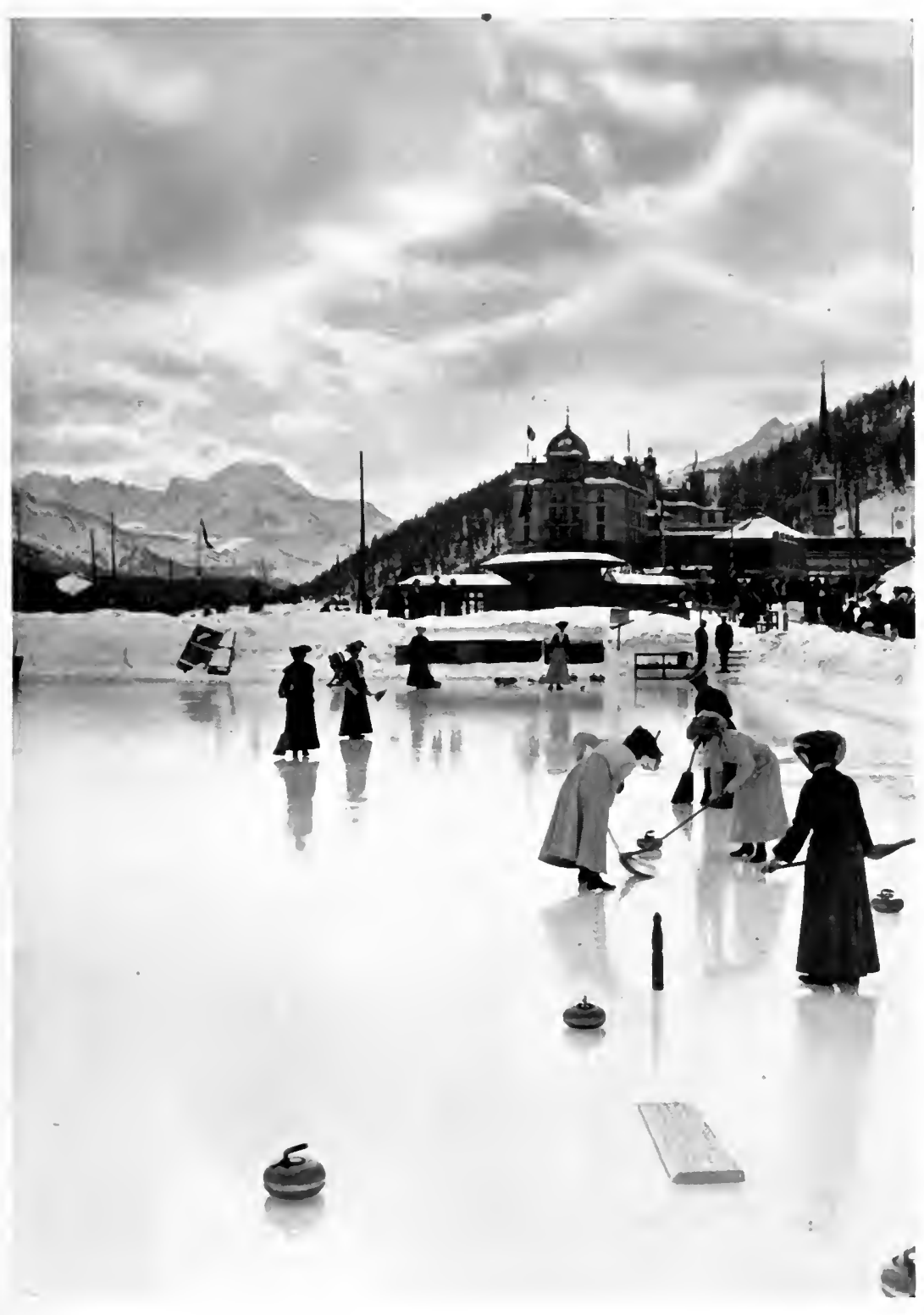

Plate XY

LADIES' CURLING MATCH, ST. MORITZ 



\section{CHAPTER IV}

\section{TOBOGGANING}

To descend an ice-run like the Cresta at St. Moritz is no doubt a most thrilling and skilled adventure, but the vast majority of people who say (with perfect truth) that they enjoy tobogganing would sooner think of ascending in an aeroplane than descending the Cresta, and would freeze with fright at the thought of embarking on it. On the other hand, the skilled Cresta runner would no more think that the quiet descent of snow-covered roads on a Swiss luge was tobogganing in his sense of the word, than the aeroplanist would allow that a man practising high jump was flying. From which we may rightly infer that there are various sorts of movement which are covered by the word tobogganing.

As a matter of fact there are, commonly practised in Switzerland, three broad and widely differing species of tobogganing. They are as follows :

(i) Proceeding-quickly or leisurely-down frozen roads or artificial snow-made runs.

(ii) Proceeding-as quickly as possible-down artificial iceruns.

(ii) Bobsleighing (or bobbing) -as quickly as possible-down roads or artificial runs.

The number of folk who practise the first of these immensely 
outnumbers those who practise the other two; for everybody in Switzerland in the winter is guilty of the first practice, from the small Swiss native, aged perhaps eight or under, who marches up to school with its books tied on to its luge, and gaily and jauntily returns home seated on it, steering and guiding with its ridiculous little feet, and shouting "Gare" or "Achtung," according to the canton, up to the skilled racer on the skeleton who carries off the Symonds bowl in the race on the Klosters road at Davos. . But all these, different as their performances are, are going on snowruns. The snow may in places, it is true, where it has thawed and frozen again, intimately resemble ice. But the ice-run is different in kind from any snow-runs.

For ordinary travel, let us say from your hotel down to the rink, where there is no question of racing, but just getting there, the toboggan generally used is the Swiss toboggan or luge. It is a high wooden frame (high, that is, compared to the skeleton) with two runners shod with steel or iron, and you sit on it exactly as is most comfortable-it is never very comfortable-and tie your lunch and skates on to it, and push off. If you want to turn to the right, you put your right heel into the snow, or dab with your hand on the right side; if you want to go to the left, you perform the same operation in a sinister manner. If you want to stop, you put both heels into the snow. If you want to go quicker, you, while still sitting down, walk with both feet simultaneously. This sounds complicated; but it is quite clear the moment you feel you want to go quicker-it is done instinctively. Finally, if you are going fast, and must make a sudden stop, 


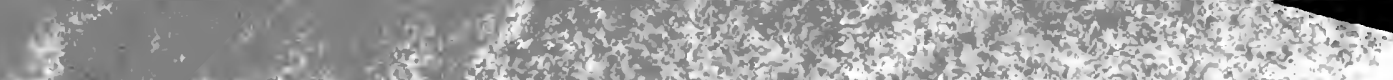

"! DVUTHDA"

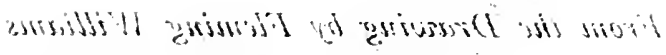

$+\infty$

$\frac{3 x y}{2 x y 3}$

$\therefore$ is 


\section{"ACHTUNG!"}

From the Drawing by Fleming Williams 







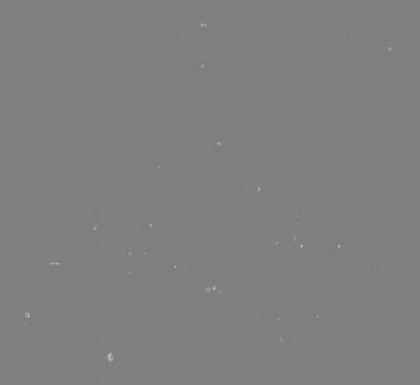

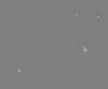




\section{TOBOGGANING}

owing to some obstacle in the shape of an old lady or a sleigh immediately in front of you, you turn into any convenient snowbank at the side of the road, and having picked yourself up, look injured, which physically you are not. Or, if there is no convenient snowbank, you fall off to one side or the other, and often observe your malicious luge proceeding calmly on its course without you. In fact, you do anything that occurs to you at the moment, except upset the old lady or charge the sleigh.

The foregoing is a complete compendium of all that it is necessary to know or do, when tobogganing on an ordinary road. It is as simple as walking and generally quicker. The same, in the main, applies to the use of luges on an artificially-made run. But every artificial run implies the idea of racing, and thus the object is to get down it as quickly as possible. But every artificial run has turns in it, and the idea is to get round these turns without capsize and with as little loss of speed as possible. The outside of these turns is therefore banked up (i.e. if the turn is to the right, the left side of the track is banked up, and vice versa), so that you do not (if you manage properly) run out of the track, but climb the bank and descend again into the track. But if you do not manage properly, one of three things will happen to you.

(i) You go over the bank and are heavily spilled. This is fatal if you want to win a race, unless everybody else does the same.

(ii) You upset on the bank. This is not necessarily so fatal, unless you entirely part company with your toboggan, which then finishes triumphantly without you. 
(iii) In excess of caution, you diminish your speed so much before you get to the bank that you merely crawl round the bend. This is moderately fatal.

But we need not waste more time over artificial snow-runs. They are only a compendious form of road-running, and what is necessary in the way of steering and judgment of pace on them, is equally true with regard to such fine natural runs as the Klosters road. Here there are no artificial banks to keep the runner in his course. : He has to get round the corners by judicious steering, and crawling when necessary, and, above all, by adjustment of weight. On the ordinary luge or Swiss toboggan there is little adjustment of weight that can be made, but it is a very different affair when you negotiate the same road on racing toboggans, namely skeletons, which are also used on ice-runs.

Here, instead of this little high wooden platform on which you sit, there is a very low framework supported on round steel runners, blunt nosed in front, and instead of sitting on it you lie on it, face downwards. The runners, sharply bent upwards in front, return and form the support of the low frame, and you grasp these with your hands, and lie down with arms bent or extended as required. But the cushion on which you recline moves backwards and forwards in the manner of a sliding seat, so that you can lie with legs right out behind the base of the machine, and can use great part of your weight, inclining it to one side or the other of the toboggan, in order to get it round curves. Similarly, the hands have an immense leverage behind them, and with one foot lying out behind and raking the snow, a curve can be made at high speed, which it 
would be impossible to get round on a Swiss toboggan without heavy braking and great loss of velocity. When riding a skeleton, the toes of the boots are fitted with toothed irons, so that they can be used together as brakes, or singly, in order to make the toboggan curve in the required direction. The runners of these toboggans are not rectangular like those on luges, but of circular shape, thus producing the minimum of friction on their travelling surface. Even on snow-tracks these are capable of tremendous speed, though that speed does not approach what they compass on frozen ice-runs, where they travel almost frictionless.

Apart from the "storm and stress" of racing, there is a wonderful pleasure, if the track is smooth and trafficless, in this swift gliding over frozen snow, and one of the most romantic of experiences in all the gamut of motion is tobogganing by moonlight. Never will the writer forget one such night on the Klosters road. We had sleighed up from Davos, a party of friends, to Wolfgang, on one of those magical nights when no breath of wind stirred the lightest jewels of hoar-frost on the pines, when the moon was full, and the stars burned like diamonds aflame. All the way up, after dinner, there had been talk and laughter, and standing ready to go, we arranged that there should be two minutes' pause between the despatch of the toboggans, and one by one we slid off into the unspeakable silence of the Alpine night. It so happened that $I$ was the last to go, and for two minutes I waited at the head of the track in a stillness that is unimaginable. When I started there was in all probability not a living soul within half 
a mile, and the nearest was sliding swiftly further away every moment. For a little way the track lay open to the full blaze of the zenithed moon, but soon it plunged beneath the impenetrable canopy of pines. It was possible to see the white glimmer of the road ahead, otherwise there was nothing visible. Then, with the suddenness of a curtain withdrawn, the blackness became a celestial and ineffable glory of close burning constellations, with the full disc of the moon shining imperially among them. Far below, distant and dim, I could see the lights of Klosters, and half-longed to reach them, in order to get out of this awful and burning and frozen solitude, half-longed that my travel might be lengthened into an eternity of wheeling stars and flying road. Sometimes it seemed that I was rushing headlong through space, sometimes it seemed that I was stopping absolutely still, and that it was this unreal world of trees and road and bridges and banks that hurled itself by me, and that the stars and I were the steadfast things. Once the sudden roar of a stream over the bridge of which I passed sounded loud and menacing, but in a moment that was past, and the hissing spray of frozen snow coming from the bows of my toboggan was the only sound audible. And then the lights of Klosters gleamed larger and nearer, and this wonderful swift solitude was over.

(As a matter of fact, I had an awful spill by the cabbage garden corner: but though that was very vivid at the time, there remains nothing of it, except the fact, in my memory. It would have been more romantic, but less realistic, not to have mentioned it.) 


\section{Ice-runs}

There is one Mecca: there is one St. Peter's : there is one Cresta. As is Mecca to the Mohammedan, as is St. Peter's to the Catholic, so is the Cresta run at St. Moritz to the tobogganer. It is the ice-run. There may be others, and there certainly are, but what does the Cresta care? It has a cachet which no other possesses.

The Cresta was first engineered, I believe, in the year I884, and its chief architect was Herr Peter Badruth of St. Moritz. From that time onwards it has yearly been built up with as much thought and care as is lavished on a cathedral; every yard of it is staked out, and the angles, curves, and shaping of its banks and corners most accurately calculated. It is built up from the bottom upwards, so that the lower part of it can be used while the construction of the upper part is still going on, and the whole run is generally open not until after the middle of February. Every winter is this amazing architecture in crystal planned and carried out under the direction of Mr. W. H. Bulpett, who has for many years been chief architect.

To begin with, the snow is trampled down, after the manner of making the foundation of an ice-rink, so as to form a firm solid base, and where the banks are to be built snow is brought in sleigh-loads, shovelled on to it, and beaten down. More snow will then be still required, and again more, till the whole of the banks are solid and of the necessary height and curve. Then the banks and the rest of the course (the straights) are sprinkled with water 
and again beaten down, and the glazed ice surface begins to be made. When this has frozen, water is again sprinkled on it, and again and yet again, till the whole section has become, banks and course alike, a surface of smooth hard ice. Down each side of the narrow racing track (except at its banked corner it is only a few feet wide, a riband of ice) are little walls of firm built snow, also iced, so that the runner, if he is going moderately straight, cannot leave the track, though he often comes into slight collision with these walls. But even slight collisions when travelling at a speed that sometimes exceeds 70 miles an hour are not experiences to be encountered unarmed, and the elbows and knees are thickly protected by felt pads, while on the toes of his boots are toothed rakes made of steel, which are used to guide the runner round the bank and to check his speed if it is so excessive that, unchecked, he would run over the tops of the banks.

A very high degree of nerve, skill, and judgment is required on such an ice-run as this. The rider's object being to cover the course in as few seconds as possible, he must clearly take his banks (i.e. get round the curves) with as little loss of speed as possible, and he will only use his brakes when his judgment tells him that if unchecked he would be carried over the top of them. On the other hand, he does not want to brake unless it be necessary, and you will often see him with his top runners within an inch or two of the edge of these huge sloping ice-curves. At Battledore and Shuttlecock, the two biggest banks on the Cresta, he enters the second immediately after coming out of the first, and the two form a great $\mathrm{S}$ curve. Lower down again, before he threads the 
VUS AT2ZSO HHT ИO

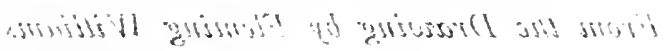




\section{ON THE CRESTA RUN}

From the Drawing by Fleming Williams 







\section{TOBOGGANING}

arch of the railway bridge, there is another called Bulpett's corner, designed to protect him from running out to the left of the course, and then a headlong descent takes him to the winningpost, which is at the bottom of the hill. Passing this he snaps a thread with an electric connection, which registers the exact fraction of a second at which he passes it. Then, on his run out, he whirls up a steep ice-covered slope, for if this were not iced too, his speed would be so abruptly checked that he and his toboggan would be bowled over and over like a shot rabbit, and comes to a stop just outside the little village of Cresta. But even with this steep slope to check him after his race is over, the momentum acquired is so great that, if he does not brake heavily all the way up this hill, he will, on reaching the level ground at the top, shoot high into the air, toboggan and all.

Some idea of the speed at which toboggans travel on the straight reaches of the course may be gathered from the average speed at which the course can be run. It is over 1300 yards in length, and has been traversed in a shade over 60 seconds! This means that the highest rate of speed must be well over 70 miles an hour. This on a pair of steel runners, head foremost, with your face a few inches above the solid ice, with nothing to check you except a small-toothed rake on the toe of each boot! Yet so wonderfully skilful is the construction of the run, so cunningly is it built to safeguard the headlong traveller, that accidents are very few. Two fatal ones, indeed, there have been, but of these one had nothing to do with the course itself, but was owing to the fact that a rider started from the top before one of the 
barriers across the course, which show that it is not open for racing, had been removed. In the other, the rider ran over a bank and his toboggan fell on the top of him. One of the great difficulties which the builders and managers of this run, in company with other ice-runs, have to contend against, is the power of the sun. It is, of course, absolutely necessary that the icing of the run should be so solid that there is no chance of the runner of a toboggan going through it, which would naturally mean a bad spill. But it is also necessary that certain of the banks must have the sun blazing into them all day long, which would cause them to lose ice faster than it could be made by the sprinkling which goes on when the sun is off them. At such points, therefore, big canvas screens are put up, which shade the bank from the direct rays; also tobogganing is never permitted to go on all day. It starts early in the morning, when the run has been recuperated by the night of frost, and is closed when, in the opinion of the management, the sun has so softened the banks that there is danger of a toboggan cutting through the crust.

\section{Bobsleighing (or Bobbing)}

This charming form of the sport may be described as combined tobogganing, and in bobbing races teams of four enter against each other. The form of toboggan used is, of course, immensely larger than that employed in single tobogganing, since it will hold five or six persons, and its construction is altogether different and most elaborate. It consists of a long, low platform 
some ro feet in length, and is mounted, not on one pair of runners, but on two. The pair that supports the fore part of the bobsleigh is a sort of bogie-truck, pivoted under the platform, and it can be turned to the right and left in order to direct the course of the bob round curves. This turning of it is done by the captain, who sits first at the bows of the sleigh, and is worked by ropes, which he holds in his hands, or by a wheel which controls its movements. In long runs, as on the Schatz-alp at Davos, the wheel is far better than the ropes, since it entails so much less strain on the hands of the steersman : on a short run the ropes are as good. Behind the captain sit the members of his crew in line, with the loops of rope just outside the framework of the sleigh, in which they fix their heels. Last of them all sits the brakesman, at the stern of the sleigh, who has in his control a powerful steel-toothed brake, which crosses the sleigh behind and is worked with levers. But it is the captain who is in command of the bob, and the brakesman and other members of the crew only perform his orders. The word " bobsleigh" is derived from the movement of leaning or " bobbing" forward, which is done by all the crew together, to get up speed or increase it. They come forward quickly with a jerk, and go back again slowly and steadily, and this without doubt accelerates the movement of the sleigh.

As in all other forms of tobogganing, braking is employed to diminish speed in coming to corners, where otherwise the momentum would cause the whole concern to leave the track altogether. So also, just as the ice-tobogganer inclines his body 


\section{26}

inwards in a similar position, the captain and crew lean to the inside of the track when going round a corner so as to help the toboggan round it, while the inclination of the front pair of runners is directed to the same end. By strong leaning inwards, combined with the inclination of the bogie-pair of runners, quite considerable curves may be taken at high velocity without the use of the brake at all, and the consequent loss of speed. But all this is left to the judgment of the captain, who has to decide whether by direction of the bogie-runners alone, or by that in conjunction with the leaning inwards of his crew, he can safely negotiate a corner without calling for the use of the brake. And the responsibility is entirely in his hands. At the same time much depends on the prompt obedience of the crew to his orders, for it is easily possible that a corner might have been safely coasted round if they had obeyed his call to lean inwards, which would spill them all if his call was not immediately responded to. How great the effect of this inward shifting of the weight can be, if it is thoroughly carried out, may be guessed from Plate XXXI. In this same photograph the inward direction of the front pair of runners may also be seen assisting the work of the crew. And it is this "teamwork," the sense of working in unison under orders, which gives much of its charm to bobbing. Everyone feels-rightly-that much of the success of the run depends on his individual work, even though his individual work is only to lean as far as possible out of the bob without parting company with it altogether.

Bobbing can be practised on an ordinary road covered with hard snow, or, in excelsis, on runs constructed for this express 


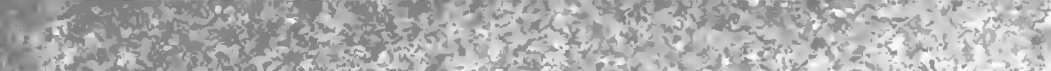

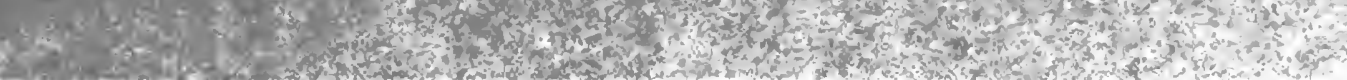

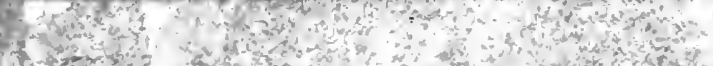

T.

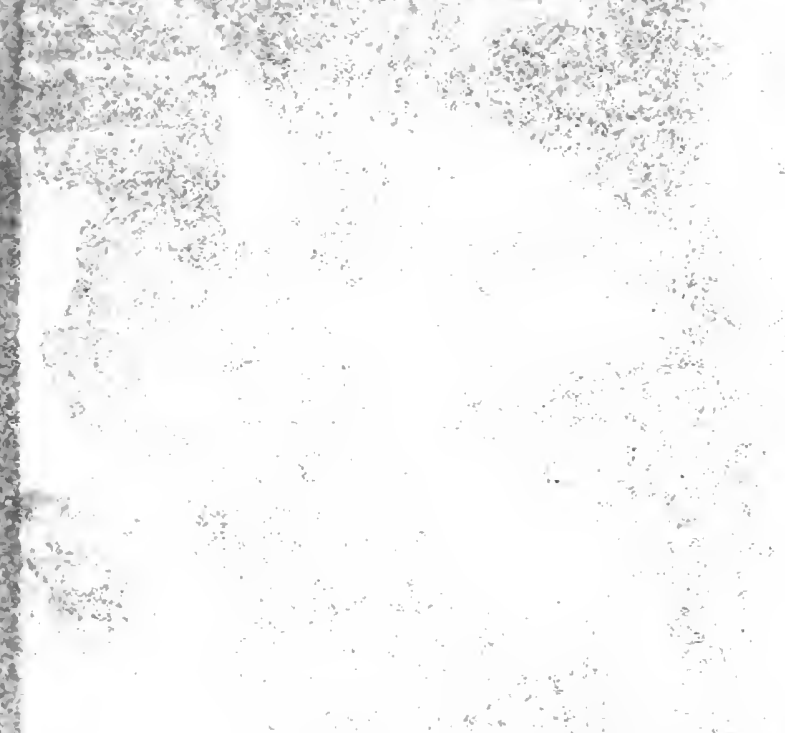

\section{DVIIIA T}

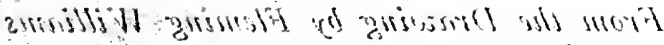






\section{TAILING}

From the Drawing by Fleming Williams 


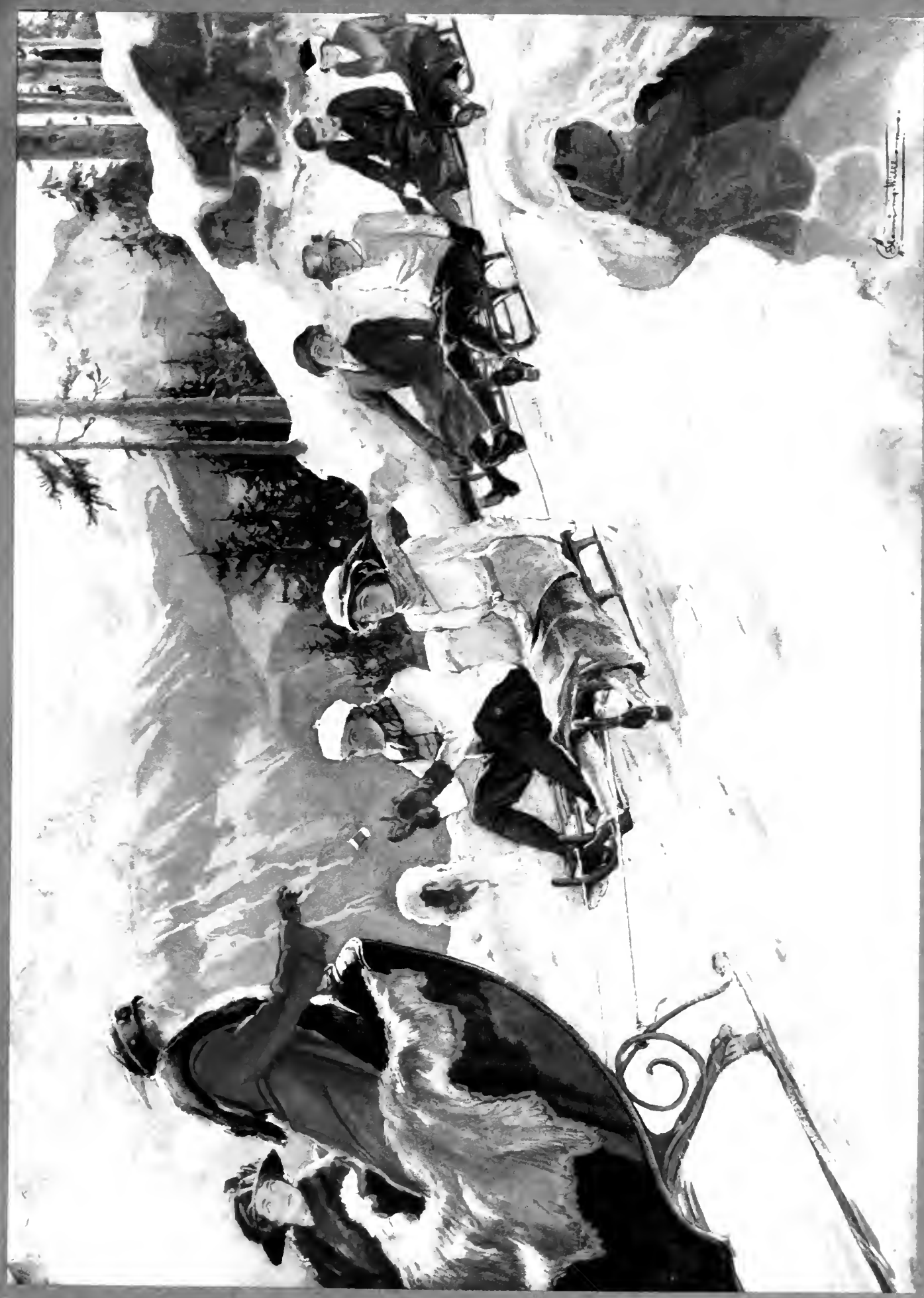




\section{TOBOGGANING}

purpose. Of these the two most famous are the St. Moritz bobrun, which starts by the Bandy rink and finishes side by side with the Cresta ice-run, after passing under the railway bridge, and the Schatz-alp run at Davos. Previous to its construction, not many years ago, bobbing at Davos chiefly took place on the Klosters road, which was the same track as that used by the ordinary toboggan, but now each has its own course. These artificially constructed bob-runs are engineered with the same care and nicety as ice-runs for the single toboggan, and at corners curved banks are built solidly of beaten-down snow. The track is then iced, for no snow could stand the continual passage of the heavy bobs over the same banks and narrow course without speedily being worn into ruts that would entirely spoil the going and upset the goers, and the ice is then sprinkled over with loose snow to prevent the toboggan skidding. But the greater part of bobbing is done on the public roads, which are frozen and hardened by the passage of sleighs. At most Swiss winter resorts there are facilities for this delightful form of sport. 



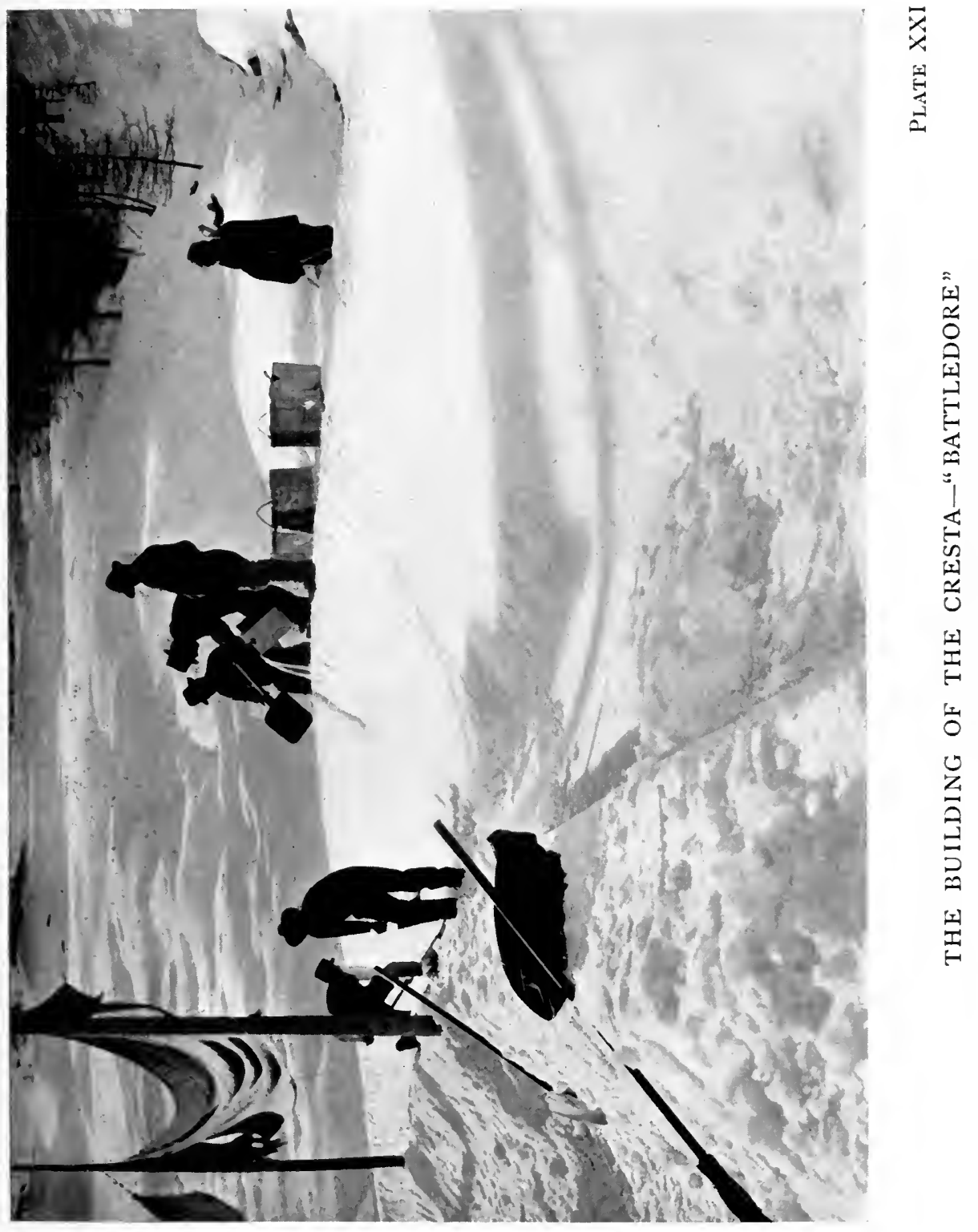





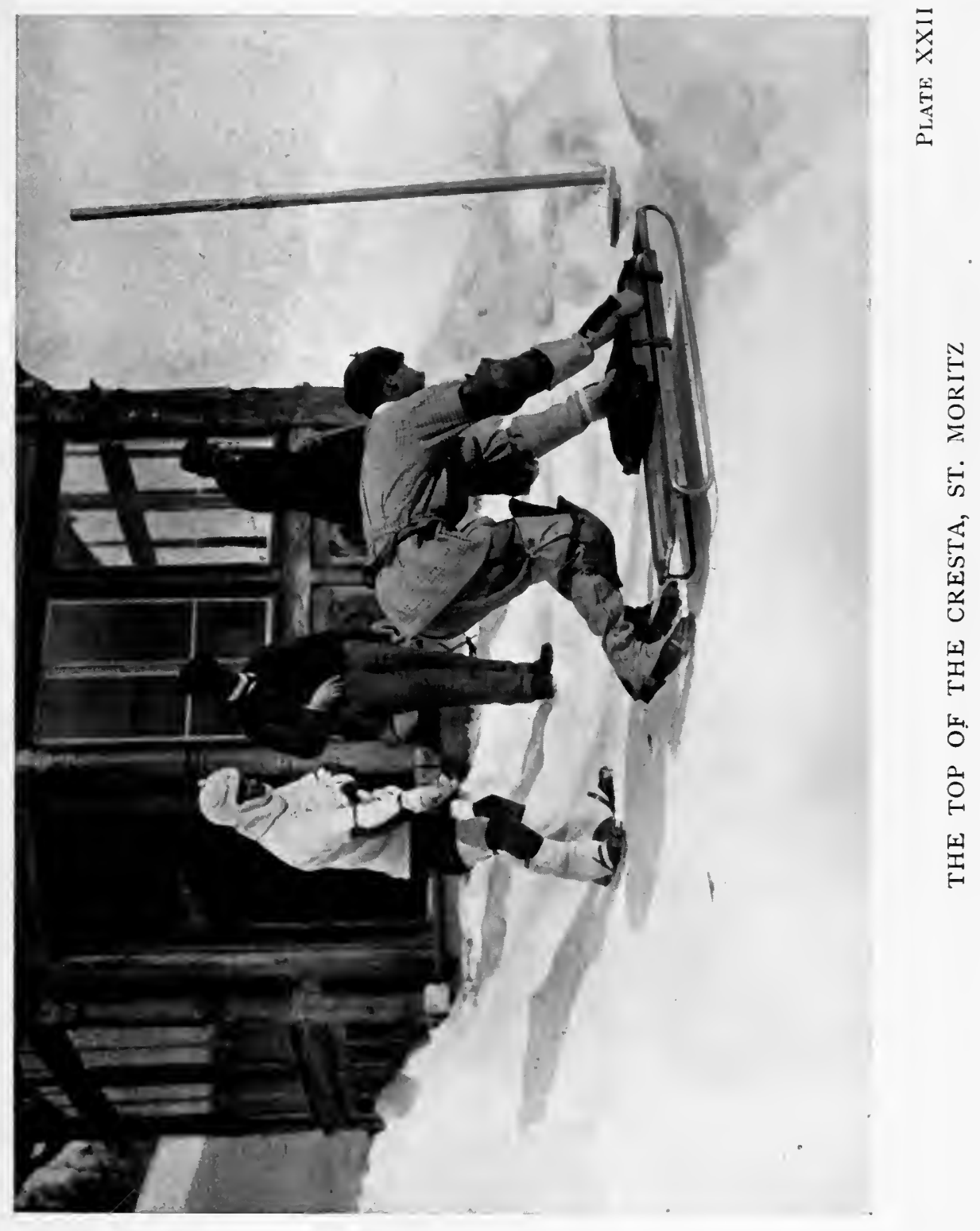











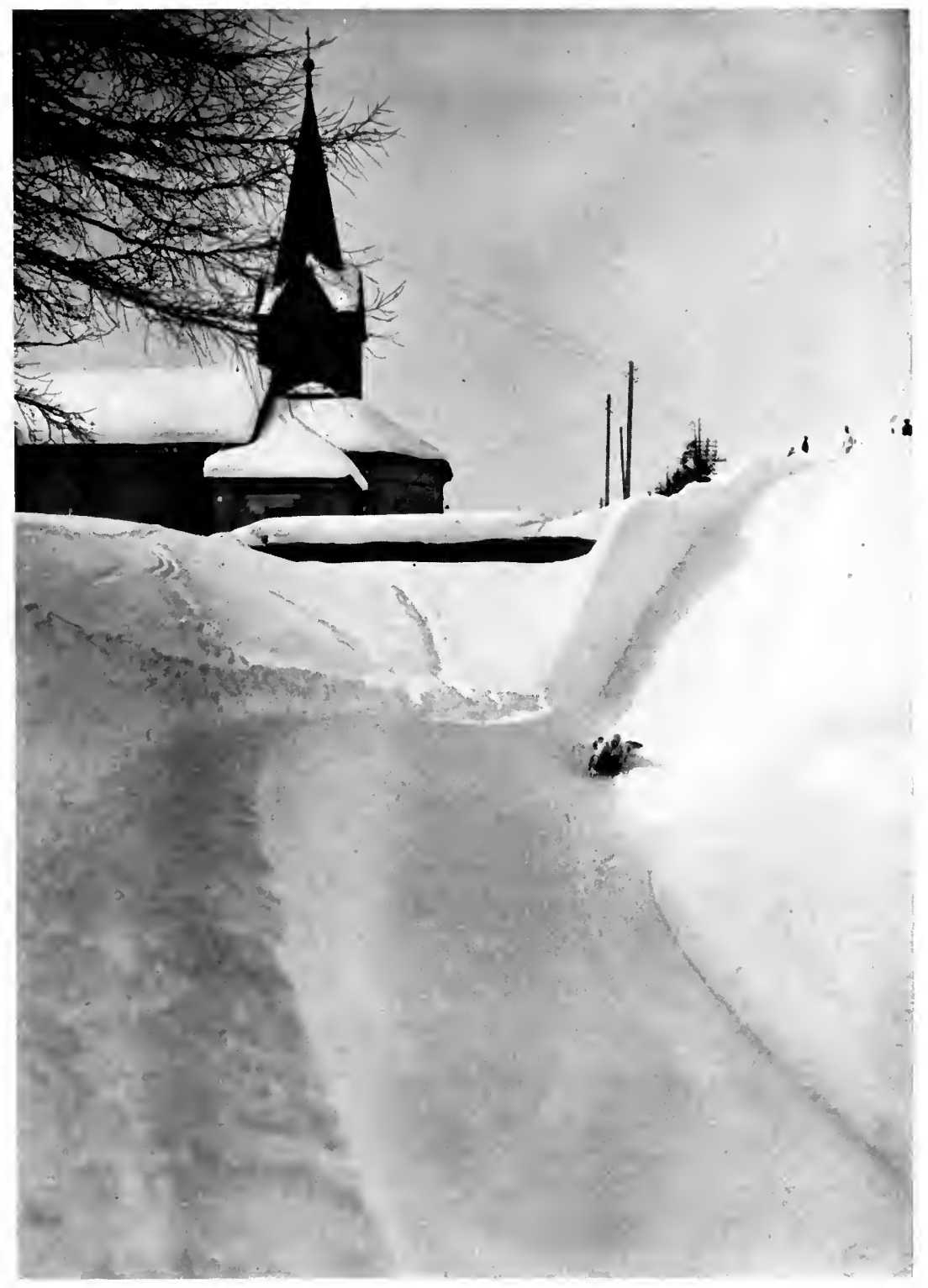

Plate XXIV

CHURCH LEAP, CRESTA RUN 



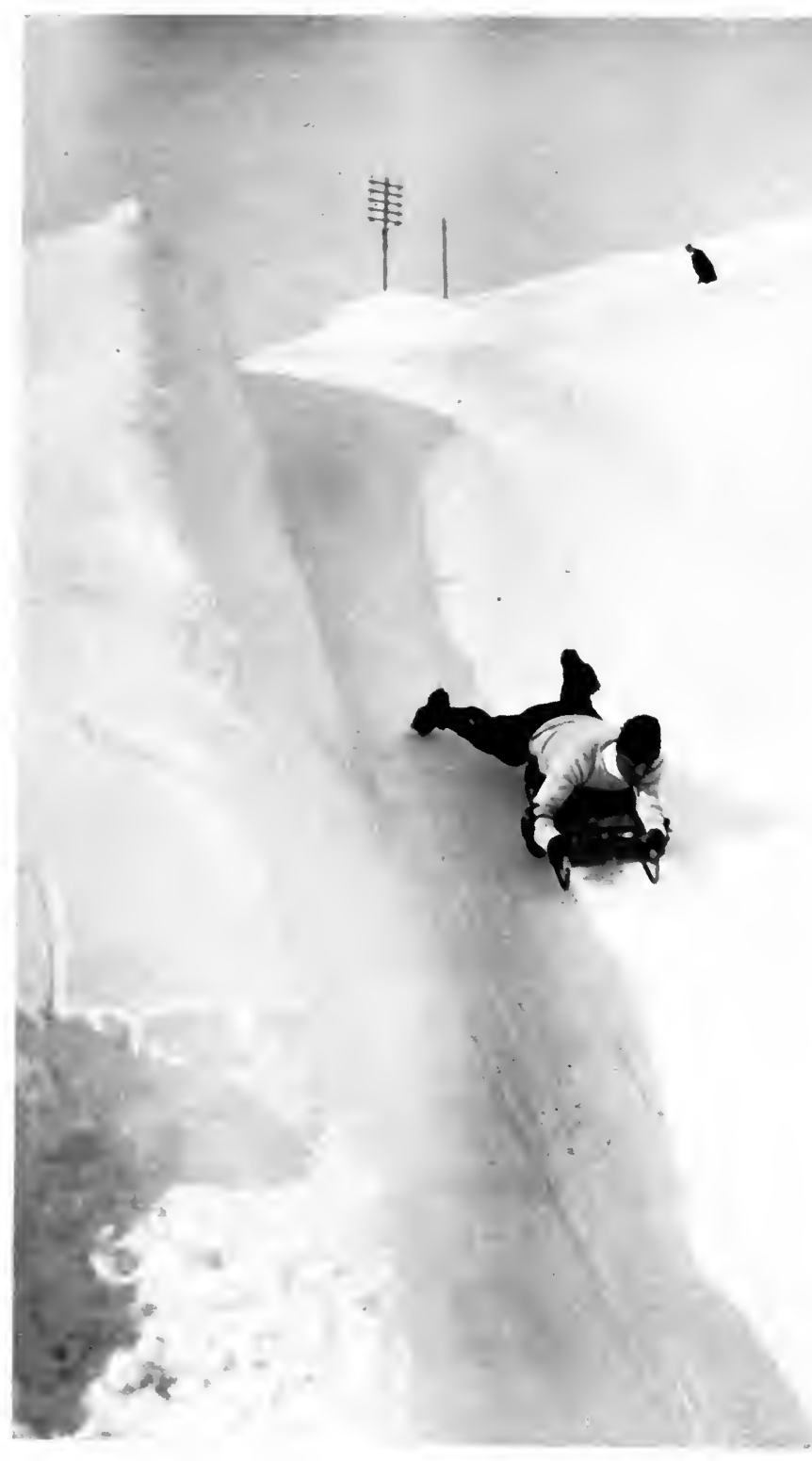

CHURCH IEAP, CRESTA RUN

PIATE XNV 



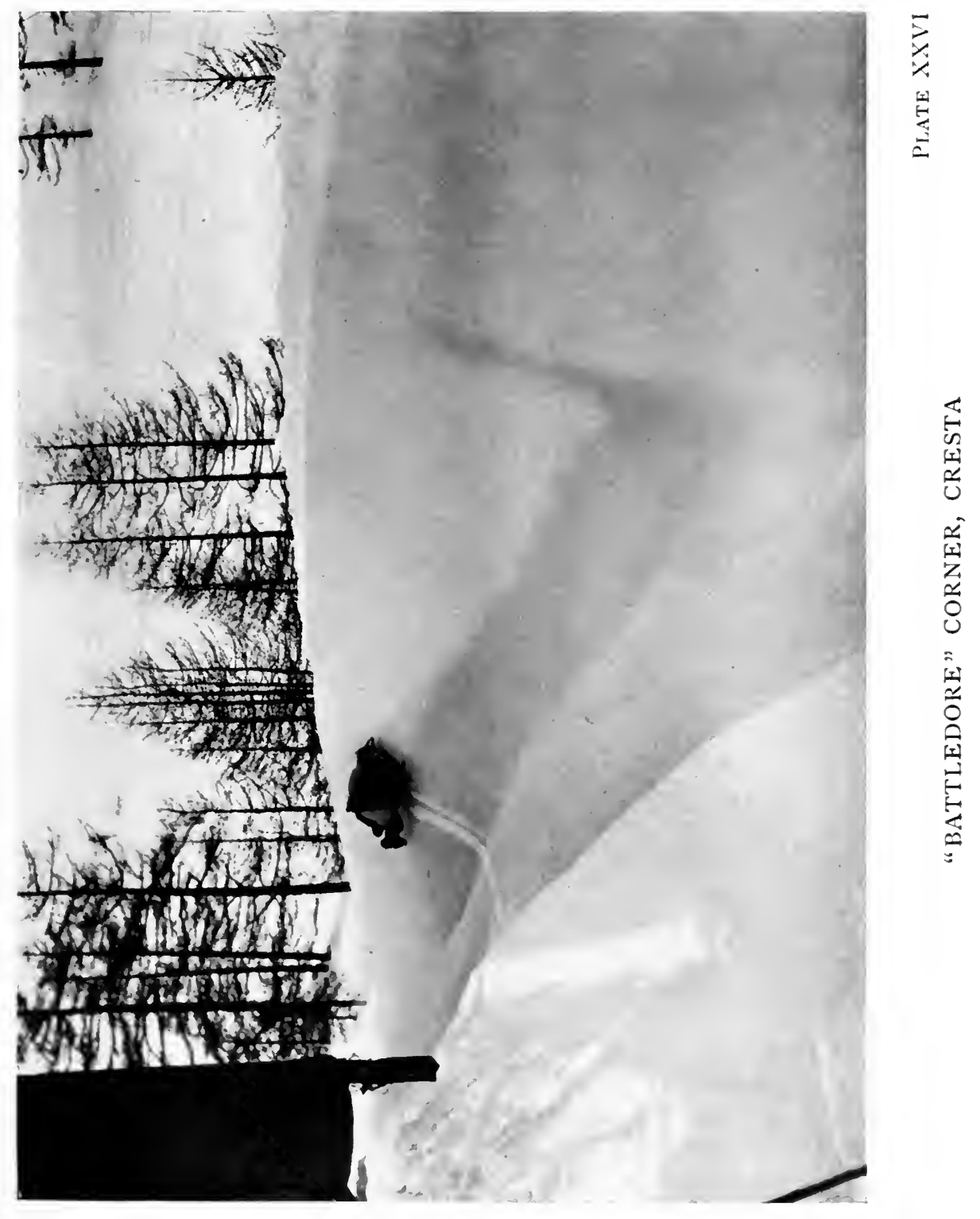




$$
\text { , }
$$




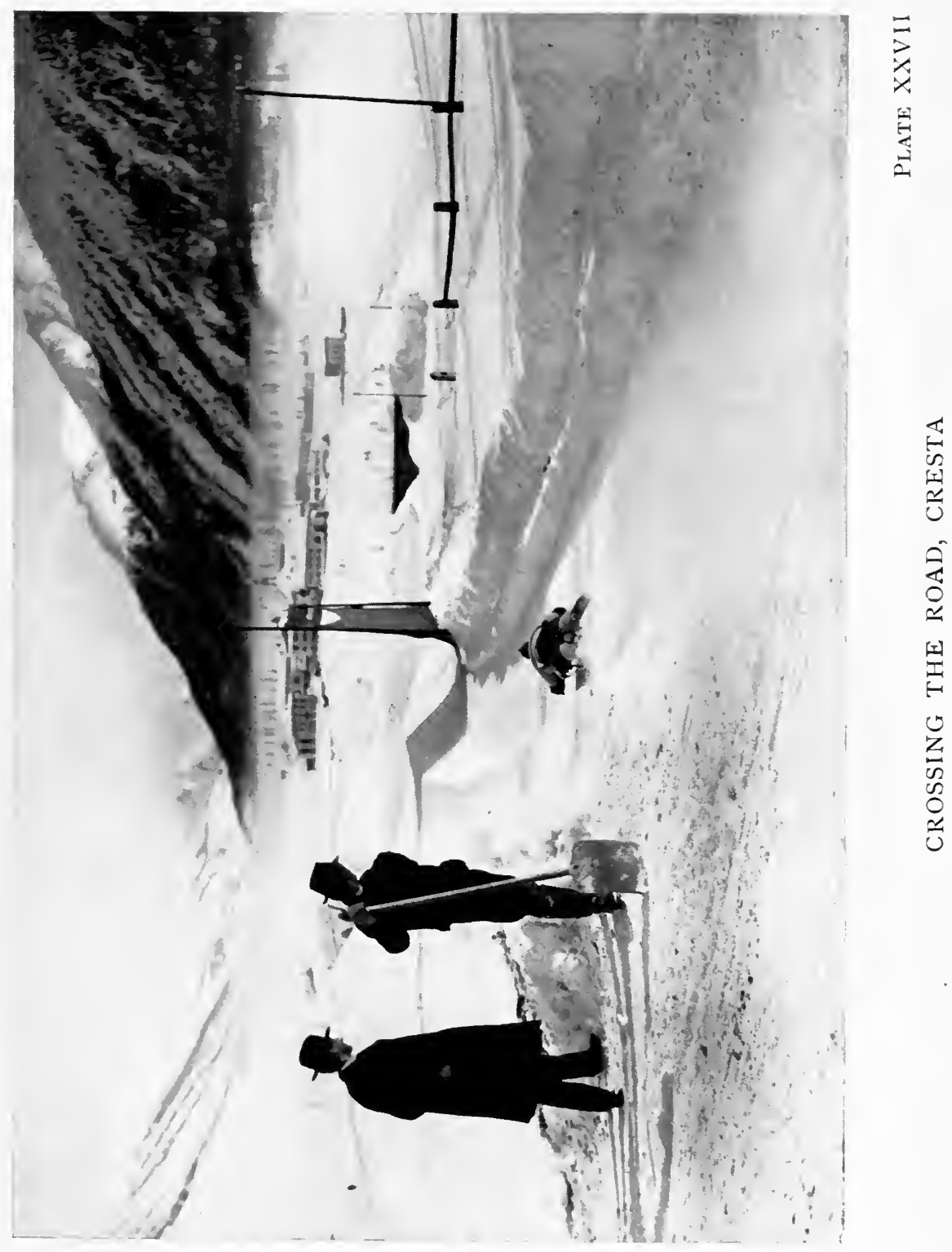





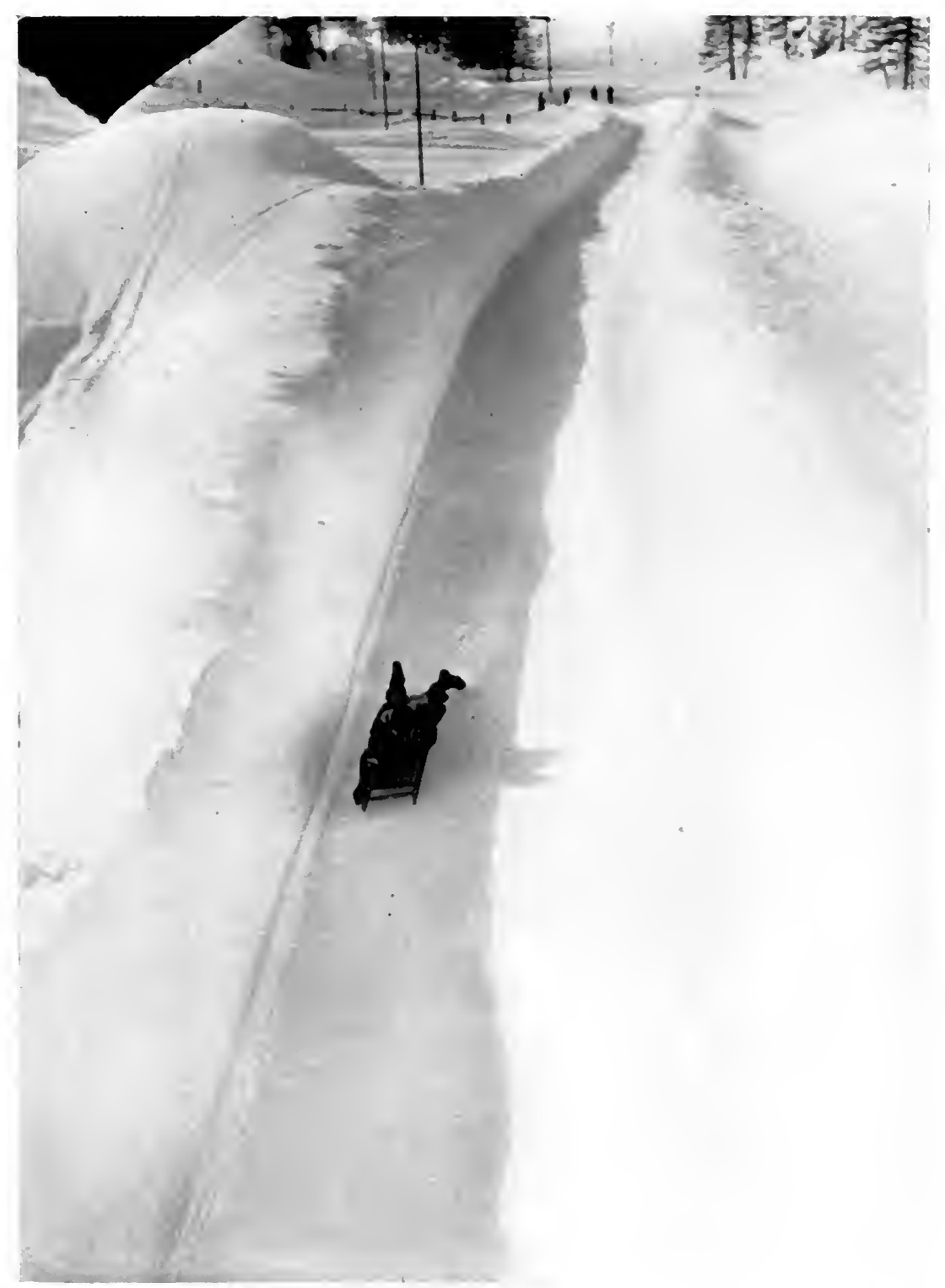

NEAR THE FINISH ON THE CRESTA 


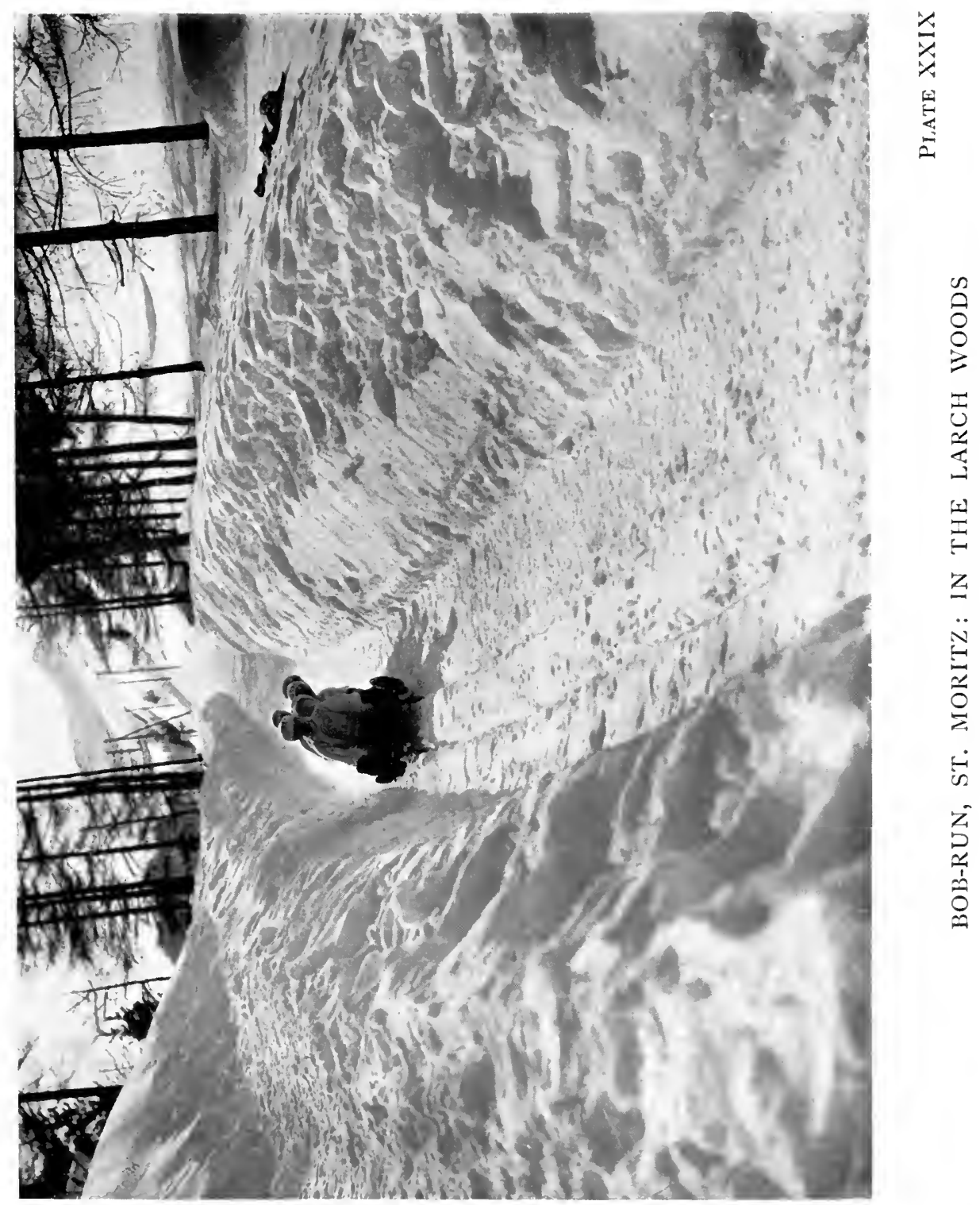




\section{•}









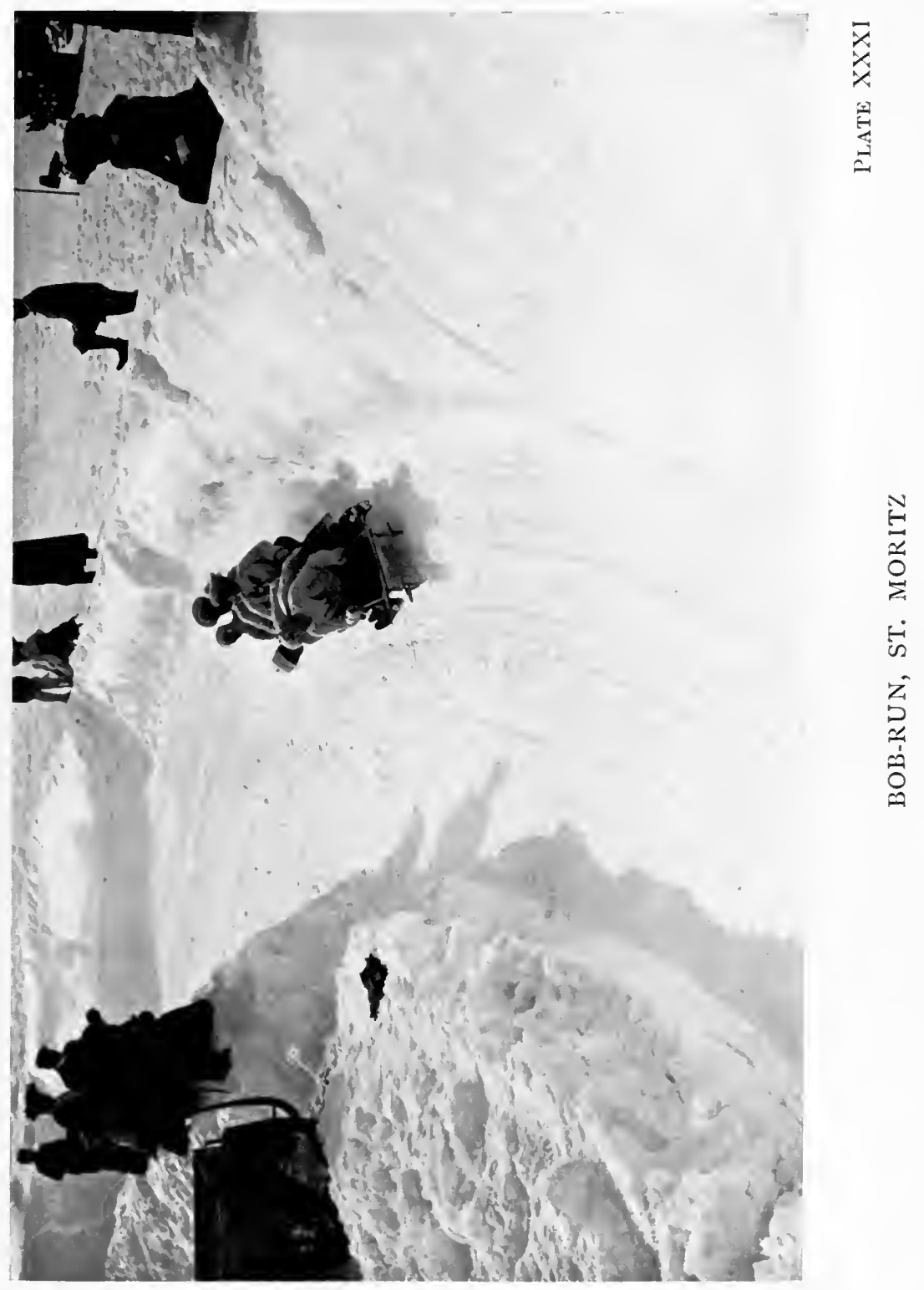




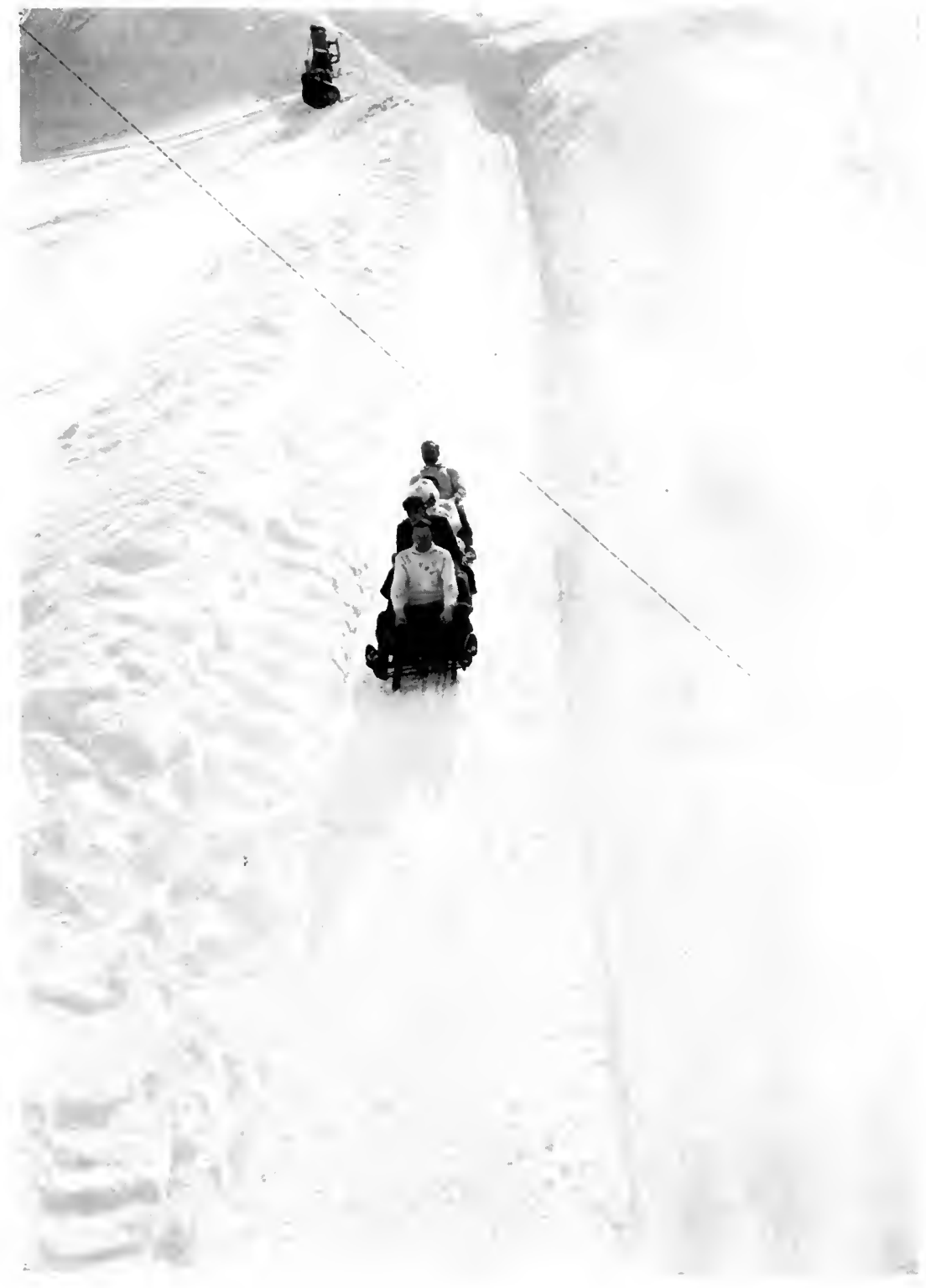

PLATE XXXII

THE STRAIGHT FROM THE BRIDGE, ST. MORITZ BOB-RUN 
: 


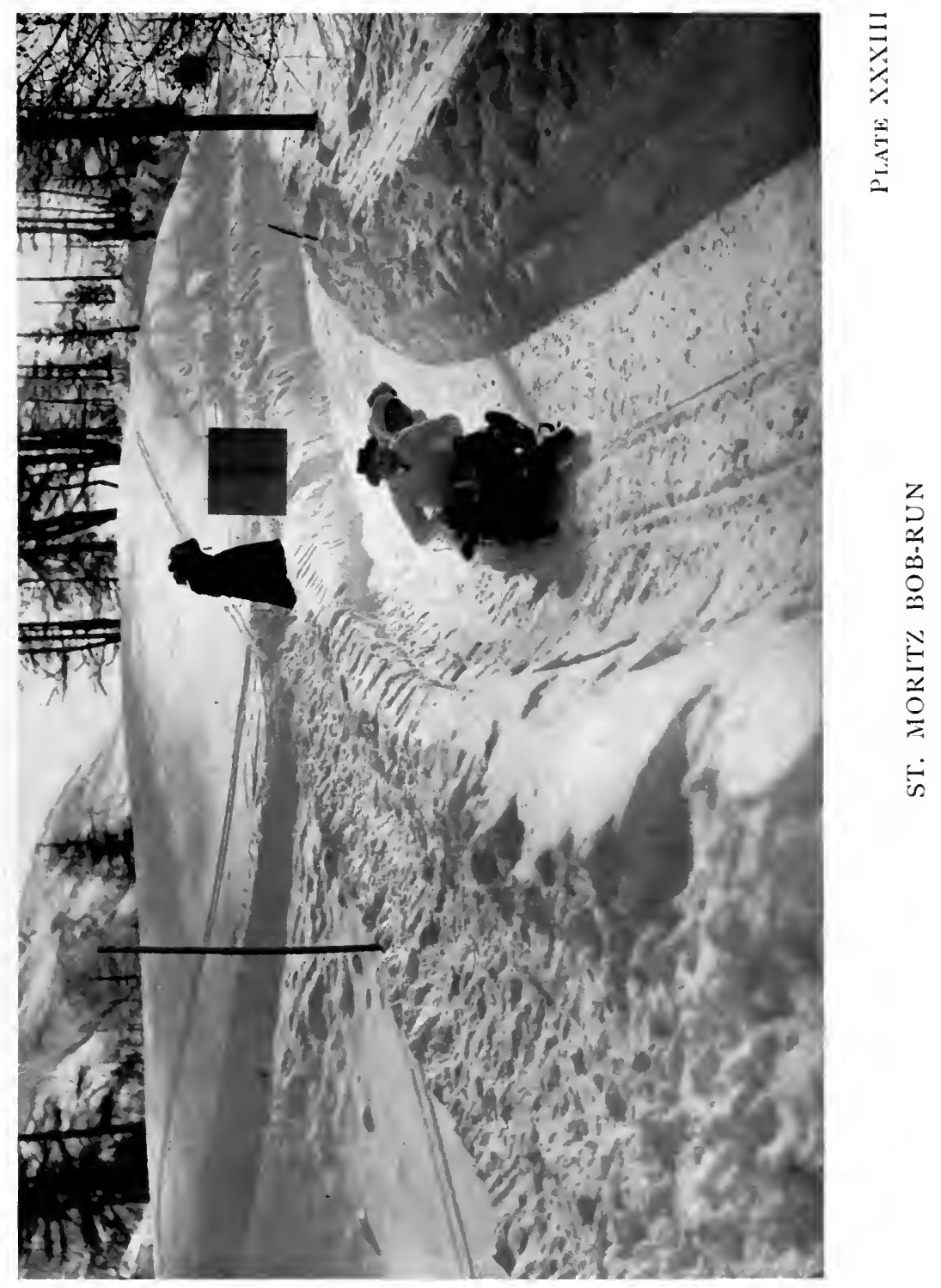





\section{CHAPTER V}

\section{ICE-HOCKEY}

MANY of the Swiss winter-resorts can put into the field a very strong ice-hockey team, and fine teams from other countries often make winter tours there; but the ice-hockey which the ordinary winter visitor will be apt to join in will probably be of the most elementary and unscientific kind indulged in, when the skating day is drawing to a close, by picked-up sides. As will be readily understood, the ice over which a hockey match has been played is perfectly useless for skaters any more that day until it has been swept, scraped, and sprinkled or flooded; and in consequence, at all Swiss resorts, with the exception of St. Moritz, where there is a rink that has been made for the hockey-player, or when an important match is being played, this sport is supplementary to such others as I have spoken of. Nobody, that is, plays hockey and nothing else, since he cannot play hockey at all till the greedy skaters have finished with the ice.

And in most places hockey is not taken very seriously: it is a charming and heat-producing scramble to take part in when the out-door day is drawing to a close and the chill of the evening beginning to set in; there is a vast quantity of falling down in its componence and not very many goals, and a general ignorance about rules. But since a game, especially such a wholly admir- 
able and delightful game as ice-hockey, may just as well be played on the lines laid down for its conduct as not, I append at the end of this short section a copy of the latest edition of the rules as issued by Prince's Club, London.

For the rest, everybody knows the " sort of thing " hockey is, and quite rightly supposes that ice-hockey is the same "sort of thing " played on a field of ice by performers shod in skates. As is natural, the practice and ability which enable a man to play ordinary hockey with moderate success are a large factor in his success when he woos the more elusive sister-sport; another factor, and one which is not sufficiently appreciated, is the strength of his skating. It is not enough to be able to run very swiftly on the skates: no one is an ice-hockey player of the lowest grade who cannot turn quickly to right or left, start quickly, and above all, stop quickly. However swift a player may be, he is practically useless to his side unless he can, with moderate suddenness, check his headlong career, turn quickly, and when the time comes again start quickly.

I have often been asked whether ice-hockey is " bad " for skating. Most emphatically it is not: on the other hand, it is extremely good for most skaters, since it gives them strength of ankle and accustoms them to move at a high speed. Strength, as we have seen before, is not the prime need of a skater, but balance : strength, however, is a most useful adjunct. But though hockey is good for the skater, he will certainly find that he will not skate well or accurately immediately after playing hockey, any more than he will skate well the moment he has taken off his skis. But the 
feeling that to play hockey unfits the skater for that which he may regard as his more artistic job, is, as far as can be seen, unfounded.

It is a wonderful and delightful sight to watch the speed and accuracy of a first-rate team, each member of which knows the play of the other five players. The finer the team, as is always the case, the greater is their interdependence on each other, and the less there is of individual play. Brilliant running and dribbling, indeed, you will see; but as distinguished from a side composed of individuals, however good, who are yet not a team, these brilliant episodes are always part of a plan, and end not in some wild shot but in a pass or a succession of passes, designed to lead to a good opening for scoring. There is, indeed, no game at which team play outwits individual brilliance so completely.

But such is not the aspect of the game that will strike the observer who watches the usual pick-up or inter-hotel match on the rink, which generally begins as soon as skaters hear the curfew of the tea-bell. Here will be found the individualist who, sooner than pass when he has once got the puck, would infinitely prefer to fall and be trampled on; and you will see him, while still sitting on the ice, hacking wildly at the beloved india-rubber, in flat contravention of the rule. Common, too, are the "nonstops" (like Wimbledon trains) who, once having got up speed, are practically brakeless. Indeed, it was in connection with non-stops that the present writer saw the most ludicrously comic incident that it has ever been his good luck to encounter in these winter places, where so many funny things happen. And it was in this manner. A round dozen of these delightful non- 
stops had made up a hockey match. The rink where they played was bounded on three sides by snow-banks; on the fourth, at the edge of which was one of their goals, an extremely steep descent (caused by the levelling up of the ground to make the rink), about I5 feet in height, plunged into the snow-covered field below. It was a very cold afternoon, and (so rightly) the two gentlemen who were deputed to keep goal preferred to plunge into the fray and go for the puck whenever they could catch sight of it. In general, there were some four or five out of the twelve players on their feet simultaneously : the rest were momentarily prone. All this was delightful enough, but $\mathrm{I}$ had no conception how funny they were all going to be.

It so happened that the puck was in the neighbourhood of the goal away from the steep bank down into the field : it so happened, also, that all the twelve were on their feet. Somebody in the mélêe near the goal hit the puck with such amazing violence that it flew half-way down the rink. The whole field, with ever-increasing velocity, poured after it, spreading out on both sides of it. Another.whack brought it close to the goal at the edge of the steep bank, and again at top-speed every player on the field was in pursuit. Faster and ever faster they neared the goal : somebody, with stick high uplifted in the manner of a three-quarter swing at golf, made a prodigious hit at it, but completely missed it. The next moment every single one of those players had poured like a resistless cataract down the steep snow-slope into the field below, leaving the rink completely untenanted except for a small innocentlooking puck, which lay a few yards in front of a yawning goal. 


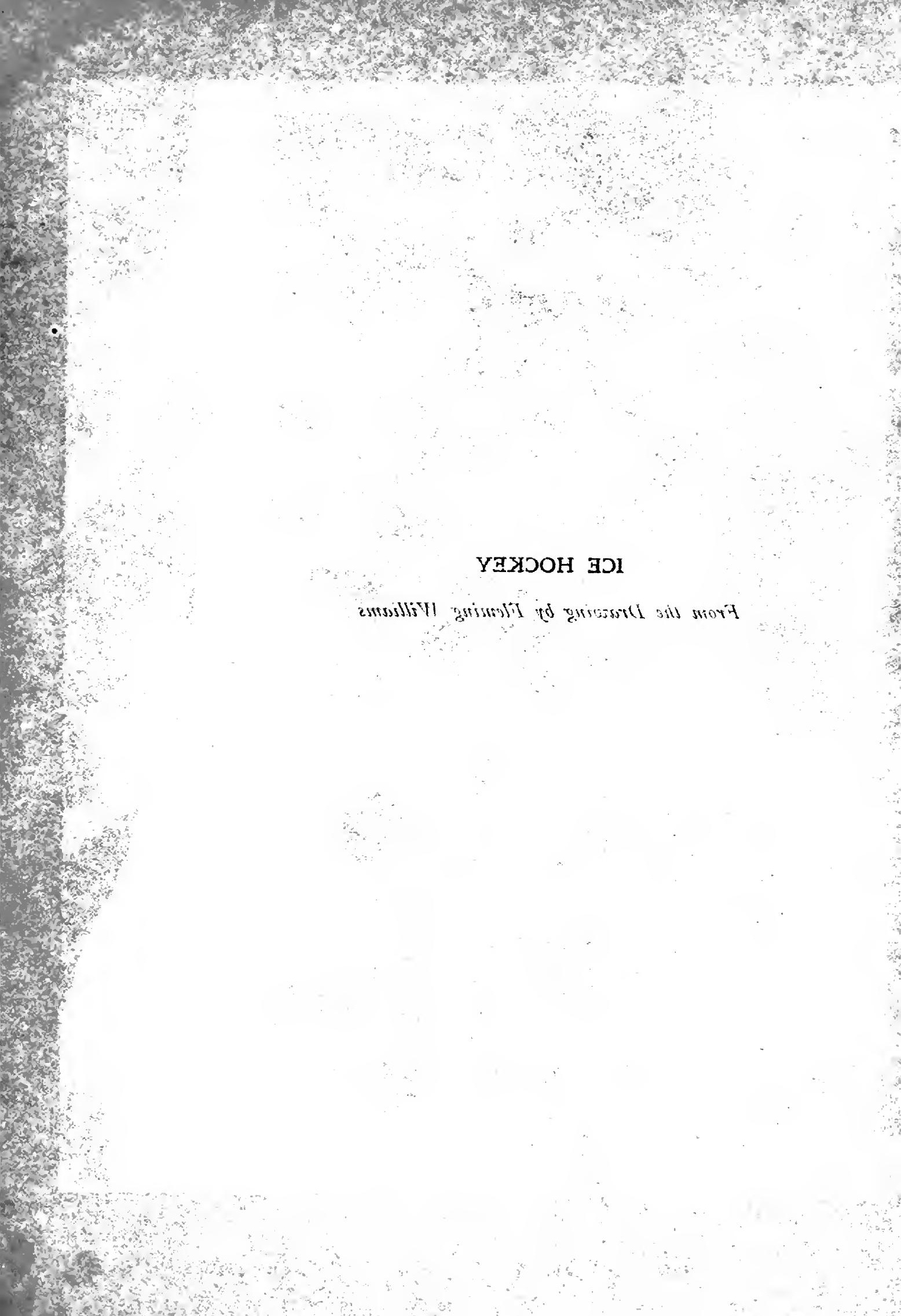




\section{ICE HOCKEY}

From the Drawing by Fleming Williams 


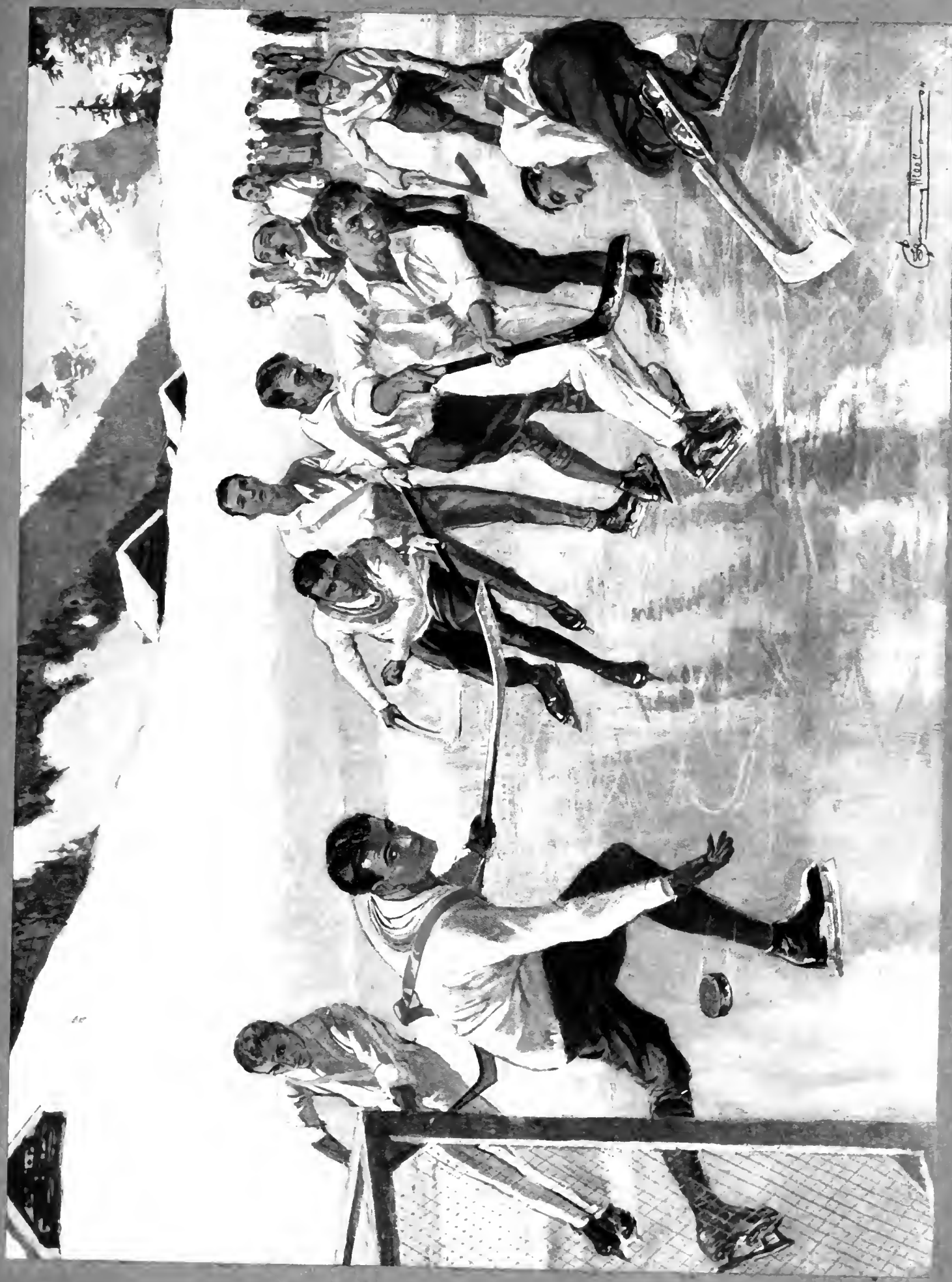



For a little while this impressive stillness and depopulation lasted. Then the first "strayed reveller" returned, heavily limping. He took his time, and with a superb, lightning-like shot sent the puck whirling through the unguarded goal. Simultaneously he sat down. Simultaneously a second player showed his head over the ice-bank and shouted "Offside!" Simultaneously also, the puck hit him in the face. It is hard to believe, I know; but I assure the reader that it was harder to stop laughing.

At any rate, here are the rules:

\section{Rules of Match Play}

I. The puck shall be made of india-rubber, 3 inches in diameter, I inch thick, and shall weigh $\mathrm{I} \frac{1}{4}$ lbs., or shall be of such other size or shape as shall from time to time be decided.

The stick shall be so made that it can pass through a ring 3 inches in diameter.

2. The goal-posts at each end of the ice shall be 4 feet high and 4 feet apart.

3. The team shall consist of six players.

4. The goal is scored when the puck passes between the goalposts.

5. The game shall consist of two halves of 20 minutes each. The teams change goals at half-time.

6. The match is won by the team who scores the greater number of goals. If, when time is called, the number of goals 
is the same on both sides, the match is said to be a tie. Five minutes each way must then be played until the tie is decided, or the teams may arrange another match.

7. A referee shall be appointed whose duty it shall be to decide all disputed points, and his decision shall be final.

He shall appoint, if possible, four goal umpires, two at each end.

The referee shall have power to stop the game for any cause and for such time as he shall think fit.

In the case of unfair or rough play he shall caution the offender, and if the offence is repeated, he may order the offender off the ice for a certain interval, or for the rest of the match.

If no referee is appointed, the captains shall arbitrate all disputes.

8. The game shall be started by placing the puck between two opposing players on the half-way line in the centre of the ice ; the sticks of the two players must meet three times before either may touch the puck. After a goal the puck shall be placed in the centre of the ring and restarted as above.

9. When the puck goes off the ice, it shall be restarted as in Rule 8, and from a point 3 yards from the side where it left the ice. In case the puck leaves the ice behind the goal line, it shall be restarted at a point 5 yards from the goal line and 3 yards from the side.

Io. No charging, crossing, riding off, pushing or tripping is allowed.

II. The player may not raise his stick above his shoulder.

I2. No player may carry, stand on, kick or throw the puck 
except the goalkeeper, who may kick it, catch it, or knock it away with his hand or leg, or stop it with any part of his body.

I3. A player having fallen is considered hors de combat, and may take no part in the game until he has regained his feet and his stick.

I4. Should the game be stopped by the referee by reason of the infringement of any of the rules, or because of an accident or change of players, the puck shall be started at the spot where it was last played before the infringement, accident or change of players shall have occurred.

I5. No player shall play a forward pass unless at the time of his so doing there are not less than two of his opponents (including the goalkeeper) between him and the opponents' goal line (the goal line for this purpose being an imaginary line drawn from the goal-posts to the side). In the event of such forward pass being played by or hitting such player as aforesaid, or of his interfering with the game in any way, the puck shall be restarted at the point where such forward pass was made.

I6. In the case of one of the players being disabled, the captain of the opposing team may decide whether he will allow a substitute or take out one man from his own side.

I7. No alteration shall be made in the rules unless it be supported by at least two-thirds of those present at a Special General Meeting called for the purpose, of which at least seven days' notice must be given in writing to each member, or by seven days' notice posted on the Club Notice Board-the suggested 


\section{I36 WINTER SPORTS}

alterations to accompany any such notice or to be affixed to the Club Notice Board. Any amendment to be brought forward at such Special General Meeting must be signed by the proposer and sent to the Hon. Secretary at least four days before the date of such Special Meeting. 


\section{CHAPTER VI}

\section{SKI-ING}

OF all the hundreds of folk who yearly spend a few weeks or, if they are excessively fortunate or opulent, more than a few weeks in Alpine resorts during the winter, there are many who devote themselves almost entirely to one sport. Thus you may, as a rule, never meet a man except on :
(i) The skating rink,
(ii) The curling rink,
(iii) The ski-ing slopes, or
(iv) The toboggan runs.

Weather bad for his particular branch of sport may temporarily drive him to another and slightly despised diversion, but when possible, where his heart is, there will his legs be also. He will be adopting one particular method of sliding (I count curling a method of sliding, because your object is to make your curling-stones slide in a definite manner) to the exclusion of others, and sliding in some form or other, whether on skates or toboggan or skis, lies at the base of all winter sports. That is why we all go to Switzerland in the winter, because there we find frozen water (or hope to) in abundance. We then, having fixed on the particular and hazardous manner in which we wish to slide over frozen water, 


\section{38 WINTER SPORTS}

with steel blades or long wooden shoes, proceed to do so. In all cases the desire to slide instead of walk regulates the choice of our holiday. Exclusive tobogganers we must regard as a comparative rarity, for there are few who practise tobogganing whenever possible and nothing else at all. As a rule, tobogganers do not toboggan for the whole of every day. It entails too much hillclimbing.

But of these three classes, I think the confirmed and inoculated skier is most absolutely wedded to his sport. You will find him a rarer visitor to either form of rink than is the inoculated skater or curler to the ski-ing slopes. It will often happen, also, that the inoculated curler visits the skating-rinks, or the inoculated skater the house and the hog. But the man who comes out to Switzerland in order to ski very seldom visits either. For various and intricate as are the manœuvres which the expert can perform on skates, and various as are the movements which the expert can cause his curling-stones to perform, there is at the command of the skier a greater expanse of conquerable territory. Not only has he his figures, so to speak, to cut on the snow-fields, his Telemark and Christiania swings, and his stemming turns, which correspond roughly to the threes and rockers and change of edge in the skater's art, and the outwicks and inwicks of the curler, but he has his travel over the snows for travel's sake: he is an artist in climbing, and the whole horizon (omitting such mountain peaks as the Matterhorn or the Aiguilles) are part of his rink, which reaches, broadly speaking, wherever there is snow. And some part of his rink, however bad the weather, is pretty certain 
to be in order. The skater's rink may be (as has been known within the memory of man to happen) an inglorious series of pools, or have vanished entirely under a covering of snow, and similarly, the curler's rink is occasionally found to resemble a sort of cold wet toffee. But the skier's rink is hardly ever altogether impracticable, and he can both travel and in his travelling cut his figures. Hardly ever, though he may have to go far to get it, will he fail, except when a severe fall of snow is actually going on, to find slopes on which he can at any rate "play about." Consider also the infinite variety of his tumbles. His falls are more complicated, have more pleasing uncertainty about them, than those which any skater can indulge in. Also they hurt far less. There are few skaters who can manage to fall more than about half a dozen times a day, unless they are exceptionally young, or, as the inquests say, very "well nourished," and yet continue their practice with undiminished vigour. But there are few skiers, old or young, lean or otherwise, who will be the least discouraged by twice that number of tumbles.

Here, too, is another reason for the fidelity of the skier to his sport. It yields him, if he is a novice, a quicker dividend of pleasure than skating yields to the beginner, or curling to the curler. After a week's practice, starting from the beginning, the skater will scarcely yet have felt himself firmly travelling on an outside edge, which, when he has accomplished it, is after all only the beginning of further trouble, while the curler, after the same lapse of time, will not have kegun to deliver his stones with the most distant approach to what could possibly be called accuracy. But the 
skier will already be cognisant of the rapture of sliding swiftly downhill on the hissing snow, and though the "frequent fall" awaits him, he will have experienced a genuine taste of the authentic joy. He will, too, have climbed high and heavenwards, have seen new horizons spread themselves, have seen further peaks in the magic of the Alpine air and sunshine rear their austere heads. Stumblingly, perhaps, he will have penetrated into new valleys among the " holy hills," and felt the surprise and sting of exploration. He will also, if he has devoted himself to the tricks-the skating-figures of his art-be appreciably nearer the achievement of stemming turns than the skater will be to the accomplishment of a simple three, or the curler to the hope of coming into the house round a guard. Thus, if anyone who can get three weeks in Switzerland, without solid hope of getting more in subsequent years, were to ask how, being active of body, he could get the maximum of enjoyment out of those three weeks, I should unhesitatingly advise him to practise ski-ing, though, should he have a reasonable prospect of coming out in future years, I should just as unhesitatingly recommend him to persevere for a little while, anyhow, with his skates, or stick to the curling-rink if he desires a less hazardous sport. But if he has a short holiday, without reasonable prospects of coming out again, I think if he is young and active he will get more fun in a short time if he betakes himself to the skis. Moreover, whatever resort he honours with his presence, he is certain to find there fair ski-ing slopes, especially in unfavourable weather, and in the vast majority of cases, excellent ones. Indeed, if he only anticipates one visit 
to Switzerland, he will find everywhere slopes that will be for him excellent.

Also there is a greater simplicity about his needs. Nature provides his rink, and it stretches further in every direction (except downwards towards the valleys) than he is able to go. He wants no marking out of house and hog-line, he wants no surface nightly renewed and rendered flawless. He only wants his equipment, as the skater his skates, and the curler his stones and his broom. And if, like the curler, he is, so to speak, "never up " for a day or two, he is never down for long, and cannot hurt his side, and probably will not hurt himself. Also, the minimum of experimentalism will enable him to enjoy himself, and I doubt whether the skater really enjoys himself with so little expenditure of time and trouble, unless his only object is to progress in a straight line. To progress in a straight line, in fact, is no fun for the skater, but it is great fun for the skier.

Without going into any excessive details with regard to his equipment, certain facts about it must be broadly stated. The ski itself, as anyone seeking those altitudes in winter is probably aware, is a long narrow slip of wood turned up at the bows and fastened to his foot. It is smooth on the under-surface, thicker under the place where his foot comes than elsewhere, and should have a shallow groove running up the middle of it. In length it should be a few inches shorter than its owner if he stands with his arms outstretched above his head. In other words, a man 6 feet high will want a ski about 7 feet long. This is only a rough-and-ready rule, and if the skier arrives at his Alpine resort 


\section{2}

with the intention merely of hiring skis, he should not choose them shorter than this. It is easier to travel on skis that are too long than on those which are too short. But, however long the skis are, they cannot be too narrow. Mr. Caulfield (an adept and authority) lays down that at the narrowest part (i.e. where the foot rests) they should never be more than $2 \frac{3}{4}$ inches in breadth. Instantly the novice will exclaim that his boot at the ball of the foot is broader than that, and that his boot will project beyond the skis. He is perfectly right: it will. But Mr. Caulfield is right too. He should also see that the grain of the ski lies longitudinally, and that the ski itself is slightly arched, the top of the arch lying underneath the wearer's foot. If the ski is quite flat, it will bend downwards in soft snow under the weight and impede the going. These directions, which sound slightly advanced for him who has never seen a ski at all, are really most elementary. No beginner should attempt to ski on contraptions that do not fulfil all these requirements. He might as well begin learning to walk in boots that are not adapted for ordinary wear.

Next comes the awful, the intricate, the debated question of " bindings," by which is denoted the system by which the boot of the skier is fastened to the ski. Into the merits of the different schools concerned with this I do not propose to enter, nor (under the breath be it spoken) does the fervour of the disputants seem quite to be warranted by the importance of the subject. Provided that the bindings are easily adjustable, and when adjusted are not easily displaced, and provided they are not so rigid as to render likely, in case of the "frequent fall," a serious strain on the 
foot, resulting in a sprain or a broken bone, they must be considered satisfactory enough. Such bindings are :
(i) The Huitfeldt binding;
(ii) The Ellefsen binding.

Many experts will be found to disapprove of each of these : on the other hand, each of them is supported by expert opinions. But the beginner, in choosing his skis, is solemnly warned against selecting unknown and patent bindings unless advised of their excellence by an expert who is familiar with them. He is safe, however (if anything connected with the skis can by any stretch of imagination be considered safe), if he selects either of the two above-mentioned bindings. They differ enormously in principle but are both excellent. A third binding, the Lilienfelt, has also many devotees : its opponents, however, assert that it is dangerously rigid. But it is possible to fall down, quite often, when using any of these bindings, with the most satisfactory results.

Of the actual equipment (i.e. of tools necessary for ski-ing at all) the next matter is sticks. Of these the skier should always carry two, by the help of which he makes a supplementary punting movement when going along the level or up gentle slopes; while on a steeper upward slope he leans on them to distribute his weight, and thus prevent back-slipping of his skis. They should therefore be strong and light, and made of cane. They terminate at their lower end in sharp steel points, and some few inches above those points they should be fitted with a light circular disc of wickerwork which prevents them sinking into the snow. Otherwise the 
holder, leaning on them, would merely be plunged up to his shoulders in soft drifts, which would not serve his purpose. They also help to steady him, in the manner of an ice-axe, when climbing very steep slopes or when zigzagging, and should be at least shoulder high. Coming downhill the beginner, when the pace grows too fast for his liking, is accustomed to lean heavily on them, grasping them together in both hands and making of them a brake to his headlong career. This manœuvre is called "stickriding," and is unanimously discouraged by all experts, however divergent may be their views on the subject of bindings. Later, when the beginner is joining himself to these austere folk, he will cease to stick-ride, and make stemming-curves and Telemarks and Christiania-swings instead. But as long as the world goes round, and the force of gravity continues to exercise its accelerating force, so long, whatever the experts may teach, shall we see the beginner descending a slope, bending low, with eyes starting out of his head in pleasing terror, and leaning heavily on his conjoined sticks. It is safe also to assert that the austere experts did exactly the same when, in the dark ages, they were starting on their glorious careers. Therefore, by all means, let the beginner select strong sticks. Any anchor, however illegitimate, is better than an anchor that snaps in half. For the counsels of perfection are only appreciated when the possibility, not of perfection, but of moderate skill, begins to dawn on the rosy heights. Till then, $O$ fellow-tyro and novice, gaily descend slopes that terrify and unnerve you, conscious that, when the terror becomes unbearable, you can lean heavily on your sticks and check your mad 
career. This is profoundly immoral advice, but the knowledge that you have strong sticks in your hands will enable you to contemplate and thus imperfectly negotiate these places in a straight direct line. You will know what it feels like to face straight down these abominable precipices, and will have gained a sensation. But without the knowledge that you held in your hands a powerful instrument of retardation you would, very likely, have never gained the sensation at all. This is a counsel of imperfection, and if you design to be a first-rate skier you will not follow it. But if you have, as in our hypothetical case, only a few weeks in these uplands, without prospect of more, launch yourself with your strong sticks on a blood-curdling incline, see what it feels like, and, when your nerves cannot bear it, lean heavily on both sticks.

But the moment we progress a little further than the hypothetical case of the man who for one winter has three weeks of Switzerland in front of him, and then, as far as seems probable, no more Switzerland at all, the joys of the skier increase in a quickly ascending scale. Just as the skater in the English style finds that the threes and the rockers and the counters that he has so painfully learned are not only delightful in themselves, but help him towards qualifying as a good skater in the combined figures, and just as the Continental skater finds that those same figures assist him to produce a first-rate programme in free-skating, so also does the skier who on easy slopes has made himself acquainted with the various turns, find that his education there vastly increases his enjoyment in and proficiency at the glorious 


\section{I46 WINTER SPORTS}

excursions which are all to be made on his immense rink. Slopes and descents that would be impracticable for him to descend if he had not learned the tricks, the figures of his sport, are easy and pleasurable if he can make his Telemark, his Christiania, his stemming turns, and not only do they become practicable, but his negotiation of these slopes becomes an artistic performance instead of being a terrified and stick-riding descent, just as to make a vol-plané from the skies is a beautiful feat, whereas to slide down a rope merely hurts the hands. In the same way, the ascents, which were a mere succession of stumblings and misdirected efforts, and sweatings unspeakable, lose their arduousness when he has learned how to climb steep slopes with the minimum of exertion. All his practice with other elementary enthusiasts in the field behind the hotel (or in front of it) - there is everywhere some such field at a suitably steep angle-works into what must always be in ski-ing, the main object of the sport, which is to be able to traverse the snows and make mid-winter expeditions over the high enchanted country, which is otherwise inaccessible. For on skis you can with ease climb slopes which are absolutely impossible to the pedestrian, since the skier goes unsinking over soft snow and drifts that would engulf the man in boots as in a frozen quicksand; while in descents over such places the difference is only emphasised. A ski-runner will in a few minutes descend, thrilled with the joy of a movement that really resembles flying, places which at the least take the pedestrian hours of plunging labour. He is indifferent as to the depths of snow, since he is only concerned with an inch or two of it, and rapturously descends 
a thousand feet, while a walker is cursing at the first hundred of them. But the ski-runner's enjoyment and speed, both in the climb and in the descent, are vastly increased if he has learned the elements of his art. Thereby he saves effort, saves time, saves tumbles, and saves temper; at the end of a run his mental bank is rich with pleasure, whereas a man who has not taken the trouble to learn these tricks of the trade comes in with a debit balance, so to speak, mis-spent labour, unnecessary falls, and loss of time and temper. He must learn the elements of climbing, of turning, and of braking, not by heavily leaning on his strong poles, but by the far simpler and less tiring methods of using his skis to do the braking for him.

The first difficulties that beset the beginner must be considered as concerned with climbing, since he has to get to the top of his hill before he can experience the pleasing terror of proceeding to slide down it. As he flounders and falls and back-slips, he will be astonished to see some more practised performer strolling along up the slight slope which he finds so baffling, without the slightest effort or exertion. Looking more closely he will perhaps notice that this expert is stamping his feet a little as he walks, merely as if to warm them on this cold morning. Then for a moment perhaps he seems to slip, and the beginner anticipates the delight of seeing somebody else flounder in the snow without being able to get up. But he sees nothing of the sort. Hardly has the slip begun before the expert has put down one ski behind the heel of and at right angles to the other. The slip is stopped, and the next moment he moves easily on again. 
Higher up the slope becomes steeper, and, still watching, the tyro observes that the skier has changed his direction, and instead of mounting in a straight line is crossing the slopes in a slanting direction, zigzagging across them. He has moved perhaps a hundred yards to the right, but is then confronted by a wall of rock obviously unscaleable. But without effort he lifts one foot rather high and turns it, putting it down again in the direction opposite to that in which he has been zigzagging. The other foot comes round too, and immediately the climber begins progressing again in the reversed direction, having executed that easy and necessary manœuvre called the kick-turn. Then a belt of trees closes his new zigzag, and here, by way of variety, he bends down and jumps, revolving in the air as he jumps and lands facing round the other way. This, of course, the beginner imagines to be a merely acrobatic and impossible performance: he resents it as we resent a conjuring trick.

Then it seems that the climber has got tired of his zigzags, and facing the hill directly again he proceeds, this time with some slight appearance of effort to walk straight up it with his feet and skis turned outwards in something of the attitude of the frogfootman in Alice in Wonderland. Each ski just avoids treading on the heel of the other, and clears it by an inch or two, so that the track left resembles the outline of a piece of herring-bone brickwork. There is the same resemblance in the name of this manœuvre, since it is called herring-boning. Then once more the climber varies his style of progress, for here the slope is exceedingly steep, and he has come to a narrow gully, where his zig- 
zags would have to be very short, and instead of interspersing every few steps with a kick-turn he stands sideways to the slope and puts down one foot horizontally across it and brings the other close up to and parallel with it. Then he steps sideways again with the first foot, and repeats the manœuvre. Twenty or thirty paces of this sort bring him to the top of his gully, and he stops a moment looking over the view which his climb has opened out to him. (That also is a frequently-practised ski-ing manœuvre and quite easy. The view-trick is indulged in after a steep bit of climbing, and is dictated by a love of scenery combined with the need of getting your breath again.)

Now all these devices, the stamping of the skis, the stopping of the slip, the kick-turn, the jump even, the herring-boning and the side-stepping are all quite easily learned, and, if we except the jump round, which is never necessary, since the kick-turn produces the same result (i.e. change of direction), the beginner will in a few days have so far mastered the elements of them that he will be able, without undue fatigue, to climb slopes on which at first he helplessly floundered. But he is advised to make practical acquaintance with all of these conjuring tricks, for they each have their special uses. On certain slopes there may not be sufficient room to zigzag without continually turning, while again the surface of the snow may be so hard and icy that herring-boning, which is quite easy if there is soft snow on the top, may be practically impossible, in which case the side-stepping must be employed. But any slope negotiable at all on skis is negotiable by one of these methods, which are none of them at all hard to acquire. 
Now, it is no part of any of these treatises to do more than state how various manœuvres on ice or snow or with the curling-stones are done, and in ski-ing (even as much as in skating) written instructions would be of very small use. What is far more to the point is to sally out (in print) on to a fairly easy slope and attempt to make these phenomena appear, so that the beginner will understand them when he sees them, and try to imitate with a knowledge of what he has to imitate. Best of all is it to get somebody actually on skis to show you what the thing looks like. Then-for we are all descended from the monkeys-it is part of our human birthright to attempt to ape what is shown, and a practical illustration, followed by actual practice, will do more for the beginner than a host of learned treatises. Still, when dusk has fallen, and he can no longer even see to fall down, he is strongly recommended to study some practical manual of ski-ing. Of these I will mention three, all of which are illustrated by a series of admirable photographs, which make a visual guide more valuable than any written instruction. These are :

(i) How to $S k i$, by Vivian Caulfield. (Nisbet.)

(ii) The Ski-runner, by E. C. Richardson. (Richardson \& Wroughton.)

(iii) Ski-ing, by W. R. Rickmers. (Fisher Unwin.)

Here he will find careful analyses of ski-ing manœuvres, clearly and at length explaining them, and elucidating the explanation by photographs. The curious student will no doubt find certain differences of opinion expressed by these Masters, but, 


\section{SKI-ING}

if he is wise, he will leave academic disputation alone, and try to put into practice the precepts and instructions given by any one of them. He may rest assured that, however disputatious the pundits become over any theories advanced by these authors, there is a great deal to be said for them. Indeed, their very disputatiousness shows how much there is to be said!

To return to our forlorn beginner on the slope, who has seen vanish from his ken the figure of the expert climber, we will suppose that he occupies himself with his flounderings while others with equal ease and absence of effort pass him in their ascension. Some of them, it appears, are not going out for any expedition, for they pause when they have got to a sufficient height and begin descending again. And here the tyro should surely find encouragement, for he will observe that they often stagger, fall, and are smothered in snow. That does not in the slightest degree deter them, and probably he will begin to realise that falling, even in the case of experts, is part of the day's work, and, as a rule, does not hurt at all. Indeed the skier who does not fall is either so cautious a performer that he cannot be called a skier in any sense of the word, or so supreme a master that he is evidently not human but some form of Alpine ghost. On the skating-rink he will see the same thing, for even the "plus-players," so to speak, if they are really practising, execute the most amazing tumbles, while on the curling-rink, the gods and demigods make shots of the most putrescent nature.

But as he watches he will notice that these ladies and gentlemen who are ski-ing are busy not with merely descending the slope 
they have climbed, but descending it in a particular manner, and interspersing their descent with certain definite manœuvres. Sometimes, perhaps, one who has climbed into the gully out of which the first expert has disappeared, will stand for a moment facing downhill, and then launch himself on a perfectly straight course. He will be standing upright, but leaning forward, which is not a contradiction in terms, if this phrase is considered. In other words, his whole head, body, and legs will be inclined a little forward, but he will also be upright because there is no bend in his knees or hips or neck. In other words, he will be standing at right angles to the slope, though leaning forward. His skis will be quite close together, so that they make but one track in the snow, and his right foot probably will be a few inches in front of his left. His arms will be a little raised, so that his sticks, which swing pendulum-like from his hands, do not touch the snow, and his descent is that of a stooping hawk. A spray of fine snow rises round the toes of his skis, like the feather of water round the bows of some lightning-speeded boat. A moment ago he was but a speck high up on the mountain-side, the next he is but a speck at the end of the slope below. If not so fortunate, he is somewhere in the middle of that sudden-spouting billow of snow that mars the smooth whiteness of the hill. But in any case, the beginner has seen a specimen of ordinary straight-running, the figure upright and inclined forward, the skis close together, with sinecure for the sticks. And if our beginner's courage is high, he will instantly attempt, from the more gradual slope on which he stands, to do the same. Probably, if he remembers to 


\section{SKI-ING}

ape this flying Mercury in the points mentioned, he will progress quite a considerable number of yards at his sedater speed without falling. Then a wild panic will seize him at the thought that his pace is steadily increasing, and that he has not the slightest idea how to check it. That thought alone will most likely be sufficient so to unsteady him that he will instantly fall down and find that he has grasped one method, anyhow, of stopping. He may then employ the few moments' pause that invariably succeed a tumble to observing whether, from the tracks his skis have left, he has kept his feet together. If he has, he may feel justifiably pleased with himself, but must not be discouraged if the tracks resemble the old broad gauge of the Great Western Railway.

Then comes another descender. $\mathrm{He}$ is going quite straight also, but he appears merely to be strolling down the same slope that the other fellow flew down. Yet he does not use his sticks to lean on, but stands upright also, but with toes pointed inwards, legs apart, and heels pointing outwards. Instead of travelling on level skis, it is clear that he leans on their inside edges; and since they are not pointing straight down the slope it is obvious that they are side-slipping all the time instead of sliding straight. That is the case: he is "stemming," descending straight, but using the sideways position of his skis to check his speed. Our beginner, warming to his work, tries this also. He instantly gets the toe of one ski across the toe of the other, and has discovered another method of abruptly stopping. This time he will very likely fall forward in the manner of $\mathrm{A}$ breaking wave on to a snowy shore. 
This time the question of the technique of getting up obtrudes itself. Probably his skis are still lovingly entwined together, and, leaving them in a fond embrace, he will attempt to rise. Nothing happens : at least he is only conscious of violent and enraged effort, which is productive of no appreciable alteration in his position. Then it occurs to him that he had better have his feet free of each other, and this he strugglingly accomplishes, pointing them both symmetrically downhill. Again he attempts to rise, digging his sticks in the snow, upon which his feet slide sweetly and smoothly away from under him, and he is prone on his back again. But if, after disentangling his feet, he plants them sideways across the slope he will find they cannot slip away, because they are edged into the snow and are as firm as everlasting mountains. But this is instruction.

A third runner comes down the slope, this time running slantways. But after a little he assumes the stemming position, and then his right ski crosses in front of the other, and he comes round in a curve to the left. Then his left foot takes the lead and he swerves again to the right . . . da capo, da capo . . . he describes a slow serpentine line, running with feet together on his zigzags, and widening the distance as he approaches the turn. First one foot and then the other goes in front at their appropriate corners, and down this precipitous slope he comes, but at moderate speed, weaving his dance. Each turn is made in the stemmingposition-for these be stemming-turns.

Thereafter comes a more inexplicable runner. He progresses straight for a little way, and then advancing his right foot, he 


\section{SKI-ING}

proceeds apparently to kneel down on his left knee, bending the right leg also, but keeping the knee up. Then it is clear that his weight is almost entirely on the advanced right leg, the other but trails behind. Then with a visible effort he leans on the inside of his right ski and turns it round in front of the other towards his left: As by a conjuring trick he slews round altogether towards his left, and comes to a dead stop facing nearly in the direction from which he has run. And if anybody is standing near our beginner the latter will probably hear for the first time the mystic word Telemark.

Here, then, is a more comfortable manner of stopping dead than that of falling down. The latter is nature, the former is art. On the steepest slope, provided only there is a decent covering of softish snow, the expert will make this short sharp turn and come to a standstill facing nearly or quite uphill. Or, if so he please, he will make a half-Telemark, bring himself sideways to the slope, and then continue his downward descent, starting from rest again. Should he wish to turn towards the right he will kneel on his right knee, or nearly kneel, with heel raised, and, advancing his left ski, put all his weight on to that, trailing the right one behind, which acts, as Mr. Caulfield points out, like the rudder of a boat. Probably our beginner will attempt this also. His first difficulty will be to kneel down at all without upsetting. If he safely accomplishes this, he will have a crisis of nerves in finding himself in so abnormal a position, and dig his stick into the snow. Anything whatever may bappen then.

A fifth and final runner on this morning of revelation begins 


\section{56 WINTER SPORTS}

his descent, travelling not quite straight down the slope but on a steepish zigzag. He does not proceed to pray in the Telemark attitude, but, standing straight, advances his right foot, leaning his weight on it, and trailing his left behind. Then he makes a twist of his shoulders and body towards the right, exactly as if he was cutting a three-turn on skates, and, lo, he has turned round in exactly the same manner as in the Telemark. He does not, it is true, continue the back-edge downhill, but halts on the cusp, as it were, facing uphill, as at the end of the Telemark swing. But what he has done is to make a Christiania swing, with the foot towards the direction of his turn advanced instead of the opposite foot, as in the Telemark. But the effect is the same: he has stopped in the middle of a swift downward descent without falling down or braking. Probably, to touch for a moment on minutice, he has made his Christiania on a hard and ice-crusted place, whereas the Telemarker has selected a spot of soft snow for his performance. So, if the beginner is tempted to try this last manœuvre, he is advised to look out for an icy patch where the sun has thawed the surface of the snow, which has subsequently frozen again. On arriving at such a patch, he will probably conclude (as our American cousins say) to reserve the Christiania for another day.

Now this gifted series of practisers on the slope have, in imagination, presented to the would-be skier all that is demanded of him in the practice of ski-running. When he has learned the more effortless ways of ascending slopes, as exhibited by the expert whom he first observed, and when he can make in his descents, 
VЯUT XЯAMBJAT BHT

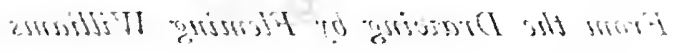




\section{THE TELEMARK TURN}

From the Drawing by Fleming IVilliams. 


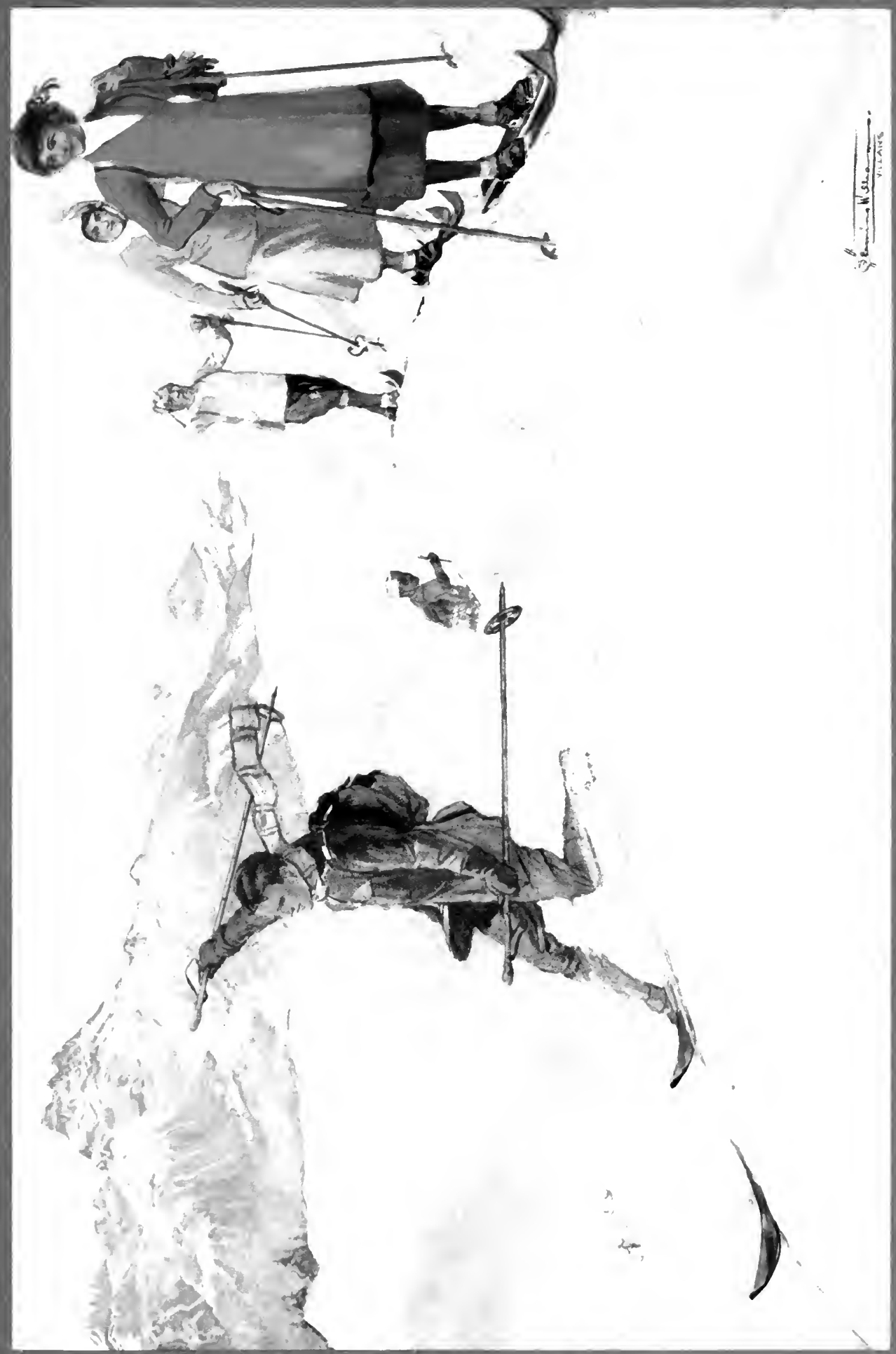



with a fair prospect of success, the stemming-turn, the Telemark, and the Christiania, he is, for all practical purposes, an accomplished ski-runner, a master of that delightful art. But for as many years as he is active of body, he will gain in facility in accomplishing these things, and probably no skier has ever reached anything approaching perfection, any more than any skater has attained that undesirable goal. It is advisedly that I say "undesirable," since to our limited skill it seems to me that half the fun of any sport would be subtracted if we could possibly become perfect in it. But, on the other hand, the skier, if he is at all master of his limbs, will more easily attain that moderate degree of excellence which will enable him to join comfortably and easily in these climbs and expeditions which are the joy of ski-running, than he would attain the excellence required of a member of a fair combined figure in skating or of a player in a respectable curling team. But whereas in skating and curling he can only spoil the amusement of other people (or perhaps, if they are humorously inclined, add to it), he incurs grave danger if he attempts to go on arduous ski-ing expeditions without having got some facility in the easier ski-ing figures, such as the kick-turn on his ascents and the stemming-turn on his descents. Odd as it may appear, everyone has not the nerve to fall down in time, in case a sudden obstacle appears in front of him, or, which is perhaps worse, a sudden absence of anything at all, in the guise of a precipice. But a man who can, with the ease of habit, make a stemming-turn or, better still, both of the other turns, can stop when he chooses. To attain such moderate skill is not at all a 


\section{58}

\section{WINTER SPORTS}

difficult matter, but without it, only a lunatic would join any long expedition. If he is incapable of climbing slopes except with an infinite degree of slipping and stumbling, he is a nuisance to his companions; while if in the descents he is incapable of any turn, he may, if he has the nerve to fall down promptly, be only a worse nuisance; but if he has not, he may become a source of much danger to himself.

Further, however expert a skier he may eventually become, he should never dream of making an expedition alone, unless he is always close to some well-frequented track or road, or unless he is certain that other skiers will pass that way before nightfall. For the best skiers in the world are not exempt from falling, and it is always possible that a fall may result in a very severe sprain, such as will make it impossible for the injured man to go on, or in a broken bone. It is quite true that such injuries are rare, but no consolation will be found in the rarity of your injury if you find yourself on a high and unfrequented snowfield towards evening in an incapacitated condition. For nobody has skill enough to eliminate this danger from his own case, just as no climber will go alone, if he has a grain of sense in his head, on places where there is any reasonable prospect of his slipping. $\mathrm{He}$ makes his party, whether with guides or without, takes a rope, and puts it on when a slip might lead to severe injury or worse. It is only the ignorant who take unreasonable risks, or the foolhardy. It is the same case with the skier. But with him any steep slope may result in a tumble, and any tumble may result in an incapacity to move. Therefore, without any exception, a 
skier, however skilful, should never go alone on any expedition that takes him away from frequented paths. Nor, on such an expedition, should unfrequented places be left behind until all the members of the party have negotiated them. And in such it is the unskilful straggler who falls continually, and having fallen does not know how to get up, and has to ride his stick and go slow over all steep places, who is so unmitigated a nuisance to his companions.

A word more of warning. Clothing is a most important item in the skier's equipment. He perhaps will start from his hotel in a blaze of sun, and knowing there is a long ascent in front of him will adopt an investiture which is altogether unsuitable for that which lies before him, forgetting that though he will certainly get extremely warm during the course of the day, he may also run the risk of frost-bite. He may perhaps be no worse than the man who clothes himself scantily for reasons of the hot upward ascent, and remembering that close-fitting thick garments are productive of extraordinary warmth, will proceed to put on thick woollen stockings, which make the donning of his boots over them a matter of some difficulty. "Thick leather, thick stockings," says he to himself, " now I can't be cold." But he could not have adopted a worse procedure, for it is just through this thick, closely-fitting clothing that frost-bite penetrates. Outside, on the boot, is a frozen spray of snow, inside is the moisture of the foot asking, positively demanding, to be frozen also. The tightness of the boot and stocking further impedes the surfacecirculation, and a frost-bitten foot is very likely the response to 


\section{0}

\section{WINTER SPORTS}

this well-meant protection of it. Instead, the boot should be so large that it can easily accommodate two layers of woollen stuff loosely. Then the natural heat of the body, unchilled by surface pressure, is diffused through these woollen coverings, and makes, instead of a layer of icy moisture, a temperate atmosphere round itself. Similarly with the hands: loose gloves, instead of thick tight ones, should be worn, and the finger-receptacles should be made all in one piece, as is the fashion with babies. Then they warm and comfort each other, instead of being each enclosed in a solitary prison.

In other respects the clothing should be that of the mountain climber, warm but as little heavy as possible. For the lower part of the legs putties are admirable, for it is necessary to protect the chinks between boot and stocking: otherwise snow collects there and forms into icy deposits. Coat and knickerbockers should be made of smooth and wind-proof material, and such a garment as a sweater should not be worn as an outer covering, for the roughness of it causes the snow to cling to it. The coat should be capable of being buttoned closely round the neck, so that in tumbles the snow does not get inside it, and for the same reason long gloves covering the opening of the sleeves are useful. A woollen cap, of the type known as " crusader," which can be brought over the ears and neck when encountering cold winds, and be rolled up, when so desired, is as good a head-covering as can be devised. Snow spectacles of smoked glass, to shield the eyes from the intense glare, should always be carried, and put on before (not after) the eyes begin to smart and water from the 
dazzle of whiteness. Otherwise it is easy to get a touch of snowblindness.

Now, when the snow is soft and inclined to thaw, it has an odious habit of balling on the sole of the ski, so that you walk uphill clogged with a great lump of snow dependent from each foot, which makes it heavy to lift, and at the same time makes lifting necessary, since it is impossible to slide forward on it. But since it is equally impossible to slip back, the beginner will find a certain consolation if the snow balls slightly on his ascent, for he will climb severe slopes laboriously indeed, but without slipping. But no consolation rewards him when he begins his descent. In vain he encourages his skis to slide, for the loose mass of soft snow sticking to them effectually prevents their doing anything of the kind, and unless he has come prepared for such a contingency he will assuredly have to stamp along all the way home. But balling can be largely avoided by waxing the bottom of the skis, preferably before he starts. This wax can be obtained anywhere in tubes, and when rubbed on to the skis prevents the snow from sticking to them, and you will see a man whose skis have been well waxed running swiftly and easily over snow that would entirely prevent his moving if this had not been done.

On the other hand, the snow on an ascent may, instead of being soft and balling, be hard and icy, so that it is a difficult matter even for the expert to prevent back-slipping. To discourage this tendency he sometimes will tie a cord to the toes of his skis and pass it several times round them, fastening it to the bindings. Others tie strips of seal-skin to them, which also counteracts the 
tendency to slip. These, of course, are removed when the ascent is over.

\section{JUMPING}

Of all spectacular feats compassable upon frozen snow surfaces, ski-jumping is, to the minds of most people, the most amazing, and compared with it all performances on ice-rinks and toboggan-runs seem to the spectator almost tame. Not having the smallest or most elementary practical experience of it ( $\mathrm{F}$ should freeze with terror if told that $\mathrm{I}$ had to go over even a very mild ski-jump, and probably be found hiding in the station waiting-room to take the next train home), I can but give an impression of it as it strikes the observer.

The glad word is passed round the hotel one evening that some famous ski-jumper has arrived and will give an exhibition next day; and next day, accordingly, you trudge out on to the slope where the jump has been erected. This is a long steep hillside, and the platform for the jump has been put up some hundred yards from the top of it. It is a champion jumper who has arrived, and the apparatus is on the big scale. Out from the slope of the hill is this platform, built in the manner of a dormer window in a house-roof or a headerboard above a pool. It is made of wooden planks supported on posts, and covered with a layer of down-trodden snow. It is some 5 yards or so in length, 5 or 6 feet broad, and the edge of it is some 6 feet perpendicularly above the slope at its base. At the corners of it, to guide the jumper who approaches it, are 
boughs of fir stuck into the snow, or flags. Above it the slope is of moderate steepness, sufficient, anyhow, for a skier to get up a considerable speed when running straight down towards it from above; below the hillside is considerably steeper, and continues at a steep angle for two or three hundred yards. Both above and below the platform the snow is being industriously trodden down by those engaged on the preparations, so as to make a smooth firm run for the jumper before he gets to his platform, and a smooth firm landing-place after his flight through the air. The reason of this is that it is absolutely essential that the jumper should have no check when he touches ground again after his flight : if he landed in soft or deep snow he would quite certainly have a bad fall. But with hard smooth snow to land on there is no such check, and on landing he continues his course at high speed straight down the hill. It is also extremely important for him to land on a steep slope; for if the slope was but gentle, the shock of coming in contact with it from such a height would clearly be extremely severe, and broken bones would undoubtedly result. But the steep slope lends itself to the pace he is going and the height from which he comes, and, as it were, continues his flight on the ground. Also, the steeper the slope is, the longer obviously will the jump be, as measured from the platform to the point where he first lands.

A good place to see the jumping from is to the side of the track down which the jumper will come and a little way below the platform: here let us suppose ourselves standing. On each side of the course stretch out lines of spectators, and a hundred yards 


\section{I64 WINTER SPORTS}

above the jumper is standing talking to friends and seeming positively to enjoy what lies in front of him. Then the word is given, and, steadying himself on his two sticks he points his skis straight down towards the jump. He shoves off with his sticks, leaving them standing in the snow (for no jumper uses sticks when he jumps, which would be highly dangerous), and at swiftly accelerating speed glides down the slope. As he approaches the jumping-platform he crouches low, and just as he traverses it he springs upwards and forwards into the air. High above your head, a veritable flying man, he soars, with all the impetus that his run and his spring have given him. For a hundred feet or more he continues this amazing flight in a superb curve, and you wait breathless, scarcely able to believe that when he touches the ground again at that pace and from that height there will be anything but a heap of broken bones there. But he alights without shock or the least appearance of unsteadiness, and simultaneously, it appears, he is already another hundred feet down the slope, going like an arrow. Then comes perhaps the most astounding feat of all : he suddenly kneels, and in a moment has swung round with a Telemark, and has come to rest, facing up the hillside over which he has flown and skimmed. And then this extraordinary young man (he is usually rather young) will climb his slope again and instantly repeat the process, in evident enjoyment, or, more remarkable yet, he will get hold of another like himself, and they will take their jump hand-in-hand, let go of each other on landing, and Telemark, one to the right the other to the left !

This jumping is certainly ski-ing in excelsis, and jumpers tell 
ats 1., $x^{2}$

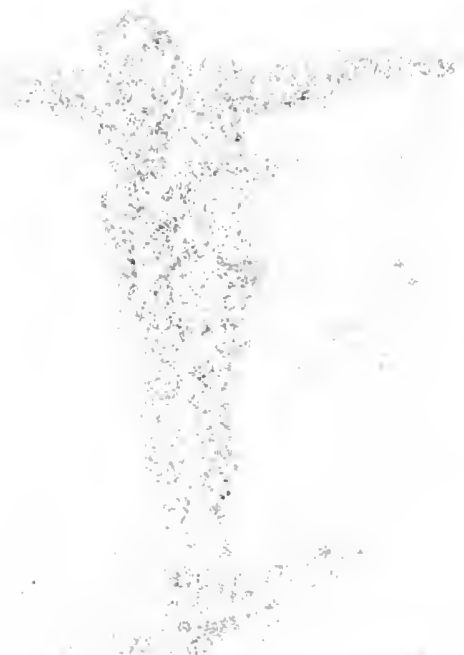

\section{MUI उHT}

smmits
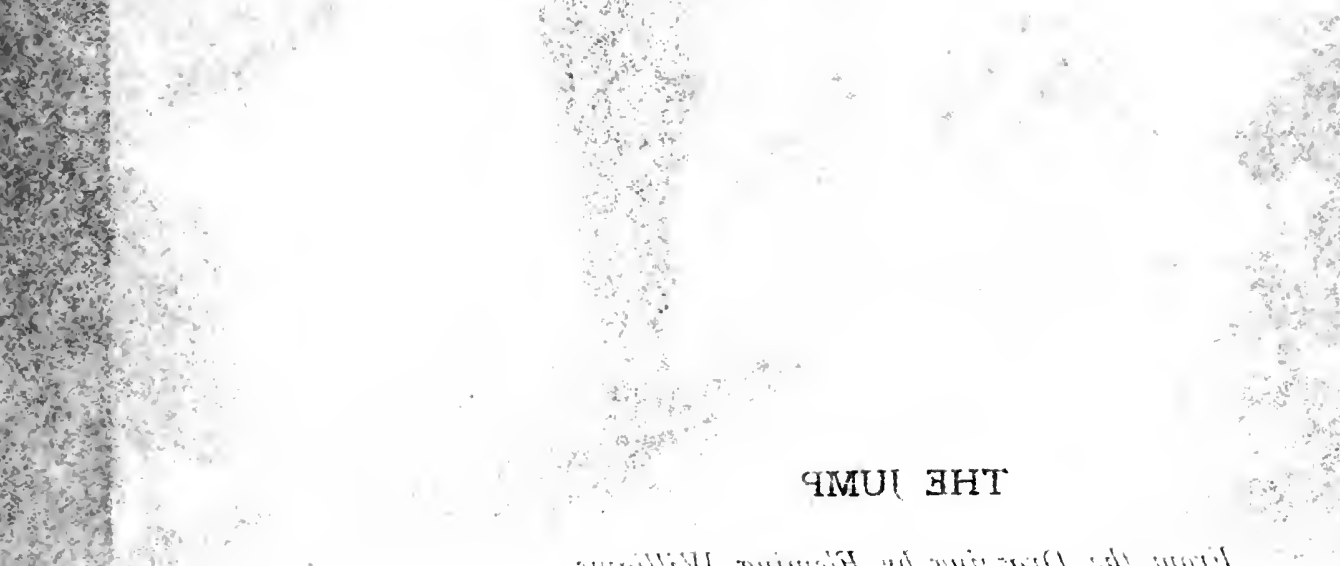

Cxistis

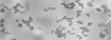

forth th

tion 


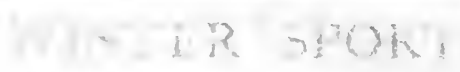

\section{THE JUMP}

From the Drazuing by Fleming Willians

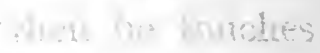

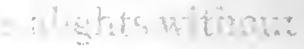

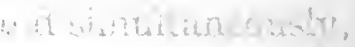

Whe siople,

- ascometring

twoing benstal

inteld ave

iil: $\cot x-$

will thes bis

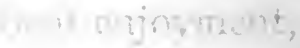

wh stut kincelf.

a of cell wher

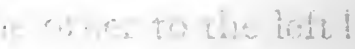

na we anpes tell 


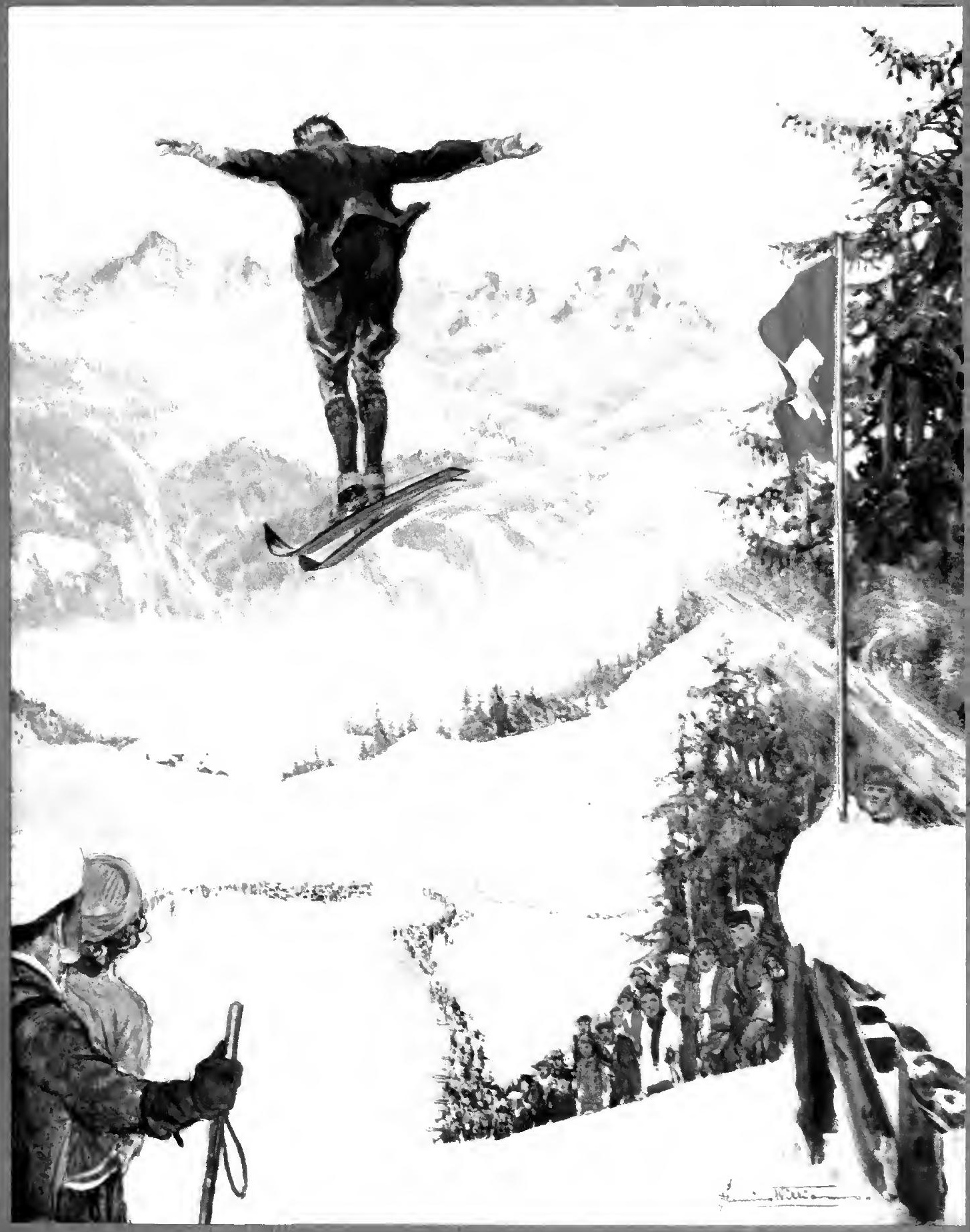




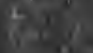

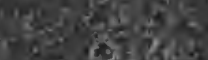

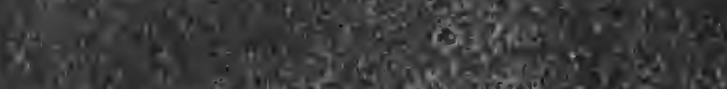

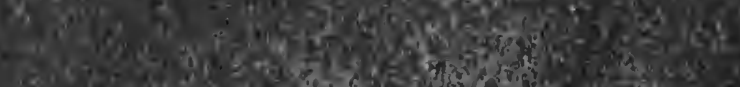

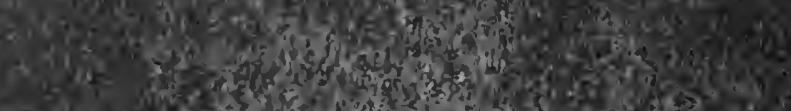

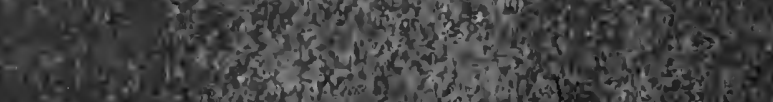

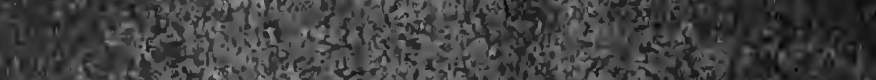

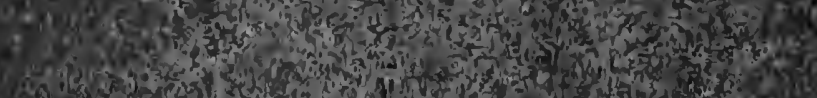

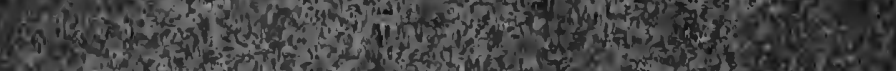

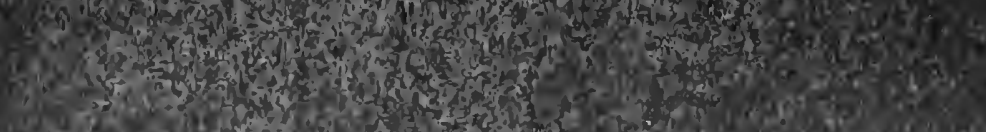

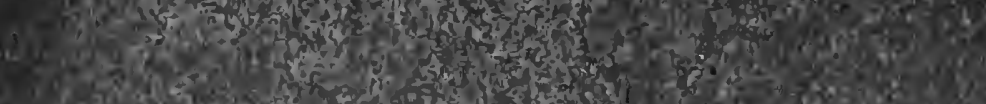

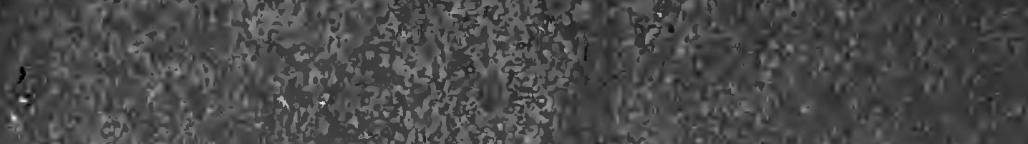

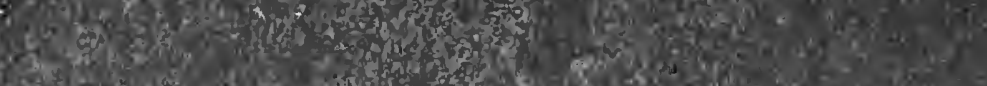

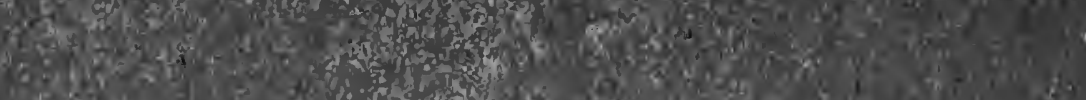

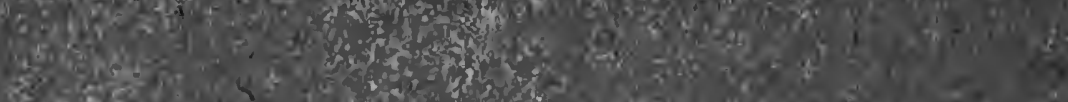

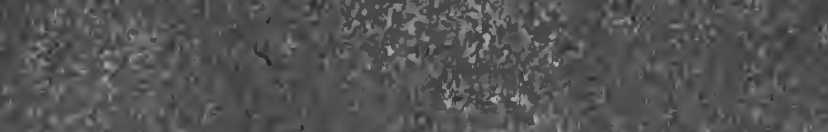

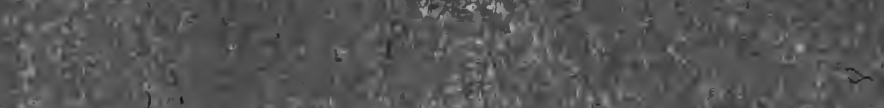



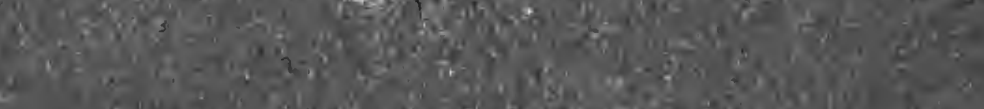

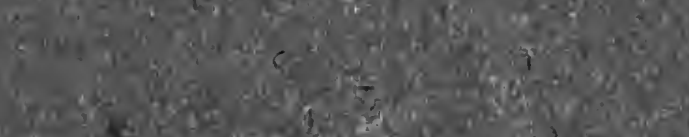

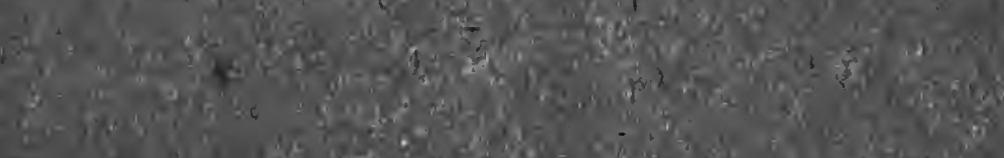

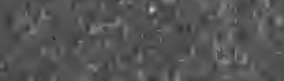

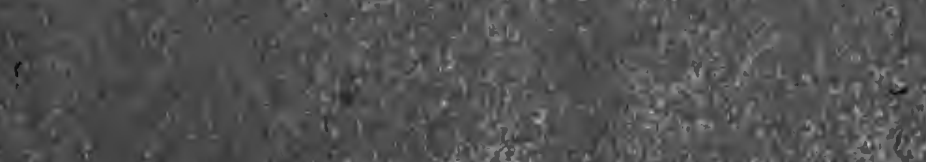

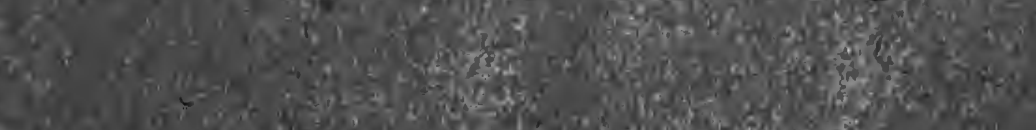
Q1.

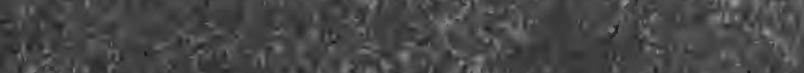
Yor. 1.

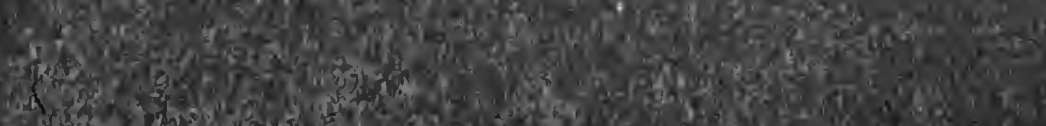

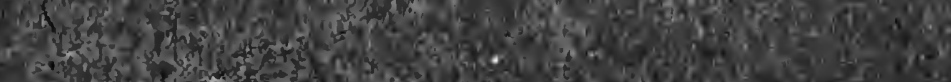

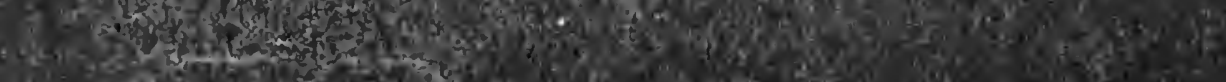

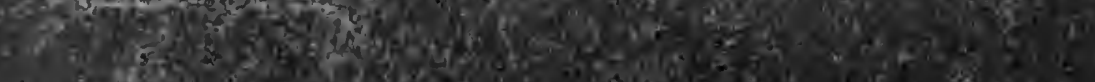

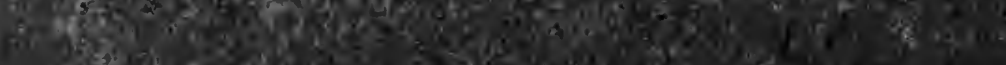

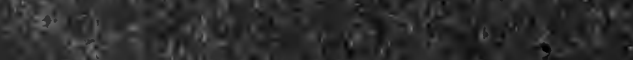

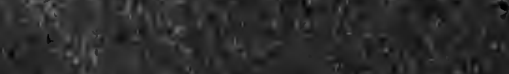


us that if the beginner starts with small jumps, and is careful to do everything correctly and in the proper style from the beginning, he will not find it either a difficult or dangerous pursuit. But he must be careful to make his movements (his crouch, his spring, his angle in the air, the levelness of his skis as he alights, \&c.) with accuracy and correct timing; while it is not less important that the jump itself should be properly constructed and the slopes that lead to and from it be of suitable steepness. Indeed, what appears to the ignorant onlooker the most hazardous part of the whole affair, namely, the landing on a very steep slope, is safe only if the slope is steep, and the real obstacle that lies in the way of most men taking up jumping as a sport, is not that it is dangerous so much as that their nerves tell them that it must be, and refuse to make the crouch and spring (the säts, as the Norwegians call it) with vigour and confidence, even if they can master their nerves so far as to let themselves run down on to the platform at all. But having once reached the platform, the spring must be made : otherwise the would-be jumper will merely flow stickily, so to speak, over the edge, bury the toes of his skis in the snow, and certainly have a bad fall. But, indeed, the nerves must be in good condition, for the platform, approaching it from above, looks exactly like a cliff's edge, and, jutting out as it does from the slope, it entirely conceals the slope below it: your eye tells you that you are merely leaping over the end of all things. But if, after considering the question, you decide, as most people do, that you will not begin jumping this season, you have only to repeat that prudent resolution for a few more seasons, and then you will 
be able to tell yourself and everybody else that it is no use trying to learn to jump unless you begin it quite as a boy. This does not really happen to be the case ; but it is one of those excuses that are always granted acceptance, and, having firmly established it in your own mind, your nipped ambition will cease to worry you any more.

A further delightful pastime to be indulged in on skis is that known as ski-joring. For this it is necessary to secure the co-operation of a horse, and fit him with long reins or ropes, which you hold one in each hand, and stand behind the horse out of the way of his heels. He is lightly harnessed, and from his collar passes a long leather loop of rein, which passes round the ski-jorer's body. You then encourage your horse to proceed, and if he is good enough to do so, he will naturally pull you along on your skis by this loop of rein from his collar. It is a fascinating pursuit to watch, and can be practised over a frozen lake or along the downtrodden snow of roads. Especially in the Engadine you will hear the sound of bells, and observe a horse trotting or cantering briskly on the road, followed at a yard or two distance by an upright figure that glides along after him, a charioteer with only his skis as chariot. But though it is concerned with skis, it is not exactly concerned with ski-ing, which enters into it, as an art, less than does the knowledge of horses and the use of reins. 


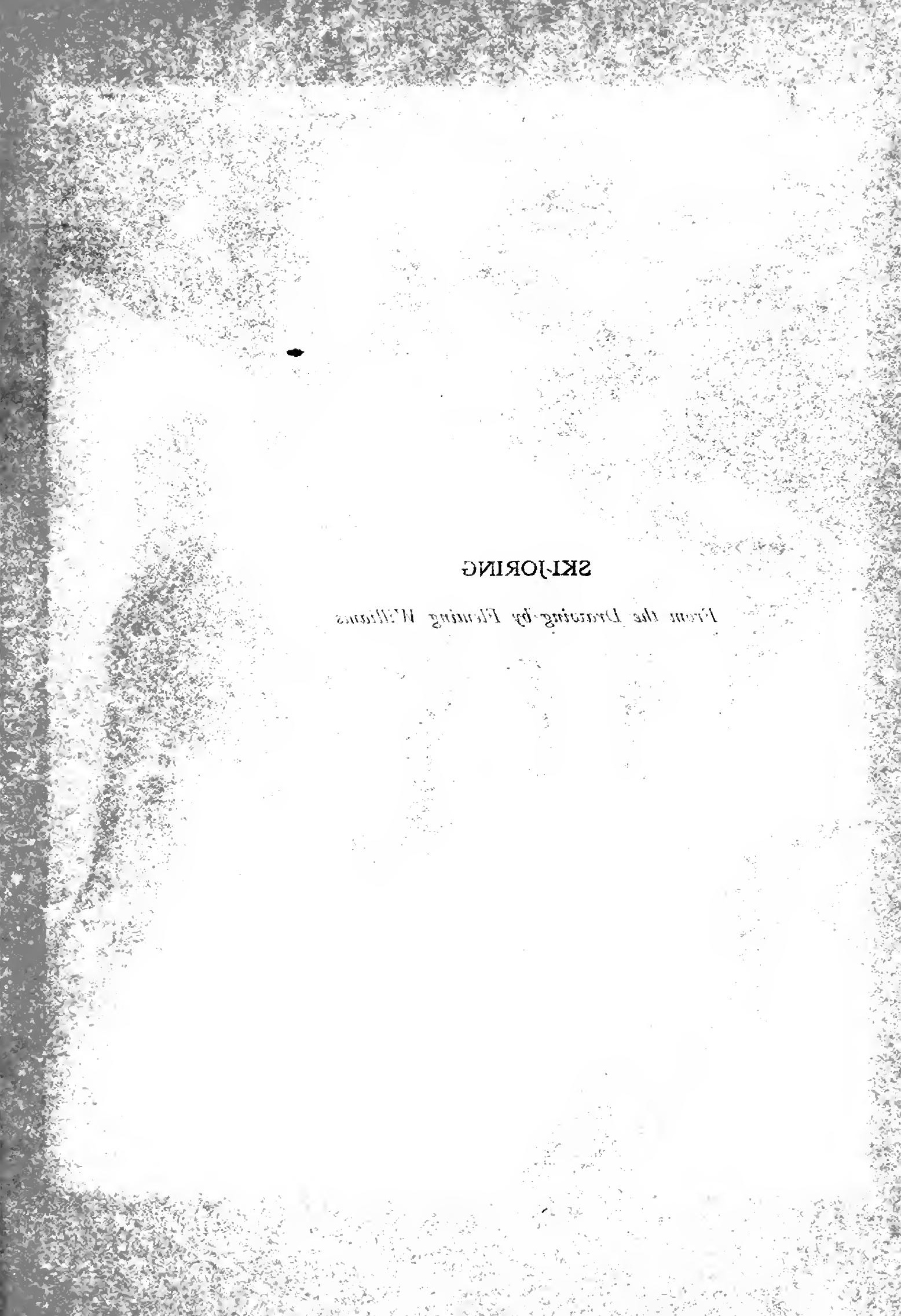




\section{SKI-JORING}

From the Drawing by Fleming Willians 


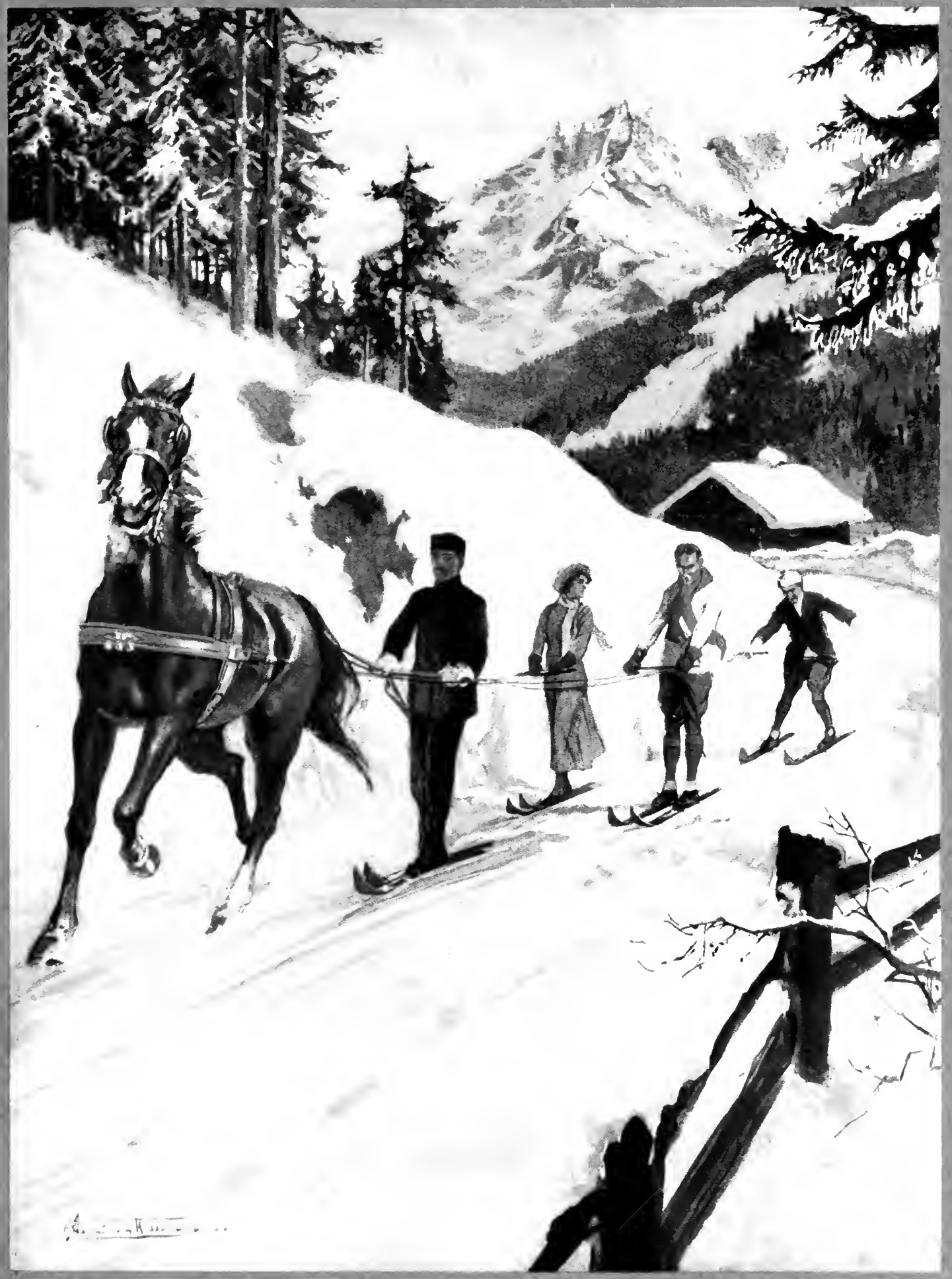






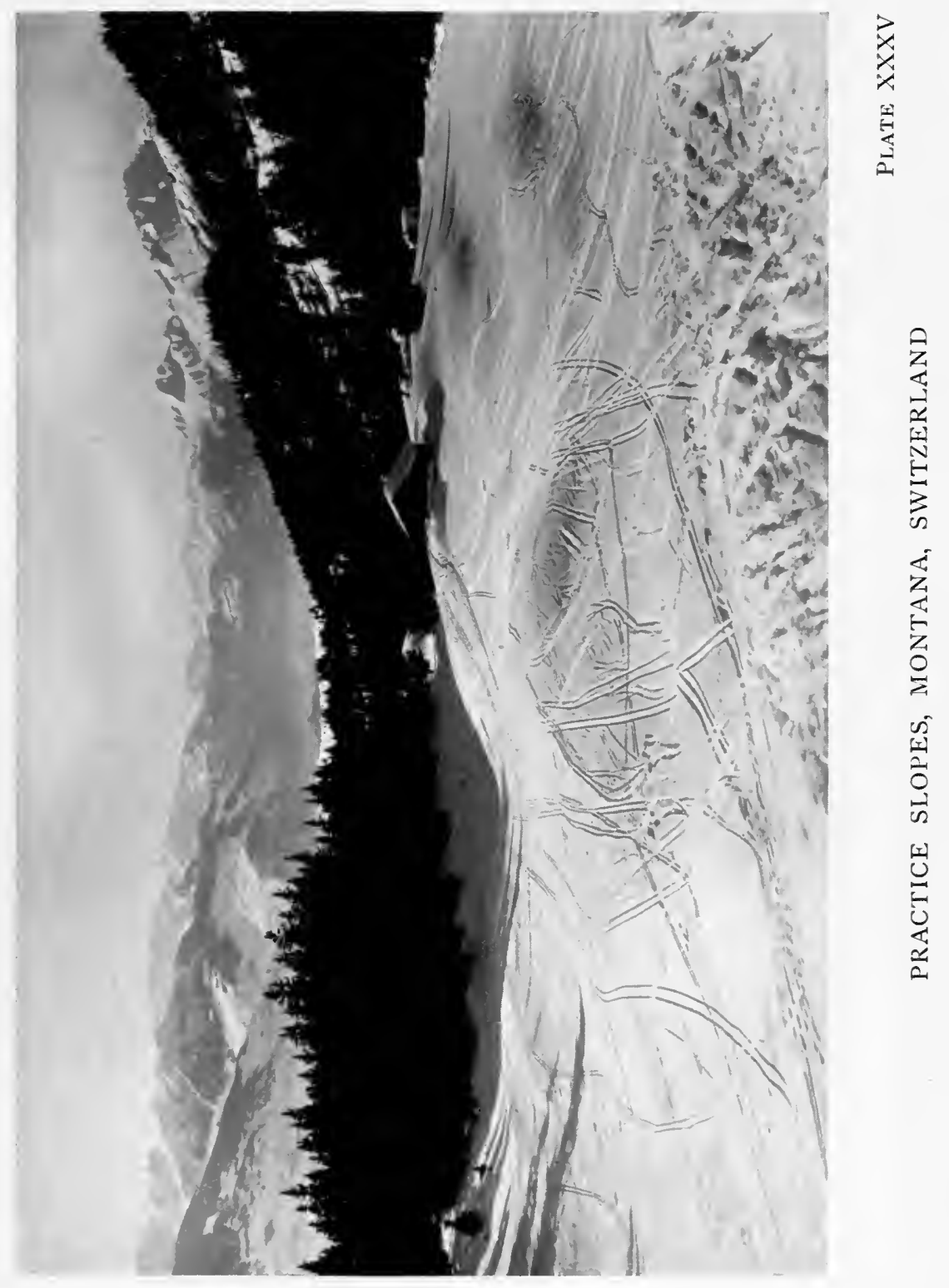




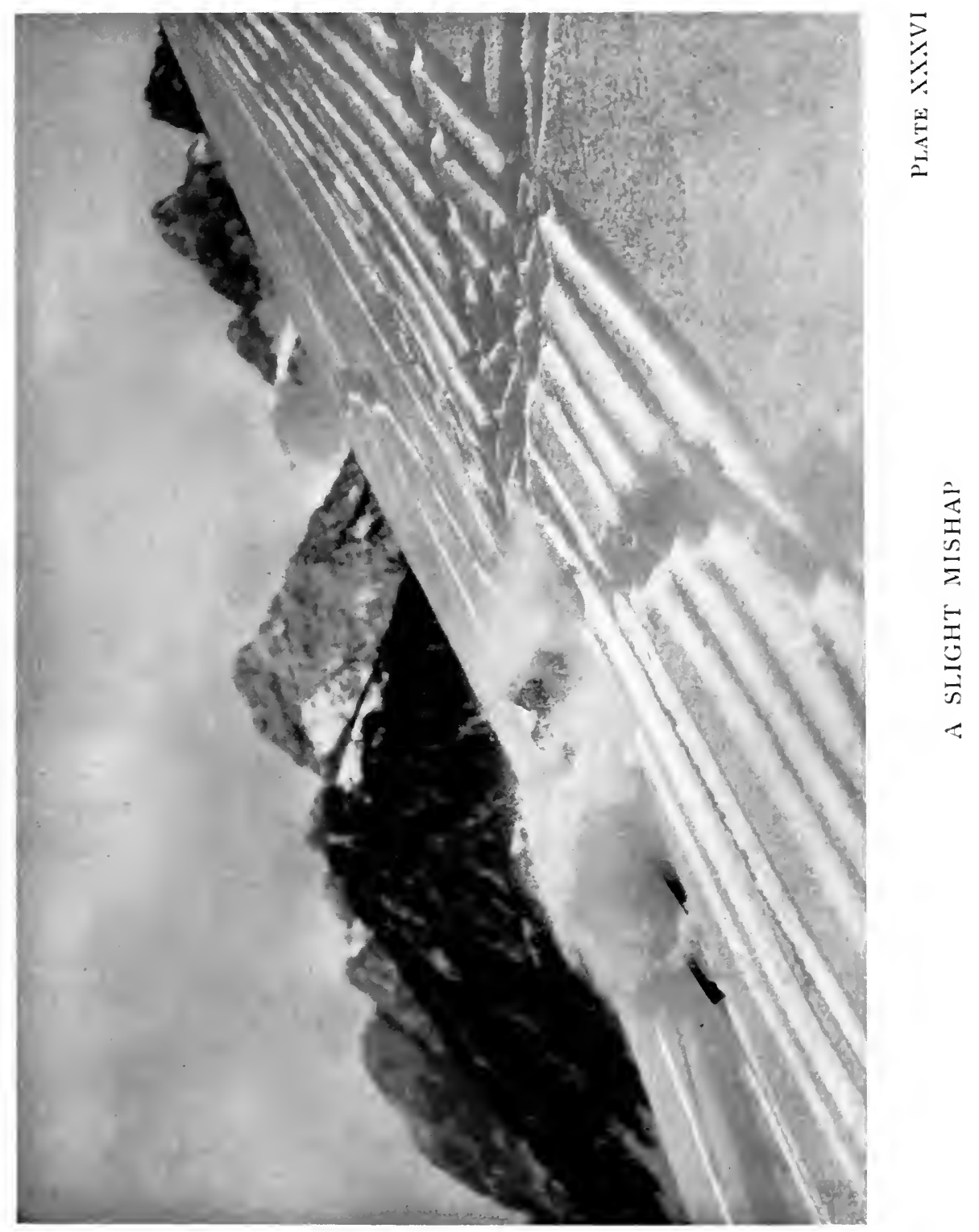





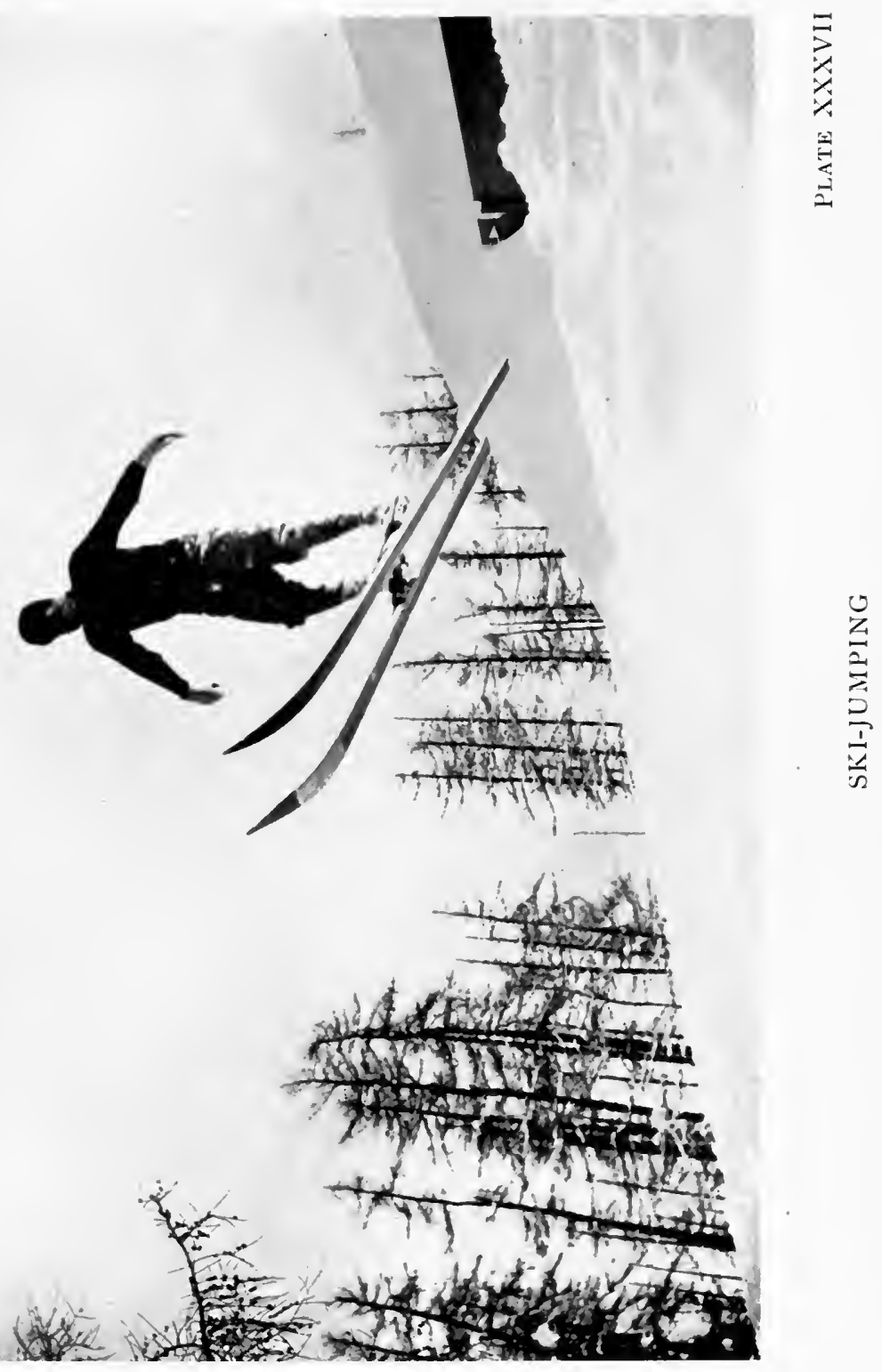




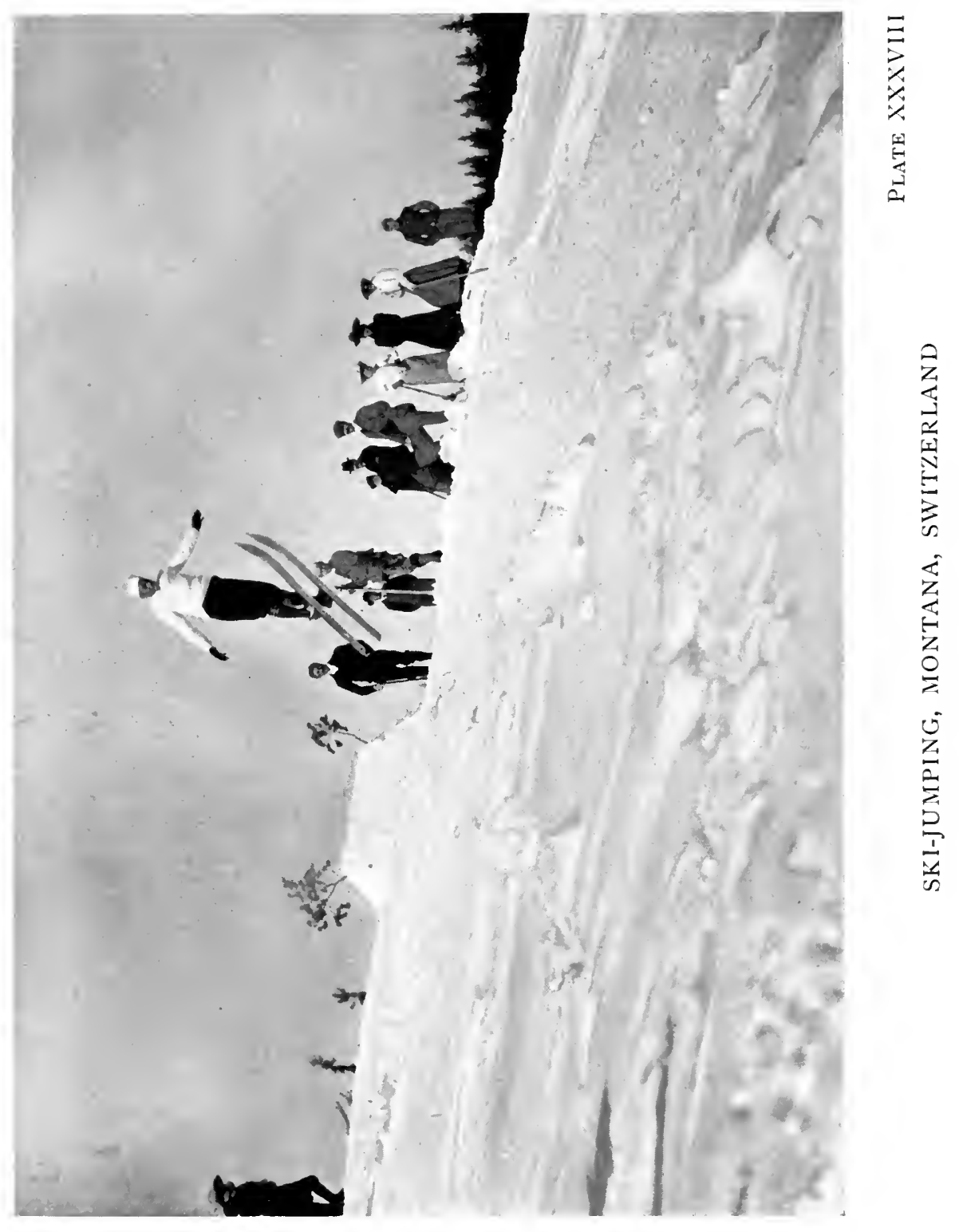


$>$ 


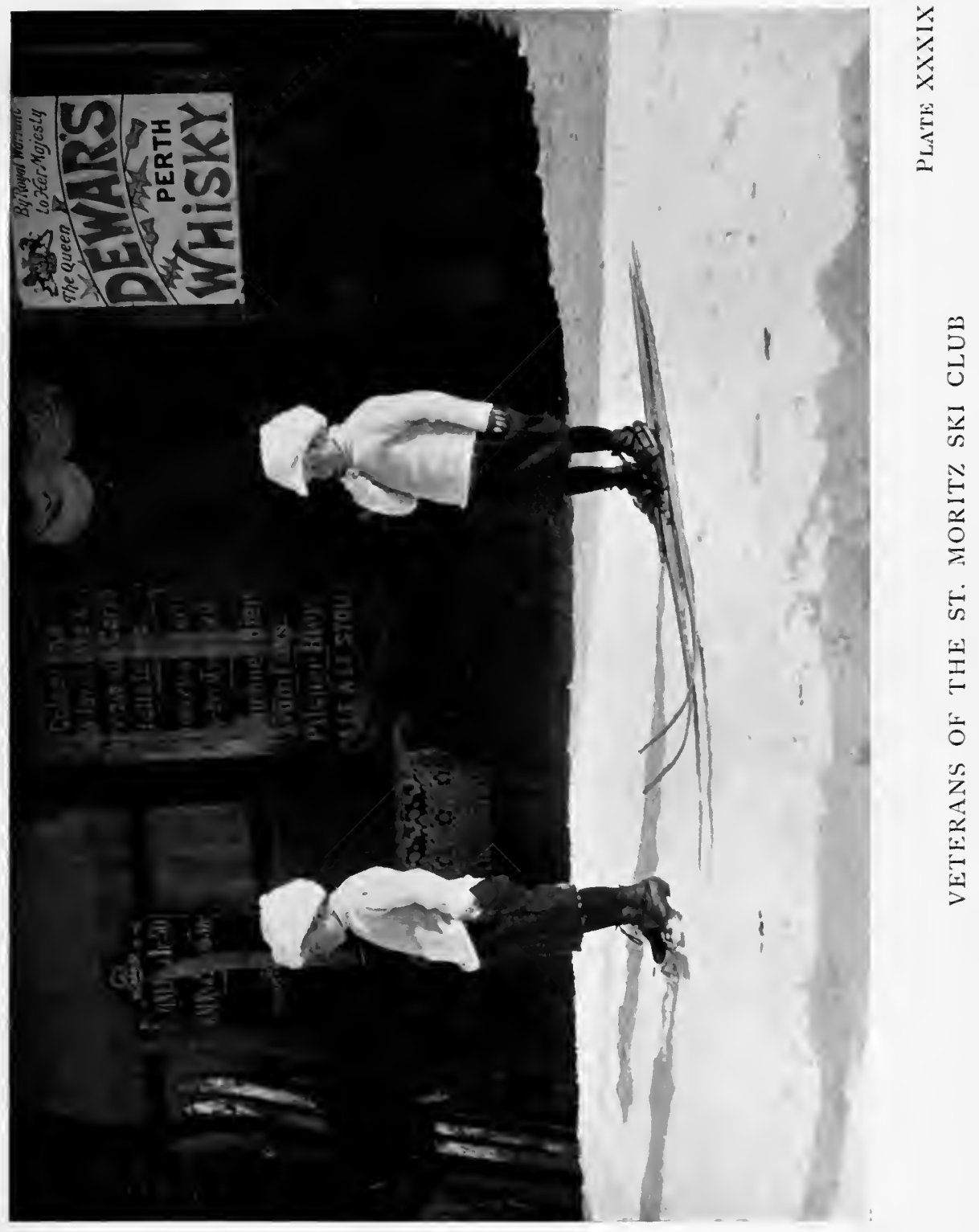





\section{CHAPTER VII}

NOTES ON WINTER RESORTS

Of late years the number of the English and other nations who annually go to spend a portion at any rate of the winter at some High Alpine resort has enormously increased, and in consequence every year fresh hotels are opened in valleys which hitherto have hybernated like dormice beneath their snow-laden roofs, during the months of short days. But it is by no means every highperched hotel that is suitable as a centre for winter sports, for there are several conditions to be considered. In the first place, such a spot must be sufficiently high up to make it probable that there will be fairly continuous frosts there throughout the winter, and this again depends not only on height but also on aspect. As regards height you cannot reasonably depend on getting this continuity of frost (allowing for reasonable breaks) under the height of round about 4000 feet, especially if the place in question is to enjoy long hours of sun. True, an exceptionally severe winter may come, and the strictness of the binding of the frost may hold, week after week, at a much lower altitude, but it is natural that the holiday-maker, who has only a week or two abroad and wants during all his hours of daylight to be employed in sliding movements, should wish to be fairly safe to find the conditions suitable, and he has, obviously, a better chance of finding them 
if he goes high. But there are'several places considerably below this 4000-foot level, such as Grindelwald, which lies in a very cold valley, where he may in an average year find himself unhampered and rendered idle by thaws, and it is wonderful how continuous frost is at Grindelwald. But there both skatingrink and curling-rink are, all day long at midwinter, entirely in the shade, for the sun does not rise high enough at noon to look over the great barrier of rock that lies to the south of it. That protection, of course, preserves for the place its excellent ice, whereas if, as at other winter resorts, it basked in the sun all day, the rink would speedily be metamorphosed into a degraded glue with discouraging pools interspersed. But if you go to greater heights, you can combine the pleasures of skating with those of sitting in the sun, and that to this writer is a remarkably charming combination. But in order to enjoy that you must have greater height than is possessed by Grindelwald, and a place like Montana, where the sun is on the rink by nine in the morning, and continues to beat down on it till somewhere about five in the afternoon, would see its ice and snow disappear into slush and torrents of water were it not perched nearly 5000 feet above sea-level. St. Moritz and Mürren are throned higher yet, and it has to be a very warm winter indeed which will cause a general thaw at such places. And there is nothing more irritating than to have gone to some comparatively low place and find that day after day goes by in melting mood, and at the same time to know that a thousand feet higher up ideal conditions are being experienced.

The skier naturally is less dependent on the altitude of his 
village, provided that there are high hills abounding in suitable slopes round him. It is part of the essence of his sport that he climbs for it, whereas skaters and curlers demand their playgrounds at the door and no climbing at all. Thus the high valley leading across from Montreux in the Rhone valley to Spiez by the Lake of Thun is, though its highest villages and hotels are below 4000 feet, ideal for the skier, since it has on each side of it lofty hills which are rich in good slopes. But for the others, skaters, curlers, and tobogganers alike, it is important that the frost should hold in the immediate vicinity of their hotels. They do not seek their various joys on the tops of neighbouring mountains.

Now this question of sun is, of course, a personal one, and the popularity of Grindelwald shows that there are multitudes of folk who do not mind skating and curling in the shade. For them, then, that is all right, but if you happen to like skating and curling in a blaze of sun, you will be wise to go somewhere not below the 400o-foot level. Even there, of course, you cannot be safe against thaws, and the deplorable series of days known as the winter of I9II-I9I2, when thaw succeeded thaw at almost all Swiss resorts, taught us all that the malice of climate is infinite and incalculable, and the summer of I9I2, here in England, where the general temperature was about the same as that of the previous winter in Switzerland, repeated the same lesson. But in the average year winter places over 4000 feet in height can be trusted to let the visitor enjoy sunshine and hard frost together.

A second consideration is wind. It would be no use at all to spend the winter on a mountain-top: what is necessary 
is a high sheltered valley, like that of Davos or St. Moritz, or a high sheltered shelf on the mountain-side, like Villars or Mürren. To be able to skate at all, it is necessary that the day should be practically windless, and quite a gentle breeze spoils it altogether. Moreover, even gentle breezes are currents of moving air above or below freezing-point. If they are above freezing-point they spell ruin, for they melt both snow and ice with amazing swiftness; if they are below freezing-point they feel quite intolerably cold. Therefore, all winter places should be screened from the wind on the north and east, so that, if such airs are astir, they pass over the valley in which you are, and their icy blasts are unfelt. It does not matter so much whether the valley is screened from southerly winds, for this blowing of a southerly wind means in itself that warm currents of air are coming up from the Mediterranean, and as long as that lasts there must be more or less of a thaw, and a screen to the south almost necessarily implies a cutting off of the sun. This southerly wind, so justly abhorred by all altitudinists, is generally known as the föhn wind. Philologists may try to interest us in it by telling us that the word is derived from the Latin favonius, or south wind, but when the föhn blows you are not the least consoled by knowing its derivation: you only wish it had another destination. It brings clouds, mists, sleet, and even rain, all undesirable aliens, into our sunny valleys.

So much, then, for the two main conditions-sun (for those who like it) and absence of wind for everybody. And the next prime essential is a good rink, for out of every hundred people who 


\section{NOTES ON WINTER RESORTS}

come out in the winter, it is safe to say that at least eighty either skate or curl. And not only is a good skating-rink necessary, but good skaters also, for the encouragement and instruction of the learner, and, we may add, the mutual admiration of each other. But it is extraordinary how a good rink seems to breed skaters: sooner or later (usually sooner) good skaters are attracted to it, like flies to honey, though we hope they do not stick in it, and other mere beginners rapidly develop into sound performers. The Davos rink developed skaters thus, and more recently the immense rink at Villars has brought to birth a whole fresh school of English skating. The writer is tempted to be anecdotal. Not more than six or seven years ago he first went there and found that the only skating-rink was one flooded lawn-tennis court. On it the most accomplished skater in the place was instructing and demonstrating to two pupils. She was showing them the change of edge, and as, perhaps a little falteringly, she passed from one edge to the other she proclaimed: "The change from the outside edge to the inside is possible, but the change from the inside to the outside is impossible." Indeed that would save an infinity of trouble to many of us, if we thought it was strictly true. But Villars made up its mind otherwise, and nowadays the great rink, which would hold hundreds of lawn-tennis courts, holds hundreds of skaters also who demonstrate the falsity of that sublime pronouncement.

Now ice varies enormously, not only in smoothness or roughness of surface, but in texture and in hardness, and without doubt the pleasantest and at the same time the easiest ice to skate on 
is that which has been frozen at temperatures not unreasonably low. Should the thermometer have stood all night at zero or below, the ice made under that benumbing influence will be both very hard and rather brittle; whereas if the rink had basked in a mellow moonlight of say Io or I5 degrees. of frost, the ice, though perfectly solid and dry, will be far kinder to the skate blade and lend itself more amenably to the edges. Indeed, after a very cold night, the ice is absolutely unskateable on until the sun has relaxed its adamantine rigidity; the edges of the skate will not bite. This appears to be due to the amazing fact, not generally known, that the skate actually moves over a thin layer of water, which its passage, its weight and friction causes to be momentarily produced. This transient, minute and local thaw (which instantaneously ceases in the wake of the skate) does not take place when the temperature is abnormally cold, and, in consequence, the skate, instead of travelling smoothly and firmly, cannot be prevented from skidding on the marble-like and uncuttable surface, and even when the sun has to some extent mitigated this hardness, the ice tends to be brittle and unkind. Thus, since in very high places there are recorded a large number of very low temperatures, the skater will probably find pleasanter ice at lower altitudes. Much, of course, depends on the making of it, and the whole question perhaps may be regarded as trifling, but in the writer's opinion the resorts at which, as a rule, very low temperatures do not occur, yield the greatest abundance of jolly ice. On the other hand, the higher the place, the greater is the probability of immunity from thaws. 
So much, then, for the more technical considerations. But however absorbed we may be in our inwicks, our Telemarks, our brackets, there are still moments when we happen to look up and regard and appreciate our surroundings. In fact, though we do not go out to Switzerland primarily for the sake of the view, the natural beauty of the places we go to make, even to the sternest and most determined athlete, a certain appeal. And though every place alike has the witchery and magic with which the radiant frost clothes peak and mountain-side, there are four places, three of which are set on high shelves on the mountain-side facing south, which, to my mind, altogether outshine the rest, and these are Mürren, Montana, Grindelwald and Villars. Of Mürren mention has already been made in the first chapter of this book, but those who have seen it only in summer have no idea of the incomparable majesty of the huge outspread panorama of the Oberland when the winter suns shine on the winter snows. Nowhere else in all Switzerland is there to be had so near and unimpeded a view of so great a stretch of big mountains. Eiger and Monch and Jungfrau and Silberhorn, and the amazing precipice of the Ebnefluh are all spread out immediately in front, with only the narrow valley of Lauterbrunnen interposed between you and them. Their size and nobility of form when thus seen close at hand is almost overwhelming : almost you join in the worship of the mountains and hills that so visibly are praising the Lord.

Utterly different, yet in its way no less sublime, is the immense panorama of big peaks as seen from Montana. Here again 


\section{I74 WINTER SPORTS}

(though perhaps, strictly speaking, you are in the Rhone valley) there is no impression of being in a valley at all, so lofty is the shelf on which Montana stands, so swiftly the ground plunges into the Rhone valley proper below. But this is no narrow cleft as at Mürren, and the hills that climb out of it on the further or southern side are miles away. But what a row of glistening giants is piled up on those hills. The kings and captains of all the Zermatt ranges soar skywards against the incredible blue, Weisshorn, Roth-horn, Dent Blanche, Gabelhorn, Matterhorn are standing in their immemorial stations, and in the west Mont Blanc, with its guard of arrow-headed aiguilles, looks down over France and Switzerland. Nowhere else, unless you climb the inhospitable peaks themselves, shall you enjoy so immense a range of vision that contains so many giants of the mountain world.

Utterly different again is the quality of the view at Grindelwald. Unlike these other eyries Grindelwald is tucked away at the head of a valley, and immediately above it rise the appalling presences of the mountains. High and menacing above it climb the sheer walls of the Eiger, not those sunny crags that face towards Mürren, but the black and sunless precipices of the north and east. Further away are spread the snows of the Wetterhorn, and the precipice to the north of it, over which the wicked avalanches pour and thunder; while over the ridge just to the south of the hotels the Finster-Aarhorn points its single pinnacle to the sky. But there, long after the sun has set to the valley, Wetterhorn burns in rosy flame, and the Finster-Aarhorn is incandescent above the black night-beleaguered slopes. But splendid as are 


\section{NOTES ON WINTER RESORTS}

these overhanging walls of rock, there is something to my mind of imminence and threat about them. They are crushing.

Villars, again, in the Rhone valley, is neither of the type of Mürren nor Grindelwald : it is of the Montana class, though with less austerity. It lies among pine woods and gentle slopes, and its high southern-facing shelf has a wonderful charm and amenity. Below it the hillside tumbles swiftly away into the Rhone valley, and opposite is spread an entrancing panorama. The Dent du Midi, one of the most distinguished of mountain-forms, dominates the nearer distance; behind, much closer than at Montana, rise the prodigious aiguilles of Mont Blanc. If you walk but for ten minutes either up or down from Villars towards the east, a gap opens out, and you shall see the most part of the Chamounix range, and the vast dome of Mont Blanc itself. Magical are the wonders of cloudland spread out before you in the Rhone valley below. Sometimes an ocean of cloud, solid as if made of grey marble, and to all appearance as level as the sea, is spread from the promontories a little below where Villars stands straight across to the hills on the far side of the valley. It seems as if some cloudboat would put out from behind a cape opposite and glide across this grey sea. Or again, the valley will be full of cloud in form of breaking waves, and tossing crests throw themselves against the hillsides and are shattered into wreaths of cloud-spray. No boat could live in so turbulent a water. Then, as the sun declines to its setting, rosy beams of fire pierce this wonderful sea, and it is shot with flame, and lit from within by a glow that baffles all language. On another day and for many days together not 


\section{I76 WINTER SPORTS}

a speck of mist or shred of cloud hangs above the valley, and it is mapped out at your feet 2000 feet down and half a dozen miles away with the clearness of etching. And sometimes, I am sorry to say, when the weather is behaving morosely, the cloud comes up from the valley and envelops Villars itself. Then we take our skis or toboggan and flee up the hillsides through the pine-woods, all encrusted with the miracle of hoar-frost, into the unobscured sunshine that lies like a benediction on the heights of the dazzling Chamossaire.

Switzerland, as regards its winter resorts, may be broadly divided into districts, such as the Engadine, the Oberland, the Rhone valley, and the strip of country between Montreux on the Lake of Geneva, and Spiez on the Lake of Thun, and pride of place must certainly be given to the Engadine and Davos, which are the cradle of winter sports. And the following are (at present) the chief hill-stations, with the sports for which they are famous.

(i) St. Moritz.-This is the highest and probably the most populous of winter resorts. It is situated 6090 feet above sealevel, and is eminent for its rinks and toboggan-runs; namely, the Cresta or ice-run, spoken of already at length, the bob-run, and the village-run for luges. Rinks both for skating and curling are numerous, and below the town lies the St. Moritz lake, and further off towards the Maloja pass the Sils lake. The bandyrink is one of the largest rinks in Switzerland; bandy is played here every day, and numerous skating contests are held. Owing to its height, the winter weather, as a rule, lasts here till well into 
March : indeed it is not till March that the big events happen on the Cresta.

Round about St. Moritz are other smaller winter resorts: Celerina, with a fine skating-rink, lies a little below the end of the Cresta run, and further down, towards Chur, is Samaden. In the other directions, towards the Maloja pass down into Italy, is Campfer, with rink and greater length of sun than even at St. Moritz, from which it is distant about a mile and a half. The ski-ing also is much better there than at that place. St. Moritz and all these other smaller centres are fortunate in the number of hours of sun that they enjoy: they are less fortunate in the wind that rather frequently blows up from the Maloja pass, a chilly and disconcerting current of air that not very infrequently starts to blow shortly after mid-day. But there is probably no place in Switzerland which enjoys a larger proportion of perfect winter days, and in none are the rinks more carefully made and preserved. It was one of the earliest places in which the pursuit of winter sport began to develop, and from the earliest days the St. Moritz school of English skating was renowned for the strictness of its requirements. Of late years the International style has greatly developed there, owing probably to the very large number of German visitors who annually go there. But there is enough ice for everybody, since many of the hotels have private skating-rinks of their own, and there is no reason why the two schools should not flourish side by side. Just round about St. Moritz itself there is not any very extraordinary display of Alpine scenery, for the larger peaks are not visible therefrom. But there 
are, in addition to the winter sports already mentioned, innumerable excursions to be made, and the lake-skating, when the chronology of snow-fall and frost is propitious, is a tremendous though usually a short-lived attraction. The journey from England can be luxuriously made in the Engadine express, which reaches St. Moritz in the middle of the day after which the voyager has left London.

(ii) Davos, in an adjoining valley, is now closely linked up to St. Moritz by train, so that it is accessible from it without a long detour by rail, or by crossing on sleighs the Fluela pass. It is rather over 5 Ioo feet above sea-level, and, as already recorded, was probably the earliest place at which an attempt was made, by Mr. John Addington Symonds and a few friends, to construct an artificial ice-rink. This they did by industriously working the handle of a pump which stood in a meadow. Davos was originally known to the world as a resort for consumptives and the place where the open-air treatment was first scientifically adopted. There are to-day many sanatoriums for patients there, and readers of this essay may have heard of a false and wicked report that in consequence the whole native population is now riddled with consumption, and that there is a certain risk in staying there. No more absurdly malicious and unfounded statement could be made, and there is probably far more risk of catching consumption by walking down a London street than in staying at Davos. For since the dry cold of this wonderful valley is fatal to the bacillus, it is hard to see how it could be supposed to spread! In addition, to ensure a double security, the most 


\section{NOTES ON WINTER RESORTS}

stringent regulations are enforced and every requirement of hygiene insisted on. Visitors, therefore, can go to Davos with precisely the same security as to any other place.

Davos is excellent alike for its rinks, its ski-ing slopes, and its toboggan-runs. Of the latter there is the excellent Klosters road for luges and skeletons, which leads from the hills above Davos down to the village of Klosters, where tobogganists find a train neatly drawn up close to the end of their run, in which they can return to Davos, if they will, or to Wolfgang again to make another descent. For this is no affair of a few hundred yards: the course is several miles in length. Lately a first-rate bob-run has been constructed from the Schatz-alp down into Davos: this is served by an electric railway for the ascent. Just below Davos, on the level land at the basin of the valley, lie the skating-rinks, three in number, an enormous public rink, the rink constructed by the English for purposes of English skating, and the curlingrink. Here all manner of important competitions are held: European championships in the International style, speed skating competitions round the circumference of the large rink, and for English skaters the annual Davos bowl. Indeed, Davos has had more to do with the formation of the modern school of English skating, especially in the matter of combined figures, executed large and fast, than any other place, and there is scarcely a single skater of any eminence in this style who has not "studied," so to speak, at Davos. Usually the ice is of very good quality, but a better surface would probably be more often attained if the management would resort to sprinkling more, instead of letting a 
flood make ice for several days' use. Above the town is a lake of considerable extent, on which occasional skating can be had. But a commoner phenomenon than the skater on that lake are the horse-drawn sledges which are loaded with solid blocks of ice sawn out of the frozen surface and taken away to make puddings with instead of figures on. The valley is gloriously free from wind, and extraordinarily healthy with its very dry cold air and abundance of sun.

(iii) Between Chur and St. Moritz lies a high upland valley some 4800 feet above sea-level, and reached from Chur by a drive of some twelve miles, which, however, include 3000 feet of ascent. Here is situated Lenzenheide, one of the new winter resorts opened by the Public Schools Winter Sports Club, which is responsible for so much of the increased sporting population of Switzerland in winter, and has developed many fresh and suitable centres. There is a good skating-rink, curling-rink, a toboggan-run, and unlimited expeditions for skiers on country admirably adapted for the sport. Like Davos, it lies in a very sheltered valley, and is singularly free from wind. It is a four and a half hours' sleighdrive to Chur, while St. Moritz is two hours distant.

\section{Oberland District}

(i) First among the Oberland resorts, by virtue of its age and established attractions, must be mentioned Grindelwald. It is one of the lower winter centres, but, as has already been mentioned, the limitation is largely discounted from the point of view of skaters and curlers, because the rinks during 


\section{NOTES ON WINTER RESORTS I 8 I}

the months of mid-winter lie practically entirely in the shade, and thus preserve their solidity. And if Davos and St. Moritz must be called the cradle of English skating, Grindelwald has no less earned the title of cradle of scientific ice-making. For years the Boss family, who own the Bear Hotel, have studied this intricate and delicate question, and their methods are beyond doubt productive of the best possible ice. Grindelwald, it is true, is not liable to exceedingly low temperatures, and thus the ice does not often become of that very hard and brittle quality which results therefrom; but, though the Bosses have not had to contrive how to deal with these unpleasant conditions, they must be considered the parents of the school of scientific ice-production. Originally Grindelwald was exclusively of the English school of skating, but it has now passed into International tutelage. Indeed there was hardly room for two schools ; for excellent as is the quality of the ice, it is certainly defective in area, and the rinks should be increased in size or number, for even the Bear rink, which is the largest there, is but of very moderate extent, and cannot hold many skaters in comfort. There are curling-rinks of the same superlative quality of ice, good road toboggan-runs, both for luges and the bob-sleigh, while in every direction almost (except that of the Eiger precipice) there are admirable ski-ing runs. It is situated $345^{\circ}$ feet above sea-level, and is reached by a light railway from Interlaken.

(ii) But if instead of taking that portion of the train from Interlaken that branches off to the left up to Grindelwald, the voyager disposes himself otherwise, he will be carried straight up 
the Lauterbrunnen valley, until he arrives at that village. On the right the incredible funicular ascends to Mürren, while a cog-line, lying in loops and curves up the hillside to the left, brings him to Wengen, which, like Mürren, has lately been opened up as a winter resort by the Public Schools Alpine Sports Club. It faces the Eiger, the Monch, and the northern and precipitous face of the Jungfrau, and is admirably sheltered from the north and east. It stands about 4500 feet above sea-level, basks for a long day in the sun, and is excellently equipped in the way of rinks for skating and curling. There are two rinks, one about 8000 square metres in extent, the other half that size. Here, as at Grindelwald, the International style "hath the pre-eminence." The cog-railway by which the village of Wengen is reached continues up the Wengern Alp, where are excellent ski-ing slopes, and you can take a lift, instead of climbing, up towards the Scheidegg, from which the skier can descend to Grindelwald. Wengen was opened originally for the winter season in the years I909-I9ro, and has already grown enormously in popularity.

(iii) Opposite Wengen (or rather a little further south) and on the other side of the Lauterbrunnen valley, stands Mürren, at an altitude of 5500 feet, rooo feet higher than Wengen. It has only been opened lately as a Swiss winter resort, and is blest with many natural and artificial excellences. A curling-rink adjoins the large skating-rink, and the ice, made in the "Boss method," is wonderfully good. Here the Continental and English skaters may be seen side by side, and the two schools flourish, as is reasonable, without the smallest friction. For the skier 
there are any amount of expeditions, and the very large extent and variety of the northern slopes above Mürren, combined with its height, render it safe even in bad winters from continued thaws: it owns also (for the more daring) one of the best jumps in Switzerland. This year (I9I2) the railway has been continued to the top of the Allmendhubel, from where a bobsleigh run will start, and will give skiers a lift to the upper snows. The inter-university ice-hockey match has for the last three years been played here. Apart from its excellent facilities for sport, it is a place of unrivalled natural beauty . . . but perhaps you have heard enough about the view. It is excellently shielded from the northerly winds, and its height, as in the case of Davos and St. Moritz, gives it a reasonable chance of immunity from thaw.

(iv) On the other and northern side of the Lake of Thun, and looking across the lake and the Interlaken valley straight at the Monch and Jungfrau ( $\mathrm{I}$ am sorry to introduce this lady and gentleman again, but they cannot help dominating Oberland resorts) stands Beatenberg. It lies below the 4000-foot level, being only 3750 feet above sea-level, and in a warm winter (like that of IgII-IgI2) has the penalties of its day-long sun rigorously exacted from it. For the skier there are admirable runs above it on the Amisbühl, and there are good skating and curling rinks, and an artificial toboggan-run. But Beatenberg is distinctly a place to be visited in severe weather, in which the conditions there are ideal. But from its comparatively low altitude and its enormous abundance of sun, it must necessarily be among the places that soonest feel a thaw. It is an exceedingly picturesque village, 
and the lake below and the Oberland beyond make a charming panorama. It is within an easy sleigh-drive from Interlaken.

Slightly away from the Oberland lie two other attractive resorts-Kandersteg and Adelboden. Of these Adelboden is reached by a short train transit from Spiez on the Lake of Thun, followed by a sleigh-drive. It is essentially one of the high valley places, as opposed to the high "shelf" villages like Mürren and Wengen, and has admirable ski-ing expeditions to be made from it. The skating to be obtained there is not of the best; it has not "caught on" as a skating centre, and the rinks, when last the writer was there, were not up to the mark of that which the skater who goes to Switzerland for the sake of skating is entitled to expect. Skaters, for some reason, have not been enticed there, and thus that inter-breeding of good skaters and good rinks seems not to have taken place. But it lies in a high valley, the altitude being about 4500 feet, and both tobogganing and bobbing are catered for. Undoubtedly it is charming in situation, as all these upland valleys are, but, apart from the ski-ing expeditions which can be made from it, it does not boast any special attraction.

Kandersteg is approaiched also from Spiez, and lies high on a valley base leading to the Gemmi pass. It is lower than Adelboden, being only 3800 feet above sea-level, but is capable of extreme frigidities, since it lies in a northward sloping valley. But though it has been opened to winter sports only six or seven years, it is already a sort of Mecca for curling, and for the curler it is already a classical name. For the last eight years there has been instituted an International Bonspiel for curling, in which Scottish, 


\section{NOTES ON WINTER RESORTS I 85}

English, Canadian, and Swiss teams have taken part, and out of these eight annual events the contest has been held four times at Kandersteg. Indeed the curler who has not been there, excellent though his prowess may be, has got his Swiss St. Andrews to go to, and there is probably no place that has had so many different nationalities so often intent on winning a cup as Kandersteg. On the first occasion of the institution of this bonspiel, twentyeight rinks were competing, and all curlers who have been there will acknowledge "the atmosphere" that surrounds it. At the approach of the bonspiel a holy hush dominates the valley. Curling is in the air, and the great event obscures all other interests. A skater of the highest eminence might make his appearance, a skier who could negotiate the most incredible jumps, a tobogganer who could ride the Cresta backwards might be announced, but all these masters of their craft would be looked on as amiable aliens if the bonspiel was at all imminent. At such a time there is no talk but of curling. The immediate ski-ing is not very good, but there are excellent long excursions.

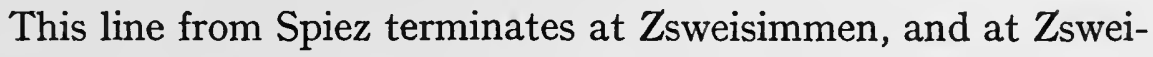
simmen begins a light mountain railway which traverses the upland valley southwards, and debouches at Montreux on the Lake of Geneva. This valley itself is of an average height of between 3000 and 4000 feet, but on either side of it are lines of hills of considerably greater altitudes, which abound in admirable ski-ing slopes. Zsweisimmen, Saanan, and Gstaad are all first-rate centres of the sport, and there is skating and tobogganing, including bob-sleighing, to be had. But the clou of all these 
places is the ski-ing, which is excellent both in quantity and quality.

Further on towards Montreux stands Château d'Oex, an exceedingly charming little place with a good skating-rink. It is not more than 3200 feet above sea-level, and thus the visitor cannot expect the greater security in the matter of frost that the higher places afford, but the ice there is often excellent, and in an average cold winter his enjoyment of it should be uninterrupted. After that the line passes through Les Avants, which is about the same height as Château d'Oex. Here there is a rink, and facilities for tobogganing and bobbing. Finally, at the level of about 3600 feet, Caux, with its palace of a hotel, overlooks the lake itself, much in the manner that Beatenberg overlooks the Lake of Thun.

We are now on the Lake of Geneva, at the upper end of which begins the Rhone valley, which extends right away up to the Simplon pass and the tunnel into Italy. Here are situated three winter resorts, opened and controlled by the Public Schools Winter Sports Club, and a hill-station called Leysin, which, however, in the main, is a place of out-door cure and sun for invalids. These other winter-sport centres are Montana, Villars, and Morgins.

Of these Morgins lies on the south side of the Rhone, at a height of 4600 feet, and is in a well-sheltered basin. A light railway goes up from Aigle to a small village called Trois Torrents, from which Morgins is reached by a sleigh-drive. It is surrounded by excellent ski-ing slopes, and there are good expeditions to be made. This year (I9r2-rgr3) it has also started into ardent activity as a 


\section{NOTES ON WINTER RESORTS}

nucleus of skating in the English style, and has a very fine rink of about ro,000 square metres. Lying as it does on northern slopes (since it is on the south side of the valley), it is far colder than places of corresponding height facing south, and thus in the matter of the permanence of its ice and snow. At mid-winter the hours of sun are rather short, about four.

Opposite, on the north side of the Rhone, stands Villars, on a shelf of the mountain-side rather than in a valley. It is reached by a mountain-railway from Bex on the main line, and has an altitude of $\mathbf{4 2 0 0}$ feet. Climatically it is absolutely ideal in a decently cold winter, and the big hills which shield it to the north and east afford several very good ski-ing expeditions. It has not, however, from a skier's point of view, the limitless scope of Davos, and it is in the main as a centre of English skating that it has become so popular and widely known. The rink is in extent second only to the public rink at Davos, being about I7,000 metres in extent, and is maintained on the principles of ice-making which have come from Grindelwald. But at Villars the whole expanse of the rink lies in the blaze of the sun, and, as at Davos, there is a restaurant immediately adjoining. Of this big ice-surface a certain part, of adequate size for practice and combined figures, is reserved for those who have passed the National Skating Association's Third Test, or the lower of the two Villars tests. This, then, forms a club-rink for English skating, which is the only school that at present exists at Villars. There, rink and skating alike have quickly grown big from the small beginnings of some seven years ago, and annually a large number of good skaters spend a month 
there. Elsewhere on the rink is a strip reserved for curlers, who have also another small private rink. For tobogganers there is provided both an artificial snow-run for the use of luges, and for skeletons a very good ice-run, not, indeed, of the arduousness of the Cresta, but fast and well banked. In addition bob-sleighing can be had on the mountain-track up to La Bretaye, and there are the usual suitable slopes for luges. The place has now been open some eight years, and yearly the four big hotels are crowded with visitors. Nor is this to be wondered at, for, apart from the excellence of its provisions for all manner of winter sports, Villars, set in its pine-woods and faced by the splendid open view across the valley, is possessed of an extraordinary charm of situation and natural beauty.

On a similar northern shelf of mountain, but higher up the Rhone valley, and also higher up in the air, stands Montana. It is reached by an amazing funicular from Sierre, and is 4900 feet above sea-level. Behind and above it and around it stretch limitless ski-ing slopes, and there are any amount of expeditions to be made from it. There are two good rinks: one for curlers, another for skaters; and after a considerable period of Laodicean apathy, Montana seems to have made up its mind to be of the English school. But up till lately it had put its chief energies into ski-ing and curling, and had not pursued skating in that tense and scientific spirit which it deserves. There is a fairly good artificial ice-run for toboggans, and another snow-run down valleywards, and plenty of those quiet, hard-trodden paths down which the amateur tobogganer likes to ramble. There are two 


\section{NOTES ON WINTER RESORTS I 89}

lakes which, when the snow has made an agreeable arrangement with the frost, can be used for skating, and in summer, when the sun has come to an understanding with the snow, a fine golfcourse is found to reveal itself. But all winter long the sun blazes on Montana, while its altitude and the cold of its nights preserves its frozen mantle. Of the view $I$ have already spoken : there is something to be said for a view in the intervals of falling-down, and in the meditation and quiescence which such falls sometimes entail. 



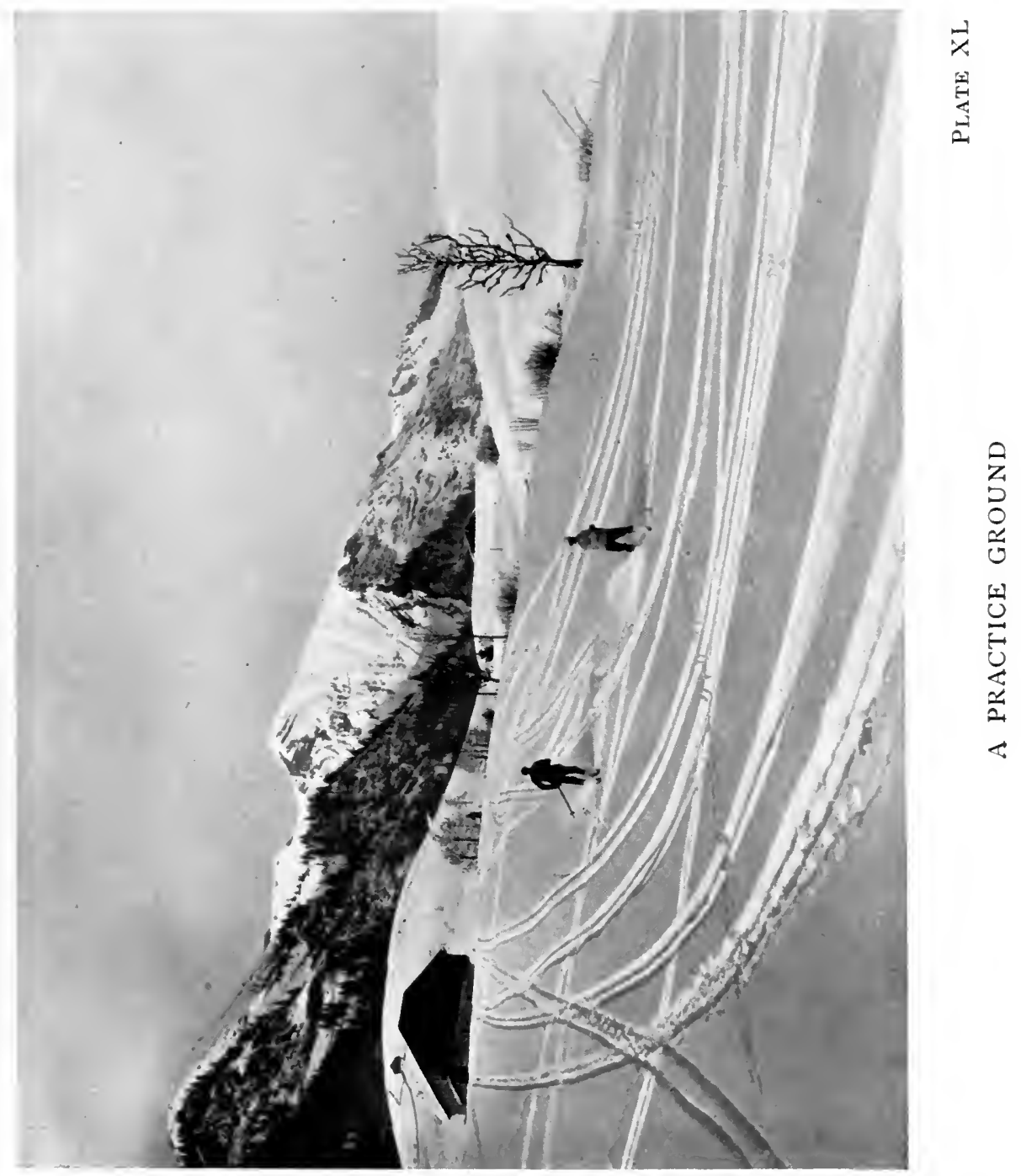




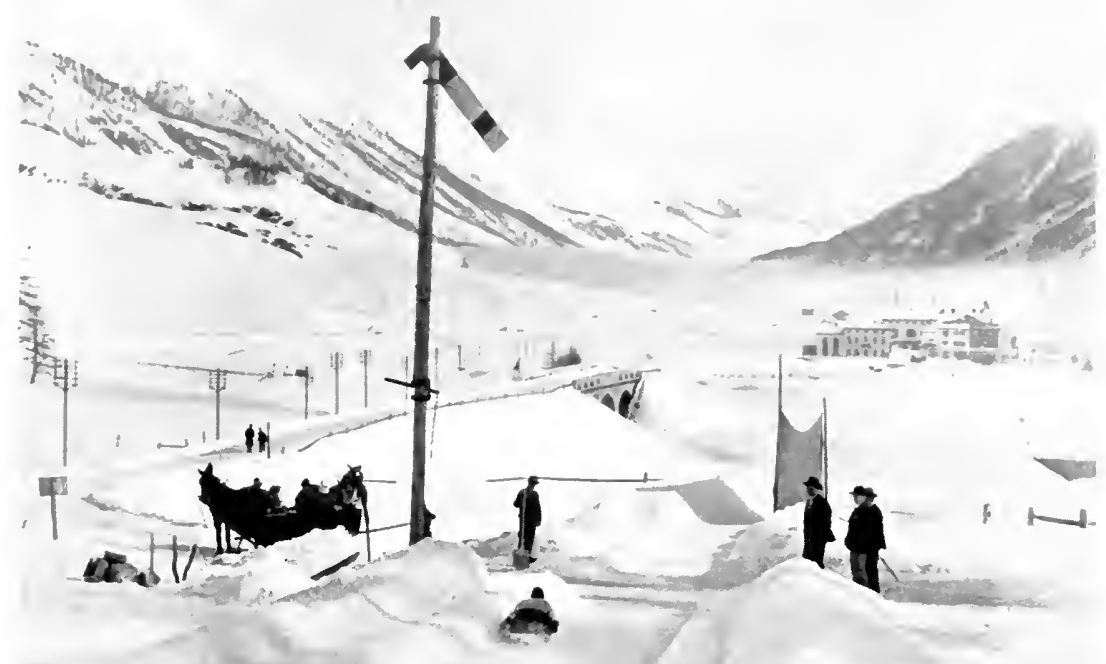

CROSSING THE ROAD ON THE CRESTA 


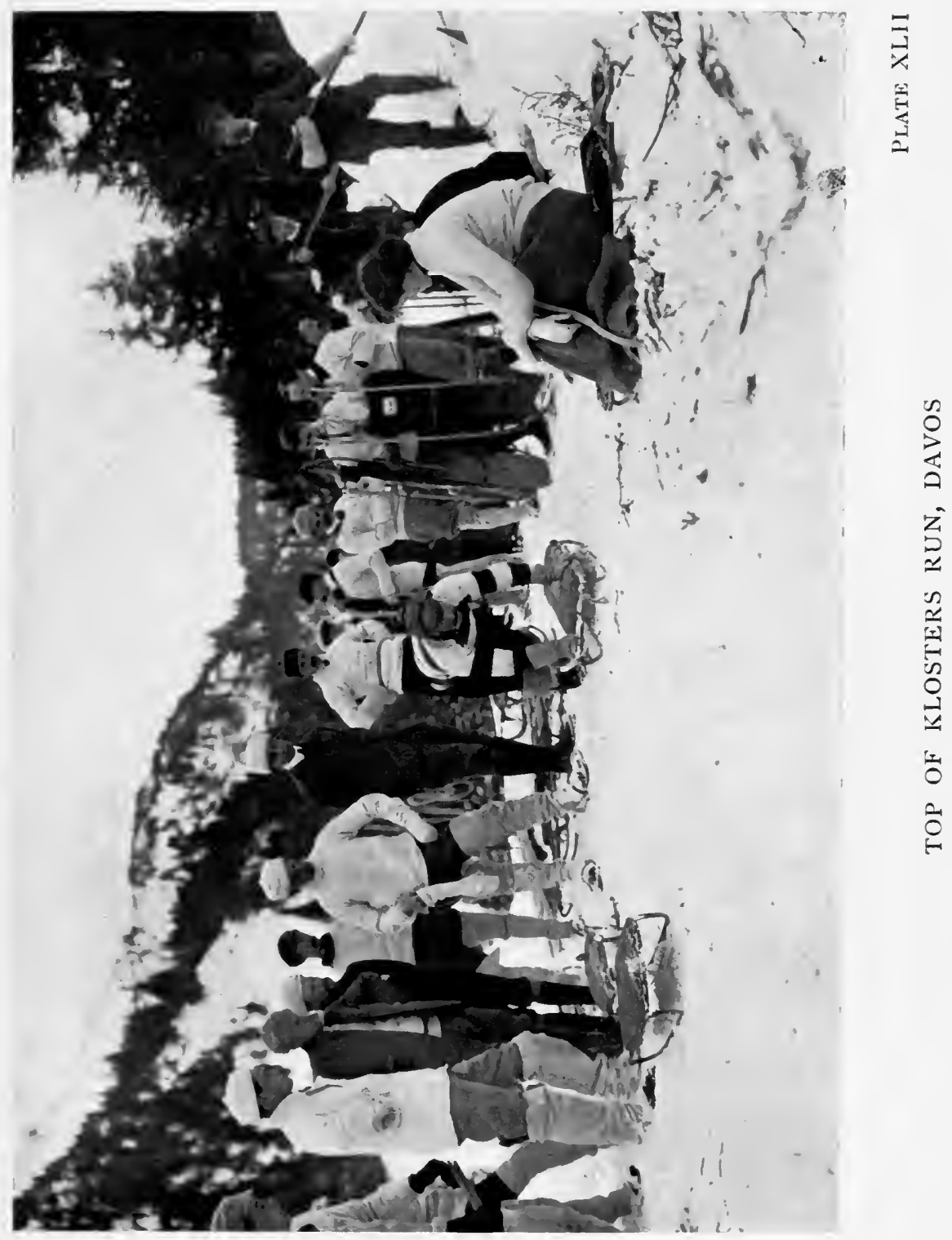




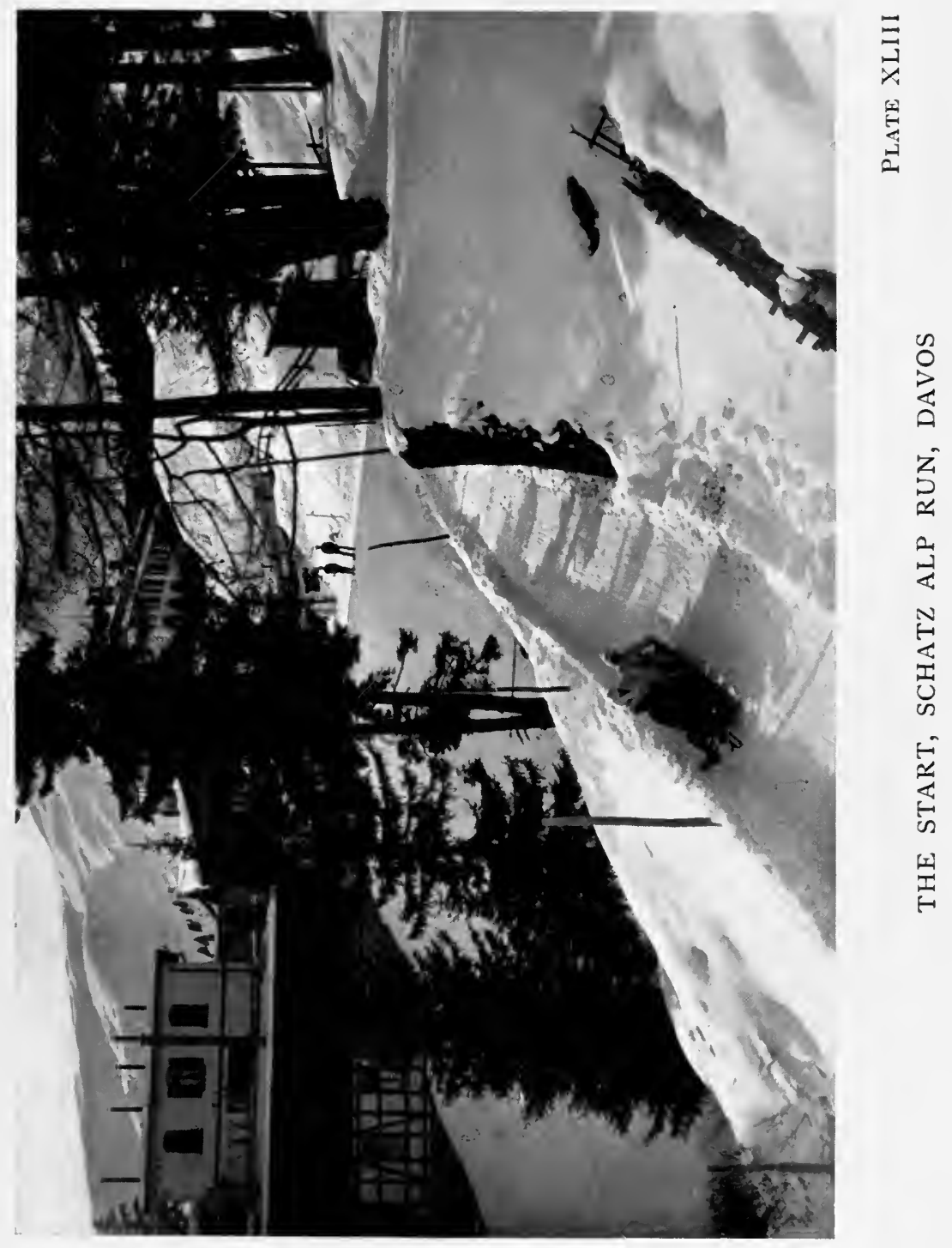





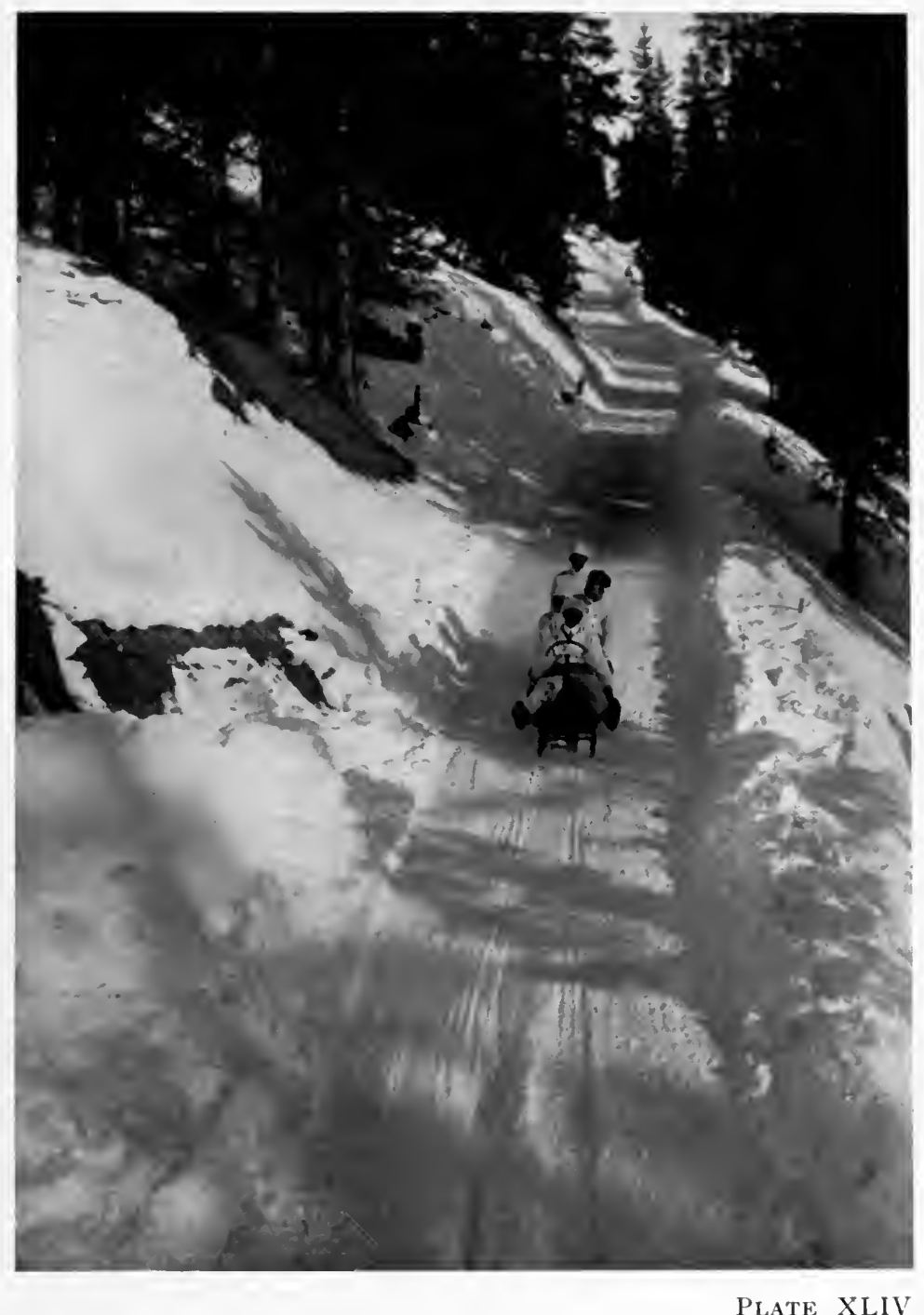

BOBBING ON THE SCHATZ ALP RUN, DAVOS 



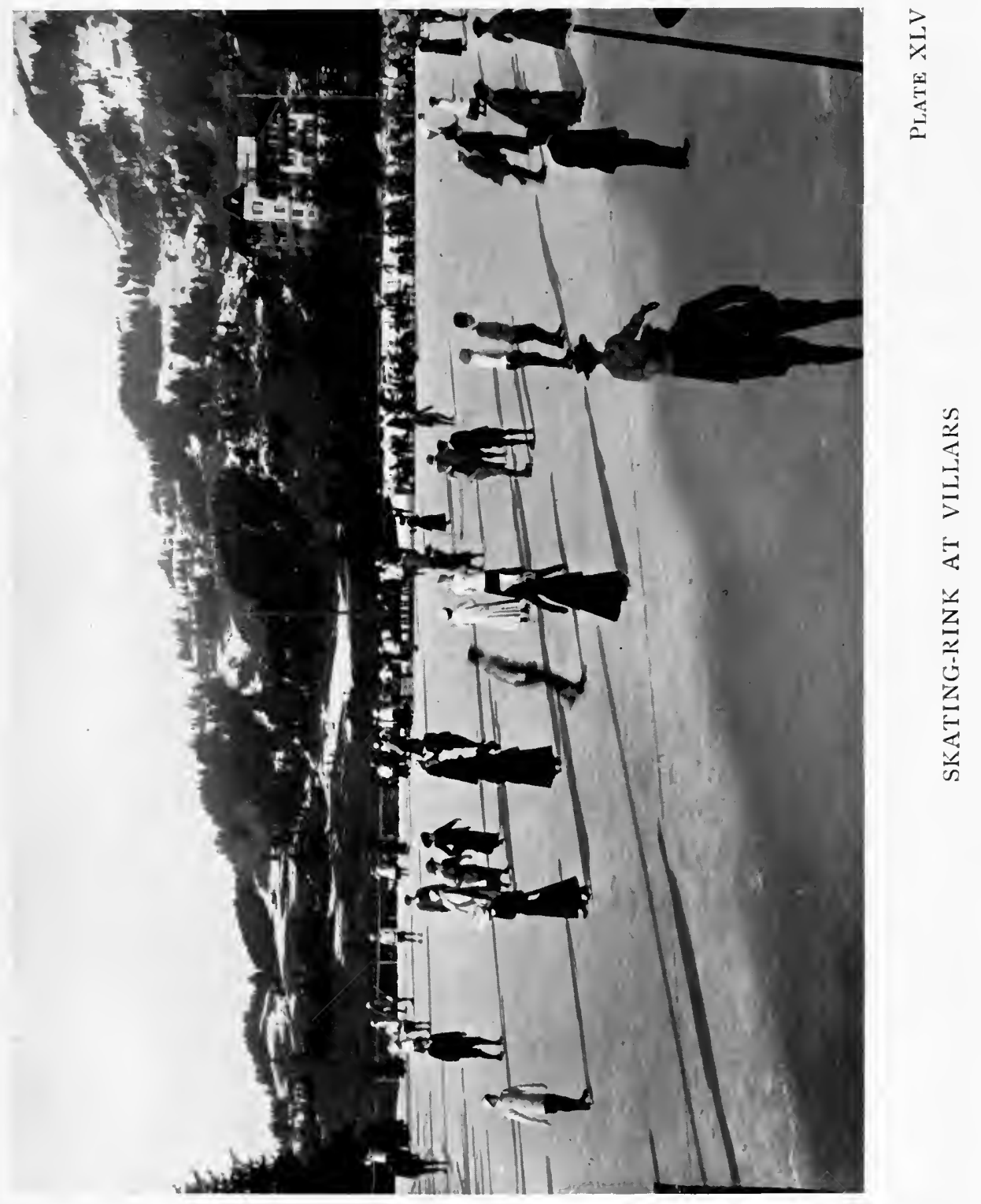




\section{.}




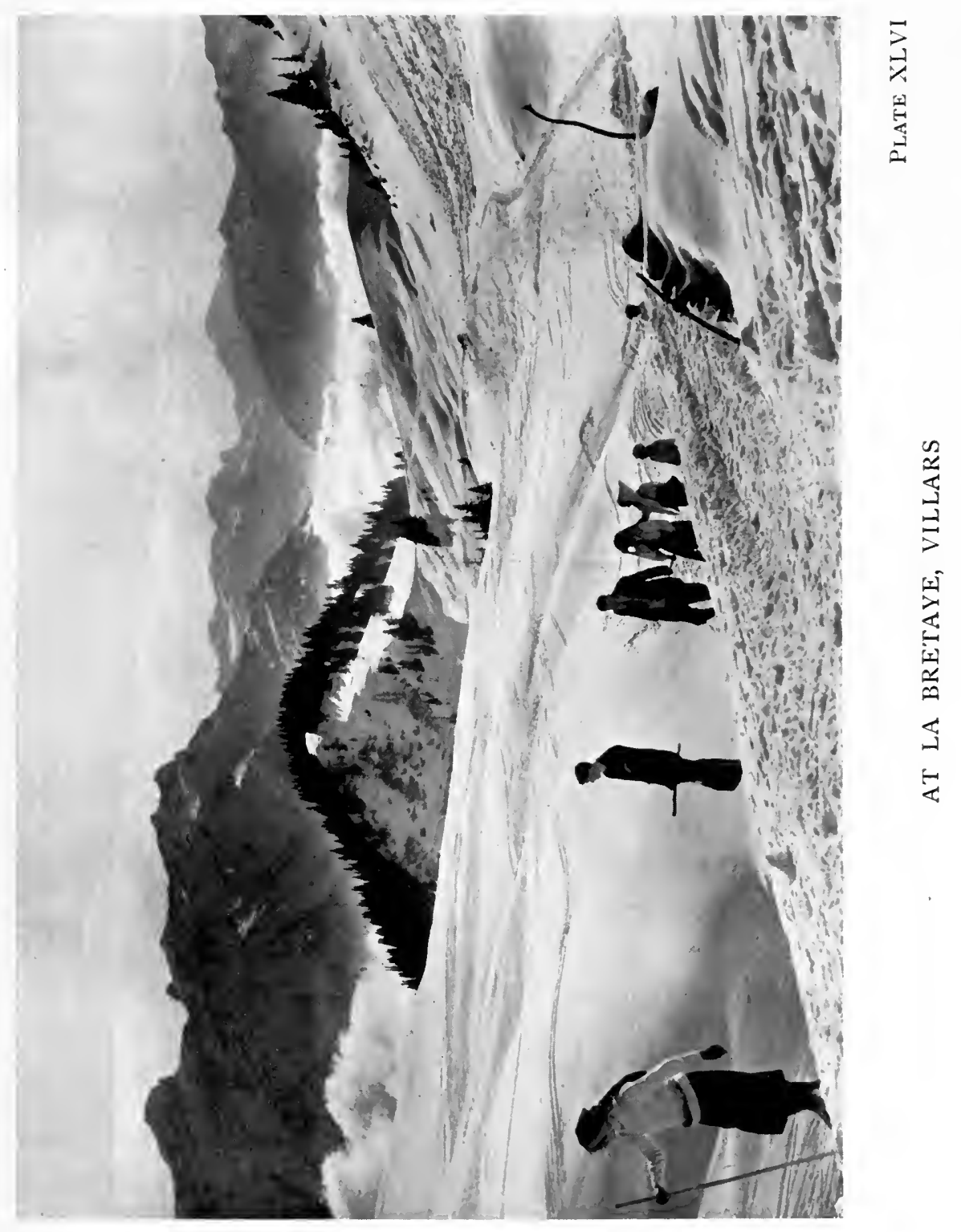




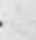




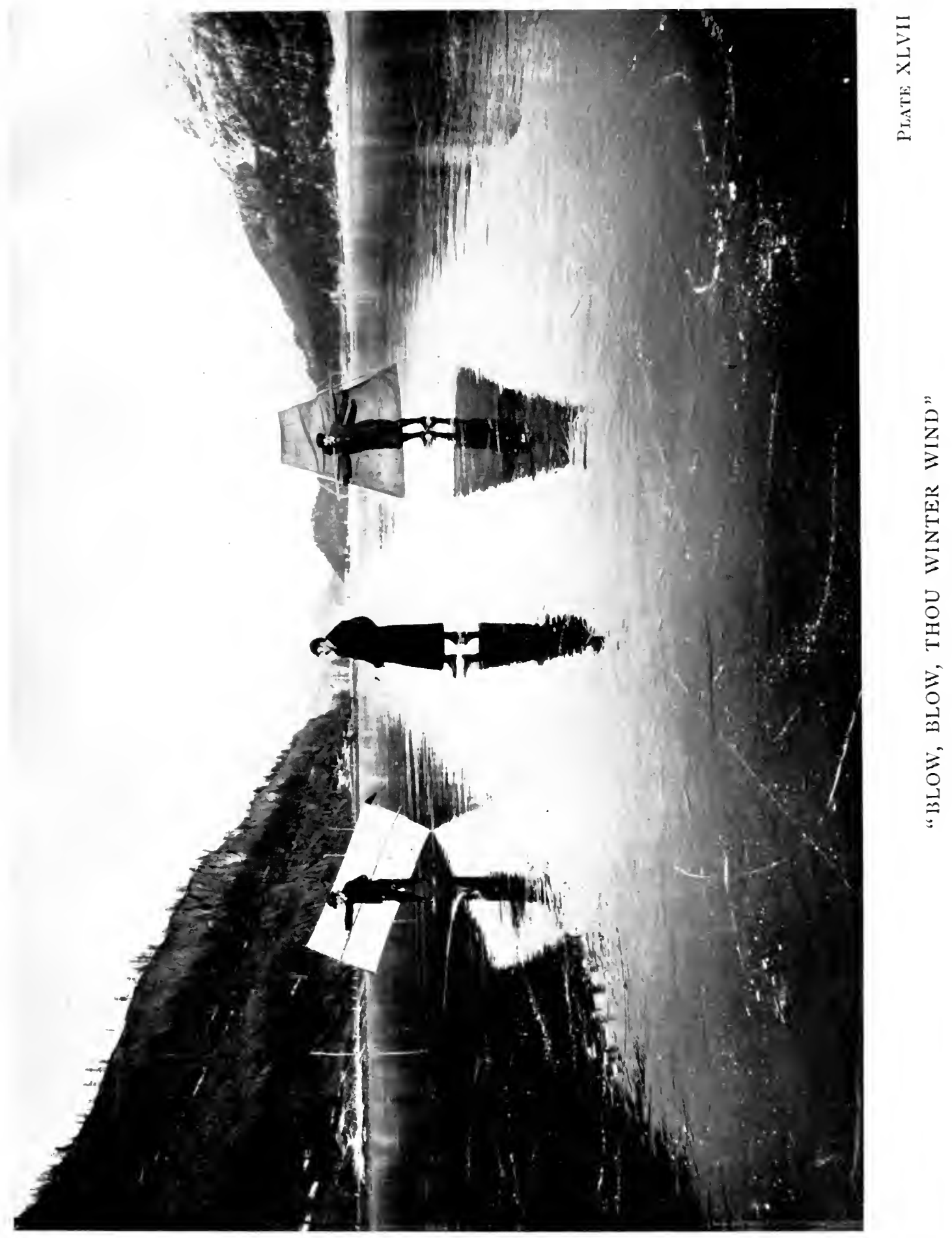




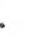




\section{CHAPTER VHI \\ FOR PARENTS AND GUARDIANS}

I HAVE attempted in the foregoing pages to give some general account of the out-door sports which are, as a rule, indulged in by altitudinists in winter. But any picture of this enchanting Swiss life, however slight, would be imperfect without some allusion to other entertainments which take place between sunset and sunrise. As a matter of fact, there are a good many such, and at most Swiss resorts there is in one hotel or another a dance, or a fancy-dress ball, or a concert, or very often more than one of these, practically nightly.

Now this piece of information, which I have thus baldly set down (for I do not believe in the gradual breaking of bad news), will, I am aware, strike a species of terror into many middle-aged and austere breasts. There are large quantities of folk who would sooner die than dance, and who would feel themselves affronted if, at the end of an active day out of doors, they were expected to sit in rows and be sung to or amused, or even worse, were expected to sing or amuse. At the most, they think they would desire merely to sit quietly and read or converse, or perhaps occupy a morose corner in a card-room, and the thought of being kept awake after they have retired to their early beds by the sound 
of bands or dancers would rouse them to a state of frenzied rage. As for dancing themselves

Now, I hasten to add words of consolation for all sedate folk. There is not the slightest need for them to be apprehensive, for they will find their quiet corners and card-rooms provided for them, unraided by the frivolous, and nobody wants them to dance and sing unless they feel inclined to. They have an erroneous notion, from hearing enthusiastic young friends on their return from Switzerland say that they had a dance every night, often fancy-dress, except when there was an ice-carnival or a concert, that they are expected to appear as Pierrots or Columbines, or otherwise cover themselves with shame and glory by public performances of some such kind, or, after dinner, sally forth again with a false nose and tights and proceed to dash about the skatingrink among squibs and fireworks. But there is no kind of reason why they should harbour any such fears; they can be as quiet and sedentary as they like.

But the probability is that they will not, when they have become altitudinists, feel quite so sedentary as they do in, let us say, Cromwell Road, after the day's work in town. Without doubt there is something slightly intoxicating to the mind, some sort of juvenile effervescence in the air and the sun of these high places, which seems to affect the steadiest head, and it is not uncommon to see sober persons of middle-age capering about in a manner altogether surprising. They get a sudden access of youth and high spirits, and make themselves ridiculous (this would be their judgment on themselves while still in Cromwell Road) 


\section{FOR PARENTS AND GUARDIANS I93}

with immense enjoyment and élan. Probably in Cromwell Road they would never dream, for instance, if there was a fall of snow, of making a snow-man in the back-garden, even if the snow was not covered with smuts, but out here if by chance a heavy fall renders rink and toboggan-run impracticable for the moment, they are perfectly likely (they will not believe me, but it is quite true) to build up a sumptuous piece of statuary. Similarly, unaccustomed as they are to go out of doors on a winter's night after dinner, except to be taken in a taxi to the theatre, it is quite probable that they will don coats and gouties and see what is going on at this absurd ice-carnival, which they have been told is to take place on the rink. And really it is almost worth seeing, even if you take no part in it.

A circle of light from hundreds of electric lamps, or a less potent but more variously-coloured illumination from lines of Chinese lanterns, surrounds the rink, so that in that blaze of light the great frosty-burning stars are invisible in the vault overhead, and even the full moon seems no more luminous than a circle of pale yellow paper. These are reflected, wherever there is room for reflection, on the ice they enclose, but there is not very much room for anything, as the whole surface of the rink is covered with brilliant, gaily-dressed figures gliding about in some interval of the dancing. Each carries a Chinese lantern on a stick, and the whole place is an intricate pattern of interweaving lights and colours. Then the band rings out again ("ringing" is the only word that the least describes the sound of violins and horns in this resonant frosty air), and instantly this sheet of weaving light and figures 
begins to be permeated by rhythm. Couple by couple are swept into this rhythm, circling, oscillating with long gliding steps, their lanterns making a series of luminous loops as they swing to the measure of the dance. What was but a company of mysterious, huge fire-flies, all darting about on separate businesses, is turned into a rhythmical and living pattern of flame, controlled by the lilt and measure of the band. Eye and ear alike are dazzled by this musical and moving and illuminated rhythm. Faster grows the tune as it approaches its end, faster is formed this living and luminous pattern. Then it stops, and the pattern dissolves itself again into streaks of darting lights; the dance of the uncontrolled fire-flies again. And it is far from unlikely that the middle-aged and sedate will hurry back to the hotel to get some skates and a lantern, and some sort of preposterous headgear.

Or, while still the fireworks and Bengal lights are unlit, you can walk to the end of the rink, and, turning your back on its brightness, look out over the lower valley below and the hills beyond. Away from the glare of the festooned lights, your eye gets accustomed to the gloom, and presently it ceases to be gloom at all. Ivory white shine the untrodden snows beneath the full moon and the glory of innumerable stars: far below, perhaps, a level sea of cloud extends like a marble floor over the valley, and across it the aiguilles of Mont Blanc, and nearer the summits of the Dent du Midi stand sparkling like crystals. Then from behind you sounds the swish of an aspiring rocket, and across the firmament streams a line of light. Slower and slower it mounts, then from the end of it bursts a huge constellation of coloured 


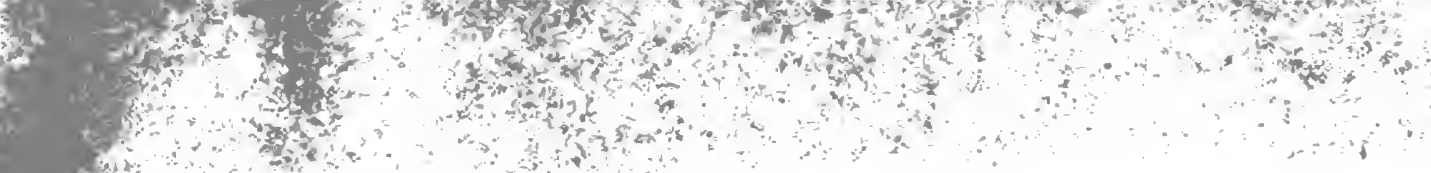

\section{JAVIVAAO IOI IHT}


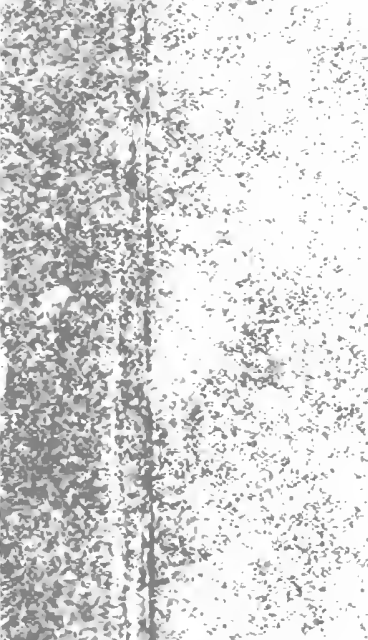
THE ICE CARNIVAL

From the Drawing by Fleming Williams 


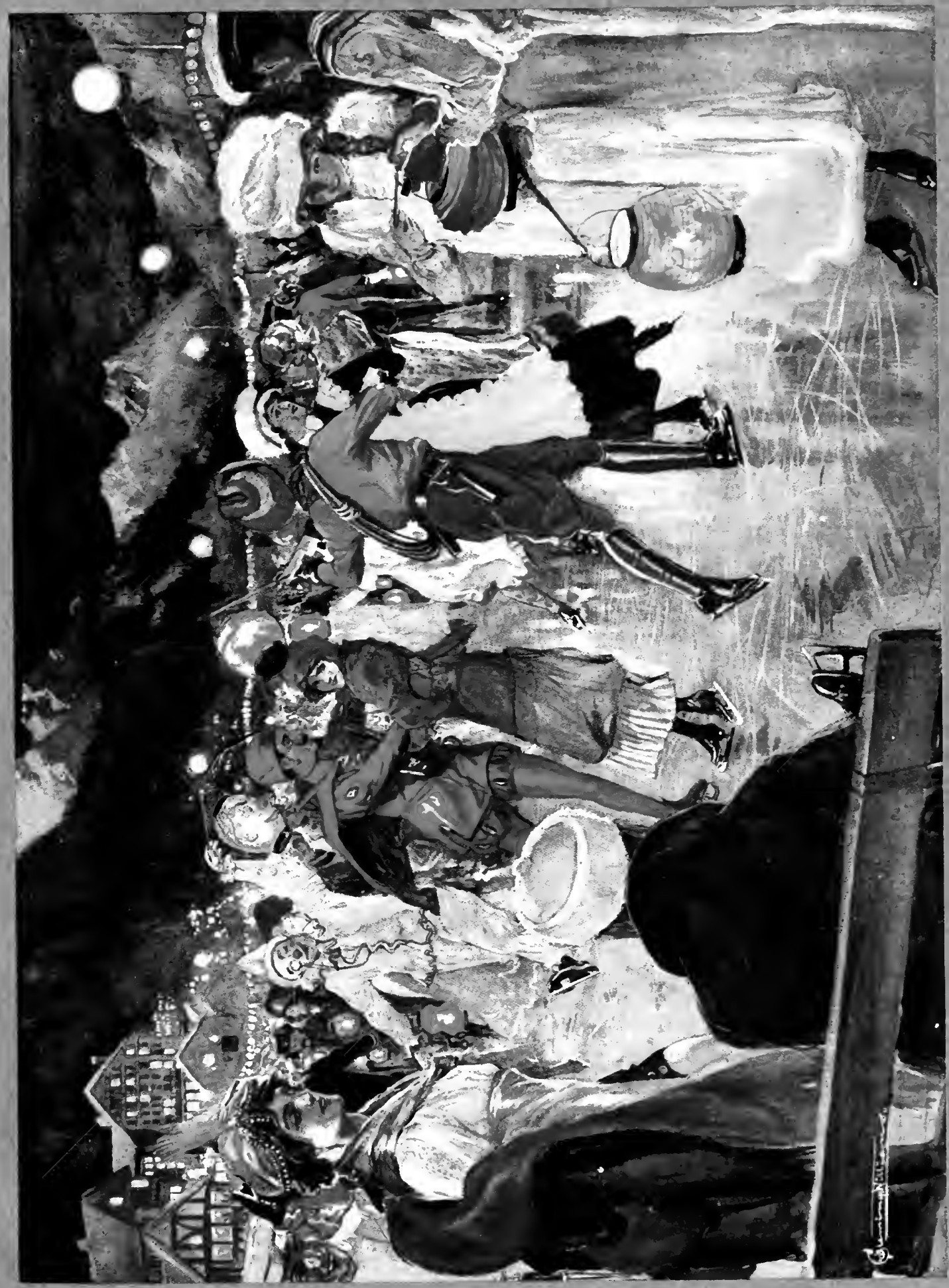




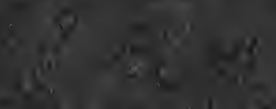

2. 3.

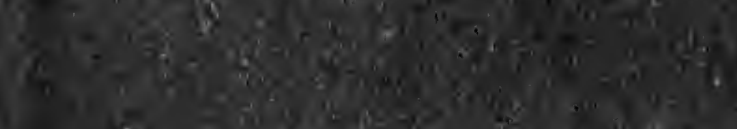

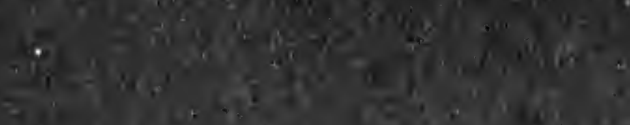

II

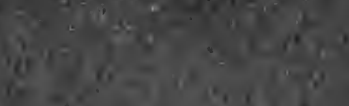

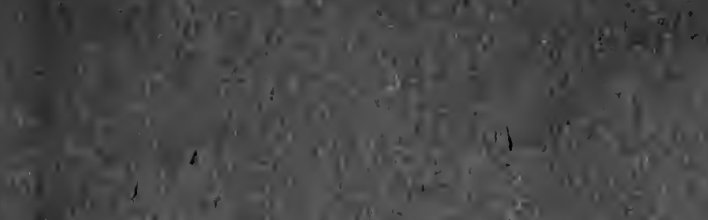

(1.

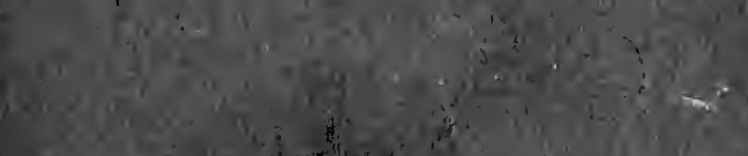

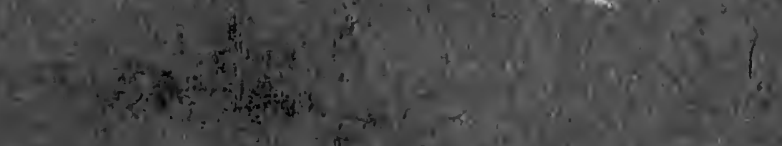



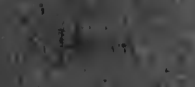



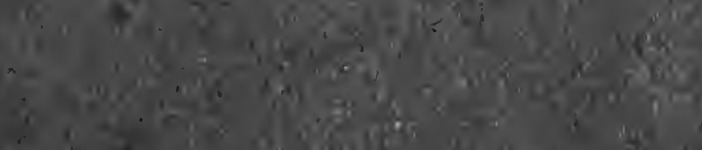

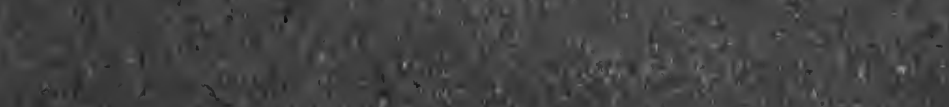

i. 18

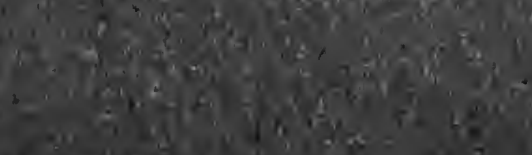

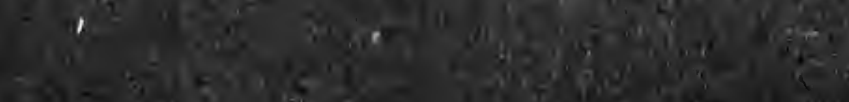

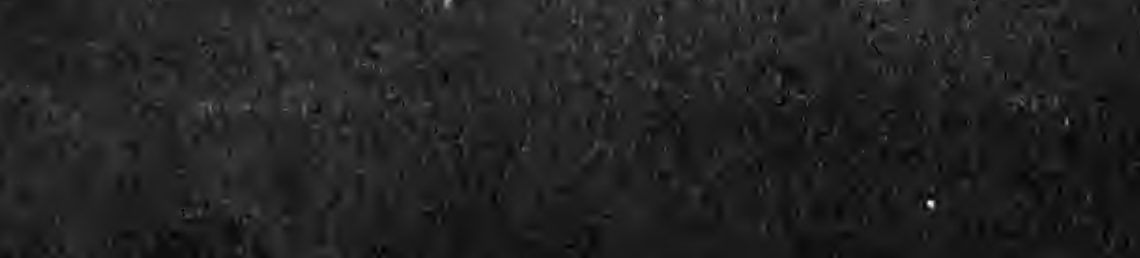




\section{FOR PARENTS AND GUARDIANS I95}

globes of flame. Then suddenly the whole hillside, the village, the pine-trees, and the snow-slopes begin to shine with a red glow as if the whole world was on fire. Then stars are quenched, the moon resigns altogether, even the lights on and around the rink grow dim in the glow that turns everything into molten fire. But it is only a Bengal light behind the châlet. " Only" indeed ! As if there was anything more magical than these blood-red snows and red-hot pines beneath the cold of the winter night! For it requires a hideously-sensible person to outlive the joys of fireworks.

Then after a while the lights are quenched and the band goes home, and you walk back beneath the moon to your hotel. All that artificial fire has not stained the white radiance of the guardians of the night. They whirl steadfast and remote and sparkling, turning the snow to glistening ivory and the shadows to ebony, as they " quire to the bright-eyed seraphim." And all night long (thoughts come strangely and incongruously mixed in this intoxicating air) the patient and laborious ice-man will be clearing up the rink, and sprinkling it through the dark hours, so that to-morrow you shall have a virgin field for your quavering rockers.

The most absorbed votary of quavering rockers must not mind an occasional violation of his frozen sanctuary by day as well as by night, for there are entertainments known as ice-gymkhanas that must from time to time be permitted to those more frivolous than he. In other words, he will come down to the rink on some fine morning with perhaps a new and illuminating theory that shall 
make all his difficulties with regard to rockers vanish like breath on a frosty morning, to find his ice desecrated by the presence of crowds in gouties, and shovels and potatoes and sacks and barrels. Eager young people will put other eager young people on the shovels and race against each other : they will pick up a series of potatoes singly, and see who can deposit them most speedily in a receptacle placed at the end of the line. They will have obstacleraces and climb through barrels, or more probably stick in them, they will perform every imaginable antic on a surface which renders those antics most perilous, and they will assuredly shout with laughter all the time, and cut up the ice in a manner that makes the grim skater's heart to bleed. But it really is all great fun, and if he finds he cannot bear it he had better go for a walk until it is over. The best plan of all, however, when such things are going on is to join in them. The worst that can happen to you is that you are disqualified for some profoundly unsatisfactory reason.

But the main point for parents and guardians to remember is, that they will feel quite different, when they are at a sufficient altitude on a sunny day, from what they do when they are coming out of the twopenny tube into a London fog. An exhilaration, approaching, as I have said, to a sort of intoxication, will invade their stately limbs, and they will feel inclined to do all kinds of things which their sober and city minds tell them are silly and ridiculous. But then a sober and city mind, like the tubercle bacillus, cannot live in this enchanted atmosphere. Fortunately or unfortunately, it does not quite die, for it slowly resumes its activity 
when they have returned to Cromwell Road, and they will find that it is probably quite unimpaired by this temporary anæsthetic of the air at 4000 feet up in winter. They need not feel afraid of becoming schoolboys permanently again, or of behaving like the adorable Mr. Bultitude when his son had changed places with him in Mr. Anstey's Vice-Versa. Their business capacities will be quite unimpaired when they get home : indeed they will very likely prove to have been brightened up by such experiences.

And already the year is on the turn again, and these foolish long summer days are beginning to get short. Very soon it will be time to settle whether we go to A- or B-, or try that new place $\mathrm{C}$ - . . . . And then people speak well of $\mathrm{D}$ but on the other hand E_- which we went to three years ago, has got a new ice-run, and the rink has been enlarged. But there is more sun at F- and even in that awful winter of IgIII9I2, when Switzerland was a mere puddle, G- held out against the thaw. But the hotels at $\mathrm{H}$ - are very comfortable, and the ski-ing is good, though not so good as at I__. . . . That is the only Debating Society in which I enjoy taking a part. 

The original Drawings in colour by $C$. Fleming Williams reproduced in this book are for sale.

For particulars apply to the Publishers. 


\title{
Recent Fine Art Books
}

\section{HANS HOLBEIN \\ THE YOUNGER}

\author{
By ARTHUR B. CHAMBERLAIN \\ ASSISTANT KEEPER OF THR CORPORATION ART GALLERY, BIKMINGHAM
}

With 252 Illustrations, including 24 in Colour

Demy 4to. Two Volumes. Cloth, gilt top, £3, 3s. net

With Complete Lists of the Artist's Pictures and of those exhibited, a Bibliography, \&c

In this book the writer has endeavoured to give as complete an account as possible of the life and career of the younger Holbein, together with a description of every known picture painted by him, and of the more important of his drawings and designs. It is primarily intended to provide a complete biography of the painter, embodying all the more recent discoveries regarding his pictures.

\section{HOMES AND HAUNTS OF RUSKIN By Sir EDWARD T. COOK}

With 28 Full-page Illustrations in Colour and $\mathrm{I} 7$ in Black and White by Miss E. M. B. WARREN. Demy 4 to. Cloth, gilt top, 21s. net.

Daily Telegraph._-“This beautiful book supplements the valuable literary labours bestowed on the life and art of John Ruskin."

\section{EDITIONS DE LUXE. By MAURICE MAETERLINCK THE LIFE OF THE BEE}

Translated by Alfred Sutro. With 13 Plates in Colour by E. J. Detmold Demy 4to, gilt top, 21s. net

M. MAETERLinck writes: "All Detmold's plates which represent bees are real, incontestable chefs-d'œuvres, and are as fine as a Rembrandt. The interiors of the hives seem works of genius."

\section{HOURS OF GLADNESS}

\section{EIGHT NATURE ESSAYS}

Translated by A. Teixeira de Matros. With 20 Plates in Colour by Edward J. Detmold. Demy 4to, gilt top, 215. net

M. MAETERLINCK writes: "The Illustrations by Detmold are very remarkable. It was infinitely difficult to give style to the flowers, and to give them character . . . all technically correct."

LONDON: GEORGE ALLEN \& CO., LIMITED 


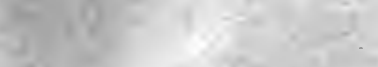

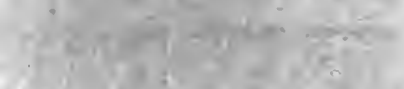

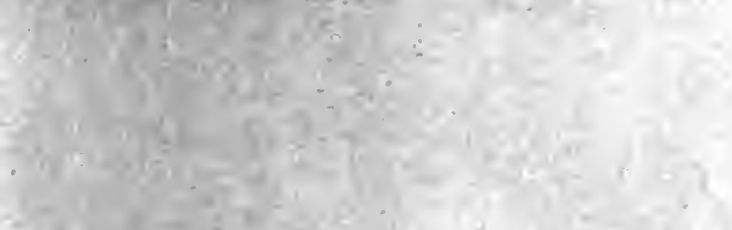

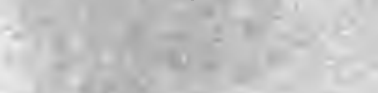




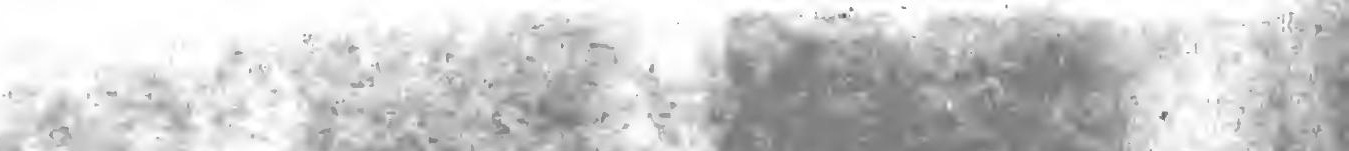

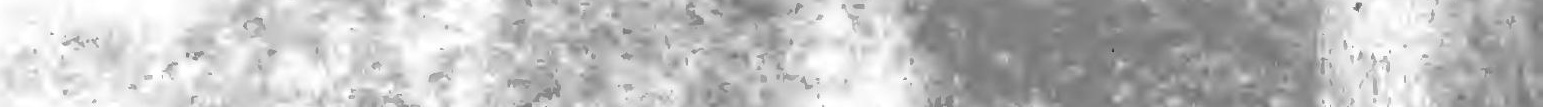

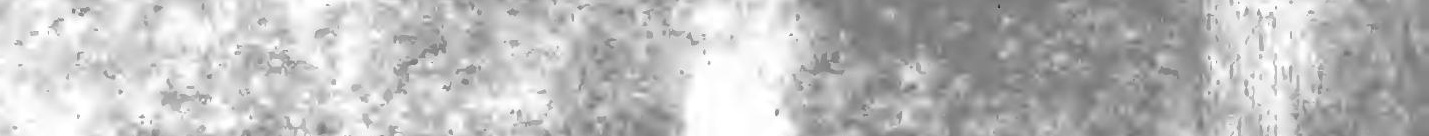

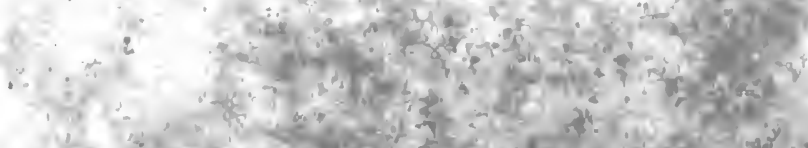

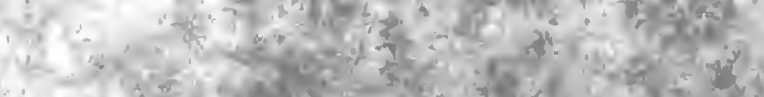

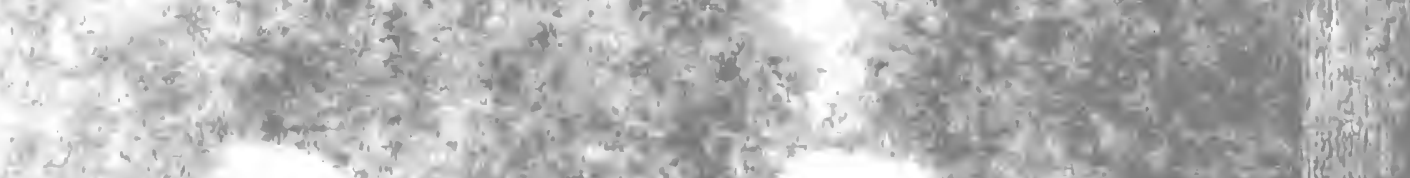

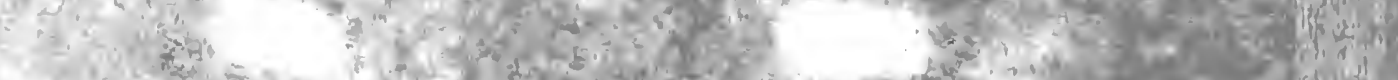

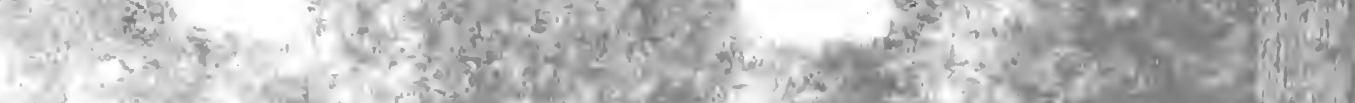
, n

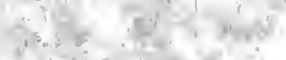
int

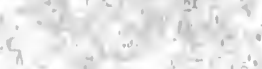
initis

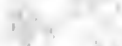

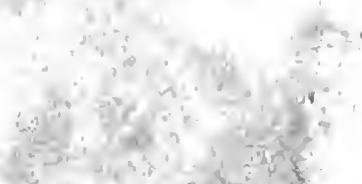
(f)

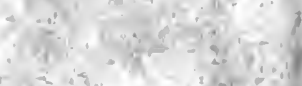

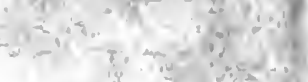

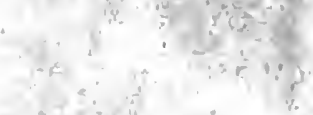

is

$\frac{1}{2}$



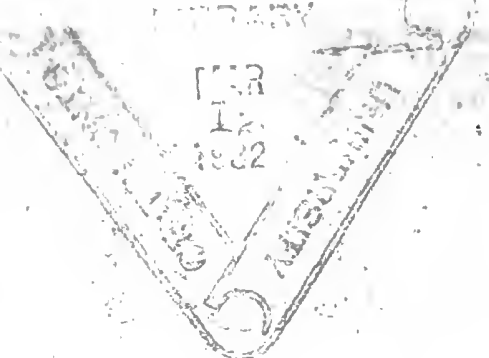



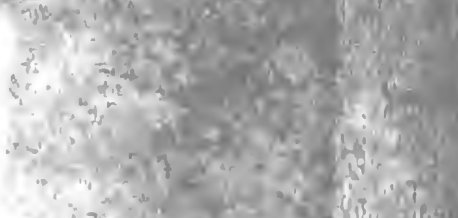

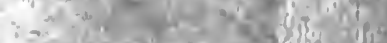

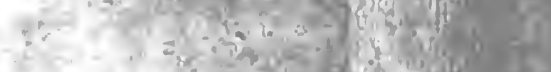



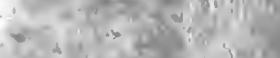

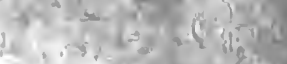

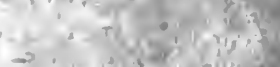

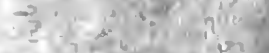

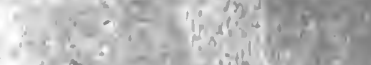

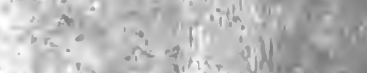

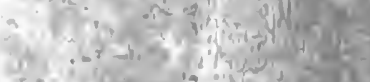

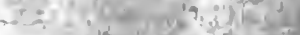

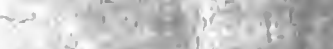



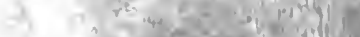

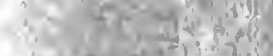

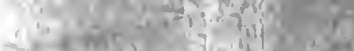

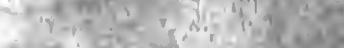



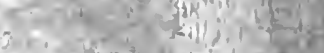

$x^{2}+3 x^{2}+x^{2}+4$



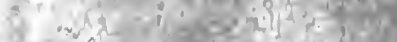

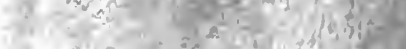

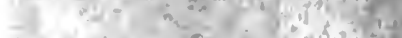

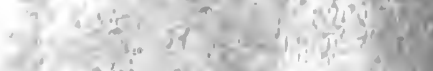

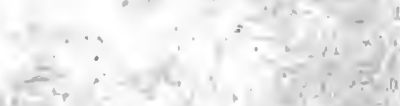

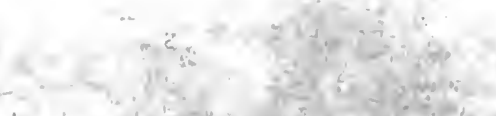

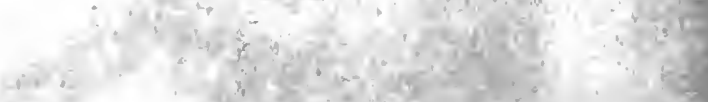

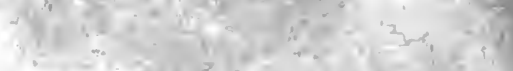




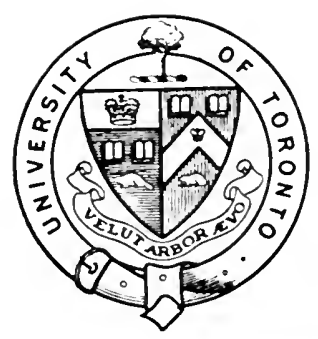

GV

840

.7

S9B45

Benson, E. F. (Edward

Frederick)

winter sports in

Switzerland 


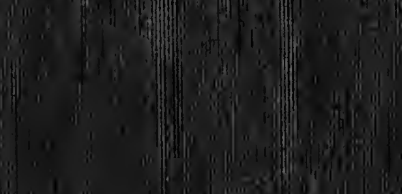

